Cómo citar este artículo / How to cite this article: Fernández Díaz, A. y Castillo Alcántara, G. (2020). Cenefas y orlas caladas en la pintura romana de Hispania. Lucentum, XXXIX, 177-245. https://doi.org/10.14198/LVCENTVM2020.39.10

\title{
CENEFAS Y ORLAS CALADAS EN LA PINTURA ROMANA DE HISPANIA*
}

THE «GALONS BRODÉS» AND THE «BORDUES AJOURÉES» IN THE ROMAN PAINTING OF HISPANIA

ALICIA FERNÁNDEZ DÍAZ

Universidad de Murcia

aliciafd@um.es

https://orcid.org/0000-0002-3083-6277

GONZALO CASTILLO ALCÁNTARA

Universidad de Murcia

gonzalo.castillo@um.es

https://orcid.org/0000-0003-3908-219X

Recepción: 11-05-2020

Aceptación: 29-06-2020

\section{Resumen}

Las cenefas y orlas caladas constituyen un elemento característico de la pintura del IV estilo pompeyano y de la producción local en las provincias a partir de la segunda mitad del siglo I d. C., y hasta el siglo II d. C. aproximadamente, siendo un elemento clave para la datación e identificación de talleres itálicos y locales. El presente trabajo constituye una compendio y análisis de todas las documentadas en contextos hispanos con el objetivo de catalogarlas y establecer una clasificación en base a su tipología y cronología a partir de los datos contextuales obtenidos de cada uno de los yacimientos a los que corresponden. Pretendemos que este trabajo sirva de referencia para la futura identificación y datación de cenefas y orlas caladas, así como de los conjuntos que decoran.

Palabras clave. IV estilo pompeyano; pintura provincial; cenefa calada; orla calada; tipología; cronología; contexto.

\begin{abstract}
The «galons brodés» and the «bordures ajourées» are a characteristic element of the painting of the Fourth Pompeian Style and of the local production in the provinces from the second half of the 1 st century A.D. to approximately the 2 nd century A.D. They are a key element for the dating and identification of italic and local workshops. This paper constitutes a compendium and analysis of all those documented in Hispanic contexts with the aim of cataloguing them and establishing a classification based on their typology and chronology from the contextual data obtained from each of the sites. In this way, this work will serve as a reference for the future identification and dating of these decorative motifs, as well as the sets that they decorate.
\end{abstract}

Key words. Fourth Pompeian style; provincial Wall painting; filigree border; typology; chronology; context.

\footnotetext{
* Este trabajo se enmarca dentro del Proyecto PID2019-104983GB-I00-Pictores et officinae per provincias II. La circulación de modelos pictóricos urbanos y rurales por el sur de la Tarraconense, Lusitania y Bética desde una perspectiva integral, parcialmente financiado por el Ministerio de Economía y Competitividad y los Fondos Feder (2020-2023).
} 


\section{INTRODUCCIÓN}

La pintura mural romana supone una importante fuente material dentro del estudio de los contextos públicos y privados del mundo rural y urbano, dada la gran cantidad de información de carácter cronológico, técnico y socioeconómico que puede extraerse de la misma. Todo ello deriva del hecho de que la pintura mural supone la expresión del gusto, la idiosincrasia y las creencias de una sociedad en un tiempo concreto y cuya mayor o menor suntuosidad se encuentra directamente unida al poder económico del comitente de la obra.

De este modo, y gracias a los hallazgos de Pompeya y Herculano bien datados, así como, posteriormente, de los diversos conjuntos procedentes de otros contextos itálicos y provinciales de los que también conocemos su datación, hoy día contamos con un amplio estudio y clasificación de los estilos pompeyanos y la pintura provincial que, junto a la realización de análisis físico-químicos, se han convertido en herramientas indispensables para una completa comprensión de los contextos edilicios de época romana.

En este campo y desde hace ya varias décadas, se han llevado a cabo diversos estudios centrados en una serie de elementos decorativos o esquemas compositivos concretos que, por sus características, constituyen por sí mismos delimitadores cronológicos válidos para establecer una datación sobre un conjunto concreto previo a su análisis técnico-estilístico durante el trabajo de laboratorio o al estudio de su contexto estratigráfico y cerámico asociado. En este sentido, podemos citar algunos trabajos como el desarrollado respecto a los elementos arquitectónicos en la pintura del IV estilo en Campania (Eristov, 1994), los tipos de candelabros (Barbet, 1985), las imitaciones de mármol (Eristov, 1979), la imitación de moteado en la pintura hispana (Guiral Pelegrín et al., 1986) o los sistemas de relación continua (Barbet et al., 1997), así como, de manera parcial, respecto a las cornisas del IV estilo en Pompeya (Gallo y Tessuto, 1989), entre otros.

El estudio de las cenefas y orlas caladas no constituye un elemento nuevo, en tanto que también ha sido objeto de un breve estudio realizado por Riemenschneider (1986) y de un extenso trabajo monográfico por parte de Barbet (1981), aunque su análisis se centraba únicamente en los ejemplares procedentes de Pompeya, dejando al margen la producción de los talleres locales que se desarrolla en las provincias, algo que abordaron de manera parcial más tarde esta misma autora (Barbet, 2008) y Strocka (2014). Es por ello que, si bien esta última obra ha servido como referencia para el estudio y clasificación de las cenefas y orlas caladas de producción itálica que se han hallado en Hispania, la producción local ha quedado relegada a un segundo plano, en muchas ocasiones meramente descrita o relacionada de manera sucinta con la obra itálica como una transformación. No obstante, este motivo constituye por sí mismo uno de los elementos más característicos de la obra local ${ }^{1}$, en tanto que muestra de manera clara, más aún que otros, cómo a lo largo del tiempo los modelos itálicos se imbrican con motivos propios del gusto de cada territorio para dar lugar a una evolución de las formas del IV estilo que, ya en el siglo II d. C., ofrece ejemplares completamente ajenos a la tradición campana.

De este modo, gracias a la amplia labor arqueológica y al estudio de una gran cantidad de conjuntos pictóricos que se ha producido en los últimos años, este trabajo pretende llevar a cabo una nueva clasificación que contemple no solo la producción itálica sino también la local, de manera que pueda establecerse de forma clara la evolución tipológica que experimenta este elemento decorativo entre la segunda mitad del siglo I y el siglo II d. C. ${ }^{2}$ en territorio hispano ${ }^{3}$. Así mismo, ello permitirá, junto a la información contextual que fecha de manera clara cada uno de los ejemplares, establecer posibles círculos productivos de un mismo taller o un grupo de talleres dentro de una ciudad, un territorio o entre varios territorios, aspecto ya probado gracias al estudio de la técnica de decoración en relieve que hallamos en Mérida y Cartagena (Fernández Díaz, 2007; Barrientos Vera y Guiral Pelegrín, 2007).

\section{DEFINICIÓN, ORIGEN Y DESARROLLO}

En primer lugar, debemos tener clara la diferencia terminológica entre cenefa y orla calada, en tanto que

1. En este sentido, debemos añadir que se trata de un elemento decorativo que, en algunos contextos, como es el caso de la ciudad de Carthago Nova, desaparece rápidamente de los conjuntos ya desde época flavia, dando muestra de la adopción de una estética propia que, en este caso, prescinde del uso de este. Es por ello que creemos que constituye uno de los motivos que muestra de manera más clara la expresión de la estética local, en especial entre finales del siglo I e inicios del siglo II d. C., dada su desaparición generalizada a partir de este momento, ya sea mediante su ligera transformación, la creación de modelos completamente nuevos o su no utilización.

2. A pesar de la existencia de algunos ejemplares fechables en el siglo IV d. C., el motivo de cenefas y orlas caladas se desarrolla principalmente entre la segunda mitad del siglo I y el siglo II d. C., constatándose su práctica desaparición a partir de la segunda mitad de este último, por lo que los casos tardíos son una excepción o su datación no ha sido realizada en base a un contexto estratigráfico claro.

3. En este sentido, debemos hacer mención al trabajo de Abad Casal (1982b: 399-400), quien llevó a cabo en su tesis doctoral una recopilación de los ejemplares conocidos hasta la fecha de cenefas y orlas caladas. No obstante, hoy día, la aparición de gran cantidad de conjuntos, la existencia de nuevos medios para su documentación y, especialmente, para su exposición gráfica, así como la ausencia de referencias a los casos procedentes de Portugal en dicho trabajo, hacen imprescindible llevar a cabo su revisión. Ello es especialmente importante en el caso de la Lusitania, donde la producción pictórica debió estar estrechamente relacionada, tal y como se advierte si los comparamos con los conjuntos emeritenses. 
hacen referencia a un elemento decorativo que difiere en un único elemento y que, por tanto, se ha empleado de manera indistinta y equivocadamente en gran cantidad de publicaciones.

Entendemos por cenefas y orlas caladas los motivos decorativos que se desarrollan en forma de bandas verticales y horizontales haciendo uso de un elemento repetitivo o alterno, en ocasiones entrelazado, ya sea vegetal, geométrico o figurativo. En el caso de las cenefas caladas, estas presentan, además, un color de fondo distinto al del panel que encuadran, en el que se disponen los elementos decorativos, siendo las combinaciones más usuales un interior violáceo, negro o azul sobre un panel amarillo, aunque también existen otras combinaciones como una cenefa de fondo amarillo sobre blanco que podemos encontrar en la estancia 11 de la casa di C. Julius Polybius (IX 13, 1-3) (Ciarallo y De Carolis, 2001) de Pompeya. Por su parte, en el caso de las orlas caladas no hay diferencia de color entre el interior y el exterior a excepción del color de los filetes y los motivos decorativos (Barbet, 1981), pudiendo señalar este tipo como el más numeroso dentro de la producción pompeyana e hispana ${ }^{4}$. En estas últimas, la combinación de colores es algo más amplia, siendo la más extendida el empleo de color amarillo sobre fondo rojo, si bien también encontramos amarillo sobre fondo negro o verde, amarillo y azul sobre fondo blanco, blanco sobre fondo rojo, amarillo o negro y combinaciones de blanco, amarillo y azul sobre fondos rojos, así como otros ejemplos minoritarios como el negro sobre fondo amarillo.

Este elemento decorativo se emplea en la ornamentación interior de zócalos, paneles de la zona media y techos (Barbet, 1981: 919). Así mismo, las orlas caladas aparecen empleadas para decorar otra serie de elementos como los frontones de las arquitecturas ficticias o espacios entre las mismas, como es el caso de la exedra de la casa de Pinarius Cerialis (III 4,b), en un cubiculum de la casa de la Fontana Piccola (VI 8, 23) (Fröhlich, 1996) o en la casa dei Delfini (V $7,7)$ en Pompeya, esta última recientemente excavada, así como en los límites de las imitaciones de paños y cortinajes que decoran las zonas media y superior, como los procedentes de la estancia 8 de la casa del Tramezzo di Legno de Herculano (III 1,1) (Esposito, 2014) o de la villa romana de Positano (Jacobelli, 2018). Así mismo, su desarrollo no se limita únicamente a una forma cuadrangular, sino que pueden adoptar formas curvas como sucede en la estancia 10 de la casa de Julius Polybius (IX 13, 1-3) de Pompeya (Ciarallo y De Carolis, 2001) o en los casos en los que decoren paneles con extremos curvos fruto de la imitación de telas colgantes, los denominados «pannelli a drappo», como sucede en el ala sur de la casa

4. En francés denominadas como «galons brodés» para las cenefas caladas y «bordures ajourées» para las orlas caladas o en italiano «bordi di tapetti» sin diferenciación. dei Vettii (VI 15, 1) (Archer, 1982) o con esquinas dobladas, como sucede en la exedra de la casa de Pinarius Cerialis (III 4,b) de esa misma ciudad. No obstante, se trata de ejemplos, la mayoría de ellos, que no se han documentado en los ambientes hispanos, y cuyos referentes encontramos en Pompeya y Herculano, así como en diversos contextos itálicos. Así, en el caso de Hispania, los ejemplares de cenefas caladas son bastante escasos, centrándose todos ellos en encuadrar interiormente los paneles de la zona media, mientras que, en lo referente a orlas caladas, contamos con algunos ejemplos de zócalos y techos, siendo casi todos de paneles de la zona media y que no presentan la complejidad que encontramos en el área campana. Junto a esto, la mayoría cuentan con un desarrollo simple como encuadramiento interior completamente cuadrangular, pudiendo citar únicamente algunos ejemplos donde adquieren formas distintas, como el procedente del techo de la tumba de Servilia en la necrópolis de Carmona (Abad Casal, 1982b: 187190, figs. 293-298), de desarrollo circular.

En cualquier caso, estas bandas, sean cenefas u orlas caladas, presentan, por lo general, un encuadramiento a base de filetes, pudiendo encontrar en ocasiones únicamente dos que enmarcan el elemento central, dos con el motivo dispuesto sobre el filete interior o cuatro, dos internos enmarcando el motivo y dos exteriores a veces decorados, siendo escasos los ejemplares que se desarrollan sin ningún filete.

Los elementos decorativos que ornamentan el interior de las cenefas y orlas caladas alternan entre formas geométricas, vegetales, palmetas, gotas, figuras cordiformes o incluso elementos figurados, combinados con distintas formas entre sí, generando un patrón que puede entrelazarse de manera directa o queda compartimentado mediante formas circulares o cuadrangulares que se repiten o alternan el motivo decorativo y la forma. Del mismo modo, es usual en el caso de las orlas caladas encontrar distintos motivos en los laterales de los encuadramientos internos de los paneles, como es el caso de la habitación 6 de la casa della Venere in Conchiglia en Pompeya (II 3, 3) o en la villa romana de Positano (Jacobelli, 2018), así como diversos tipos en los paneles de una misma estancia, como sucede en el triclinium de la domus de la calle Añón de Zaragoza (Guiral Pelegrín et al., 2019: 230, fig. 11) o en la denominada habitación de las pinturas de la casa del Mitreo en Mérida (Abad Casal, 1982b: 48-54, fig. 31).

El origen de las cenefas y orlas caladas muestra una dualidad de fuentes, en tanto que bebe de la tradición griega para la adopción de modelos y motivos decorativos al tiempo que cuenta con otros puramente romanos. En este sentido, uno de los motivos que muestra de manera más clara la extrapolación de elementos del mundo griego, procede de la cerámica, la arquitectura y la decoración escultórica y lo hallamos en las bandas de palmetas, flores de loto y olas de finales del siglo VI a. C. (Barbet, 1981: 936). Por otra parte, los esquemas 
a base de triángulos, cuadriláteros o con elementos en posición oblicua constituyen un repertorio original romano (Barbet, 1981: 939).

En cualquier caso, parece claro que tanto las cenefas como las orlas caladas tienen su origen en la pintura a partir de las bandas decorativas que encontramos en el III estilo pompeyano, donde ya se muestra la sucesión de motivos vegetales, geométricos y figurados de manera repetitiva y sobre un fondo de color distinto al fondo de la pared o los paneles 5 . No obstante, en este caso su desarrollo se limita a una banda horizontal o vertical, sin la función de encuadramiento que adquiere a partir del IV estilo, momento en el que estas se desarrollan y así será como perduren en la producción provincial. En este sentido, podemos citar algunos ejemplos como los de la estancia superior de la casa de Augusto (Iacopi, 2007), con bandas de olas que enmarcan la decoración del techo, del cubiculum «B» de la villa Imperiale en Pompeya (Pappalardo y Grimaldi, 2018), con una estrecha banda con alternancia de motivos geométricos que se desarrolla debajo de los pinakes de la parte alta de la zona media, la estancia 13 de la casa di Orfeo en Pompeya (VI 14, 20), con una banda que alterna espacios verdes y violáceos decorados con elementos vegetales y geométricos, o los techos de los cubicula «c» y «d» de la casa del Salone Nero de Herculano (VI 13) (Esposito, 2014), que muestran, el primero una banda con alternancia de rectángulos y círculos, y el segundo, una banda con alternancia de flores de loto y esfinges encuadrando la zona central y una banda de palmetas en la parte exterior del conjunto (Barbet, 1985). Así mismo, podemos encontrar también los primeros ejemplos de orlas caladas en conjuntos del III estilo, como sucede en el caso de casa di Trebius Valens (III 2, 1) (Spinazzola y Aurigemma, 1953) o en la casa di Paquius Proculus (I 7, 1) (Ehrhardt, 1998) en Pompeya (Guiral Pelegrín y Martín-Bueno, 1996: 102).

De este modo, parece claro que los primeros ejemplos de orlas caladas deben situarse en la transición entre el III y el IV estilo pompeyano, encontrando ejemplos de orlas caladas combinadas con triples filetes, elemento característico del III estilo, como

5. Así mismo, la aparición de algunos de los motivos que se emplean en las orlas y cenefas caladas, como los motivos cordiformes, las palmetas, los motivos en «S» o de tres cuartos de círculo, se produce casi de manera simultánea en la producción estucada y en la pintura, de modo que ambos constituyen una fuente de influencias recíprocas para el desarrollo y la plasmación de esquemas que, si bien no son nunca idénticos, sí beben de un mismo origen. Situación similar encontramos en la producción musivaria, que hace uso del mismo tipo de motivos empleados en el estuco, pudiendo identificar esquemas que se ejecutan en la pintura mural, como sucede en el caso del mosaico del ala al norte del atrio de la casa di L. Caecili Iucundi $(\mathrm{V} 1,26)$ en Pompeya, que presenta una sucesión de motivos de «S» con palmetas y elementos vegetales alternos. (Barbet, 1981: 939-942). encuadramiento interior de los paneles. Este tipo de representación presenta dos variantes, bien quedando estas hacia el exterior del panel, como es el caso de los ejemplos de la casa degli Amorini dorati (IV 16, 7) (Seiler, 1992) o de la recientemente excavada casa del Giardino (V 3) de Pompeya, o hacia el interior, como sucede con los ejemplares de la calle Cabo Verde y del vertedero de Blanes en Mérida, que en ambos casos se fechan en torno a mediados del siglo I d. C.

En lo que respecta a su ejecución, al igual que otro tipo de motivos decorativos de carácter repetitivo, las cenefas y orlas caladas hacen uso de trazos preparatorios para marcar las líneas base del esquema y los elementos que lo componen con el fin de evitar fallos ${ }^{6}$. Estos trazos eran realizados sobre el enlucido húmedo antes de aplicar el pigmento, pudiendo diferenciarse tres métodos (Barbet y Allag, 1972; Abad Casal, 1982a; Barbet, 1998; Fernández Díaz, 2008; Íñiguez Berrozpe, 2014). En primer lugar, se encuentra el cordelillo trenzado, que generaba sobre el enlucido una impronta discontinua generalmente utilizada para marcar las líneas rectas del motivo o elemento, especialmente sobre paredes irregulares dada su mayor facilidad de adaptación, siendo uno de los casos con menor presencia en Hispania, pero del cual contamos con algunos ejemplos en este trabajo como uno procedente de Blanes (1.1.12). En segundo lugar, contamos con el trazado pintado, en este caso realizado por lo general con color ocre, aunque también se ha comprobado el uso de otros pigmentos como el blanco, el rojo o el verde, que tuvo mayor difusión y podemos encontrar especialmente en los motivos internos, como parece ser el caso de varios ejemplos de Mérida (1.1.1, 2.2.6, 2.2.7 y 2.2.8). Por último, el más extendido de todos, tanto para la ejecución de conjuntos en general como para las cenefas y orlas caladas, fue la incisión realizada mediante estilete, tanto para líneas rectas como para otros elementos, que podía estar acompañada de una regla o ejecutarse a mano alzada (Guiral Pelegrín y MartínBueno, 1996). A estos debemos añadir el empleo del compás para trazar circunferencias y semicircunferencias, pudiendo constatarlo en la mayoría de esquemas de este tipo, especialmente el hueco generado donde se debía clavar la punta del compás, que podemos ver bien reflejado en los ejemplos de Bilbilis (Guiral Pelegrín y Martín-Bueno, 1996: 112-113) y Portmán ${ }^{7}$.

6. En adelante solo indicaremos la presencia de trazos preparatorios en aquellos ejemplares en los que se haya documentado.

7. Los conjuntos que más claramente lo muestran, procedentes de las habitaciones 7 y 8 , se encuentran aún en fase de estudio. 


\section{CLASIFICACIÓN ${ }^{8}$}

Para llevar a cabo la clasificación de los distintos tipos de cenefas y orlas caladas conservadas en Hispania, hemos seguido la metodología empleada por Barbet para las orlas caladas de Pompeya (1981), dividiéndolas en función del esquema decorativo en varios grupos y subgrupos. No obstante, en este caso hemos seguido un orden cronológico dentro de cada uno de los tipos, a fin de poder establecer los cambios que sufre cada modelo en su evolución entre el IV estilo y la producción local, en base tanto a criterios técnico-estilísticos como contextuales. Para ello, cada ejemplar ha sido analizado en base a unas variables tales como el tipo de motivo y esquema empleado, las dimensiones totales, su contexto arqueológico, en los casos en los que ha sido posible definirlo, y su cronología.

En lo que respecta a las dimensiones, creemos que, para un correcto análisis, se debe tener en cuenta no solo la anchura de los motivos sino del espacio total comprendido en el interior de los filetes que los enmarcan en el caso de que los haya, incluyendo estos últimos, así como los motivos que se apoyan sobre estos hacia el exterior. Ello se explica porque su funcionalidad es, por una parte, la de delimitar el desarrollo del motivo ornamental y su presencia queda supeditada a la de este, mientras que, por otra, constituye también un elemento que ornamenta la propia cenefa u orla, en ocasiones con motivos secundarios, especialmente en el ámbito provincial. En este sentido, Barbet indicaba en su estudio que los filetes que acompañan a las orlas constituyen un artificio para dar volumen a esquemas estrechos y que rara vez están presentes junto a esquemas con motivos de mayor tamaño (Barbet, 1981: 932). No obstante, si observamos algunos de los ejemplares que abordamos en este trabajo, podemos observar cómo la presencia de dos o cuatro filetes ornados con motivos secundarios no está limitada a los ejemplares de menor tamaño, por lo que no se puede condicionar su funcionalidad a la de un efecto de engrosamiento, sino que debe contarse como un ornamento más de la orla. Tal y como hemos podido observar en los casos que se exponen a continuación, ello implica una variación en las dimensiones de todos los ejemplares recogidos en este trabajo si los comparamos con sus paralelos del ámbito pompeyano, cuyo estudio se llevó a cabo sin incluir los filetes (Barbet, 1981: 932). Por tanto, a la hora de comparar nuestros

\footnotetext{
8. El repertorio de cenefas y orlas caladas recogido responde a los casos conocidos hasta el momento, si bien es cierto que no podemos considerar esta clasificación completa dada la imposibilidad de incluir algunos ejemplos que, por la falta de información acerca de su esquema o dimensiones, así como la ausencia de dibujos o fotografías que permitan un estudio razonado, no es posible analizar. A estos debemos añadir también aquellos ejemplares que aún se encuentren sin publicar o algunos de los recogidos por Abad Casal (1982b: 399-400) cuyo estado fragmentario imposibilita restituirlo y compararlo.
}

ejemplares con los procedentes del ámbito pompeyano, debemos tener en cuenta que las dimensiones referidas por Barbet serían en todos los casos ligeramente superiores a las expresadas si incluimos los filetes y ornamentos exteriores, de manera que gran parte de nuestros ejemplares pueden encuadrarse en los cánones pompeyanos si se obvian estos elementos?

Así mismo, hemos incluido dentro de una misma categoría aquellas cenefas $u$ orlas caladas que hagan uso de un mismo elemento en sus diversas variantes, como son los círculos, semicírculos y cuartos de círculos. De este modo, se han podido clasificar un total de 13 tipos con un número variable de variantes en función de la cantidad y diversidad que hemos identificado en cada uno $^{10}$, a los que hemos sumado un grupo con aquellas orlas que por su morfología no podemos encuadrar en un grupo concreto y que responden a formas más complejas y recargadas.

\section{III.1. TIPO 1: TRIÁNGULOS ${ }^{11}$}

El primer tipo se corresponde con las cenefas y orlas caladas con un esquema de triángulos, entre los que podemos encontrar cinco variantes o subgrupos, como son los triángulos contrapuestos sin alternancia (1.1), los triángulos de perfil curvo contrapuestos sin alternancia (1.2), los triángulos de perfil curvo contrapuestos con alternancia (1.3), los triángulos dobles contrapuestos sin alternancia (1.4) y los triángulos alternos (1.5). La práctica totalidad de las cenefas y orlas caladas con motivos de triángulos proceden de Mérida, mientras que solo dos de Bilbilis, sin haber podido documentar ejemplares en otras áreas de la península.

\section{III.1.1. Triángulos contrapuestos sin alternancia}

Dentro de esta variante, si atendemos a sus características técnico-estilísticas, así como a la cronología y materiales del contexto, los ejemplos más antiguos proceden de la UE 65 del vertedero de la calle Cabo Verde de Mérida (Pérez Maestro, 2007). En este caso, si bien no se puede establecer la procedencia de los mismos, las características del mortero y los pigmentos permiten

9. A este respecto, Barbet no especifica si esta metodología de medición se aplica de la misma manera a las cenefas caladas, que por lo general cuentan con un fondo de color distinto que se extiende más allá de los filetes que encuadran el motivo central. En nuestro caso, hemos seguido tanto para cenefas como orlas el mismo planteamiento, contando la anchura total hasta el final de los filetes que delimitan la cenefa.

10. En lo que respecta al apartado gráfico, hemos incluido la restitución en color de todos los ejemplares introduciendo los fragmentos únicamente en los casos que no han sido publicados previamente.

11. Este grupo y sus variantes se corresponden con los tipos 40-48 del grupo VI de Barbet (1981). 


\section{Triángulos contrapuestos sin alternancia}

登N

1.1.1 Cabo Verde (Mérida)

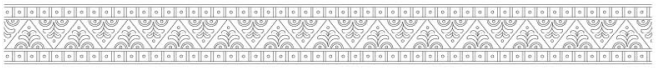

1.1.2 Cabo Verde (Mérida)

1(9) (9) (a) (a) (a) (9) (9) (9) (9) (9) (a) (a) (a)

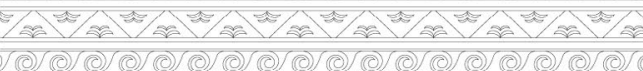

1.1.3 Cabo Verde (Mérida)

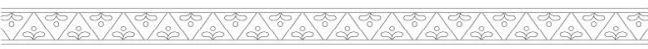

1.1.4 Termas de Bilbilis

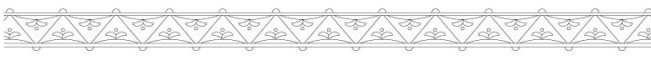

1.1.5 Termas de Bilbilis

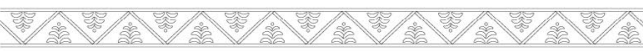

1.1.6 Blanes (Mérida)

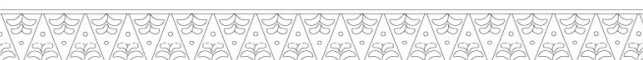

1.1.7 Blanes (Mérida)

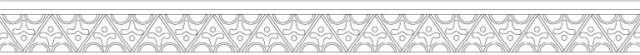

1.1.8 Blanes (Mérida)

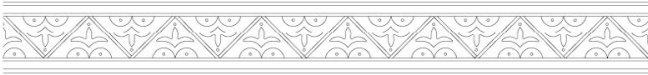

1.1.9 Casa del Mitreo (Mérida)

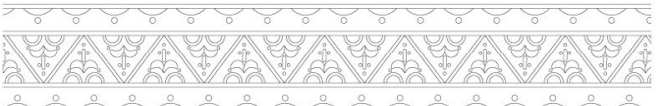

1.1.10 Blanes (Mérida)

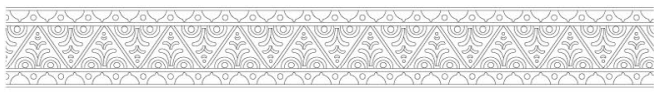

1.1.11 Blanes (Mérida)

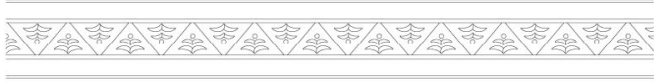

1.1.12 Blanes (Mérida)

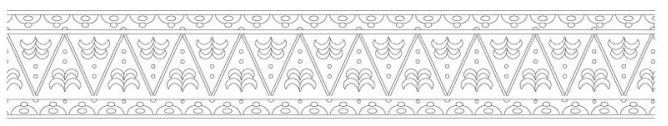

ดดดดดดดดดดดดดดดดดล

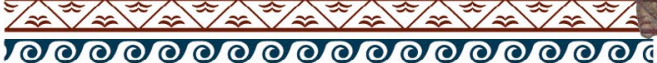

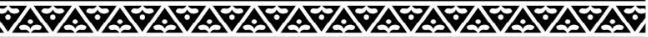

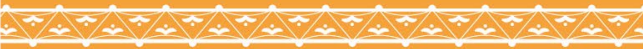
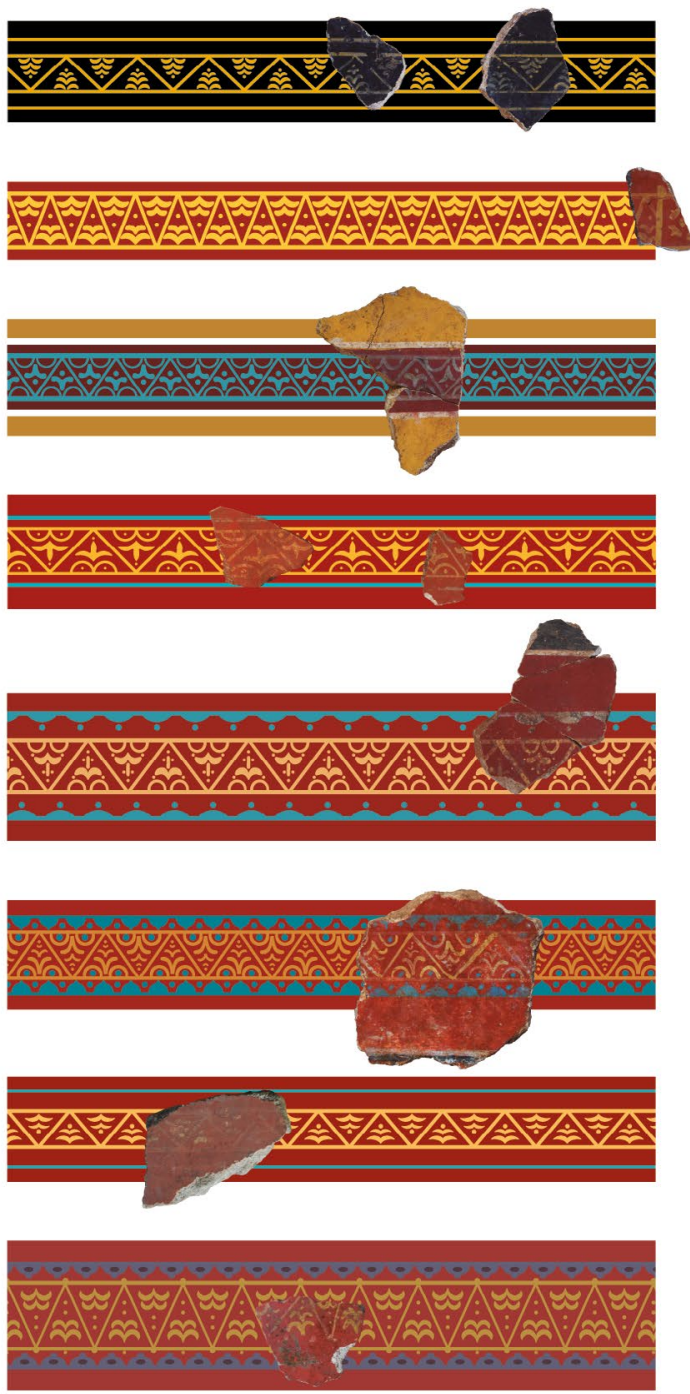

1.1.13 Cabo Verde (Mérida)

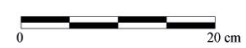

Figura 1: Cenefas y orlas caladas del grupo de triángulos. Fuente: elaborada por los autores 
plantear la hipótesis de una misma estancia para las dos cenefas identificadas con esquema de triángulos. En ambos casos se trata de cenefas de fondo violáceo sobre un panel amarillo y cuyos motivos decorativos se han realizado en color blanco. El primero de los ejemplos, de 5,5 cm de anchura, presenta dos filetes blancos externos y dos azules internos, de manera que estos últimos enmarcan unos triángulos de 4,5 cm de lado decorados en su interior mediante dos líneas formando semicírculos a los que se superpone un bifolio. Hacia el exterior presenta una sucesión de gotas azules (Fig. 1.1.1.1). El segundo de los ejemplares, de 6,1 cm de anchura y más complejo, presenta cuatro filetes blancos, enmarcando los dos internos triángulos de $5 \mathrm{~cm}$ de lado que encierran en su interior dos líneas formando un semicírculo con una gota al interior a los que se superponen dos bifolios uno encima de otro, el superior más pequeño, y una gota ${ }^{12}$. Hacia el exterior se suceden, a ambos lados, cuadrados de $1 \mathrm{~cm}$ que encierran gotas (Fig. 1.1.1.2). Ninguno presenta marcas preparatorias incisas, aunque parece probable el empleo de marcas pintadas.

En lo que respecta al contexto arqueológico, a pesar de que los datos son escasos, los fragmentos se asocian a una gran cantidad de terra sigillata marmorata (Pérez Maestro, 2004) y pintura mural que no permite fecharlo más allá de época flavia, lo que lleva a plantear una cronología de entre época claudia y neroniana, dado que debe existir un margen entre su ejecución y su amortización (Fernández Díaz et al., e.p.). En lo que respecta a los paralelos, podemos señalar, para el primer caso, un modelo de procedencia desconocida recogido por Zahn (1842-1844) que presenta una alternancia entre dos tipos (Barbet, 1981: fig. 9, 41a), uno de los cuales es muy similar al conservado en Mérida, pero con un bifolio menos y sin una gota como coronamiento, o el del triclinium de la casa del Principe di Napoli (VI 15, 8) (Strocka, 1984), con la diferencia de que los semicírculos no aparecen rellenos del mismo color y que tampoco tiene alternancia de motivos. Por su parte, en el segundo de los ejemplos encontramos un paralelo procedente del atrio de la casa degli Amanti (I 10, 11) de Pompeya, si bien en este caso presenta la sucesión de cuadrados con gotas únicamente en uno de los laterales (Barbet, 1981: fig. 9, 40e), así como los ya citados para el primer ejemplar.

Probablemente de cronología similar es un tercer caso procedente del mismo yacimiento, de la UE 22, que presenta la misma datación que la UE 65 de los casos anteriores, así como un grupo homogéneo de conjuntos pictóricos a caballo entre el III y el IV estilo. Se trata de una orla calada de fondo blanco compuesta por

12. El estado de conservación no permite distinguir con claridad si originalmente las dos cenefas tendrían los motivos internos en color azul, dado que en el segundo caso únicamente se conservan manchas de dicha tonalidad en algunos trazos, por lo que, en tal caso, el blanco podría haber sido un trazo preparatorio, dado que no se advierte ningún otro tipo. cuatro filetes, los externos azules y los internos rojos, que encuadran una sucesión de triángulos contrapuestos decorados interiormente por dos bifolios rojos superpuestos. Los filetes azules presentan, hacia el exterior, una sucesión de olas en color azul, dándole una anchura total de $10 \mathrm{~cm}$, lo que supone unas dimensiones muy elevadas para esta cronología, si bien es cierto que, si limitamos su anchura al motivo central, tal como plantea Barbet en los ejemplares de Pompeya, este no superaría los $3,6 \mathrm{~cm}$, por lo que estaría dentro de los cánones (Fig. 1.1.1.3). En lo que respecta a los paralelos, debemos remitir a los anteriormente citados, dado que no encontramos ninguno dentro del repertorio pompeyano que haga uso combinado de triángulos y ondas al exterior. No obstante, debemos incluir uno procedente de las provincias, en este caso de la casa $\mathrm{B} / \mathrm{C}$ de la ínsula 39 de Augst (Hufschmid y Tissot-Jordan, 2013: fig. 72) que, si bien no presenta ondas y solo tiene un bifolio, también es de color rojo sobre fondo blanco. Tal y como hemos señalado, los materiales del contexto y el resto de material pictórico (Pérez Maestro, 2004; 2007), impiden fecharlo más allá de época flavia y, si tenemos en cuenta sus características, pensamos que una cronología de época neroniana es factible.

Algo posteriores a estos ejemplares, son los de Bilbilis. El primero de ellos forma parte del zócalo del conjunto A hallado en la estancia $\mathrm{M}$ de las termas (Guiral Pelegrín y Martín-Bueno, 1996: fig. 33) ${ }^{13}$, una orla calada en blanco sobre fondo negro de $4,4 \mathrm{~cm}$ de anchura, cuyos triángulos, de en torno a $4 \mathrm{~cm}$ de lado, presentan en su interior un bifolio con un punto sobre la misma (Fig. 1.1.1.4). Esta orla es muy similar al primero de los ejemplares de Cabo Verde (1.1.1) y cuenta con paralelos muy parecidos en las casas delle Nozze d'Argento (V 2, i) (Ehrhardt, 2004), del Championnet (VIII 2, 1) o la di Apolo (VI 2, 22), así como en otros conjuntos anteriores al terremoto del año 62 d. C., como los del triclinium de la casa del Principe di Napoli (VI 15, 8) (Strocka, 1984), con las salvedades indicadas para los casos anteriores, o en el vestíbulo de la casa dell'Orso (VII 2, 45) (Ehrhardt, 1988). A ellos, debemos añadir los escasos ejemplos procedentes de las provincias, como son los de la villa de Quillanet y de Ruscino (Sabrié y Demore, 1991) y los pertenecientes a las estancias «D», «E»y «F» de la excavación de la Clos de la Lombarde (Sabrié et al., 1987).

El segundo ejemplar corresponde a la decoración de un panel de la zona media del denominado conjunto $\mathrm{B}$ hallado en la misma estancia, en este caso una orla calada blanca sobre un panel amarillo, de $6,4 \mathrm{~cm}$ de

13. Respecto a los conjuntos denominados como A y B hallados en esta estancia, si bien en un principio se planteó que formaran parte de la decoración de la misma, estudios posteriores han permitido determinar que proceden de otra estancia de una terraza superior de la que se habrían desprendido por los corrimientos de tierras. 
anchura, que presenta dos filetes blancos enmarcando la sucesión de triángulos, y que contienen en su interior un trazo curvo blanco que surge de los vértices inferiores del mismo y sobre este se sitúa un bifolio con una gota. Hacia el exterior de la orla, los vértices quedan marcados con una gota blanca. En este caso, contamos con los mismos paralelos que el ejemplar anteriormente citado, si bien presenta la diferencia del trazo curvo que no encontramos en el otro, así como el empleo de incisiones profundas como trazos preparatorios para marcar el punto de partida de la orla en posición vertical y horizontal (Fig. 1.1.1.5). En ambos casos los conjuntos han sido fechados dentro del IV estilo, concretamente en los primeros años de la segunda mitad del siglo I d. C. (Guiral Pelegrín y Martín-Bueno, 1996: 111 y 134).

De forma similar a los ejemplos de Bilbilis, aunque de cronología algo posterior, contamos con dos procedentes del vertedero de Blanes de Mérida, el primero de ellos de la UE 1412. Se trata de una orla de color amarillo sobre fondo negro, de 7,3 cm de anchura formada por cuatro filetes, los dos internos enmarcando la sucesión de triángulos que encierran en su interior tres bifolios superpuestos de tamaño decreciente y coronados por una gota (Fig. 1.1.1.6). Para este caso remitimos a los paralelos citados en los ejemplos anteriores, a los que añadimos uno procedente del Santuario della Bona Dea fechado en época flavia (Falzone, 2007: fig. 11). El contexto al que pertenece fue fechado a inicios del siglo II d. C., lo que podría indicar su pertenencia a un conjunto de entre época neroniana y época flavia (Fernández Díaz et al., e.p.), probablemente a un zócalo en base a las características del mortero, aunque no es posible confirmarlo. Al igual que sucede con ejemplares anteriores, si limitamos la anchura al motivo central de la orla, tal y como hace Barbet, esta alcanzaría únicamente los $4 \mathrm{~cm}$ de anchura, lo que la situaría dentro de los cánones pompeyanos. Junto a esto, la calidad de la ejecución, nos lleva a plantear que se trate de un ejemplar del IV estilo, más aún si tenemos en cuenta el caso bilbilitano anteriormente citado.

Junto a este ejemplar, contamos con otra orla calada de color amarillo sobre panel rojo, procedente de la UE 1360, de $6 \mathrm{~cm}$ de anchura y muy similar a los ejemplares anteriores, con decoración de dos bifolios superpuestos en el interior de los triángulos, que en este caso presentan una forma más alargada (Fig. 1.1.1.7). Entre los paralelos debemos señalar los indicados anteriormente dada la similitud de forma y motivos decorativos de todos los ejemplares de esta variante, destacando únicamente uno de los procedentes de la casa del Championnet en Pompeya (VIII 2,1) (Barbet, 1981: fig. 9, 40d) por su similitud de perfil más alargado que el resto. En lo que respecta a su cronología, la información del material cerámico, así como del resto del material pictórico, ofrece un margen amplio, dada la aparición de fragmentos del III estilo y de época flavia, por lo que, en base a sus características técnicas, nos inclinamos por una datación tardo neroniana.
Por último, dentro de esta cronología contamos con una cenefa calada de fondo violáceo sobre panel amarillo procedente de la UE 1535 , de $8 \mathrm{~cm}$ de anchura y que cuenta con cuatro filetes, los dos externos blancos y los dos internos azules, quedando en el interior la sucesión de triángulos decorada mediante dos semicírculos a los que se superpone un bifolio con una gota azul (Fig. 1.1.1.8). Se trata de un ejemplar bastante similar al anteriormente citado del vertedero de la calle Cabo Verde, pero que carece de las gotas sobre el filete exterior y alterna el color blanco por el azul, incrementando la anchura en casi dos centímetros, por lo que nos remitimos igualmente a los paralelos citados. Si tenemos en cuenta la cronología del contexto, fechado entre el 80-100 d. C. ${ }^{14}$, y las características de la cenefa, de peor calidad que los modelos anteriores, nos inclinamos por darle una cronología entre finales de época neroniana y época flavia (Fernández Díaz et al., e.p.), lo que explicaría la adopción de los tonos azules que encontramos en la mayoría de orlas flavias emeritenses, como los ejemplares que veremos a continuación, y el aumento de tamaño sin incluir otra serie de motivos propios del gusto local.

Los últimos ejemplares de esta variante permiten ver de manera más clara la evolución que experimenta este esquema a partir de época flavia. El primero de ellos procede de la casa del Mitreo, en concreto de uno de los ambientes junto a las fauces de la casa, dado que la decoración del atrio, con el que limita hacia el sur, no presenta ningún motivo de este tipo. Se trata de una orla calada de 7,3 cm de anchura de color amarillo y azul sobre fondo rojo con cuatro filetes, los dos externos azules y los internos amarillos que encierran triángulos decorados con dos semicírculos con una gota y un trifolio coronado con otra gota (Fig. 1.1.1.9). El esquema es muy similar a los ejemplares anteriores procedentes de la calle Cabo Verde y de Blanes, con la diferencia de la presencia del trifolio, por lo que nos remitimos a los paralelos citados. En lo que respecta a su cronología, si bien el informe de la excavación no aporta datos sobre el contexto, las diferentes intervenciones han puesto de manifiesto que la casa no debió edificarse antes de la segunda mitad del siglo I d. C. (Bejarano Osorio et al., e.p.), lo que, unido a las características técnicas y cromáticas de la orla, así como al resto de ejemplares de la casa que veremos más adelante, permite fecharlo en época flavia (Fernández Díaz et al., e.p.).

El segundo, similar al anterior, lo encontramos en el vertedero de Blanes, procedente de la UE 925, con idéntica combinación de colores, en este caso con 11 $\mathrm{cm}$ de anchura. Los triángulos aparecen decorados al interior mediante dos semicírculos a los que se superpone un trifolio que, en esta ocasión, aparece decorado con cinco gotas, dos junto a las puntas de las hojas

14. La cronología de la UE 1535 fue fijada por la presencia de formas Hayes 8a, lucernas tipo Dr 3, 11, 17 y 18 y un borde de ungüentario del tipo De Tommaso 42, entre otras. 
inferiores, dos a los lados de la hoja superior y una en la punta. Junto a esto, la orla presenta, sobre el filete azul y hacia el interior, una sucesión de semicírculos azules a los que se superpone una gota azul (Fig. 1.1.1.10). Este resulta un elemento característico de la gran mayoría de orlas caladas que encontramos en Mérida y que se repite en los siguientes ejemplares, pero que no sucede por norma general en Pompeya, lo que, junto a la cronología del contexto, entre el 80-100 d. C. ${ }^{15}$, nos lleva a fecharla probablemente a inicios de época flavia, pudiendo tener lugar su amortización a finales de la última década del siglo I d. C. (Fernández Díaz et al., e.p.).

Situación similar encontramos en el ejemplar procedente de la misma UE y de idéntica policromía, en este caso de $8,3 \mathrm{~cm}$ de anchura y que presenta, en el interior de los triángulos, dos semicírculos decorados con una gota azul a los que se superponen tres bifolios amarillos, el último de ellos muy esquemático y coronado por una gota amarilla. Los filetes azules se encuentran decorados al interior mediante una sucesión de semicírculos azules, en este caso peraltados y coronados por una pequeña gota azul, al tiempo que el espacio entre cada semicírculo queda decorado por otra gota del mismo color (Fig. 1.1.1.11). Al igual que el ejemplar anterior, debemos remitimos a los paralelos citados en los modelos de esta variante. Dadas sus características, así como los datos del contexto, nuevamente optamos por una cronología flavia como en el caso anterior (Fernández Díaz et al., e.p.).

Junto a estos, el último ejemplar de Blanes carece de unidad, lo que dificulta establecer una adscripción cronológica clara. No obstante, las características tanto a nivel decorativo como cromático, permiten relacionarla con el resto de orlas de cronología flavia. Se trata de una orla similar a las procedentes de las UUEE 1360 y 1412 , en este caso con cuatro filetes, los externos azules y los internos amarillos, que encierran una sucesión de triángulos contrapuestos con dos bifolios superpuestos $\mathrm{y}$ una gota amarilla, todo ello sobre un fondo rojo y con una anchura total de $8,3 \mathrm{~cm}$ (Fig. 1.1.1.12). Así mismo, los fragmentos de esta orla presentan, a diferencia de los anteriores, trazos preparatorios a base de marcas incisas discontinuas para la ejecución de los filetes, probablemente debido al empleo de un cordelillo trenzado. En lo que respecta a los paralelos, remitimos a los citados para el resto de casos.

Por último, el ejemplar procedente del vertedero de la calle Cabo Verde, en concreto de las UUEE 56 y 94. Se trata de una orla calada de $11 \mathrm{~cm}$ de anchura con cuatro filetes, los exteriores azul oscuro y los interiores amarillos, que enmarcan una sucesión de triángulos más alargados que los ejemplares anteriores y con una

15. El contexto de la UE 925 cuenta con producciones Hayes 8 A, lucernas tipo Dr. 3, 11, 17 y 18 y un borde de ungüentario tipo De Tommaso 42, entre otras, lo que ha llevado a establecer esa datación. gota amarilla en sus vértices, al igual que el primer caso de la UE 65 de este mismo yacimiento y el procedente del conjunto B de Bilbilis, presentando, además una pequeña gota amarilla en la parte central del lateral inferior únicamente en uno de los lados de la orla. Los triángulos se encuentran decorados al interior mediante una sucesión de dos bifolios coronados por dos gotas superpuestas. Los filetes azules presentan, al interior, una sucesión de semicírculos con una gota en la parte superior y una gota alargada de color más oscuro en la parte central (Fig. 1.1.1.13). Al igual que en los casos anteriores, remitimos a los paralelos citados. En este caso, las citadas unidades presentan una cronología posterior a la UE 65 (Pérez Maestro, 2007), algo que también se observa en el resto de conjuntos pictóricos, lo que nos lleva a fechar el ejemplar en época flavia.

III.1.2. Triángulos de perfil curvo contrapuestos sin alternancia

Este segundo grupo cuenta con cinco ejemplares. El primero de ellos, procedente de la UE 65 del vertedero de la calle Cabo Verde de Mérida. Se trata de una cenefa calada de fondo violáceo sobre panel amarillo que presenta cuatro filetes, los externos blancos y los internos azules, en cuyo interior se desarrolla una sucesión de triángulos de perfil curvo contrapuestos, decorados con un semicírculo con una gota en su interior y coronado por otras seis gotas. Sobre el filete blanco, hacia el interior, una sucesión de semicírculos azules ligeramente achatados que alternan con una gota del mismo color, todo ello con una anchura total de 5,7 cm (Fig. 2.1.2.1). En lo que respecta a los paralelos, podemos citar el procedente de la sala «F» de la casa di M. Lucretius Fronto (V 4, a) o el del atrio de la casa degli Amanti (I 10, 11) (Barbet, 1981: fig. 12, 47a y f) en Pompeya, así como el de la villa romana de Positano (Jacobelli, 2018), en este caso con hojas en lugar de gotas en la decoración interior de los triángulos y formando parte de una cenefa, a los que sumamos el procedente de la casa dei Mosaici de Iasos de Caria (Angiolillo y Giuman, 2014: lám. LXV, fig. 9). Los datos del contexto señalan una cronología entre época claudia y época flavia. Si tenemos en cuenta su gran similitud con el resto de cenefas de este tipo procedentes de la misma unidad, parece posible encuadrarlo en esa cronología a pesar de que presenta unas dimensiones ligeramente superiores a dos de los tres modelos vistos (1.1.1 y 1.1.2), aunque inferiores al tercero (1.1.3).

El segundo ejemplar de esta variante procede de la UE 1470 del vertedero de Blanes y está formado por cuatro filetes, los dos externos azules y los internos amarillos. Los triángulos inscritos entre los filetes amarillos presentan una sucesión de dos bifolios superpuestos con tres gotas, una en la parte superior y dos en los costados, que se desarrolla en su interior, todo ello en color azul. Junto a esto, sobre el filete azul y hacia 
Triángulos de perfil curvo sin alternancia

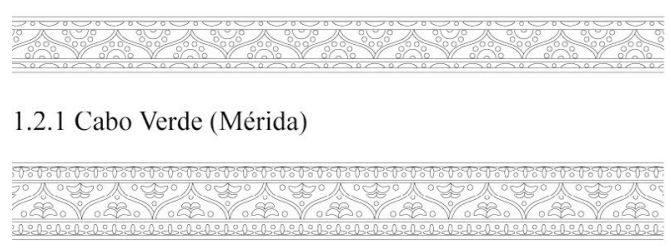

1.2.2 Blanes (Mérida)

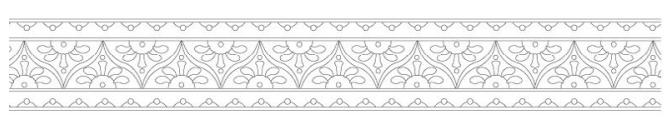

1.2.3 Huerta de Otero (Mérida)

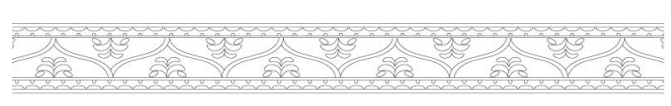

1.2.4 Huerta de Otero (Mérida)

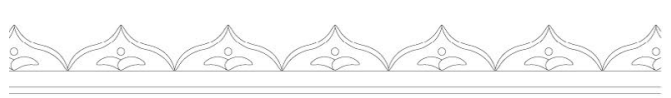

1.2.5 Casa del Mitreo (Mérida)
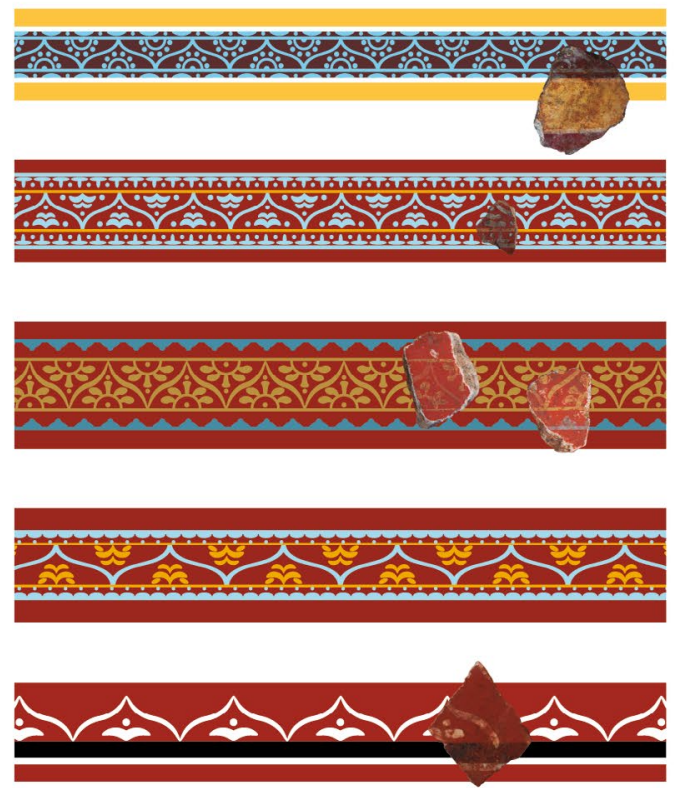

Triángulos de perfil curvo con alternancia
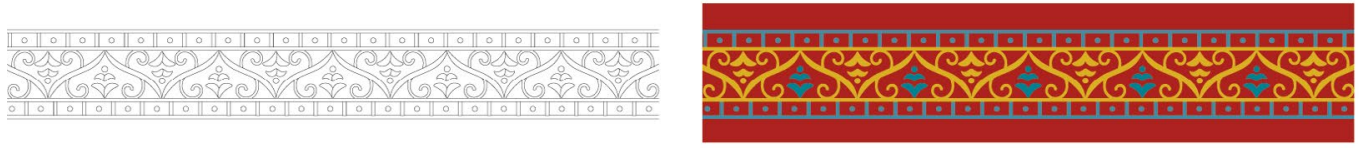

1.3.1 Casa del Mitreo (Mérida)
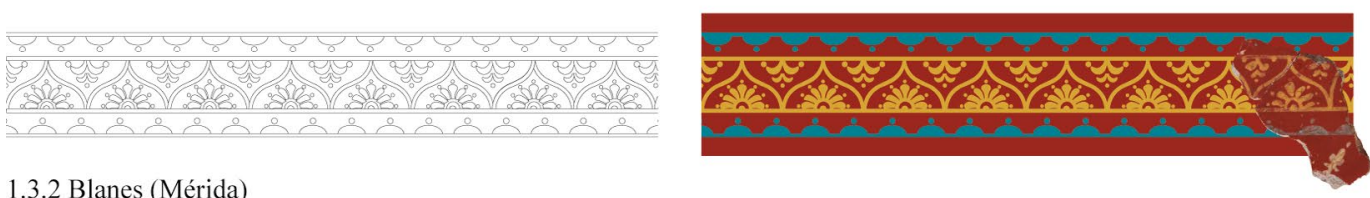

1.3.2 Blanes (Mérida)
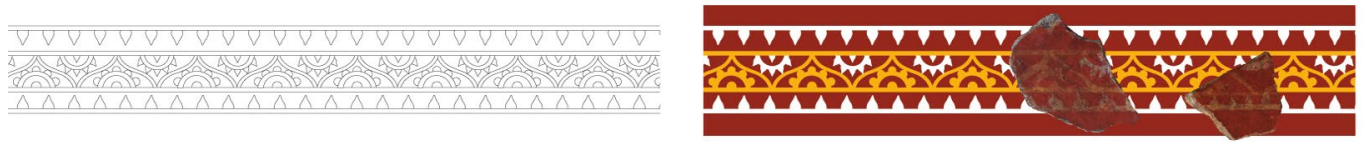

1.3.3 Blanes (Mérida)

Triángulos dobles contrapuestos sin alternancia
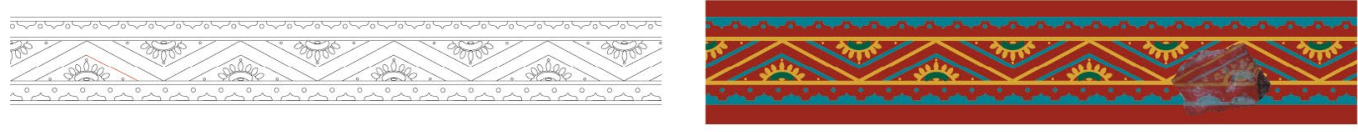

1.4.1 Blanes (Mérida)

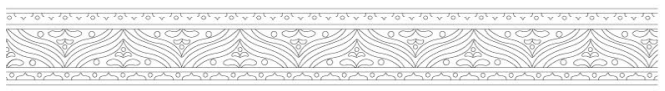

1.4.2 Blanes (Mérida)

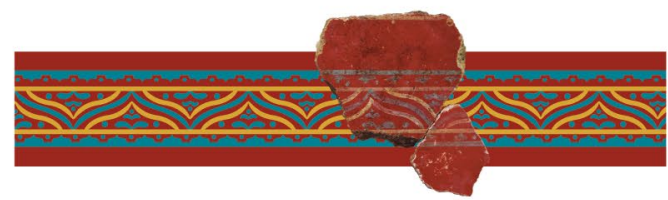




\section{Triángulos alternos}

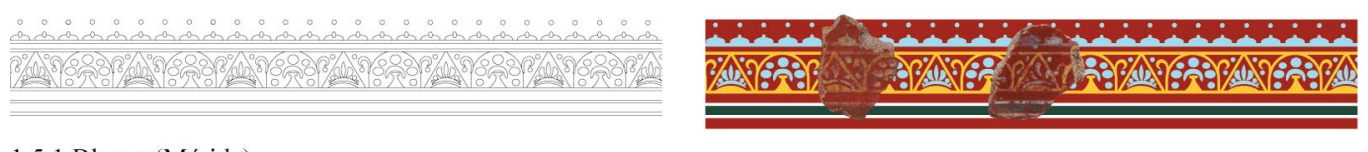

1.5.1 Blanes (Mérida)

Figura 2: Cenefas y orlas caladas del grupo de triángulos. Fuente: elaborada por los autores

el interior, encontramos una sucesión de óvalos con apéndice que alternan con pequeñas gotas también en azul, todo ello sobre un campo rojo y con una anchura total de $7,8 \mathrm{~cm}$ (Fig. 2.1.2.2). En este caso encontramos paralelos similares procedentes de la estancia «D» de la casa dell'Efebo $(\mathrm{I} 7,11)$, de la estancia 24 de la casa de la Fontana Piccola (VI 8, 23) (Barbet, 1981: fig. 12, 47b, c y d; Fröhlich, 1996) y del tablinum de la casa di Apolo (VI 2, 22) (Barbet, 1981: fig. 12, 47e) en Pompeya, con la excepción de la presencia de la sucesión de óvalos con apéndice y gotas que encontramos en nuestro ejemplar. A estos debemos sumar un último paralelo del corredor 81 de la villa di Poppea en Oplontis (Barbet, 1981: fig. 12, 47h) y uno de Moregine (Scarano Ussani, 2005: 114). En lo que respecta a su cronología, la datación del contexto entre época trajanea y adrianea, permite plantear su adscripción a un conjunto de inicios de época flavia.

El tercer y cuarto ejemplar proceden de las excavaciones realizadas en la Huerta de Otero de Mérida y que, al igual que el resto que abordaremos de esta intervención, carecen de contexto dada la falta de una metodología de excavación moderna en el momento de su hallazgo. En el primer caso contamos con una orla compuesta por cuatro filetes, los externos azules y los internos amarillos, que enmarcan una sucesión de triángulos de perfil curvo contrapuestos decorados con una palmeta en su interior con una gota en la parte central y otra sobre el pétalo central, todo ello en color amarillo. Por su parte, los filetes externos presentan, hacia el interior, una sucesión de semicírculos con apéndice azul, todo ello sobre fondo rojo y con una anchura total de 9,3 cm (Fig. 2.1.2.3). El segundo es bastante similar al de la UE 1470 que hemos analizado en este apartado, compuesto por cuatro filetes, los externos azules y los internos amarillos, que encuadran una sucesión de triángulos en color azul decorados al interior con dos bifolios superpuestos y dos gotas ovaladas debajo en color amarillo. Sobre los filetes azules, hacia el interior, presenta una sucesión de semicírculos coronados por una gota azul, todo ello sobre fondo rojo y con una anchura total de 7,1 cm (Fig. 2.1.2.4). En lo que respecta a los paralelos, remitimos a los anteriormente citados para esta variante. Dada la falta de un contexto claro y teniendo en cuenta las características técnico-estilísticas, así como el resto de ejemplares emeritenses, parece claro que deben situarse en torno a época flavia.
Por último, encontramos dentro de esta variante una orla procedente de la casa del Mitreo, recuperada del ambiente que se ubica a la derecha de las fauces de la casa durante las intervenciones llevadas a cabo en 1994. En este caso, la orla está formada por un filete blanco al que se superpone uno negro más ancho y sobre el que se desarrolla una sucesión de triángulos de perfil curvo en una sola hilera y sin contraposición, decorados en su interior por un bifolio con una gota blanca. Junto a esto y a diferencia del resto de ejemplares de este tipo, carece de filete de cierre por la parte superior, adoptando una forma abierta con una anchura total de $7,1 \mathrm{~cm}$ (Fig. 2.1.2.5). En lo que respecta a los paralelos, remitimos a los citados en el ejemplo anterior, de los que uno de la estancia 24 de la casa della Fontana Piccola de Pompeya (VI 8, 23) es el que guarda mayor similitud (Barbet, 1981: fig. 12, 47c; Fröhlich, 1996), con la diferencia de la presencia de una única fila de triángulos en nuestro ejemplar. En lo relativo a su cronología, el informe de la intervención carece de una datación debido a la ausencia de inventario del resto del material del contexto, si bien, como sucede en el resto de conjuntos de esta casa, encontramos un terminus post quem de época neroniana, lo que, unido a la calidad de la misma en relación al resto de ejemplares, nos lleva a ubicarla en los inicios del siglo II d. C.

III.1.3. Triángulos de perfil curvo contrapuestos con alternancia

Dentro de esta variante, el primero de los ejemplares proviene de la casa del Mitreo, en concreto de la que denominamos como la estancia del incendio, junto al peristilo, recientemente excavada y cuyos materiales se encuentran aún en proceso de estudio. La orla presenta cuatro filetes, los dos externos en azul y los internos en amarillo, donde se desarrolla una sucesión de triángulos de perfil curvo contrapuestos con dos volutas a modo de tallo curvo que se enroscan hacia el interior, así como dos bifolios superpuestos coronados por una gota que alternan en amarillo y azul. El filete azul queda decorado al interior mediante una sucesión de gotas azules separadas por filetes que generan espacios cuadrangulares de 2,6 cm de lado, todo ello sobre un panel rojo y con una anchura total de 9,1 cm (Fig. 2.1.3.1). Para este modelo indicamos nuevamente los paralelos señalados en la variante anterior, dado que 
muestran características similares, especialmente con el procedente del atrio de la casa degli Amanti (I 10, 11) (Barbet, 1981: fig. 12, 47f), incluyendo en este caso los del corredor «D» de la casa dei Cervi de Herculano (IV 21) (Barbet, 1981: fig. 12, 48a; Esposito, 2014) y el de la estancia «F» de la casa della Regina Margherita (V 2, 1) (Barbet, 1981: fig. 12, 48b), que si bien no cuentan con los mismos motivos sí presentan la decoración de volutas. En lo que respecta a su cronología, el conjunto al que se asocia, si bien aún se encuentra en fase de estudio, se ha fechado en época flavia (Bejarano Osorio et al., e.p.; Fernández Díaz et al., e.p.).

La segunda orla de esta variante procede de la UE 1535 del vertedero de Blanes, compuesta por cuatro filetes, los dos externos azules y los internos amarillos, que enmarcan una sucesión de triángulos de perfil curvo contrapuestos donde alternan una palmeta de siete puntas, cada una de ellas rematada por una gota en amarillo, y dos bifolios superpuestos, con dos gotas en los extremos inferiores y una coronando el motivo. Por su parte, los filetes azules están decorados hacia el interior con una sucesión de semicírculos coronados por una gota azul, todo ello con una anchura total de $10,8 \mathrm{~cm}$ (Fig. 2.1.3.2). Remitimos a los paralelos anteriores dada la similitud que presenta con estos esquemas, con la diferencia del motivo central y el que decora los filetes exteriores, que en el primer caso remite a los ejemplares pompeyanos, mientras que en el segundo se enmarca en la línea de las producciones flavias de Mérida. En lo que respecta a su cronología, el contexto fue datado entre los años 80 y 100 d. C. por lo que, teniendo en cuenta sus características técnico-estilísticas, optamos por una cronología de inicios época flavia, pudiendo haber sido amortizado en los últimos años del siglo I d. C.

El último caso de esta variante procede las UUEE 1200 y 1262 de Blanes, una orla calada con cuatro filetes, los externos blancos y los internos amarillos, con una sucesión de triángulos decorados con una alternancia de un semicírculo con una gota central y cinco gotas sobre el borde, en el primer caso en amarillo y en el segundo en blanco y con un perfil más puntiagudo, a modo de pétalos. El filete blanco se encuentra decorado al interior mediante una sucesión de gotas blancas puntiagudas similares a las que encontramos en el interior de los triángulos, todo ello sobre fondo rojo y con una anchura total de $9 \mathrm{~cm}$ (Fig. 2.1.3.3). En relación a los paralelos, volvemos a señalar los anteriormente indicados, en este caso con las salvedades que adopta la ornamentación interna, cuyos motivos son más próximos al del ejemplar 1.2.3. La cronología del contexto de la UE 1200, así como las características, permitirían situarlo entre finales del siglo I d. C. e inicios del siglo II d. C. a pesar de que la UE 1262 fue fechada a finales del siglo III d. C. ${ }^{16}$, pero

16. En el caso de la UE 1262, la datación responde a la presencia de ejemplares ARSW-A Hayes 27 y 28, ARSW-A/D Hayes 32, ARSW-C: Hayes 49 y 50c, así como a africanas de cocina Ostia I 261. parece probable que su hallazgo en dicha unidad se deba a un movimiento por posibles remociones de la unidad.

III.1.4. Triángulos dobles contrapuestos sin alternancia

Una cuarta variante engloba dos modelos con características de los dos grupos anteriores. Ambos proceden del vertedero de Blanes de Mérida, el primero, de la UE 1542, compuesto por cuatro filetes, los dos externos azules y los internos amarillos que encierran una sucesión de triángulos amarillos contrapuestos que, a su vez, contienen triángulos de menor tamaño en azul, decorados interiormente mediante una palmeta de siete pétalos sobre un semicírculo en amarillo con una media luna en verde y una gota amarilla, así como tres pequeños puntos en amarillo ubicados cada uno de ellos en una de las esquinas internas del triángulo. Sobre el filete azul y hacia el interior encontramos una sucesión de óvalos con apéndice que alternan con gotas en azul, todo ello sobre fondo rojo y con una anchura total de 9 cm (Fig. 2.1.4.1). En lo que respecta a su cronología, la datación del contexto entre época trajanea y adrianea permite adscribirla a época flavia.

El segundo, procedente de la UE 1535 presenta un esquema similar, compuesto por triángulos de perfil curvo, los de mayor tamaño en azul y los de menor en amarillo decorados interiormente mediante dos bifolios superpuestos con una gota en los laterales y una coronando la parte superior. Por su parte, sobre el filete azul hacia el interior repite el mismo esquema que en el ejemplar anterior con dimensiones similares, todo ello sobre fondo rojo y con una anchura de $7,8 \mathrm{~cm}$ (Fig. 2.1.4.2). Su contexto fue fechado entre los años 80-100 d. C. y las características técnico-estilísticas son similares a los modelos de época flavia que hemos analizado procedentes de Mérida, por lo que probablemente se encuadre a inicios de esta o hacia finales de época neroniana dada la necesidad de que exista un margen entre la ejecución y la amortización del conjunto (Fernández Díaz et al., e.p.).

En ambos casos, debemos remitirnos a los paralelos citados anteriormente para los grupos de triángulos contrapuestos y triángulos de perfil curvo contrapuestos, a los que debemos sumar un ejemplar procedente del peristilo de la casa dei Cervi (IV 21) de Herculano (Barbet, 1981: fig. 9, 40g), que, aunque presenta una policromía distinta y carece de decoración interna en los triángulos, deja ver claramente la combinación de dos grupos de distinto tamaño tal y como encontramos en nuestros ejemplares.

\section{III.1.5. Triángulos alternos}

La última variante la compone un único ejemplar, también procedente del vertedero de Blanes, en este caso de la UE 1471. A diferencia del resto de modelos 
de esquema de triángulos, encontramos aquí alternancia no solo en el motivo que decora interiormente los triángulos sino también en los propios triángulos, que se combinan con semicírculos peraltados. La orla está compuesta, en su parte inferior, por un triple filete, los dos externos blancos y el interno verde, y en su parte superior por un filete azul claro, quedando en el interior dos filetes amarillos que enmarcan la alternancia entre los triángulos y los semicírculos del mismo color. En el interior de los triángulos se desarrolla un semicírculo achatado sobre el filete al que se superpone un trazo azul con tres pétalos en la parte central y dos gotas a cada lado, a modo de palmeta esquematizada, así como cuatro gotas azules en oblicuo, dos a cada lado del triángulo por su exterior. En el caso del semicírculo, presenta un ligero peralte y dos tallos curvos hacia el exterior, uno a cada lado, mientras que el interior cuenta con una prolongación de forma triangular rematada en forma oval que parte del filete a modo de peana y sobre la cual se dispone un trazo curvo en azul y una serie de 7 gotas de distinto tamaño alrededor. Por último, el filete azul presenta, hacia el exterior, una sucesión de gotas ovaladas con apéndice, coronadas con una gota del mismo color. La orla, dispuesta sobre fondo rojo, presenta una anchura total de 7,2 cm (Fig. 2.1.5.1).

Paralelos de este tipo de orlas provienen de las estancias «K» de la casa dei Vettii (VI 15, 1) (Archer, 1982) y 5 de la casa di Fabius Rufus (VII 16, 22) (Grimaldi, 2009) en Pompeya, así como en la casa di Nettuno e Anfititre (IX 2, 27) en Herculano (Esposito, 2014), a los que debemos sumar uno recogido por Zahn (Barbet, 1981: fig. 10, 42f). Junto a estos, los más parecidos a nuestro ejemplar, existen otras variantes que presentan una unión mediante trazos rectos con los filetes de encuadramiento, como los procedentes del conjunto «K» de la casa del Principe di Napoli (VI 15, 8) (Strocka, 1984) o del conjunto «C» de la casa de Paquius Proculus (I 7, 1) (Ehrhardt, 1998) en Pompeya. El contexto fue fechado entre época trajanea y adrianea ${ }^{17}$, lo que permite datarlo en torno a finales de época neroniana e inicios de época flavia, a pesar de que a nivel técnico-estilístico la calidad y la presencia de triples filetes, inferiores a $2 \mathrm{~cm}$, sugieren una cronología anterior, probablemente de época de Claudio. En este sentido, no descartamos que se trata de parte de un conjunto anterior cuya amortización se produjo en un momento avanzado.

Además de todos los ejemplos citados, añadimos uno procedente de la UE 1234 del vertedero de Blanes que por su parcialidad no se ha podido restituir e incluir en una variante concreta pero que muestra un esquema de triángulos.

17. En este caso presenta la misma cronología y material que la UE 1470, que formarían una misma unidad que fue diferenciada durante el proceso de excavación.

\section{III.2. TIPO 2: CUADRILÁTEROS ${ }^{18}$}

Dentro del grupo de las cenefas y orlas de cuadriláteros encontramos cuatro variantes, los cuadriláteros sin alternancia (2.1), los cuadriláteros con alternancia (2.2), los cuadriláteros no yuxtapuestos sin alternancia (2.3), cuadriláteros no yuxtapuestos con alternancia (2.4) y los cuadriláteros entrelazados (2.5), si bien es posible que existan casos de cuadriláteros no yuxtapuestos sin alternancia que, hasta la fecha, no se han documentado en Hispania.

\section{III.2.1. Cuadriláteros sin alternancia}

Dentro de la primera variante encontramos un ejemplar procedente del techo de la tumba de Servilia en la necrópolis de Carmona, así identificado en base a las indicaciones de los dibujos realizados por Rodríguez Jaldón (Baceiredo Rodríguez y Fernández Gómez, 2012) tal y como lo recoge Abad Casal (1982: 190) y que actualmente se encuentran en el Museo de la Necrópolis de Carmona (Fernández Díaz, 2010) ${ }^{19}$. En este caso se trata de una orla dispuesta formando un círculo, compuesta por dos filetes rojos que enmarcan espacios cuadrangulares de entre 2,5 y $3 \mathrm{~cm}$ de anchura cortados en su interior por dos filetes oblicuos que generan espacios triangulares decorados mediante semicírculos. Hacia el exterior se dispone una gota en la unión entre cada cuadrilátero que sobresale hacia fuera de la orla, todo ello dispuesto sobre un fondo blanco y con una anchura de $4 \mathrm{~cm}$ (Fig. 3.2.1.1). Este tipo cuenta con paralelos en Pompeya dentro de la variante con alternancia, como el del peristilo de la casa di Fabius Rufus (I 7, 2-3) (Grimaldi, 2009), a pesar de que este ejemplar presenta un único motivo, y es un tipo que encontramos en conjuntos previos al terremoto del año 62 d. C. como en las casas del Principe di Napoli (VII 15, 8) (Strocka, 1984) y dell'Orso (VII 2, 45) (Ehrhardt, 1988). A estos sumamos el de la estancia 18 de la casa di Holconius Rufus (VIII 4, 4) en Pompeya (Barbet, 1981: fig. $13,50 \mathrm{c})$, aunque sin la división interna mediante filetes oblicuos que si encontramos en otros ejemplares con alternancia. En lo que respecta a su cronología, al igual que el resto de casos de la tumba de Servilia, en un primer momento se estableció una datación en torno a la primera mitad del siglo I d. C. en base al momento de construcción de la tumba a inicios de dicho siglo (Abad Casal y Bendala Galán, 1975). No obstante, estudios

18. Este grupo y sus variantes se corresponden con los tipos 50-56 del grupo VII de Barbet (1981).

19. Todos los ejemplares procedentes de Carmona que se recogen en este trabajo fueron señalados por Abad Casal como de procedencia desconocida según figuraban en los fondos del Museo de la Necrópolis de Carmona, si bien el mismo indicaba su vinculación a la tumba de Servilia en base a los dibujos de Rodríguez Jaldón, por lo que en adelante se indicará directamente dicha procedencia. 


\section{Cuadriláteros sin alternancia}

2.1.1 Tumba de Servilia (Carmona)

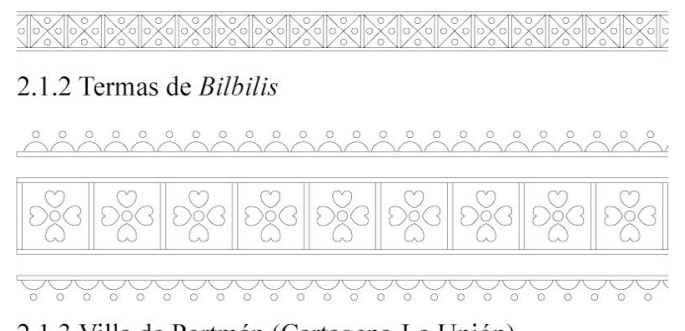

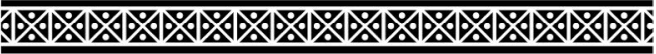

2.1.3 Villa de Portmán (Cartagena-La Unión)

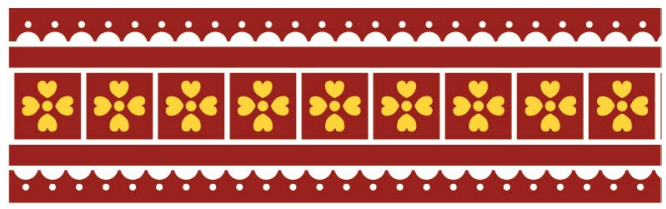

\section{Cuadriláteros con alternancia}

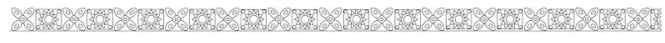

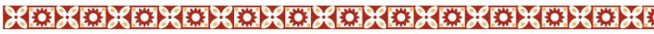
2.2.1 Tumba de Servilia (Carmona)
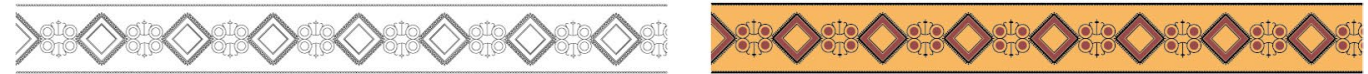

2.2.2 Tumba de Servilia (Carmona)
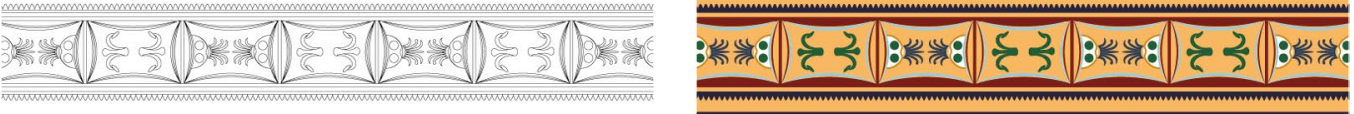

2.2.3 Tumba de Servilia (Carmona)

[.8.

2.2.4 Cabo Verde (Mérida)

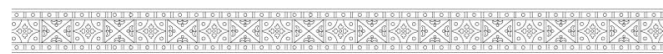

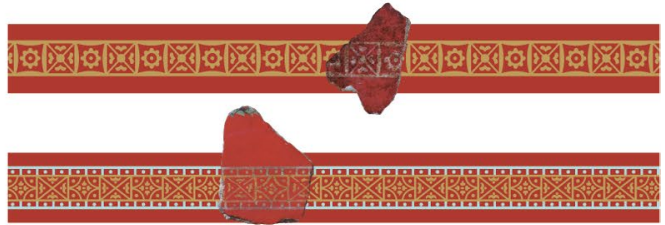

2.2.5 Cabo Verde (Mérida)

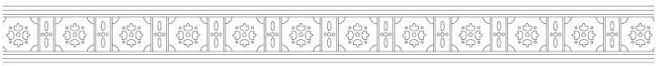

2.2.6 Cabo Verde (Mérida)

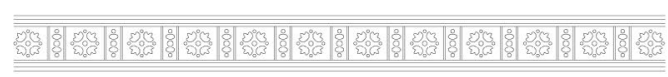

2.2.7 Cabo Verde (Mérida)

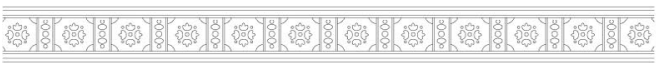

2.2.8 Cabo Verde (Mérida)

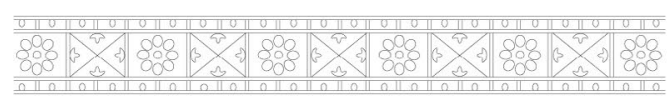

2.2.9 Calle Añón (Zaragoza)
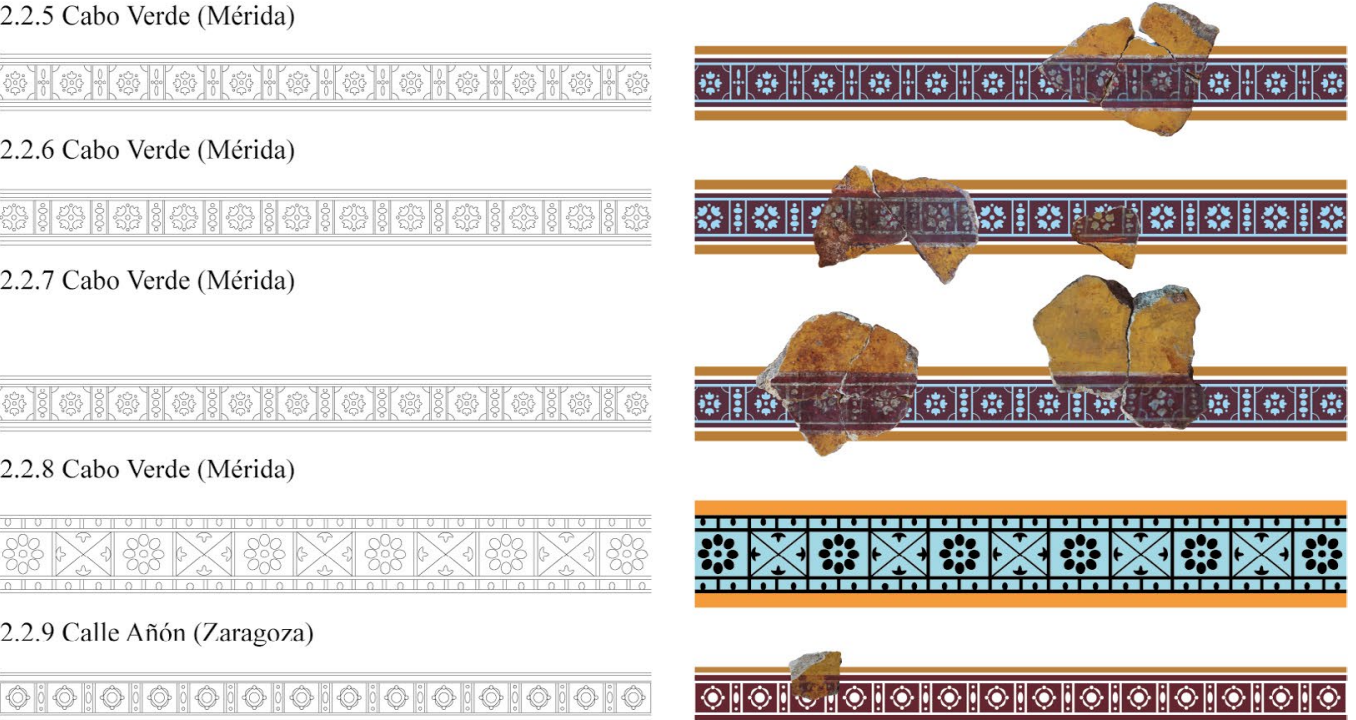

2.2.10 Blanes (Mérida)

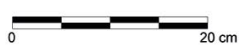

Figura 3: Cenefas y orlas caladas del grupo de cuadriláteros. Fuente: elaborada por los autores 
posteriores han modificado esta cronología, avanzando su construcción a la segunda mitad del siglo I d. C. y señalando la ejecución de los conjuntos pictóricos probablemente en torno a época de Nerón (Rodríguez Temiño et al., 2012: 139), hecho que confirmaría su adscripción al IV estilo.

El segundo ejemplar procede de Bilbilis, del conjunto A hallado en la estancia $\mathrm{M}$ de las termas (Guiral Pelegrín y Martín-Bueno, 1996: fig. 33), del cual hemos tratado un modelo de triángulos y que también abordaremos más adelante para otros esquemas. En este caso se trata de una orla en blanco sobre fondo negro compuesta por una sucesión de cuadrados de $4 \mathrm{~cm}$ de lado, decorados en su interior por dos trazos diagonales que dividen el espacio en cuatro secciones, cada una decorada con una gota blanca. La anchura total es de $4,1 \mathrm{~cm}$ (Fig. 3.2.1.2). En lo que respecta a los paralelos, remitimos a los referidos en el caso anterior dada su similitud de forma, si bien difieren en los motivos internos y externos. Al igual que el resto de orlas que componen el conjunto hallado en esta estancia (1.1.4 y 8.2.3), se ha fechado en los primeros años de la segunda mitad del siglo I d. C.

En tercer lugar, contamos con una orla calada procedente de la villa romana de Portmán perteneciente al triclinium (Fernández Díaz, 1997; 1999a; 2008), que ya muestra de manera clara la adopción del gusto local en sus elementos. La orla está compuesta por cuatro filetes blancos de los que los interiores enmarcan una sucesión de cuadrados de 7,5 cm de lado, decorados con una gota amarilla flanqueada por cuatro pétalos con forma cordiforme del mismo color. Los filetes externos presentan, hacia el exterior, una sucesión de semicírculos coronados por una gota blanca, todo ello sobre fondo rojo y con una anchura total de $17,4 \mathrm{~cm}$ (Fig. 3.2.1.3). Este tipo de orla cuenta con paralelos como el de la habitación «b» de la casa de Pinarius Cerialis (III 4, b) o el del atrio de la villa de Julia Felix (II 4, 1-12) (Bragantini et al., 1981) de Pompeya, o de la sala «b» de la casa del Bel Cortile (V 8) de Herculano, así como, en el ámbito provincial, el procedente de Augst, Diesgrube (Drack, 1950: 48 fig. 2), aunque el motivo de las flores también se encuentra en otros modelos con alternancia. En lo que respecta a su cronología, el conjunto fue fechado entre finales del siglo I e inicios del siglo II d. C. (Fernández Díaz, 2008: 371).

\section{III.2.2. Cuadriláteros con alternancia}

Si pasamos a esta variante, es probablemente el grupo más numeroso entre todos los tipos recogidos en este trabajo y que comprende, además, una horquilla cronológica entre mediados del siglo I y mediados del siglo II d. C. Entre los ejemplares más antiguos encontramos los procedentes de la tumba de Servilia (Abad Casal, 1982b: 192, fig. 289; Fernández Díaz, 2010; Baceiredo Rodríguez y Fernández Gómez, 2012), que, tal y como hemos indicado anteriormente, deben fecharse en torno a época neroniana en base a la nueva cronología establecida para la construcción de la tumba (Rodríguez Temiño et al., 2012: 139).

El primero es una cenefa calada formada únicamente por una banda roja sobre un fondo blanco, encima de la cual se desarrollan los motivos decorativos, compuestos por flores de cuatro pétalos en blanco que presentan una gota roja en la parte central y cuatro gotas amarillas dispuestas en la punta de los pétalos. Estas alternan con una flor en rojo con una gota central en blanco y con doce finos pétalos puntiagudos de color rojo, dispuesto todo ello sobre un espacio cuadrangular en blanco que cuenta con una gota amarilla en cada esquina, todo ello con una anchura total de $2,4 \mathrm{~cm}$, lo que la convierte en la más fina de todas las estudiadas (Fig. 3.2.2.1). Entre los modelos más similares podemos citar los del tipo 52 de Barbet, si bien el procedente de la escalera 13 de la villa de San Marco en Stabia (Barbet, 1981: fig. $14,52 \mathrm{~h}$ ) es el más parecido en lo que respecta a los motivos.

El segundo ejemplar es una orla calada sobre fondo amarillo compuesta por dos filetes negros que enmarcan una sucesión de cuadrados en posición oblicua de borde negro decorados al exterior por una sucesión de dentículos coronados con gotas del mismo color. Hacia el interior, el cuadrado está decorado mediante una banda roja y un filete negro, quedando el espacio central del mismo color que el fondo de la orla. Este motivo alterna con otro compuesto por cuatro círculos de borde negro con una gota roja en su interior, unidos en grupos de dos y separados, en la parte central, por una línea negra curva. Junto a esto, quedan rematados hacia los extremos superior e inferior por dos trazos curvos enfrentados y un trazo recto rematado con una gota ovalada, todo ello en negro. Por último, los filetes de encuadramiento presentan, hacia el interior, una sucesión de pequeños semicírculos, dándole una anchura total de 7,2 cm (Fig. 3.2.2.2). En lo que respecta a los trazos preparatorios, no hay constancia de su presencia dado que los datos que conservamos proceden de los dibujos realizados por Rodríguez Jaldón, si bien parece lógico que se emplearan líneas incisas tal como las hay en el resto de casos sobre fondo amarillo procedentes de la tumba de Servilia. Entre los paralelos no contamos con ningún ejemplar que presente unos motivos ni morfología similares en el ámbito pompeyano. En el caso de las provincias, podemos señalar un paralelo de uno de los motivos procedente de una orla de la estancia «K» de la casa del Grand Triclinium de Clos de la Lombarde en Narbona (Sabrié y Sabrié, 2011), que se fecha entre finales del siglo I e inicios del II d. C.

El tercer ejemplar de la tumba de Servilia lo hemos definido como una orla a pesar de que la combinación de colores puede llevar a señalarla como una cenefa. Está compuesta por seis filetes, cuatro azules hacia el exterior y dos rojos al interior que encierran una serie de espacios rectangulares cuyos lados superior 
e inferior presentan un engrosamiento del filete que genera una forma semicircular muy achatada. En el interior alternan, por un lado, un motivo compuesto por dos semicírculos blancos con borde amarillo, achatado en la parte que da hacia el centro del rectángulo y que cuenta, en el interior, con dos gotas verdes, mientras que hacia el exterior está coronado por una palmeta en azul que se enfrenta a la del lado contrario. Por otro lado, encontramos un motivo parcialmente conservado que muestra dos elementos vegetales con tres tallos en color verde dispuestos en contraposición horizontal, de los que los laterales giran hacia el exterior y quedan rematados por una gota ovalada. En ambos casos, el espacio que enmarca los motivos cuenta, por su lado superior e inferior, con un fino trazo azul que adopta la curvatura de dichos laterales y que, en los lados cortos, se repite junto a un segundo trazo curvo rojo. Por último, el filete interno azul presenta, hacia el exterior, una sucesión de triángulos a modo de dientes del mismo color, quedando la orla dispuesta sobre un fondo amarillo y con una anchura total de $13 \mathrm{~cm}$ (Fig. 3.2.2.3). $\mathrm{Al}$ igual que en el caso anterior, no hay constancia de presencia de trazos preparatorios, si bien no se puede descartar. Entre los paralelos no contamos con ningún ejemplar en el ámbito pompeyano, pudiendo señalar únicamente uno procedente de la estancia 27 de la villa di Poppea en Oplontis (Barbet, 1981: fig. 15, 52w) por la morfología de los cuadriláteros, alargados al igual que nuestro caso.

Un grupo bastante numeroso lo encontramos en el vertedero de la calle Cabo Verde de Mérida, los más antiguos procedentes de la UE 65, con cinco ejemplares de los que tres constituyen un mismo esquema con muy pocas variaciones.

El primero de ellos es una orla calada sobre un campo rojo, enmarcada por dos filetes amarillos y que encierran espacios cuadrangulares de $3 \mathrm{~cm}$ de lado, donde alternan, por un lado, cuatro bifolios hacia el exterior dispuestos en espacios triangulares generados por dos filetes en posición oblicua, que en su unión están decorados con una gota y, por otro, un círculo con una gota central y ocho gotas a su alrededor a modo de pétalos. Junto a esto, este motivo cuenta también con un ligero engrosamiento de los laterales del cuadrilátero, similar a lo que ocurre en el ejemplar 2.2.3 procedente de Carmona, aunque en este caso de menores dimensiones, todo ello en color amarillo y con una anchura total de 3,6 cm (Fig. 3.2.2.4). Entre los paralelos podemos citar algunos como el de la sala 11 de la casa dell'Efebo (I 7, 11), el del atrio de la casa di Paquius Proculus (I 7, 1), fechado entre los años 62-69 d. C. (Barbet, 1981: fig. 14, 52f y g; Ehrhardt, 1998; Esposito, 2009: 137 y 146149), el de la estancia «F» de la casa di M. Lucretius Fronto (V 4, a), de similar cronología (Barbet, 1981: fig. 14, 521; Peters y Moorman, 1993: 356-378), el de un muro a la izquierda entrando por Porta Marina (Barbet, 1981: fig. 15, 52r) en Pompeya o del frigidarium 25 de la villa de San Marco en Stabia (Barbet, 1981: fig. 15, 52x). En lo que respecta a su cronología, dada la datación de la UE optamos por ubicarla entre época claudia y neroniana.

El segundo ejemplar presenta un cromatismo similar, con la excepción de que en esta ocasión cuenta con dos filetes más al exterior en azul, decorados hacia el interior con una sucesión de espacios cuadrangulares marcados por filetes con una gota central del mismo color. En la parte interior de la orla, los cuadriláteros alternan un motivo de cuatro bifolios enfrentados dos a dos con una gota encima sobre espacios triangulares divididos por dos filetes oblicuos. Un segundo motivo está compuesto por una gota central rodeada de cuatro gotas ovaladas con apéndice a modo de hoja trilobulada algo esquemática y un cuarto de círculo en cada esquina con una gota en el interior, todo ello con una anchura total de $4,4 \mathrm{~cm}$ (Fig. 3.2.2.5). En cuanto a los paralelos, además de los ya citados, incluimos el del atrio de la casa degli Amanti $(\mathrm{I} 10,11)$ en Pompeya (Ling, 2005: 115, fig. 172.94), el de la estancia 5 de la casa del Tramezzo di Legno (III 1, 1) y el de la estancia 27 de la villa di Poppea en Oplontis (Barbet, 1981: fig. 14, $52 \mathrm{i}, \mathrm{n}$, fig. 15, 52w). En este caso optamos por la misma cronología que en el ejemplar anterior, situándolo entre época claudia y neroniana.

Por último, encontramos tres ejemplares de cenefa calada de fondo violáceo sobre panel amarillo que cuenta con dos filetes blancos externos y dos azules internos, estos últimos enmarcando una sucesión de cuadrados de $3,8 \mathrm{~cm}$ que alternan con rectángulos de $1,6 \mathrm{~cm}$. Este esquema se repite en los tres casos, variando únicamente la decoración interna de manera muy leve. La primera presenta, en los rectángulos, una gota central con una gota de menor tamaño a izquierda y derecha y dos gotas alargadas arriba y abajo, todo en azul, mientras que el cuadrado presenta una gota central con cuatro trifolios dispuestos a los costados y una gota de menor tamaño en las esquinas entre cada trifolio, así como un cuarto de círculo en cada esquina del cuadrilátero. Este modelo difiere del segundo únicamente en la decoración del rectángulo, que se sustituye por cinco gotas en posición vertical de anchura alternante, mientras que, en el tercer modelo, mantiene esta última decoración, pero altera la de los cuadrados, donde desaparecen los cuartos de círculo y el motivo central se dispone con un giro de $45^{\circ}$, y una anchura total en todos los casos de 5,7 cm (Fig. 3.2.2.6, 2.2.7 y 2.2.8). En los tres casos contaríamos con trazos preparatorios blancos, dado que se aprecia una diferencia de color entre algunos fragmentos que sugieren una capa inferior en dicho color. En cuanto a los paralelos, podemos incluir, además de los citados, el del peristilo 3 de la villa de San Marco en Stabia, así como el recogido por Gusman de procedencia desconocida (Barbet, 1981: fig. 15, 52ac, 52s). En lo que respecta a su cronología, todos ellos se fechan según el contexto, entre época claudia y neroniana, formando los tres parte de un mismo conjunto, probablemente de una misma pared o incluso de un mismo panel, dado que no es extraño encontrar paneles con motivos distintos en una cenefa $u$ 
orla calada entre los extremos superiores y los laterales, como sucede en uno de los paneles de la villa romana de Positano (Jacobelli, 2018), entre otras.

Probablemente algo posteriores a estas últimas encontramos una cenefa procedente del conjunto del triclinium de la domus de la calle Añón de Zaragoza (Guiral Pelegrín et al., 2019: 230, fig. 11), a la que debemos sumar una segunda que analizaremos más tarde. En este caso está compuesta por cuatro filetes negros que encuadran, los internos, una sucesión de espacios cuadrangulares en los que alternan, por un lado, cuatro trifolios enfrentados dos a dos dispuestos en espacios triangulares fruto de la disposición de dos filetes oblicuos y, por otro, una roseta con ocho pétalos y una gota central. Junto a esto, sobre el filete exterior se dispone, hacia el interior, una sucesión de espacios cuadrangulares separados por filetes con una gota negra ligeramente ovalada. Todo ello se dispone sobre una banda azul que decora un panel amarillo, con una anchura total de $8 \mathrm{~cm}$ (Fig. 3.2.2.9). En cuanto a los trazos preparatorios, se ha documentado la presencia de incisiones, bien a mano alzada bien mediante regla, en la parte superior de la cenefa. En lo que respecta a sus paralelos, remitimos a los citados, especialmente al del atrio de la casa di Paquius Proculus (I 7, 1), el de la estancia «f») de la casa di M. Lucretius Fronto (V 4a), o el del atrio de la casa degli Amanti (I 10,11) de Pompeya, que también cuenta con las gotas ovaladas, aunque solo en uno de sus lados, y que han llevado a fechar este ejemplar, así como el conjunto, en un IV estilo maduro, posterior al año $62 \mathrm{~d}$. C. (Guiral Pelegrín et al., 2019: 236).

De cronología ligeramente posterior a estos últimos encontramos seis ejemplares procedentes del vertedero de Blanes en Mérida, los tres primeros más próximos cronológicamente al de la calle Añón de Zaragoza. En primer lugar, una cenefa calada de fondo violáceo sobre un campo amarillo compuesta por cuatro filetes blancos que enmarcan una sucesión de espacios cuadrangulares y rectangulares alternos. En los primeros encontramos una gota central blanca flanqueada por cuatro trazos curvos en las esquinas entrelazados por una gota de menor tamaño, de manera que se dispone una en cada extremo. En los segundos, una gota ovalada se dispone en la parte central flanqueada arriba y abajo por una gota de menor tamaño, todo ello con una anchura total de 5,1 cm (Fig. 3.2.2.10). En lo que respecta a los paralelos, remitimos al ya citado del peristilo 3 de la villa de San Marco en Stabia y al recogido por Zahn. En lo que respecta a su cronología, la datación del contexto entre los años 50-100 d. C. y las características técnico-estilísticas, sugieren una cronología de época neroniana, pudiendo haber sido amortizado hacia finales de época flavia.

En segundo lugar, encontramos una orla procedente de la UE 1535, formada por cuatro filetes, los dos externos azules y los internos amarillos, que enmarcan una sucesión de cuadrados separados entre sí por un espacio rectangular con una gota amarilla central y dos azules en los extremos. Los cuadrados alternan su decoración con cuatro bifolios dobles enfrentados dos a dos coronados por una gota y que rellenan espacios triangulares generados por dos filetes oblicuos, por un lado y, por otro, una gota central con cuatro hojas en los laterales, inscritas en un rombo formado por la unión de un cuarto de círculo dispuesto en cada esquina, que encierra en su interior tres gotas amarillas. La orla se dispone sobre un fondo rojo, con una anchura total de 5,3 cm (Fig. 4.2.2.11). En cuanto a los paralelos, este caso presenta una combinación de formas y motivos similar a los ejemplares de Cabo Verde, por lo que remitimos a los paralelos citados, especialmente los de la estancia 5 de la casa del Tramezzo di Legno (III 1, 1) de Herculano, el de la estancia 27 de la villa di Poppea en Oplontis y el del frigidarium 25 de la villa de San Marco en Estabia, así como el recogido por Zhan. En este caso, forma parte del mismo conjunto que la orla 7.2.1 y, dada la cronología del contexto, fechado entre los años 80 y 100 d. C., así como las características técnico-estilísticas, optamos por una cronología de época neroniana.

En tercer lugar, una cenefa calada de la UE 925, de fondo violáceo sobre panel amarillo con cuatro filetes, los dos externos blancos y los internos azules, que enmarcan una sucesión de cuadrados y rectángulos, los primeros con una gota central y cuatro triángulos contrapuestos dos a dos con una gota entre cada uno, y los segundos con una gota central y dos bifolios contrapuestos coronados por otra gota, todo ello en el mismo color. La cenefa presenta una particularidad, dado que la zona superior de la banda violácea es ligeramente más ancha que la inferior, lo que le da una anchura total de 7,4 cm (Fig. 4.2.2.12). Entre los paralelos ya citados, destacamos el procedente del peristilo 3 de la villa de San Marco en Stabia, el más similar tanto en su morfología como en sus motivos decorativos. En lo que respecta a su cronología, la UE fue datada entre los años 80-100 d. C. por lo que optamos por situarla entre época neroniana y época flavia.

En cuarto lugar, encontramos una orla calada que se encuentra descontextualizada pero igualmente perteneciente al veredero de Blanes. Esta, parcialmente conservada, está compuesta por dos filetes amarillos que encierran cuadrados de $6,1 \mathrm{~cm}$ de anchura donde alternan dos motivos. Por un lado, un círculo flanqueado por cuatro gotas en los extremos y cuatro gotas ovaladas con apéndice en los espacios entre estos, coronadas con otra gota, todo ello en azul. Por otro lado, un círculo amarillo flanqueado en las diagonales por cuatro gotas ovaladas con un apéndice muy pronunciado que simulan un trifolio esquematizado. Dada la fragmentariedad, no se descarta la posible presencia de filetes azules al exterior, teniendo una anchura total de $8,3 \mathrm{~cm}$ (Fig. 4.2.2.13). Este es probablemente el más simple de esta variante, pudiendo citar como paralelo el de la casa del Championnet (VII 2, 1) (Barbet, 1981: fig. 14, $52 \mathrm{j}$ ), no tanto por sus motivos como por la simplicidad de las formas. En lo que respecta a la cronología, a pesar de la ausencia de contexto, parece claro, dadas 


\section{Cuadriláteros con alternancia}

\section{釷:}

2.2.11 Blanes (Mérida)

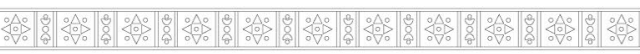

\subsubsection{Blanes (Mérida)}

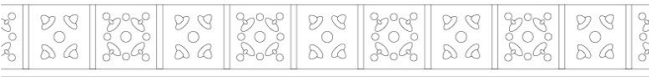

\subsubsection{Blanes (Mérida)}

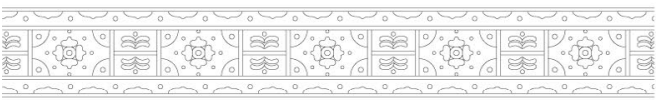

\subsubsection{Blanes (Mérida)}

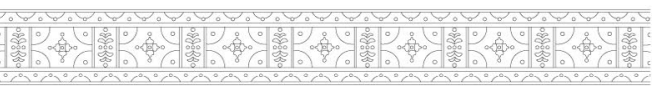

\subsubsection{Blanes (Mérida)}

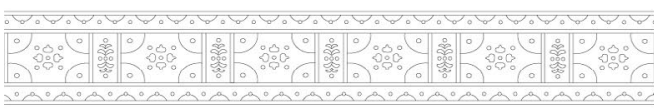

2.2.16 Casa del Mitreo (Mérida)

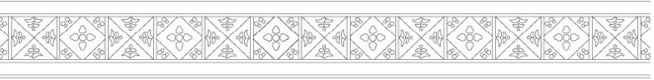

\subsubsection{Casa del Mitreo (Mérida)}

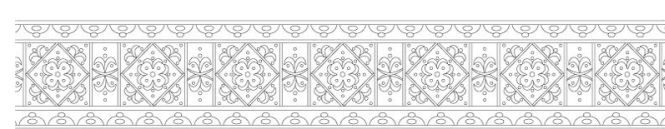

2.2.18 Cabo Verde (Mérida)

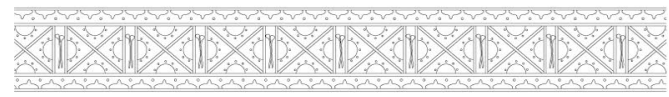

2.2.19 Calle Hernán Cortés (Mérida)

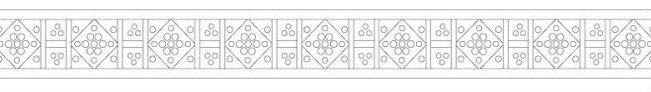

2.2.20 Casa del Mitreo (Mérida)

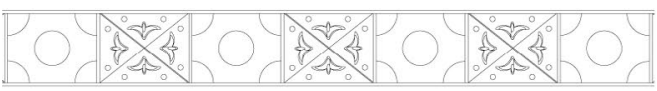

2.2.21 Palau de les Corts (Valencia)
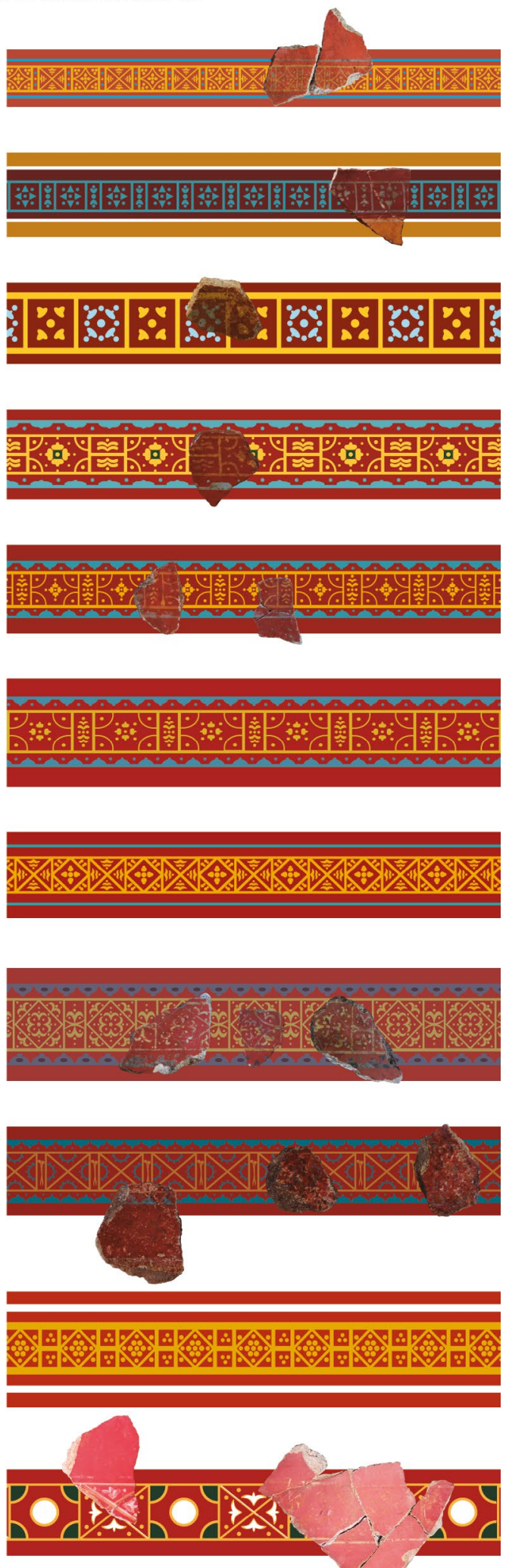

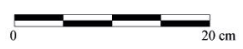

Figura 4: Cenefas y orlas caladas del grupo de cuadriláteros. Fuente: elaborada por los autores 
las características técnico-estilísticas, que pueda tener una cronología flavia.

En quinto lugar, contamos con una orla procedente de la UE 1471 formada por cuatro filetes, los externos azules y los internos amarillos, estos últimos enmarcando una sucesión de espacios cuadrangulares: el primero de ellos, con un círculo verde con una gota amarilla flanqueados por cuatro trifolios coronados por una gota amarilla y con gotas entre cada una, así como un cuarto de círculo con una gota interior en cada esquina; mientras que el segundo presenta una división horizontal en dos espacios, cada uno con dos bifolios superpuestos y una gota, de manera contrapuesta. El filete azul presenta hacia el interior una sucesión de óvalos con apéndice que se intercalan con una gota azul, todo ello sobre un fondo rojo y con una anchura de $9,2 \mathrm{~cm}$ (Fig. 4.2.2.14). En cuanto a sus paralelos, remitimos a los ya señalados, siendo el recogido por Gusman (Barbet, 1981: fig. 15, 52s) el más similar. En lo que respecta a su cronología, la datación del contexto entre época trajanea y adrianea permite situarlo en época flavia.

El último ejemplar de Blanes, procedente de las UUEE 925 y 1470, presenta un esquema similar al anterior, si bien en este caso los espacios cuadrangulares carecen de la gota central verde y tienen un menor número de gotas amarillas alrededor de los trifolios, mientras que, en los rectángulos, el filete central ha sido sustituido por una línea de tres puntos y los bifolios son más estilizados, el superior ligeramente inferior, con una anchura total de 7,7 cm (Fig. 4.2.2.15). Esta constituye un modelo especial, en tanto que se ha podido identificar un paralelo casi idéntico procedente de la denominada estancia del incendio de la casa del Mitreo, cuyo conjunto se encuentra actualmente en estudio (Bejarano Osorio et al., e.p.; (Fernández Díaz et al., e.p.), que cuenta con otra orla que hemos analizado previamente (1.3.1). En esta ocasión el, modelo es prácticamente idéntico salvo por las dimensiones, ligeramente superiores, de $9,5 \mathrm{~cm}, \mathrm{y}$ con un mayor esquematismo y menor calidad en el motivo central (Fig. 4.2.2.16). Si bien es cierto que la gran similitud existente entre ambos esquemas podría estar mostrando la obra de un mismo taller, la ausencia de más elementos del conjunto de la calle Cabo Verde impide corroborar dicha hipótesis, más aún cuando se trata de un esquema común que se representa en otras zonas de la ciudad y de Hispania con ligeras variaciones. En lo que respecta a los paralelos, remitimos al ya citado procedente del peristilo 3 de la villa de San Marco en Stabia y al recogido por Gusman. En ambos casos, tanto el contexto del vertedero como el del incendio de la casa del Mitreo, permiten plantear una misma cronología, en torno a época flavia, dado que las UUEE se fechan entre el $80 \mathrm{~d}$. C. y época adrianea.

Procedente también de esta última casa, de la intervención realizada en el año 94, contamos con una orla de la cata 3/1 que se asocia al sector sur de uno de los espacios exteriores de la casa, dispuesto junto a las fauces y que debió funcionar como una tienda o taberna (Bejarano Osorio et al., e.p.). Está formada por cuatro filetes, los externos azules y los internos amarillos, que enmarcan una sucesión de cuadrados que alternan, por un lado, ocho bifolios superpuestos y enfrentados dos a dos con una gota rematando la parte superior, dispuestos en espacios triangulares divididos por dos filetes amarillos en posición oblicua. Por otro, una gota con cuatro pétalos esquemáticos alrededor que se inscribe en un rombo formado por filetes que dejan cuatro espacios triangulares en las esquinas decorados por filas de gotas dobles superpuestas en oblicuo, todo ello en amarillo y sobre un fondo rojo, con una anchura total de $8,2 \mathrm{~cm}$ (Fig. 4.2.2.17). Además de los paralelos ya citados, incluimos, por la presencia cuadrados en posición oblicua, el procedente del atrio de la casa degli Amanti (I 10, 11) y dos ejemplares recogidos por Zahn de procedencia desconocida (Barbet, 1981: fig. 14, 52a, b y c). En lo que respecta a su cronología, si bien el informe de la intervención aportó muy pocos datos acerca del material del contexto, parece claro que debe ubicarse en época flavia, dado que no fue hasta la segunda mitad del siglo I d. C. cuando se construyó la casa y, por tanto, los espacios asociados a esta (Bejarano Osorio et al., e.p.).

De similar cronología encontramos un ejemplar del vertedero de la calle Cabo Verde de Mérida que forma parte del mismo conjunto que el 1.1.13 del tipo de triángulos vistos anteriormente. Al igual que aquel, este presenta cuatro filetes, los externos azules y los internos amarillos que encierran una alternancia de cuadrados y rectángulos. Los primeros están decorados mediante una gota central rodeada de cuatro bifolios que presentan en la parte central dos gotas superpuestas, bajo cada hoja otra gota y una más en el espacio entre punta y punta de las hojas de los bifolios. Todo ello queda en el interior de un rombo que genera espacios triangulares en las esquinas del cuadrado, decorados con otro bifolio con dos gotas en las puntas de las hojas y dos más en la parte superior. En lo que respecta al espacio rectangular, presenta, en el centro, dos trazos similares a una media luna contrapuestos sobre los que se desarrolla un bifolio con dos gotas por encima superpuestas y dos bajo cada hoja, todo ello en amarillo. La orla queda rematada con una sucesión de semicírculos con apéndice circular en azul con una gota ovalada en un tono más oscuro en su interior y que se disponen sobre el filete azul hacia el interior, con una anchura total de $11 \mathrm{~cm}$ (Fig. 4.2.2.18). En este caso, presenta un esquema que combina elementos de varios paralelos ya citados como el del atrio de la casa degli Amanti (I 10, 11), el del peristilo 3 de la villa San Marco en Stabia y los recogidos por Gusman y Zahn. Tal y como señalamos para el otro ejemplar del mismo conjunto, proponemos una cronología de época flavia.

A este debemos sumar una orla procedente de una domus de la calle Hernán Cortés de Mérida (Bejarano Osorio, 2004; Fernández Díaz et al., e.p.), formada por cuatro filetes, los dos externos azules y los internos amarillos, que encierran una alternancia de cuadrados decorados con cuatro semicírculos azules coronados 
con gotas enfrentados dos a dos en espacios triangulares generados por dos filetes en oblicuo por un lado $\mathrm{y}$, por otro, rectángulos con un elemento vegetal en amarillo. Junto a esto, el filete azul presenta hacia el interior una alternancia de gotas ovaladas con apéndice y pequeñas gotas azules, todo ello con una anchura total de $8,6 \mathrm{~cm}$ (Fig. 4.2.2.19). En cuanto a los paralelos, remitimos a los anteriormente citados, con la particularidad de la presencia del motivo vegetal en los espacios más estrechos que no encontramos en el área campana y que parece una clara concesión al gusto local o fruto de una moda. Esta orla forma parte de un conjunto fechado a finales del siglo I d. C.

Si volvemos a la casa del Mitreo, encontramos otra orla que se encuadra dentro de esta variante, en este caso procedente de la denominada como habitación de las pinturas, formada por cuatro filetes, dos externos blancos y dos internos amarillos que encuadran una sucesión de espacios rectangulares y cuadrados. Los primeros presentan una división horizontal y tres gotas a cada lado, mientras que los segundos contienen una flor a base de gotas amarillas inserta en un rombo que presenta una gota en cada vértice por su parte interna y otra en los espacios triangulares que genera hacia el exterior, todo ello sobre fondo rojo y con una anchura total de $12 \mathrm{~cm}$ (Fig. 4.2.2.20). En lo que se refiere a los trazos preparatorios, en algunos tramos se observa la presencia de filetes blancos que indicarían un trazo preparatorio pintado. En cuanto a los paralelos, remitimos a los ya mencionados, especialmente los recogidos por Zhan y Gusman. En este caso, el conjunto fue fechado entre finales del siglo I e inicios del siglo II d. C. (Abad Casal, 1982b), si bien nosotros nos inclinamos por ubicarla en los últimos años del siglo I d. C.

El último ejemplar de esta variante es el procedente del edificio del Palau de les Corts en Valencia, una orla formada por dos filetes amarillos con espacios cuadrangulares. El primer motivo que encontramos es un círculo blanco con el borde amarillo junto a un cuarto de círculo que se dispone en cada esquina, de fondo verde y borde amarillo. Por otro lado, cuatro trifolios contrapuestos dos a dos en color amarillo y con la parte interna en tono blanco, con dos gotas dispuestas a cada lado y que se ubican en espacios triangulares generados por dos filetes oblicuos, uno de los cuales presenta la mitad en blanco. Todo ello se dispone sobre un fondo rojo, con una anchura total de 7,7 cm (Fig. 4.2.2.21). Entre los paralelos destacamos los procedentes de la estancia 27 de la villa di Poppea en Oplontis, el frigidarium 25 de la villa de San Marco en Stabia y el ubicado junto a Porta Marina en Pompeya. En lo que respecta a la cronología, el conjunto forma parte de la fase flavia del edificio (Calvo Gálvez et al., 1998).

\section{III.2.3. Cuadriláteros no yuxtapuestos sin alternancia}

De esta variante contamos únicamente con un ejemplar procedente de la villa romana del Parque de las
Naciones (Albufereta, Alicante) (Rosser Limiñana, 1992: 152), una orla formada por cuatro filetes amarillos que enmarcan una sucesión de cuadrados con una gota central azul flanqueada por cuatro trifolios y con cuatro gotas en las esquinas, con un espacio entre cada cuadrado de $0,6 \mathrm{~cm}$, todo ello sobre fondo blanco y con una anchura total de 10,8 cm (Fig. 5.2.3.1). En lo que respecta a los paralelos, los más similares los encontramos en la variante con alternancia, dado que Barbet no recoge ningún ejemplar sin alternancia, el primero procedente de la casa de las Salas Soterradas de Bolsena, y el segundo del pozo 70 de la misma ciudad (Barbet, 1981: fig. 16, 53b y c). A estos, debemos sumar un tercero procedente del Museo Archeologico Nazionale di Aquilea fechado entre época neroniana y época flavia (Salvadori et al., 2016: 244-245, fig. 1). En lo que respecta a la cronología, al igual que el otro ejemplar de este yacimiento (10.3), su estudio no permitió fecharlo más allá del período altoimperial debido a la ausencia de información sobre el contexto al no haberse realizado el inventario del material. No obstante, la calidad en la ejecución, así como el resto de fragmentos del conjunto plantean una cronología de la primera mitad del siglo II d. C.

\section{III.2.4. Cuadriláteros no yuxtapuestos con alternancia}

Algo más amplia es esta variante de la que contamos con un primer ejemplar en los fondos del Museo Arqueológico Nacional de Madrid (Abad Casal, 1982b: 156-157, fig. 235), si bien no se conoce su procedencia exacta dado su hallazgo y traslado en la primera mitad del siglo XX, por lo que también presenta dudas sobre su posible datación. Está formado por un triple filete, los dos externos rojos y el interno verde que marca el límite inferior y un filete rojo que marca el superior y que encierra una sucesión de cuadrados de $4,5 \mathrm{~cm}$ de anchura. El primer motivo está formado por cuatro triángulos enfrentados dos a dos, los horizontales rojos y los verticales blancos de borde rojo, separados en espacios triangulares por filetes rojos oblicuos. El segundo lo componen cuatro gotas rojas en la parte central insertas en un doble rombo de borde rojo e interior blanco que genera cuatro esquinas de fondo verde con un trifolio esquemático. Por su parte, el espacio rectangular entre cuadrado y cuadrado tiene $0,8 \mathrm{~cm}$ de anchura, mientras que la orla presenta una anchura total de 5,9 $\mathrm{cm}^{20}$ (Fig. 5.2.4.1). En lo que respecta a los paralelos, únicamente indicamos los ya citados en la variante anterior, en este caso más similares por la alternancia, aunque no por los motivos.

20. En lo que respecta a los colores, existen discrepancias entre la descripción y la restitución pictórica, tanto mediante tramas como en color, por lo que hemos optado por seguir esta última dado que es la más reciente. 


\section{Cuadriláteros no yuxtapuestos sin alternancia}

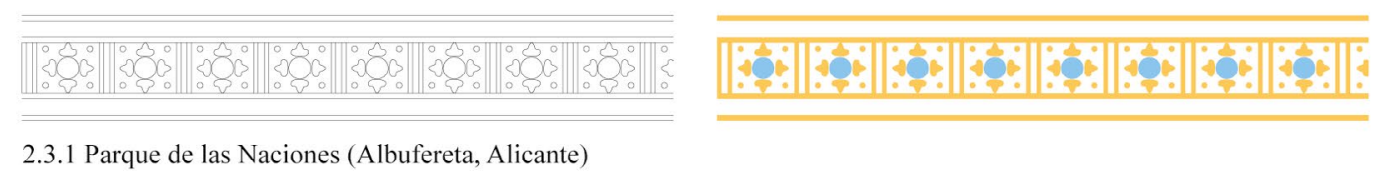

\section{Cuadriláteros no yuxtapuestos con alternancia}

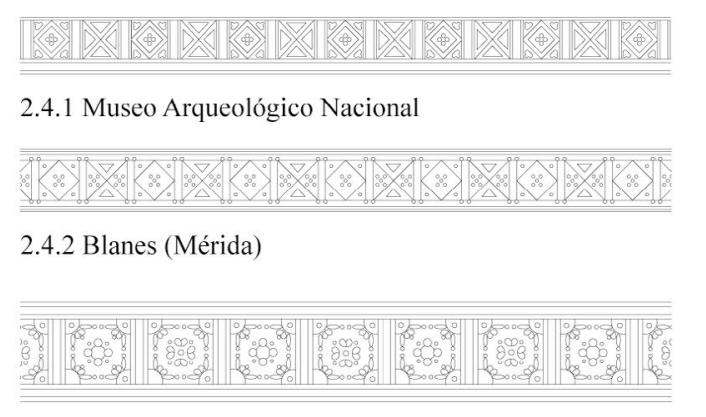

2.4.3 Domus de Avinyó (Barcelona)

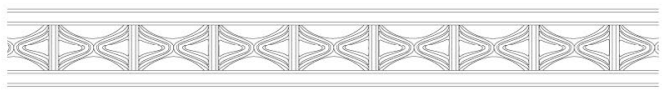

2.4.4 Villa de Portmán (Cartagena-La Unión)

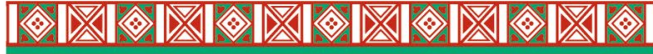
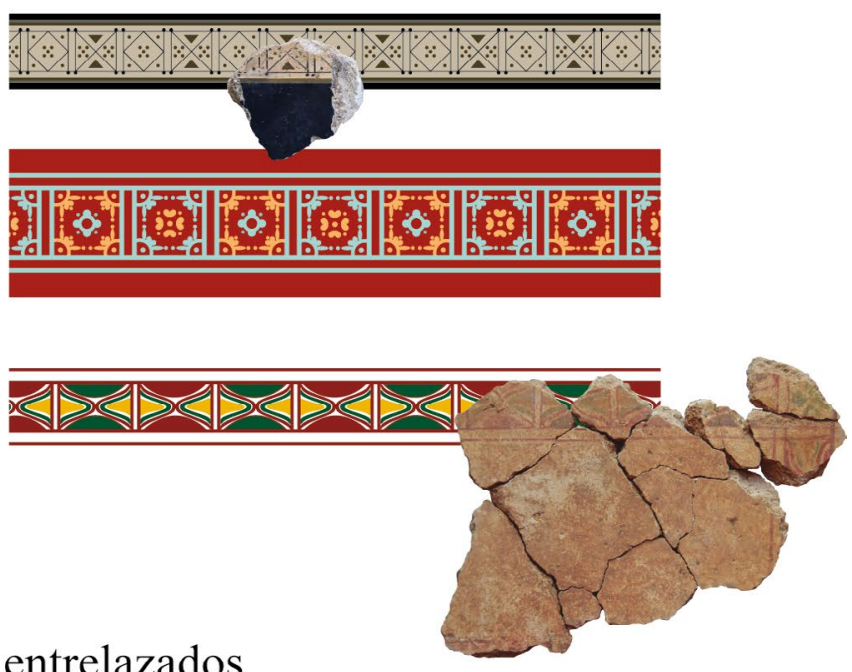

\section{Cuadriláteros entrelazados}

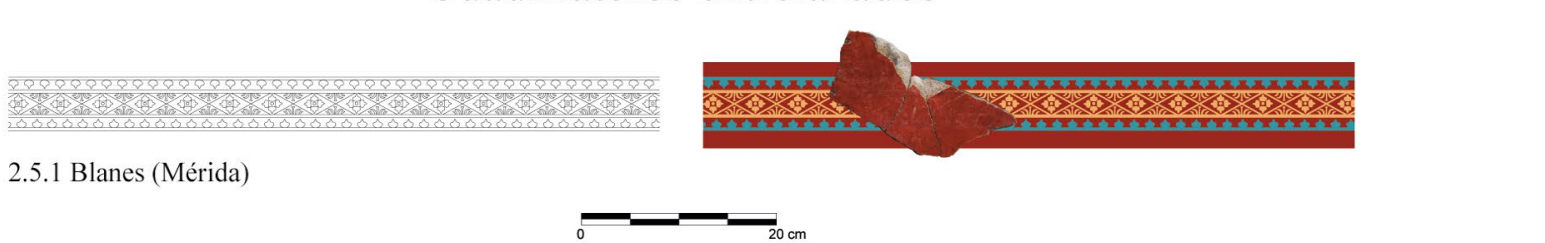

Figura 5: Cenefas y orlas caladas del grupo de cuadriláteros. Fuente: elaborada por los autores

Al margen de este último de cronología incierta, el más antiguo de este grupo procede de la UE 1423 del vertedero de Blanes en Mérida. En este caso nos encontramos con una cenefa calada de fondo beige sobre un campo negro, delimitada por dos filetes verde oscuro y grisáceo que enmarcan una sucesión de cuadrados de 4,3 cm de lado con un espacio rectangular entre cada uno de ellos de $0,8 \mathrm{~cm}$ de anchura y dispuestos sobre dos filetes negros. En el interior de los cuadrados alterna una decoración de un rombo con cinco gotas en la parte central y cuatro en las esquinas del cuadrado, todas ellas en verde oscuro, y una decoración de dos triángulos enfrentados dispuestos arriba y abajo y cinco gotas a izquierda y derecha en espacios triangulares generados por dos filetes negros oblicuos. La cenefa queda rematada mediante pequeñas gotas negras dispuestas en las esquinas de los cuadrados hacia el exterior, con una anchura total de $6,4 \mathrm{~cm}$ (Fig. 5.2.4.2). Al igual que el caso anterior, remitimos a los mismos paralelos. En lo que respecta a su cronología, el contexto cuenta con una datación muy precisa, entre los años 50-60 d. C. ${ }^{21}$, por lo que debemos asociarla a un conjunto del III estilo final, pudiendo tratarse de una banda vertical u horizontal y no de un encuadramiento.

Posterior a este, encontramos uno procedente de la domus de Avinyó de Barcelona (Fernández Díaz y Suárez Escribano, 2018: 25, fig. 2), que forma parte de un conjunto con una segunda orla que abordaremos más adelante. Esta está compuesta por cuatro filetes azules que enmarcan una sucesión de cuadrados de $7,2 \mathrm{~cm}$ de ancho sobre fondo rojo. El motivo alterna de uno a otro, si bien con gran similitud excepto en la parte central, dado que en ambos casos presenta un

21. El contexto cuenta con producciones de sigillata itálica Conspectus 18, 2, 22 y 26 con sellos de los productores Memmius y Zoilus, sigillata sudgálica Drag. 11, 15/17, 18 y 24/25, así como un As de Augusto y un Sestercio de Claudio. 
cuarto de círculo en cada esquina con una gota central y dos gotas ovaladas que se disponen en posición vertical y horizontal, coronados por una gota y enfrentados a los de las esquinas adyacentes. Junto a esto, un pequeño bifolio con una gota en posición oblicua, todo ello en color amarillo y azul de manera alterna. En cuanto al motivo central, el color es siempre el opuesto al motivo que lo rodea, con un círculo con cuatro gotas en las esquinas y pequeñas gotas entre cada una en color azul y una gota rodeada por cuatro bifolios con gotas en las esquinas en amarillo. Los espacios rectangulares entre cada cuadrado tienen $0,8 \mathrm{~cm}$ de anchura, mientras que la anchura total de la orla es de $10,2 \mathrm{~cm}$ (Fig. 5.2.4.3). En relación a los paralelos, además de los citados en la variante anterior, contamos con el del tablinum de la casa dell'Orso (VII 2, 45), que se data en un momento anterior al terremoto del año $62 \mathrm{~d}$. C. (Ehrhardt, 1988), el de la habitación 30 de la casa del Labirinto (VI 11, 9) (Strocka, 1991), fechado en época neroniana, o el de la habitación «C» de la casa degli Amorini Dorati (VI 16, 7) (Seiler, 1992), así como uno recogido por Gusman de procedencia desconocida (Barbet, 1981: fig. 15, 52s), con la diferencia de que este si cuenta con decoración en los espacios entre cada cuadrado. En lo que respecta su datación, se ha fijado a finales del siglo I d. C. debido a la calidad que presentan, así como al resto de elementos del conjunto, si bien algunos de los que encontramos en los interpaneles y el empleo del color sigue en uso hasta mediados del siglo II d. C. (Fernández Díaz y Suárez Escribano, 2018: 27).

El último ejemplar de esta variante lo encontramos en la habitación 8 de la villa romana de Portmán, actualmente en fase de estudio y que ha ofrecido tres modelos distintos de orlas que analizaremos más adelante. El que nos interesa está compuesto por cuatro filetes rojos que enmarcan una sucesión de un mismo motivo que varía únicamente en su policromía y de manera parcial, generando una alternancia basada en un solo color. Encontramos un rectángulo con un semicírculo en los extremos superior e inferior de color verde y con borde rojo, mientras que en la parte central y apoyados en los límites izquierdo y derecho encontramos una sucesión de dos filetes curvos, el externo rojo y el interno verde, y un dentículo amarillo en el interior, dispuestos de manera enfrentada. El siguiente rectángulo repite el mismo esquema de idéntica forma, en este caso con los semicírculos completamente rojos, todo ello sobre fondo blanco. Entre cuadrado y cuadrado existe un espacio rectangular de $0,4 \mathrm{~cm}$ de anchura, mientras que la orla presenta una anchura total de 7,9 cm (Fig. 5.2.4.4). Este tipo no cuenta con paralelos en el ámbito pompeyano, dado que se trata de un modelo puramente local que, si bien hace uso de un esquema como es el de cuadrados en alternancia que hemos visto en los ejemplos anteriores, incluye un motivo ornamental distinto, esquemático y de una ejecución más tosca. En este caso, el conjunto se ha fechado en la primera mitad del siglo II d. C. en base a la fecha de construcción de la terraza superior, en una de cuyas estancias se ubica, y que no debió producirse con anterioridad a finales del siglo I d. C. (Fernández Díaz et al., 2019).

\section{III.2.5. Cuadriláteros entrelazados}

Por último, contamos con una última variante que solo ofrece un ejemplar, en este caso procedente de la UE 1535 del vertedero de Blanes. La orla, compuesta por cuatro filetes, los dos externos azules y los internos amarillos, enmarca una sucesión de cuadrados dispuestos a modo de rombos entrelazados por sus extremos, que encierran en su interior una gota flanqueada por cuatro trifolios esquemáticos, mientras que en el espacio que se genera entre rombo y rombo se coloca una palmeta, quedando estas enfrentadas. Por su parte, el filete azul presenta, hacia el interior, una sucesión de gotas con apéndice, todo ello sobre fondo rojo y con una anchura total de 5,4 cm (Fig. 5.2.5.1). En este caso, el dibujo se encuentra muy perdido en todos los fragmentos, pero pueden advertirse tonalidades blancas que podrían estar indicando el empleo de trazos preparatorios pintados. Encontramos diversos paralelos procedentes de la estancia 11 de la casa dell'Efebo (I 7, 11), de la estancia «G» de la casa dell'Ara Massima (VI 16, 15), del conjunto 17 de la casa del Centenario (IX $8,6)$ y de la villa di Poppea en Oplontis (Barbet, 1981: fig. 16, 56a-d). En lo que respecta a su cronología, el contexto fue fechado entre los años 80 y 100 d. C., por lo que, en base a las características técnico-estilísticas y las dimensiones, podría datarse entre época neroniana y época flavia y formar parte de un modelo de transición que adapta esquemas itálicos con elementos que, bien responden al gusto local o son propios de una nueva moda.

Además de las cenefas y orlas descritas debemos sumar dos fragmentos de la casa del Mitreo de los que no es posible establecer su restitución completa pero que formarían parte de alguna de las variantes de este grupo.

\section{III.3. TIPO 3: CírCULOS, TRES CUARTOS DE CÍRCULO Y SEMICÍRCULOS $^{22}$}

La tercera categoría es la más numerosa de todas debido a la gran cantidad de variantes que podemos encontrar en la combinación de esquemas y elementos decorativos, pudiendo establecer trece variantes, como son los círculos sin alternancia (3.1), los círculos con alternancia (3.2), círculos secantes (3.3), círculos entrelazados (3.4), tres cuartos de círculos sin

22. Este grupo y sus variantes se corresponden con los tipos 70-155 de los grupos IX, X y XI de Barbet (1981). 
alternancia (3.5), tres cuartos de círculo con alternancia (3.6), semicírculos sin alternancia (3.7), semicírculos con alternancia (3.8), semicírculos superpuestos (3.9), semicírculos con particiones intermedias (3.10), semicírculos secantes (3.11), semicírculos contrapuestos sin alternancia (3.12) y semicírculos contrapuestos con alternancia (3.13).

\section{III.3.1. Círculos sin alternancia}

Dentro del primer grupo encontramos cinco ejemplares, el primero procedente de la casa 1 de Ampurias (Nieto Prieto, 1979-1980: 305-306, figs. 42-43; Abad Casal, 1982: 124, fig. 175). Se trata de una orla calada sobre un campo rojo formada por una sucesión de grupos de dos círculos concéntricos tangentes decorados en su interior mediante una flor de ocho pétalos similar a una margarita, todo ello en color blanco. Hacia el exterior, los círculos están coronados arriba y abajo por una gota, y los espacios entre cada grupo están decorados con un bifolio también blanco y con una anchura total de $10,5 \mathrm{~cm}$, pudiendo constatarse el empleo de compás para la realización de trazos preparatorios (Fig. 6.3.1.1). En lo que respecta a los paralelos, encontramos diversos ejemplos en Pompeya como el de la casa dell'Orso (VII 2, 45) o el del techo GG de la casa de C. Julius Polybius (IX 13, 1-3), así como los del tablinum de la casa del Colonnato Tuscanico (VI 17) (Barbet, 1981: fig. 33, 150a-c) y el cubiculum de la casa dell'Atrio Corinzio (V 30) de Herculano (Barbet, 1981: fig. 33, 150e). A estos debemos añadir, ya en las provincias, los de una domus de ClermontFerrand (Puy-de-Dôme), de época flavia (Groetembril y Ollivier, 2013: 358-359), de la casa sur de la ínsula 10 de Avenches y de la villa de Wagen, fechadas entre el 60-90 d. C. (Fuchs y Dubois, 1997: 181). En lo que respecta a su cronología, fue fechado en torno a mediados del siglo I d. C.

El segundo y tercer caso proceden del macellum (Monraval Sapiña, 1992: 49) y el edificio bajo el Palau de les Corts de Valencia respectivamente. La primera orla calada está compuesta por una sucesión de círculos decorados interiormente por una pequeña gota central flanqueada por otras cuatro de mayor tamaño entre las que se disponen cuatro bifolios en posición diagonal contrapuestos dos a dos, así como cuatro pequeñas gotas que coronan las de mayor tamaño. Fuera del círculo, dos gotas de mediano tamaño en el extremo superior e inferior, mientras que el espacio entre cada uno se encuentra decorado mediante dos bifolios superpuestos hacia el exterior, todo ello en color blanco sobre fondo amarillo y con una anchura total de $6,7 \mathrm{~cm}$ (Fig. 6.3.1.2). En relación a los trazos preparatorios, en algunos fragmentos se aprecian pequeños agujeros que podrían coincidir con el punto de anclaje del compás, pero no se advierte en el trazado del círculo, por lo que, de haberlos, serían similares a los empleados en
Bilbilis, Caesaraugusta y Arcobriga que veremos más adelante.

La segunda, por su parte, está formada por cuatro filetes, los externos amarillos y los internos blancos, que encuadran una sucesión de motivos muy similares al modelo anterior. En este caso, en el interior de los círculos, únicamente encontramos una gota central y cuatro bifolios a los costados contrapuestos dos a dos y coronados por una gota de menor tamaño, mientras que al exterior se repite una gota en cada extremo, quedando el espacio entre círculo y círculo coronado por dos bifolios con una gota superpuesta. Aquí, sin embargo, no se aprecian marcas de posible compás y el trazado más descuidado de las circunferencias sugiere que se realizara a mano alzada, con una anchura de 9,2 cm (Fig. 6.3.1.3). En ambos casos remitimos a los paralelos anteriormente citados dada su similitud, pudiendo ubicarlos cronológicamente en época flavia en función de la datación de las fases a las que pertenecen (Calvo Gálvez et al., 1998).

Los dos últimos ejemplares de esta primera variante proceden de las habitaciones 7 y 8 de la villa romana de Portmán. La primera orla, sobre fondo blanco, está formada por cuatro filetes, los externos rojos y los internos amarillos, que enmarcan una sucesión de círculos dobles rojos con cuatro pétalos acorazonados en su interior, mientras que el filete rojo presenta hacia el exterior una sucesión de semicírculos con apéndice coronados por una gota, con una anchura total de 15,4 cm (Fig. 6.3.1.4). Se aprecia el empleo de trazos preparatorios incisos mediante compás, que deja una incisión en la parte central y en el recorrido de la circunferencia, así como un trazo inciso en la parte central de la orla y en los márgenes externos para marcar la dirección vertical u horizontal. Por su parte, la segunda está compuesta por cuatro filetes rojos que enmarcan una sucesión de círculos tangentes del mismo color, decorados al interior por cuatro pétalos que alternan entre amarillo y verde, todo ello sobre fondo blanco y con una anchura total de 7,9 cm (Fig. 6.3.1.5). En este caso no se aprecia ningún tipo de trazo preparatorio, algo que encaja con la mayor irregularidad de las circunferencias. En lo que respecta a los paralelos, al margen de los ya señalados, citamos el de Chartres, que no cuenta con ninguna decoración interior y enmarca un interpanel, fechado en el siglo I d. C. (Allag y Kleitz, 2018: 357, fig. 4). En ambos casos, los conjuntos a los que pertenecen se han fechado en la primera mitad del siglo II d. C. en base al material del contexto y a las características técnico-estilísticas, así como a la fecha de construcción de la terraza superior de la villa, que no debió realizarse con anterioridad a los últimos años del siglo I d. C. (Fernández Díaz et al., 2019) $)^{23}$.

23. Ambos conjuntos se encuentran aún en fase de estudio. 


\section{Círculos sin alternancia}

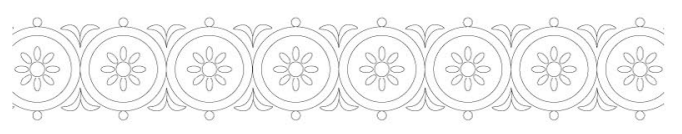

3.1.1 Ampurias

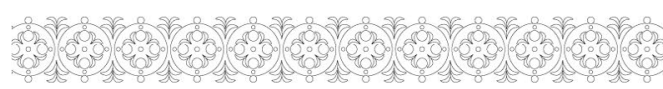

3.1.2 La Almoina (Valencia)

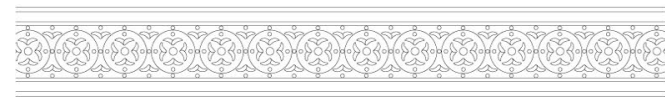

3.1.3 Palau de les Corts (Valencia)

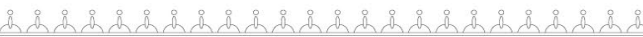

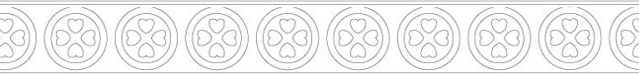

3.1.4 Villa de Portmán (Cartagena-La Unión)

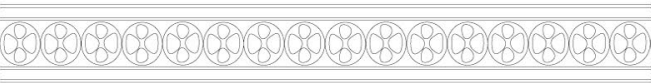

3.1.5 Villa de Portmán (Cartagena-La Unión)
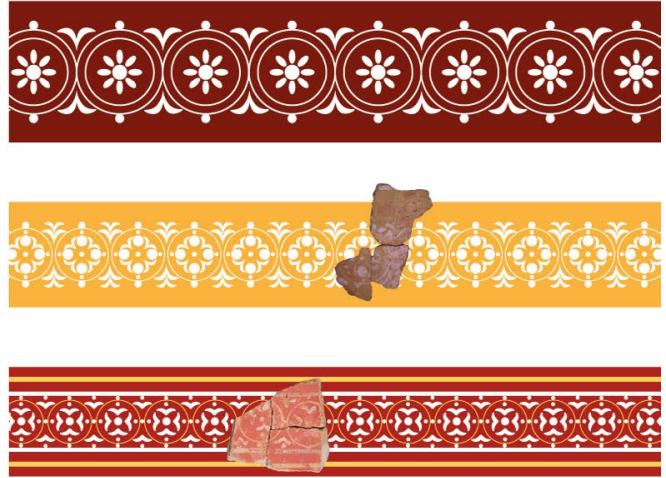

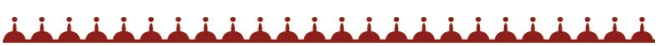
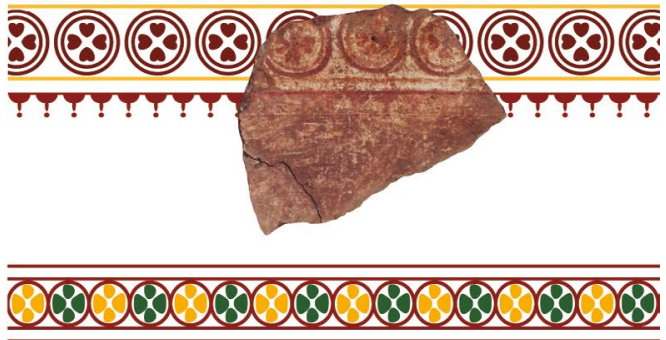

\section{Círculos con alternancia}

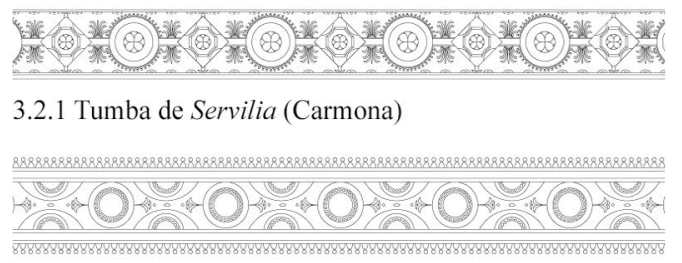

3.2.2 Tumba de Servilia (Carmona)

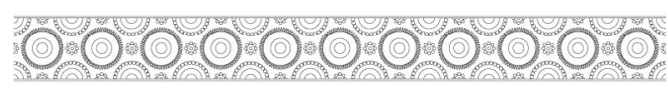

3.2.3 Tumba de Servilia (Carmona)

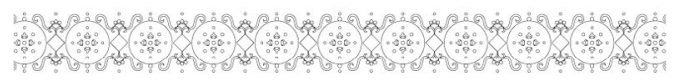

3.2.4 Termas de Bilbilis

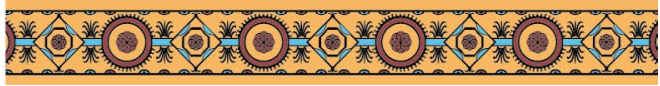

\section{-}

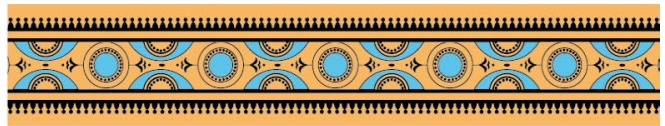

3.2.5 Blanes (Mérida)
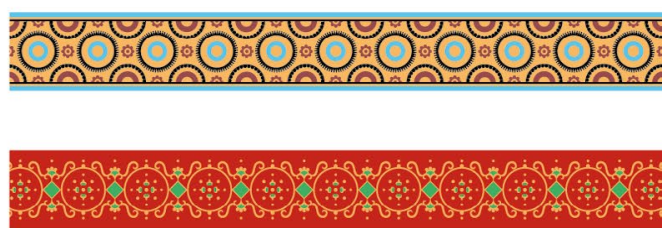

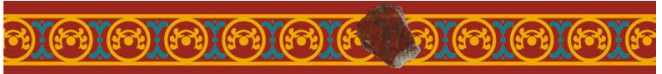

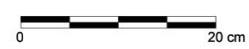

Figura 6: Cenefas y orlas caladas del grupo de círculos, tres cuartos de círculo y semicírculos. Fuente: elaborada por los autores

\section{III.3.2. Círculos con alternancia}

En lo que respecta a esta variante, contamos con cuatro ejemplares. Los tres primeros proceden de la tumba de Servilia en la necrópolis de Carmona (Abad Casal, 1982b: 186-187, figs. 310 y 311; Fernández Díaz, 2010; Baceiredo Rodríguez y Fernández Gómez, 2012), por lo que presentan la misma cronología que los anteriormente señalados, en torno a época neroniana. $\mathrm{La}$ primera está formada por dos filetes negros que encierran una alternancia de dobles círculos y cuadrados en posición oblicua. De los círculos, el externo presenta hacia el exterior, una sucesión de pequeños semicírculos coronados por gotas, mientras que el interior está decorado mediante una banda roja, un segundo círculo negro y una roseta rosa con las hojas y el contorno marcado en negro, así como una gota central. En lo que respecta a los cuadrados, presentan, hacia el interior, 
cuatro semicírculos enfrentados dos a dos en posición oblicua de color azul y borde negro y un octógono cuyos lados oblicuos son ligeramente curvos hacia el interior, decorado con una roseta similar a la anterior pero más pequeña. Ambos motivos se encuentran unidos mediante dos filetes negros paralelos decorados al interior con una banda azul y que se rematan con una palmeta dispuesta hacia fuera. Por último, los filetes de encuadramiento presentan, hacia el interior, una sucesión de semicírculos de fondo rojo y azul de manera alterna con una gota central en negro, todo ello sobre fondo amarillo y con una anchura total de 6,7 cm (Fig. 6.3.2.1). En este caso se aprecia el empleo de trazos preparatorios incisos en la parte central de la orla en posición horizontal y también vertical coincidiendo con el centro de las circunferencias, las cuales debieron ser trazadas igualmente mediante compás, aunque no se aprecia. En lo que respecta a los paralelos, no encontramos ningún ejemplar dentro del repertorio pompeyano que presenta un marcado carácter barroco por la complejidad y cantidad de los motivos ornamentales empleados. No obstante, contamos con un ejemplo similar para la disposición de las palmetas de un interpanel de Ampurias (Nieto Prieto, 1979-1980: fig. 74) cuya procedencia exacta se desconoce, pero que se asocia al modelo 3.7.1 y puede fecharse en torno a mediados del siglo I d. C.

El segundo ejemplar presenta cuatro filetes negros que enmarcan una sucesión de círculos y semicírculos alternos. Los primeros están formados por tres círculos concéntricos de borde negro, los dos iniciales sin color de fondo y el último de fondo azul, quedando hacia el exterior de este una sucesión de gotas de pequeño tamaño. Los segundos, por su parte, presentan un primer semicírculo ligeramente más ancho en su unión con el filete sobre el que se apoya y de fondo azul, quedando en su interior otros dos, el último decorado al interior mediante una sucesión de gotas. El espacio entre círculo y círculo está decorado por dos pares de bifolios superpuestos enfrentados, coronados por una gota y con una gota ovalada en el centro. El filete exterior presenta, hacia fuera, una sucesión de gotas ovaladas coronadas por pequeñas gotas circulares, con una anchura total de 9,8 cm (Fig. 6.3.2.2). En este caso contamos también con trazos preparatorios que siguen el mismo esquema que el anterior.

El último ejemplar procedente de la tumba de Servilia constituye igualmente una orla calada sobre fondo amarillo enmarcada por dos filetes azules al exterior y dos internos negros. Estos encierran una sucesión de círculos de borde negro decorados al interior con dentículos coronados por una gota, mientras que al interior cuentan con un círculo azul cuya parte central es hueca y muestra el color de fondo de la orla. Estos alternan con una flor roja con una gota central y ocho pétalos al exterior. Junto a esto, sobre los filetes negros se desarrolla, hacia el interior, una alternancia de medias flores rojas como las que se disponen en la parte central y semicírculos de borde negro decorados al interior con pequeños semicírculos del mismo color y un círculo rojo hueco al interior, todo ello con una anchura total de $8 \mathrm{~cm}$ (Fig. 6.3.2.3). En cuanto a los trazos preparatorios, si bien no se han documentado en este esquema dado que contamos únicamente con un dibujo de Rodríguez Jaldón, parece lógico que los tuviera y siguieran el mismo esquema que en los dos casos anteriores.

La cuarta orla de esta variante procede de uno de los paneles del conjunto B hallado en la estancia $\mathrm{M}$ de las termas de Bilbilis (Guiral Pelegrín y Martín-Bueno, 1996: 115, fig. 35). Está formada por una sucesión de círculos decorados interiormente con una gota central flanqueada por cuatro gotas con apéndice y un trazo verde, coronadas por una gota amarilla y con cuatro gotas en los costados. El círculo queda a su vez decorado al exterior con dos gotas superpuestas de tamaño decreciente en los extremos inferior y superior. Este elemento alterna con una serie de cuadrados en diagonal de fondo verde y borde amarillo que conectan los círculos por los laterales y un bifolio con dos volutas y una palmeta con tres gotas y una cuarta por encima en los lados superior e inferior. La orla se dispone sobre un panel rojo, con una anchura total de $6,1 \mathrm{~cm}$ (Fig. 6.3.2.4). En este caso se ha documentado una línea incisa en la parte central que sirve como eje para trazar, mediante compás, las circunferencias, de las que se conserva el punto central inciso, dado que el trazado se realizó mediante un pincel colocado en uno de los extremos del compás (Guiral Pelegrín y Martín-Bueno, 1996). Este modelo presenta diversos paralelos, siendo el más cercano el del oecus de la casa di Trebius Valens (III 2, 1) (Spinazzola y Aurigemma, 1953), fechado en la etapa final del III estilo, a los que debemos añadir otros en ámbito provincial como el de una de las estancias de la villa de Balaca (Thomas, 1964; Frizot, 1981) o el de la Constantinsplatz de Tréveris (Steiner, 1927). Al igual que el resto de orlas del conjunto, se ha fechado en los primeros años de la segunda mitad del siglo I d. C. (Guiral Pelegrín y Martín-Bueno, 1996).

El último ejemplar lo encontramos en la UE 1234 del vertedero de Blanes en Mérida. Se trata de una orla calada de 5,2 cm sobre fondo rojo con dos filetes amarillos que encuadran una sucesión de círculos decorados interiormente por un trazo de tres cuartos de círculo con pétalos similar a una palmeta, con una gota en la parte central. Los círculos alternan con una gota rodeada por dos bifolios contrapuestos arriba y abajo y una pequeña gota que los corona, todo ello en azul (Fig. 6.3.2.5). En lo que respecta a los paralelos, citamos nuevamente el procedente de Chartres (Allag y Kleitz, 2018: 357, fig. 4), que como señalábamos para Portmán, difiere de nuestro caso por la ausencia de motivos decorativos tanto en el interior como en el exterior. En relación a su cronología, el contexto al que pertenece fue fechado a finales del siglo III d. C., sin embargo, las características del modelo impiden asociarlo a dicha cronología y sugieren una de entre época neroniana y época flavia, 
por lo que es probable que el fragmento se haya visto expuesto a remociones de tierra tal y como sucede con otros casos que abordamos a lo largo del trabajo.

\section{III.3.3. Círculos secantes}

Para esta variante encontramos únicamente un ejemplar procedente del mismo conjunto que el citado en el grupo anterior de Bilbilis, el conjunto B hallado en la estancia $\mathrm{M}$ de las termas, en este caso del panel adyacente (Guiral Pelegrín y Martín-Bueno, 1996: 115, fig. 35). La orla está formada por una sucesión de círculos secantes de 4,5 cm de diámetro que se cortan en $\mathrm{su}$ parte central, coincidiendo con la marca de la aguja del compás. Estos presentan en su interior dos gotas ovaladas con apéndice y con un trazo verde en la parte interna, contrapuestas y que se disponen dos a dos a derecha e izquierda, mientras que la zona superior e inferior queda decorada por una gota similar de mayor tamaño, en este caso completamente verde. Al exterior de los círculos, una sucesión de gotas dobles superpuestas de tamaño decreciente dispuestas en los extremos superior e inferior de cada círculo, todo ello sobre fondo rojo y con una anchura total de 7,1 cm (Fig. 7.3.3.1). Al igual que para el caso anterior del mismo conjunto (3.2.4), se conservan líneas incisas como guía del esquema y la incisión de la punta del compás para las circunferencias. Se trata de un modelo del que no existen paralelos dentro de Pompeya, si bien encontramos esquemas similares con semicírculos. No ocurre lo mismo en las provincias, donde se repite de manera común, como es el caso del procedente de Saintes (Allag, 1982), el de Estrasburgo (Forrer, 1927), el de la domus de La Fontainotte en Grand (Lorraine, Vosges) (Froeliger y Mondy, 2017: 75, fig. 6), de la segunda mitad del siglo I d. C., los de Ribemont-sur-Ancre, Betting y la villa de Nenning cerca de Tréveris (Allag, 1982) y los de la rue Catalogne en Narbona (Aude), fechados entre el III estilo final y el IV (Sabrié, 2013: 652, fig. 8). Al igual que el resto de orlas del conjunto, se ha fechado en los primeros años de la segunda mitad del siglo I d. C. (Guiral Pelegrín y Martín-Bueno, 1996).

\section{III.3.4. Círculos entrelazados}

La cuarta variante contiene igualmente un único ejemplar, en este caso procedente del vertedero de Blanes en Mérida. Se trata de una cenefa calada de la UE 1262 de fondo violáceo sobre panel amarillo, formada por cuatro filetes blancos que enmarcan una sucesión de círculos de perfil ovalado entrelazados, que presentan en su interior dos palmetas contrapuestas con una gota en la parte central y otra en los extremos, así como dos trazos en forma de cuña triangular en la parte superior e inferior. Sobre los círculos encontramos una gota blanca en los extremos superior e inferior, mientras que el espacio entre círculo y círculo queda decorado con palmetas enfrentadas coronadas por una gota, todo ello con una anchura total de 5,3 cm (Fig. 7.3.4.1). Este tipo de cenefas cuenta con escasos paralelos en Pompeya, pudiendo citar únicamente el del tablinum de la casa delle Nozze d'Argento (V 2, i) (Ehrhardt, 2004), si bien nuestro ejemplar presenta una mayor complejidad y barroquización. En lo que respecta a su cronología, esta se asocia de manera clara a un conjunto del IV estilo, probablemente entre época claudia y neroniana, que cuenta con otra serie de cenefas y orlas que abordaremos en los siguientes grupos ${ }^{24}$. No obstante, la unidad fue datada a finales del siglo III d. C., lo que implica de manera clara la existencia de remociones posteriores al momento de volcado del conjunto en el vertedero.

\section{III.3.5. Tres cuartos de círculo sin alternancia}

En lo que respecta a esta variante, cuenta con cuatro ejemplares. El primero es el procedente del techo del triclinium de la domus de la calle Añón de Zaragoza (Guiral Pelegrín et al., 2019: 223, fig. 6), de la que ya hemos descrito anteriormente otro ejemplar procedente de la zona media de la pared. La orla está compuesta por dos filetes blancos, el superior sirve de apoyo para los cuartos de círculo que, en su interior, cuentan con una palmeta. Entre cada círculo se desarrolla un pequeño bifolio con una gota a la que se suma otra gota dispuesta sobre la parte central de los tres cuartos de círculo, todo ello en color blanco sobre fondo rojo y con una anchura de 5,6 cm (Fig. 7.3.5.1). En relación a los trazos preparatorios, se ha documentado la presencia tanto de incisión por uso de compás para trazar los semicírculos, como trazos pintados bajo los filetes. En el caso del trazado mediante compás, parece claro que el extremo no contendría una punta para trazar la incisión sino un fino pincel con el que pintar directamente, tal y como sucede en Bilbilis (Guiral Pelegrín y Martín-Bueno, 1996). Cuenta con paralelos como el del cubiculum «d» de la casa del Salone Nero de Herculano (VI 13) (Barbet, 1985: 169, fig. 119; Esposito, 2014), fechado en la transición entre el III y IV estilo o el de la villa de San Marco en Stabia (Barbet, 1999; Nunes Pedroso, 1999: 274, lám. XX, 2), del IV estilo. En lo que respecta a la cronología, dadas sus características, ha sido fechado en época de Claudio, en la transición entre el III y el IV estilo, formando parte de la primera fase decorativa de la estancia (Guiral Pelegrín et al., 2019: 228). En segundo lugar, contamos con un ejemplar procedente del castro Chao Samartín, en este caso una orla calada en color rojo compuesta por un filete sobre el que se desarrolla una sucesión de tres cuartos de círculo con bifolios en el interior del mismo color y un trazo negro, todo ello con una anchura total de 5,6 cm (Gago Muñiz, 2007: 445) (Fig. 7.3.5.2). En lo que respecta a los paralelos, debemos referir a los

24. El conjunto se encuentra en fase de estudio. 


\section{Círculos secantes}

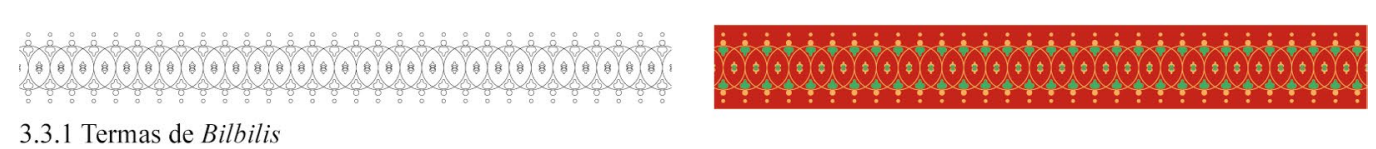

3.3.1 Termas de Bilbilis

\section{Círculos entrelazados}
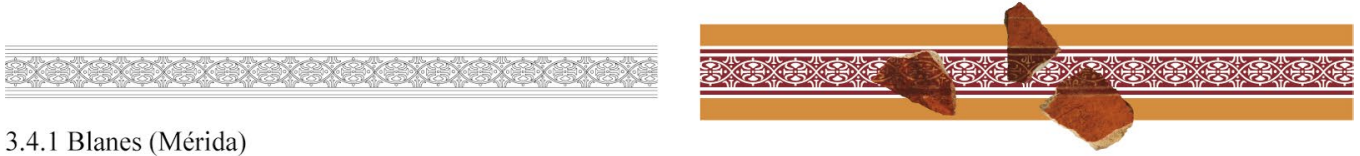

Tres cuartos de círculo sin alternancia
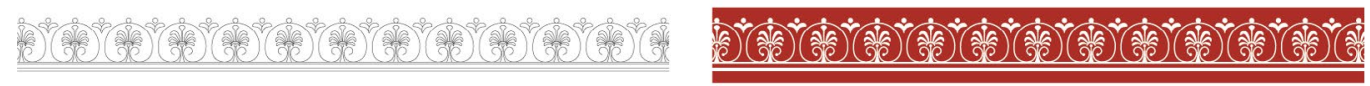

3.5.1 Calle Añón (Zaragoza)
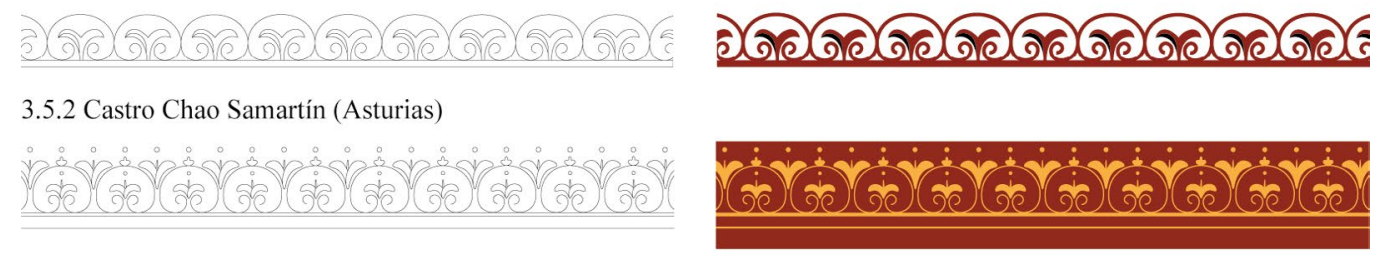

3.5.3 Casa del Pretorio (Arcobriga)
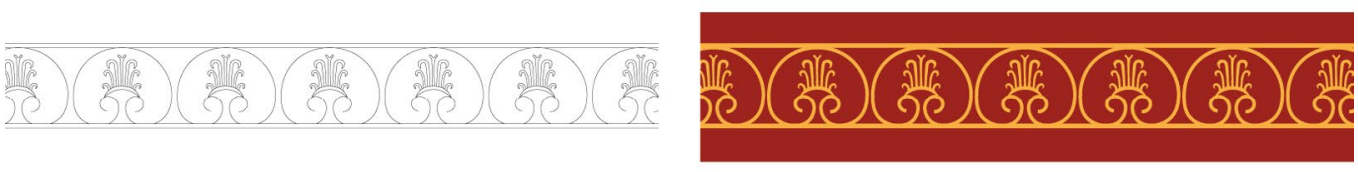

3.5.4 Domus de Salvius (Cartagena)
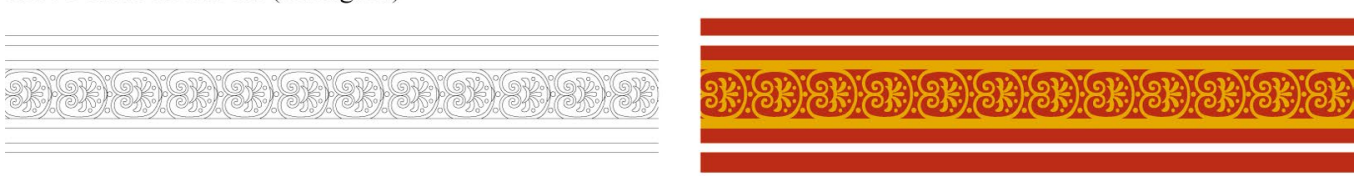

3.5.5 Casa del Mitreo (Mérida)
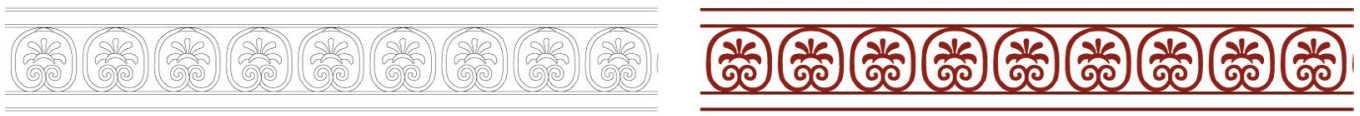

3.5.6 Villa de Portmán (Cartagena-La Unión)

\section{Tres cuartos de círculo con alternancia}

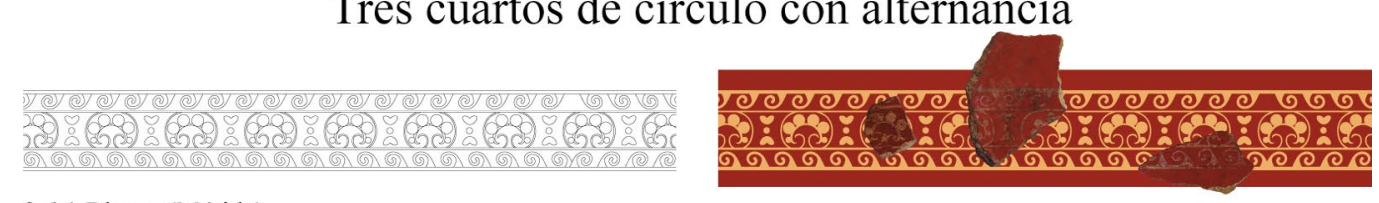

3.6.1 Blanes (Mérida)

Figura 7: Cenefas y orlas caladas del grupo de círculos, tres cuartos de círculo y semicírculos. Fuente: elaborada por los autores

anteriormente citados, siendo fechado, en este caso, en torno a mediados del siglo I d.C.

Muy similar al primero es el procedente de la casa del Pretorio de Arcobriga (Guiral Pelegrín y Mostalac Carrillo, 1992: 100-102; Guiral Pelegrín y MartínBueno, 1996), una orla calada compuesta por dos filetes, el superior sirve de base para una sucesión de tres cuartos de círculo que en su tramo final se enroscan a modo de voluta y que tienen en su interior un trifolio con una gota superpuesta. Por encima, un trifolio se dispone en el hueco entre cada tres cuartos de círculo, rematado con una gota, mientras que la parte central queda decorada con una gota ovala con apéndice rematada con otra gota. La orla, en color amarillo, se dispone sobre un fondo rojo y presenta una anchura de $8,3 \mathrm{~cm}$, así como trazos preparatorios incisos mediante 
compás de idéntico tipo a los del caso anterior (Guiral Pelegrín et al., 2019: 223) (Fig. 7.3.5.3). Dada la similitud con este último, remitimos a sus paralelos y a una fecha dentro del IV estilo (Guiral Pelegrín y Mostalac Carrillo, 1992).

El cuarto ejemplar procede la estancia 11 de la domus de Salvius en Cartagena (Fernández Díaz, 2008). El esquema es muy similar a los anteriores, con la diferencia de que presenta dos filetes amarillos que encierran el motivo de tres cuartos de círculo que cuenta con una palmeta en su interior y con una anchura total de $8,7 \mathrm{~cm}$, al igual que el ejemplar del mismo conjunto (6.5.1) (Fig. 7.3.5.4). En relación a los paralelos, remitimos a los citados para Bilbilis y Arcobriga. En lo que respecta a su cronología, el conjunto al que pertenece fue datado entre los años 50-60 d. C.

El quinto ejemplar es el que menos similitud guarda con el resto dada su morfología y disposición. Este procede de la denominada habitación de las pinturas de la casa del Mitreo de Mérida (Abad Casal, 1982b: 48-54, fig. 31), compuesta por cuatro filetes, los externos blancos y los internos amarillos, que encuadran una sucesión de tres cuartos de círculo dispuestos en posición horizontal, y que culminan en su interior en dos volutas sobre las que se desarrolla una palmeta con cinco pétalos y cuatro gotas intercaladas. Entre cada círculo se sitúan 3 gotas en posición vertical, todo ello en amarillo sobre fondo rojo, con una anchura total de $12 \mathrm{~cm}$ (Fig. 7.3.5.5). Al igual que el resto de orlas caladas de esta estancia que referimos a lo largo de este trabajo (2.2.20 y 13.7), se fecha en torno a finales del siglo I d. C.

El último caso procede de la habitación 7 de la villa romana de Portmán, actualmente en fase de estudio. La orla presenta un esquema similar a los anteriores, dispuesto entre cuatro filetes rojos y con una sucesión de tres cuartos de círculo rematados con volutas con una palmeta en el interior, todo ello sobre un fondo blanco y con 10,5 cm de anchura (Fig. 7.3.5.6). Encontramos el mismo sistema de trazos preparatorios que la orla del mismo conjunto descrita más arriba, con empleo de líneas incisas y uso del compás (3.1.4). En relación a los paralelos de estos dos últimos ejemplares, remitimos a los ya citados para el resto de casos de esta variante. En lo que respecta a su cronología, al igual que sucede con el conjunto procedente de la habitación 8 , se ha datado en la primera mitad del siglo II d. C. en base al contexto, así como a la evidencia de la construcción de la terraza superior (Fernández Díaz et al., 2019), en la que se ubica, en los últimos años del siglo I d. C.

\section{III.3.6. Tres cuartos de círculo con alternancia}

Dentro de esta variante encontramos únicamente un ejemplar procedente de la UE 1470 del vertedero de Blanes en Mérida. Se trata de una orla calada compuesta por cuatro filetes amarillos sobre fondo rojo que enmarcan, en la parte central, una sucesión de tres cuartos de círculos con una palmeta en su interior de seis pétalos que alterna con una gota flanqueada arriba y abajo por un motivo cordiforme hacia el exterior. Junto a esto, los filetes externos presentan, hacia el interior, una sucesión de olas contrapuestas, con una anchura total de 8,2 cm (Fig. 7.3.6.1). En relación a los trazos preparatorios, no puede descartarse el empleo de trazos pintados en blanco. En cuanto a los paralelos, encontramos algunos en ámbito pompeyano, si bien todos ellos son más recargados y cuentan con motivos decorativos distintos, como los del tablinum de la casa di Apolo (VI 2, 22) (Barbet, 1981: fig. 27, 123a) y el de la casa delle Nozze d'Argento en Pompeya (Barbet, 1981: fig. 28, $123 \mathrm{~m}$ ), los del pórtico 20 y la estancia 25 de la villa de San Marco en Stabia (Barbet, 1981: fig. 28, 123n) y algunos ejemplares recogidos por Zhan y Gusman de procedencia desconocida (Barbet, 1981: fig. 27c, d y f). A estos sumamos el de la villa de Nerón en Subiaco (Boldrighini, 2003: 116, fig. 149) y, ya en ámbito provincial, los de las villas de Yvonand-Mordagne y de Wagen, fechados en el 60-90 d. C. (Fuchs y Dubois, 1997: 181), el de la casa «C» de la Médiathèque de Narbona (Hathaway et al., 2014: 280), fechado a finales del siglo I d. C. y el de la estancia «K» de la casa del Grand Triclinium en Clos de la Lombarde en Narbona (Sabrié y Sabrié, 2011). En lo que respecta a su cronología, las UUEE se datan en su conjunto entre el año 80 d. C. y época adrianea, por lo que, en base a las características técnico-estilísticas del ejemplar, optamos por una cronología entre finales de época neroniana y época flavia.

\section{III.3.7. Semicírculos sin alternancia}

La siguiente variante es la más numerosa y el primero de los ejemplares procede de Ampurias, en este caso de una habitación al suroeste del foro (Nieto Prieto, 1979-1980: 340, fig. 73). Se trata de una orla calada de fondo blanco compuesta por una sucesión de semicírculos dobles tangentes, los del interior amarillos y los del exterior rojos con una gota del mismo color en la parte central. Al interior, se encuentran decorados con tres hojas verdes, mientras que, al exterior, el espacio entre semicírculos esta ornamentado mediante un trifolio esquemático coronado por una gota verde. La orla presenta una anchura total de $6,5 \mathrm{~cm}$, con presencia de trazos preparatorios ejecutados mediante compás (Fig. 8.3.7.1). En relación a los paralelos, encontramos diversos ejemplos en Pompeya como los procedentes de la casa del Championnet (VIII 2, 1), de la estancia «N» de la casa de Trebius Valens (III 2, 1), de la estancia de la casa de Pinarius Cerealis (III 4, b) y del triclinium de la casa del Moralista (III 4, 3) (Barbet, 1981: fig. 17, 70a, c, e y f), a los que sumamos el de la estancia 8 de la casa del Salone Nero de Herculano (VI 13) y un ejemplar recogido por Zahn de procedencia desconocida (Barbet, 1981: fig. 17, 70b y 70d). Si buscamos en el ámbito provincial, este es uno de los modelos más 
empleados, pudiendo citar los de la casa sur de la ínsula 10 de Avenches y de la estancia «Q» de la ínsula 8 de Martigny, fechados entre el 60-90 d. C. (Fuchs y Dubois, 1997: 181), de Pontiffroy y de la Ancienne Chambre des Métiers en la colline Sainte-Croix (Allag et al., 2014: 216), fechado a finales del siglo I d. C., de la estancia 89 de la villa de Saint-Ulrich (Heckenbenner, 1983), de la calle Catalogne en Narbona (Aude), fechado en entorno a mediados del siglo I d. C. (Sabrié, 2013: 43, fig. 12c), del caldarium de la villa rustica del Ortsteil Depot de Mülheim-Kärlich (Gogräfe, 2004: 255, fig. 8), de la estancia 6 de la domus de La Fontainotte en Grand (Lorraine, Vosges) (Froeliger y Mondy, 2017: 75, fig. 6), de la ínsula 20 de Xanten (Jansen et al., 2001: fig. 15) o de la domus de Vésone en Périgueux, de la segunda mitad del siglo II d. C. (Barbet et al., 2012: 92, fig. 40). En lo que respecta a la cronología, fue fechado hacia mediados del siglo I d. C.

Los dos ejemplares siguientes, algo posteriores y de factura muy similar, pero con distinta paleta cromática, los encontramos en las UE 1360 y 860 del vertedero de Blanes. La primera orla, sobre fondo rojo, está formada por dos filetes amarillos que enmarcan una sucesión de semicírculos triples, el externo blanco, el central amarillo y el interno azul, que encierra dos volutas contrapuestas a modo de bifolio coronado por un trazo azul con tres gotas blancas por encima y una amarilla por debajo. Junto a esto, el semicírculo blanco se encuentra cortado en su parte central y decorado con una gota amarilla. En los espacios generados entre los semicírculos se disponen pequeñas cuñas a modo de dientes cuyo vértice mira hacia el interior, de borde blanco y fondo verde y con una gota amarilla hacia el exterior. La orla queda completada por una sucesión de semicírculos y óvalos de pequeño tamaño de borde amarillo y fondo verde que se disponen sobre el filete inferior hacia el exterior, bajo la unión de los semicírculos y bajo las volutas respectivamente, con una anchura total de 9,3 cm (Fig. 8.3.7.2). La segunda presenta un esquema idéntico salvo por unas excepciones. En este caso, dispuesta sobre fondo amarillo, presenta todos los elementos en color blanco en vez de amarillo, así como los verdes en color rojo, careciendo de la gota que cortaba el semicírculo exterior, pero con el añadido de una pequeña gota sobre cada uno de los motivos que se dispone sobre el filete inferior hacia el exterior (Fig. 8.3.7.3). En ambos casos se aprecian, en algunos fragmentos, pequeñas incisiones que indican el empleo de un compás para el trazado de los semicírculos, que en este caso harían uso de un pincel como sucede en Bilbilis, Caesaraugusta y Arcobriga (Guiral Pelegrín et al., 2019: 223). En lo que respecta a los paralelos, remitimos a los anteriormente señalados. En relación a su cronología, el contexto permite datarlos entre época neroniana y época flavia.

El cuarto ejemplar, también procedente del vertedero de Blanes, en este caso de las UUEE 925 y 1535 , está formado por dos filetes en la parte inferior, el externo blanco y el interno amarillo, este último sobre el que se dispone una sucesión de semicírculos dobles, el interno blanco y el externo amarillo, decorados en su interior por media roseta con una gota central amarilla. El semicírculo externo queda rematado en su parte superior por una gota amarilla y el espacio entre estos se completa con un bifolio coronado por una gota blanca, todo ellos sobre fondo negro y con una anchura total de $6,7 \mathrm{~cm}$ (Fig. 8.3.7.4). En cuanto a los paralelos, remitimos a los anteriormente señalados. En lo que respecta a su cronología, ambas UUEE fueron fechadas entre el 80 y el 100 d. C., por lo que nos inclinamos por una cronología entre época tardo neroniana e inicios de época flavia.

Un ejemplar procedente de la casa dos Repuxos de Conimbriga (Nunes Pedroso, 2005: 365, fig. 7) ${ }^{25}$, presenta similitudes en su parte central. Se trata de una orla con cuatro filetes, los centrales encierran una sucesión de semicírculos tangentes con una gota con apéndice en su interior y un bifolio con una gota en el espacio entre cada semicírculo. El filete que cierra por su parte superior la banda de semicírculos, así como el inferior de la orla, presentan una sucesión de gotas de mediano tamaño, en el primer caso hacia el exterior y en el segundo hacia el interior. La orla culmina por su parte superior con una sucesión de gotas ovaladas con apéndice coronadas por otra gota, todo ello hacia el exterior y dando una anchura total de $11,6 \mathrm{~cm}$ (Fig. 8.3.7.5). En relación a los paralelos, remitimos a los anteriormente señalados. En lo que respecta a su cronología, la construcción de la casa fue fechada en el siglo I d. C., documentándose una remodelación hacia finales del siglo I o inicios del siglo II d. C. (Alarcão, 1999; Correia, 1997; 1999), por lo que debe situarse en la segunda mitad del siglo I d. C.

La última orla de esta variante procede de la UE 1433 del vertedero de Blanes en Mérida, en este caso formada por dos filetes blancos sobre fondo rojo que encierran una sucesión de semicírculos tangentes amarillos decorados interiormente con un semicírculo azul rematado por cinco pétalos puntiagudos del mismo color, todo ello con una anchura de $5,7 \mathrm{~cm}$ (Fig. 8.3.7.6). En relación a los paralelos, remitimos a los anteriormente señalados. En lo que respecta a la cronología, la unidad se fecha entre los años 50-100 d. C. ${ }^{26}$ $\mathrm{y}$, dadas las características de la orla, parece factible fecharla entre época neroniana e inicios de época flavia, por lo que probablemente responda a un conjunto amortizado hacia los últimos años del siglo $\mathrm{I} d$. C.

25. En este caso, dado que no contamos con información acerca de la paleta cromática empleada, se ha incluido la restitución en blanco y negro. Así mismo, carecemos de datos en relación al uso o no de trazos preparatorios.

26. La datación de la UE 1433 viene determinada por la presencia de paredes finas de la forma Mayet XLIII y Mayet LI, así como lucernas del tipo Dr. 5c entre otras. 

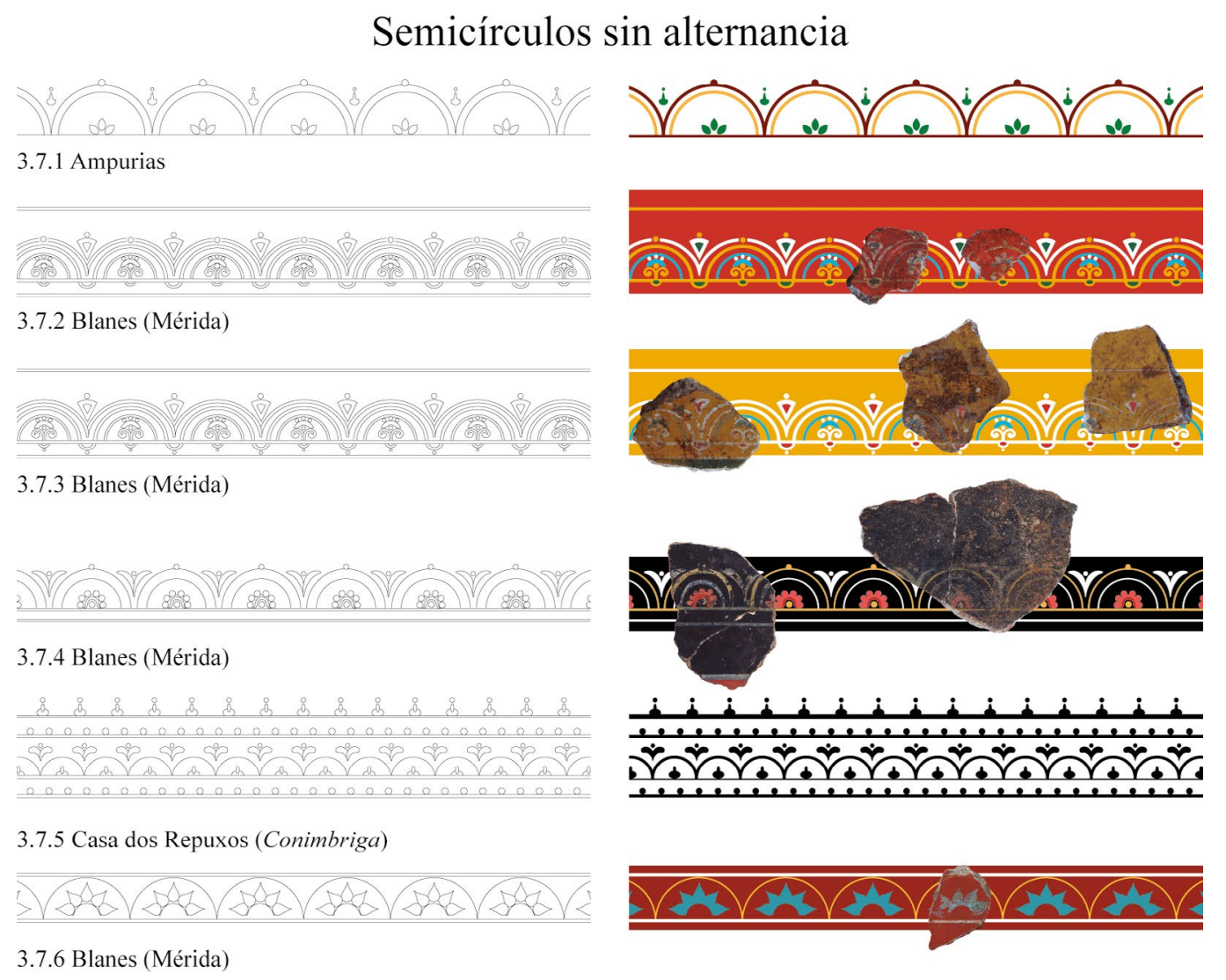

\section{Semicírculos con alternancia}

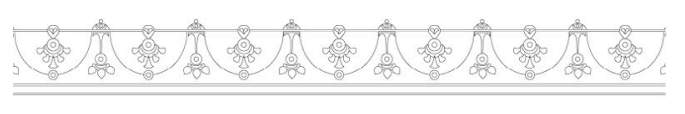

3.8.1 Cabo Verde (Mérida)
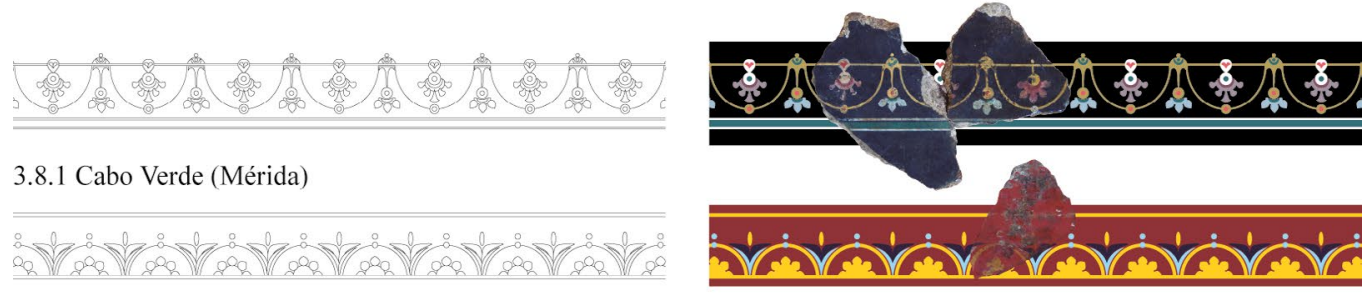

3.8.2 Cabo Verde (Mérida)

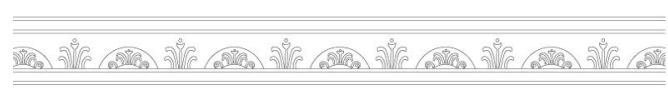

3.8.1 Blanes (Mérida)
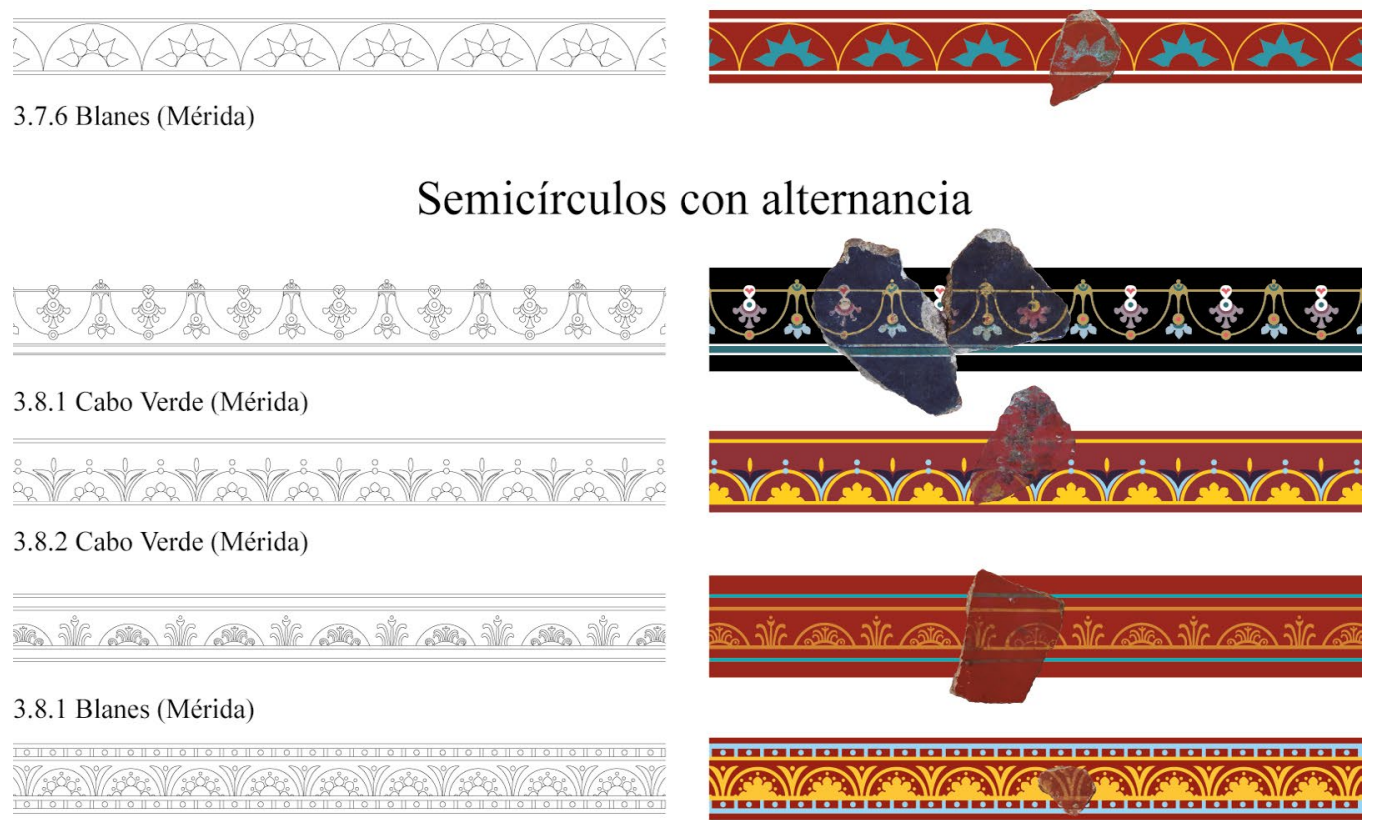

3.8.1 Casa del Mitreo (Mérida)
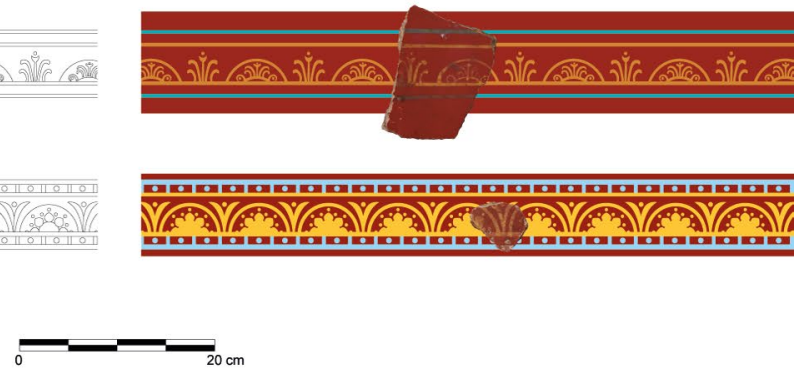

Figura 8: Orlas caladas del grupo de círculos, tres cuartos de círculo y semicírculos. Fuente: elaborada por los autores

\section{III.3.8. Semicírculos con alternancia}

En lo que respecta a esta variante, únicamente encontramos cuatro ejemplares. El más antiguo procede de las UUEE 22 y 65 del vertedero de la calle Cabo Verde de Mérida. Se trata de una orla sobre fondo negro formada por un triple filete en la parte inferior, los externos blancos y el interno verde azulado y un filete amarillo en la superior, que encierran una sucesión de semicírculos amarillos que apoyan sobre este último. Los semicírculos presentan un engrosamiento en la parte central con una gota rojo cinabrio, mientras que en el interior presentan una gota blanca de centro verde bajo la que se desarrolla una palmeta en tonos violáceos. El espacio entre los semicírculos queda decorado por un tallo amarillo que culmina en un círculo del mismo color con una gota rojo cinabrio, quedando por debajo otra palmeta azul con un trazo verde. La orla queda rematada, sobre el filete amarillo, por una gota blanca con un pequeño motivo en $« \mathrm{~V} »$ y rojo a la altura de la palmeta interior 
y un semicírculo amarillo con trazos verdes y una gota amarilla a la altura del tallo que separa los semicírculos, con una anchura total de 7,8 cm (Fig. 8.3.8.1). Entre los paralelos existentes citamos los del tablinum de la casa del Bicentenario (V 15) (Barbet, 1981: fig. 19, 72c) y el de la estancia 2 de la casa del Tramezzo di Legno de Herculano (III 1, 1) (Barbet, 1981: fig. 19, 72d), el de Bolsena (Barbet, 1981: fig. 19, 72f) o los de la casa del Championnet (VIII 2, 1) (Barbet, 1981: fig. 19, 72g) y del ala «I» de la casa dei Vettii en Pompeya (VI 15, 1) (Barbet, 1981: fig. 19, 72h; Archer, 1982), a los que añadimos dos ejemplares recogidos por Zahn (Barbet, 1981: fig. 19, 72a y b) y uno de Boscoreale (Strocka, 1991). Junto a estos, contamos con otros ejemplos en las provincias, como los de la extensión de la Préfecture rue Saint-Jacques en Touluse, fechado a mediados del siglo I d. C. (Sabrié y Sabrié, 2003), de la villa de Contigny y el vicus de Vidy en Lausanne, ambos fechados entre el 60-90 d. C. (Fuchs y Dubois, 1997: 180), de la casa «C» de la Médiathèque de Narbona (Hathawey et al., 2014: 280), fechados a finales del siglo I d. C., los de las estancias $\langle\mathrm{H} » \mathrm{y}$ «D» de la maison à Portiques y del sector Ci 27 de Clos de la Lombarde en Narbona y el de Aire du Chapître en Aix-en-Provence (Sabrié y Demore, 1991), los de Périgueaux y de Burdeos (Barbet, 2008: 187, 281a 7 y 8) o el del Quartier Clérisseau en Nimes (Boislève, 2014: 659-660, lám. CLXXXVII, fig. 2), de la segunda mitad del siglo I d. C. Las características sugieren que se trate de un conjunto de transición entre el III y el IV estilo, dada la presencia de triples filetes de tamaño inferior a $1,5 \mathrm{~cm}$, así como a la gran calidad en la ejecución de los elementos.

El segundo procede también del vertedero de la calle Cabo Verde, en este caso de la UE 22. Se trata de una orla calada compuesta por dos filetes amarillos que encuadran una sucesión de semicírculos decorados por media roseta que alternan con dos bifolios superpuestos, el inferior azul y el superior violáceo oscuro, coronado por una gota alargada amarilla. Junto a esto, el semicírculo está coronado hacia el exterior por dos gotas azules superpuestas, todo ello sobre un fondo rojo, con una anchura total de $6,7 \mathrm{~cm}$ (Fig. 8.3.8.2). En lo que respecta a los paralelos, remitimos a los anteriormente citados dada la similitud del esquema, si bien este es más esquemático en sus elementos. En cuanto a su cronología, los datos del contexto (Pérez Maestro, 2004; 2007) y las características permiten situarlo en torno a época neroniana, dado que no es posible llevarlo a un período posterior.

El tercero procede del vertedero de Blanes, en este caso de la UE 1535. Está formado por cuatro filetes, los externos azules y los internos amarillos, que encierran una alternancia de semicírculos con una palmeta y palmetas sueltas, todo ello en color amarillo sobre fondo rojo, con una anchura total de $6,8 \mathrm{~cm}$ (Fig. 8.3.8.3). Entre los paralelos citamos el de la zona superior del oecus de la casa del Principe di Napoli (VI 15, 8) (Strocka, 1984) o el de la estancia $\langle\mathrm{F}\rangle$ de la casa della Regina Margherita (V 2, 1) (Barbet, 1981: fig. 20, 74d), que cuenta con una partición en la zona superior. En este caso, la UE fue fechada entre los años 80-100 d. C., por lo que optamos por datar el ejemplar a inicios del período flavio.

El último caso de esta variante procede de la casa del Mitreo y fue recuperado en las intervenciones llevadas a cabo en el año 91, si bien no conservamos ningún dato acerca del contexto al que pertenece más allá de una anotación que hace referencia a una cata realizada en el exterior de la casa, por lo que desconocemos si puede formar parte de alguna estancia de la misma. Se trata de una orla compuesta por cuatro filetes, los dos externos azules y los internos amarillos, que encuadran una sucesión de semicírculos decorados al interior con media roseta con gotas coronando las puntas de los pétalos que alternan con un bifolio muy alargado coronado por una gota, todo ello en amarillo. Sobre los filetes azules y hacia el interior se dispone una sucesión de filetes azules en vertical que generan espacios cuadrangulares decorados por gotas azules, todo ello sobre un campo rojo y con una anchura total de 7,2 cm (Fig. 8.3.8.4). En lo que respecta a los paralelos, remitimos a los referidos para los dos casos anteriores, especialmente los de la Gallia como uno procedente de Burdeos (Barbet, 2008: 187, fig. 281a, 8). Al igual que para el resto de ejemplares de la casa del Mitreo, la fecha de fundación establecida en torno a la década de los 70 del siglo I d. C. (Bejarano Osorio et al., e.p.) sugiere una cronología flavia.

\section{III.3.9. Semicírculos superpuestos}

Dentro de esta variante contamos con tres ejemplos, todos ellos muy similares en su forma, pero con ligeras variaciones en las dimensiones y la ornamentación marcadas por su cronología y factura. El primero de ellos, procedente de Carteia y actualmente depositado en el Museo Arqueológico de Cádiz (Abad Casal, 1982b: 113, fig. 161; Fernández Díaz, 2010), es una orla formada por un triple filete inferior, los externos blancos y el interno rojo, un filete blanco superior que encierra dos filas de semicírculos superpuestos de color blanco decorados en su interior por una gota ovalada con apéndice. En este caso, sobre fondo amarillo, presenta una anchura total de 4,3 cm (Fig. 9.3.9.1). En lo que respecta a los paralelos, citamos los de la casa de Nettuno e Anfititre de Herculano (IX 2, 27) o los de la estancia 7 de la casa del Efebo (I 7, 11), la estancia «b» de la casa de Pinarius Cerialis (III 4, b) (Barbet, 1981: fig. 22, 80c, d y e), el atrio de la casa del Menandro (I 10, 4) (Stefani, 2003; Ling, 2005) y la casa del Championnet (VIII 2, 1) (Barbet, 1981: fig. 22, 80g) de Pompeya, a los que sumamos un ejemplar recogido por Zhan (Barbet, 1981: fig. 22, 80a). Junto a estos, contamos también con algunos casos procedentes de las provincias, como el de del sector Ci 25 de Clos de la Lombarde en Narbona (Sabrié y Demore, 1991). La falta de información acerca de su procedencia exacta, así como de datos del contexto al que se 
asocian, impiden establecer una cronología clara, si bien las dimensiones y la presencia de un triple filete podría estar indicando su pertenencia a un conjunto de transición entre el III y el IV estilo o de mediados del siglo I d. C.

En segundo lugar, encontramos un ejemplar procedente de la UE 1319 del vertedero de Blanes en Mérida, formado por cuatro filetes, los externos azules y los internos amarillos que enmarcan tres filas de semicírculos superpuestos con una gota en el interior. Junto a esto, los filetes azules presentan, al interior, una alternancia de semicírculos con apéndice y una gota azul sobre fondo rojo y con una anchura total de $8,5 \mathrm{~cm}$ (Fig. 9.3.9.2). En este caso, el contexto fue fechado a inicios del siglo II d. C. ${ }^{27}$, por lo que, dadas sus características, parece factible plantear una cronología de época flavia.

El último caso, procedente de la Huerta de Otero en Mérida, presenta dos filetes blancos que enmarcan tres filas de semicírculos amarillos con una gota azul, todo ello sobre fondo rojo y con una anchura total de $9,1 \mathrm{~cm}$ (Fig. 9.3.9.3). En lo que respecta a su cronología, su hallazgo en el transcurso de las intervenciones desarrolladas en los años 80 hace que carezca de información acerca del contexto por la falta de una metodología de excavación moderna, por lo que nos limitamos a plantear una datación de finales del siglo I o inicios del siglo II d. C. en base a sus características técnico-estilísticas. Para estos dos últimos ejemplares remitimos a los paralelos señalados en el primero de esta variante, dado que presentan características similares.

\section{III.3.10. Semicírculos con particiones intermedias}

Similar a estos tres ejemplos por su morfología es el conservado en el Museo Arqueológico Nacional de Madrid, que hemos incluido en la variante de semicírculos con particiones intermedias. El fragmento en cuestión es de procedencia desconocida, dado que pasó a formar parte de las colecciones del Museo en la primera mitad del siglo XX y no consta su lugar de origen ni su posible cronología (Abad Casal, 1982b: 156, fig. 227), por lo que únicamente se puede señalar el siglo I d. C. en base a sus dimensiones. En este caso se trata de una orla blanca sobre fondo amarillo formada por dos filetes que enmarcan una sucesión de semicírculos tangentes con un bifolio coronado por una gota en su interior. Sobre estos se disponen, en la parte central, filetes que generan espacios trapezoidales decorados con el mismo motivo, todo ello con una anchura total de 2,4 cm (Fig. 9.3.10.1). En lo que respecta a los paralelos, encontramos algunos

27. La cronología de la UE 1319 fue fijada por la presencia de sigillata hispánica de las formas 35/36, 37 y 39 , un sello del productor Martialis de sigillata sudgálica, lucernas tipo Dr. 5c, 11, 13, 30 y Deneuve VG y un As de Trajano. ejemplos del área pompeyana como los de la casa de la Fontana Piccola (VI 8,23), los más similares, los de la estancia 59 de la casa del Centenario (IX 8, 3) (Barbet, 1981: fig. 18, 71c y n, 71j y l) y de la casa del Championnet (VII 2,1) en Pompeya, a los que hay que añadir uno procedente de la estancia 8 de la casa del Mobilio Carbonizzato (V 5) (Barbet, 1981: fig. $18,71 \mathrm{~m}$ y 71 i) y varios recogidos por Zahn y Gusman (Barbet, 1981: figs. 17 y 18, 71b, e y f). A estos sumamos un ejemplar de Moregine (Scarano Ussani, 2005: 121) y diversos paralelos en las provincias, como un ejemplar de Corinto y otro de Cartago (Strocka, 2014: lám. VII, fig. 14).

\section{III.3.11. Semicírculos secantes}

El más antiguo de los ejemplares de esta variante lo conforma una orla calada procedente de la UE 1262 del vertedero de Blanes en Mérida, perteneciente al zócalo del conjunto de círculos entrelazados que hemos descrito anteriormente (3.4.1). Está compuesta por tres filetes, dos que enmarcan la orla y un tercero sobre el que se apoya el motivo formado por círculos secantes que unen en la parte central y que se decoran en los espacios que generan mediante una palmeta de tres círculos con tres gotas superpuestas, todo ello en amarillo y con una anchura total de 4,2 cm (Fig. 9.3.11.1). Esta orla presenta un único paralelo procedente de la zona campana, en concreto del oecus 6 de la casa del Salone Nero de Herculano (VI 13) (Barbet, 1981; fig. 23, 90a; Esposito, 2014), también sobre fondo negro, aunque con otra policromía y motivos ornamentales. Por otra parte, si encontramos gran cantidad de paralelos en el ámbito provincial, como son los de Baugy (Fuchs, 1993: 123, fig. 9), de las termas de la villa de Saint-Ulrich (Heckenbenner, 1983: 127 y 133: figs. 4-6), el hallado bajo las termas imperiales de Tréveris (Reusch, 1966: 209-215: lám. 30), el de Virunum (Kenner y Praschniker, 1947: 206, fig. 161), de la Ancienne Chambre des Métiers en la colline Saint-Croix, fechado a finales del siglo I d. C. (Allag et al., 2014: 216), el de la extensión de la Préfecture rue Saint-Jacques de Toulouse, fechado a mediados del siglo I d. C. (Sabrié y Sabrié, 2003), el del Hôpital Ambroise de Rennes (Labaune-Jean, 2010: fig. 3) o el de la villa gallo romana de Reinheim (Busse, 2014: 62). A estos, sumamos los de las termas de la ínsula 2 y de la estancia «Q» de la ínsula 8 de Martigny, de la ínsula 1 de Augst, de la villa de Contigny en Lausanne, de la villa de Baugy-sur-Clarens y de Fortungasse en Zurich, fechados todos entre el 60-90 d. C. (Fuchs y Dubois, 1997: 181). En este caso, como en el resto del conjunto al que pertenece, optamos por una datación en época neroniana, dado que la fecha del contexto, datado a finales del siglo III d. C., no encaja con las características técnico-estilísticas del conjunto, pudiendo deberse su presencia en esta unidad a un movimiento de tierra que ocasionó su desplazamiento. 


\section{Semicírculos superpuestos}
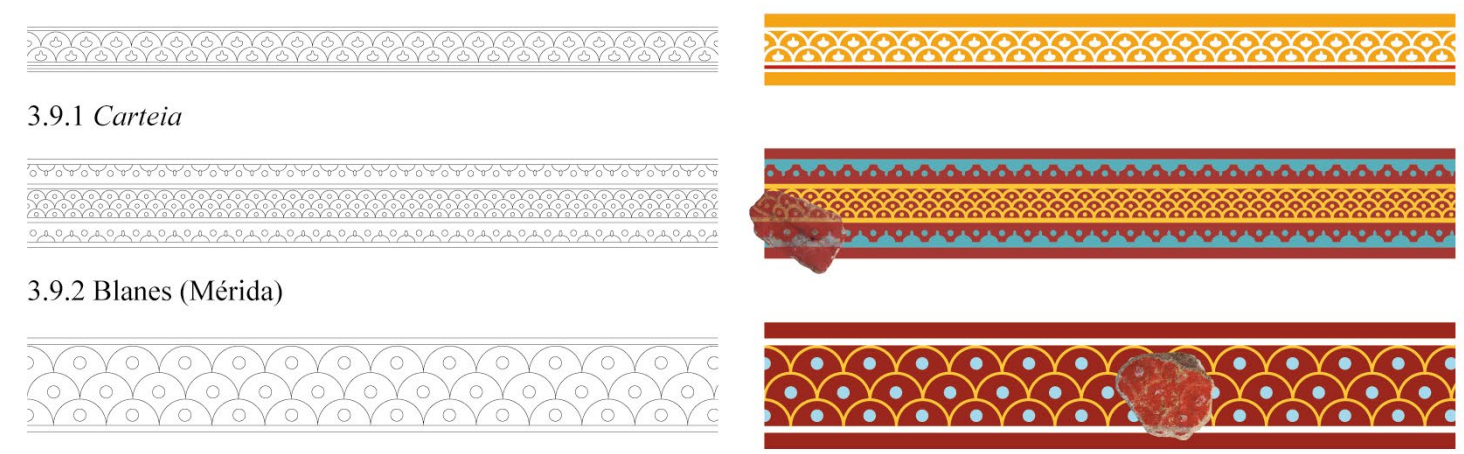

3.9.3 Huerta de Otero (Mérida)

\section{Semicírculos con particiones intermedias}

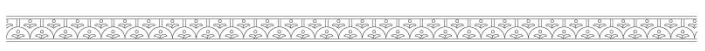

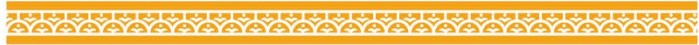

3.10.1 Museo Arqueológico Nacional

\section{Semicírculos secantes}

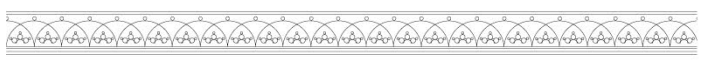

3.11.1 Blanes (Mérida)
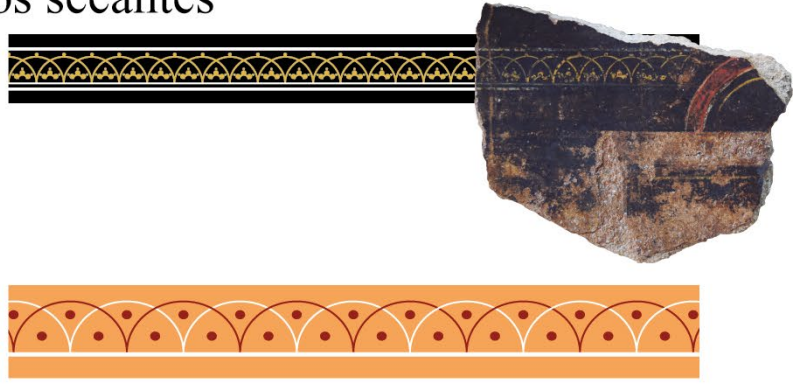

3.11.2 Casa de la Cisterna (Bilbilis)
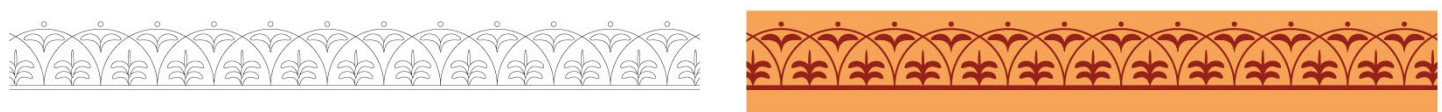

3.11.3 Casa de la Cisterna (Bilbilis)
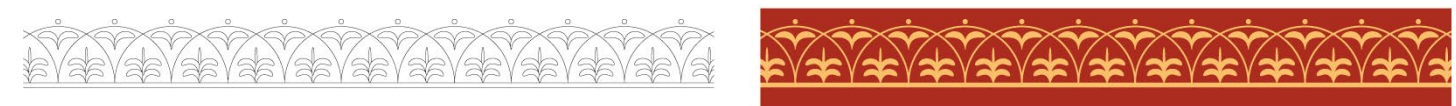

3.11.4 Casa de la Cisterna (Bilbilis)
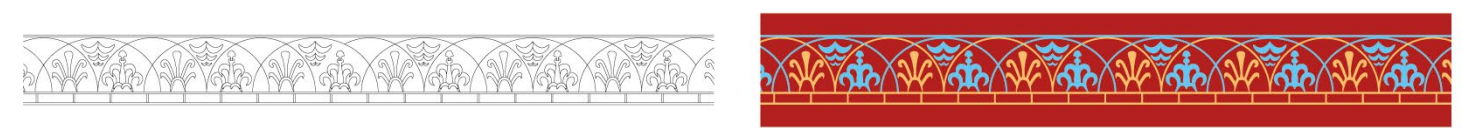

3.11.5 Calle Monroy (Cartagena)

Figura 9: Orlas caladas del grupo de círculos, tres cuartos de círculo y semicírculos. Fuente: elaborada por los autores

Algo posteriores a este ejemplar son los de la casa de la Cisterna de Bilbilis (Guiral Pelegrín y MartínBueno, 1996: 321-322; Íñiguez Berrozpe, 2014: 669, fig. 62), tres orlas correspondientes a dos paneles de un mismo conjunto. Las dos primeras forman parte de un panel de fondo amarillo, la primera sobre un filete blanco y con semicírculos secantes que alternan el rojo y el blanco y que se decoran en los espacios que se generan mediante gotas rojas, de 5,3 cm de anchura (Fig. 9.3.11.2). La segunda, sobre un filete rojo, cuenta con dos bifolios a los que se superpone un trifolio en la parte inferior de cada semicírculo y un bifolio en la parte superior, quedando hacia el exterior una gota, todo ello en color rojo y con $6,6 \mathrm{~cm}$ de anchura (Fig. 9.3.11.3). Por su parte, el tercer ejemplar presenta idéntica decoración y dimensiones, en este caso en amarillo sobre un panel rojo (Fig. 9.3.11.4). En todos los casos se ha empleado un compás con un pincel en uno de los brazos para ejecutar los semicírculos, por lo que solo se advierte la presencia de la marca de la punta del compás en la parte central y no una incisión en el recorrido. En relación a los paralelos, remitimos a los anteriormente citados dada su similitud. En lo que respecta a su cronología, se ha fechado en la segunda mitad del siglo I d. C. (Íñiguez Berrozpe, 2014: 671). 
Por último, contamos con un ejemplar procedente de Cartagena, hallado en el siglo XIX en las intervenciones realizadas en la calle Monroy y recogido por de la Rada y Delgado (Fernández Díaz, 2008). Se trata de una orla formada por tres filetes, los dos inferiores amarillos y el superior azul, que encierran semicírculos secantes decorados interiormente mediante una alternancia de dos tipos de palmetas en amarillo y azul y tres bifolios superpuestos. Junto a esto, el filete amarillo exterior presenta, hacia dentro, una compartimentación en rectángulos mediante filetes. En este caso no contamos con unas dimensiones aproximadas en anchura, dado que únicamente se conserva una referencia dibujada por el propio de la Rada y Delgado, si bien parece probable que fueran similares al resto de ejemplares, entre 5 y $7 \mathrm{~cm}$ (Fig. 9.3.11.5). Igualmente desconocemos si existen trazos preparatorios, aunque, al igual que en los casos anteriores, parece factible el empleo de compás. Así mismo, en relación a los paralelos, remitimos a los anteriormente citados para esta variante. En lo que respecta a su datación, únicamente podemos señalar su adscripción a la segunda mitad del siglo I d. C.

\section{III.3.12. Semicírculos contrapuestos sin alternancia}

Dentro de la variante de semicírculos contrapuestos encontramos, en primer lugar, un ejemplar procedente de Bilbilis que forma parte del conjunto B hallado en la estancia $\mathrm{M}$ de las termas, al igual que otras orlas de círculos que hemos descrito en este tipo (3.2.4 y 3.3.1) (Guiral Pelegrín y Martín-Bueno, 1996: 115, fig. 35). En este caso se trata de dos bandas de semicírculos tangentes contrapuestos que se unen en su parte central y que presentan, en el interior, media roseta con gotas superpuestas y un trazo verde que decora la unión entre semicírculos y, en el exterior, dos gotas superpuestas en la parte central del semicírculo y una gota con apéndice y un trazo verde a la que se superpone otra gota en la tangencia. La orla presenta una anchura total de $4,2 \mathrm{~cm}$ (Fig. 10.3.12.1). En lo que respecta a los trazos preparatorios, al igual que el resto de orlas del mismo conjunto se documenta el empleo de líneas incisas para marcar el desarrollo de la orla y compás para el trazado de los semicírculos. Este tipo cuenta con pocos paralelos dada la existencia de las dos bandas contrapuestas, pudiendo señalar el modelo de Vieil-Evreux (Gruaz, 1985) y los de una domus de Clermont-Ferrand (Puy-de-Dôme), fechados en época flavia (Groetembril y Ollivier, 2013: 358-359), al margen del procedente del castro Chao Samartín (Gago Muñiz, 2014; e.p.) que abordaremos más adelante. Al igual que el resto de orlas del conjunto al que pertenece, se ha fechado en los primeros años de la segunda mitad del siglo I d. C. (Guiral Pelegrín y Martín-Bueno, 1996: 125).

El segundo ejemplar procede de Conimbriga (Tomás García, 2018), en este caso similar al anterior.
La banda superior presenta una alternancia de bifolios con gotas en el interior de un elemento egiptizante que se ubican en la tangencia de los semicírculos, todo ello en amarillo, con media roseta blanca con un trazo verde y una gota blanca superpuesta ubicada sobre la parte central del semicírculo. La banda inferior repite el esquema, quedando en este caso la roseta por debajo, mientras la gota parte el desarrollo del semicírculo. Junto a esto, el otro motivo pierde el elemento egiptizante. La parte central queda decorada por una roseta blanca de centro verde que se une a los semicírculos mediante un trazo curvo. En lo que respecta a sus dimensiones, la carencia de una escala obliga a situar el ejemplar entre los 4 y los $7 \mathrm{~cm}$ en base a sus características, así como la relación con el resto de elementos que lo acompañan (Fig. 10.3.12.2). Al respecto de los trazos preparatorios, se ha constatado la presencia de líneas incisas discontinuas que corroboran el empleo de cordelillo trenzado en la parte central de la orla y en sus extremos. No contamos con paralelos similares, aunque el repertorio ornamental es el mismo que encontramos en este y otros grupos y guarda similitud con otro ejemplar de la siguiente variante de la misma ciudad. En cuanto a su cronología, dado que desconocemos su procedencia, no es posible determinarla, aunque su similitud con los hallados en la casa dos Repuxos (Nunes Pedroso, 2005: 365, fig. 7), plantea la segunda mitad del siglo I d. C. como la hipótesis más probable.

El último de los ejemplares se corresponde con uno de los más tardíos del repertorio, procedente de la casa de la calle Suárez Somonte de Mérida (Álvarez Sáenz de Buruaga, 1974; Abad Casal, 1982b: 82-86, fig. 112; Hernández Ramírez, 1996), cuyo conjunto se expone actualmente en el Museo Nacional de Arte Romano de Mérida. Se trata de una orla compuesta por dos filetes de encuadramiento blancos que encierran una sucesión de semicírculos amarillos contrapuestos sobre un filete verde y decorados interiormente mediante trazos que se asemejan a un tallo vegetal de tipo guirnalda, muy mal conservado en todos los casos, con una anchura de 11,3 cm (Fig. 10.3.12.3). En lo que respecta a sus paralelos, únicamente citamos los de la casa del Anfiteatro de Mérida y de la habitación 11 del Edificio del Atrio del Barrio del foro del Molinete en Cartagena que describiremos en el siguiente apartado, ambos con una cronología anterior, de entre finales del siglo I e inicios del siglo II d. C., así como el de la habitación 2 de la Hang Haus de Éfeso (Zimmermann y Landstätter, 2011: 186), que se fecha en el segundo cuarto del siglo III d. C. En los tres casos se trata de conjuntos anteriores, dado que el de la calle Suárez Somonte se fecha en el siglo IV por la presencia de las escenas cinegéticas en el centro de los paneles, así como por la aparición de una moneda de Valentiniano II en el suelo de la estancia que podría marcar el momento de abandono (Abad Casal, 1982b: 82; Hernández Ramírez, 1996). 


\section{Semicírculos contrapuestos sin alternancia}
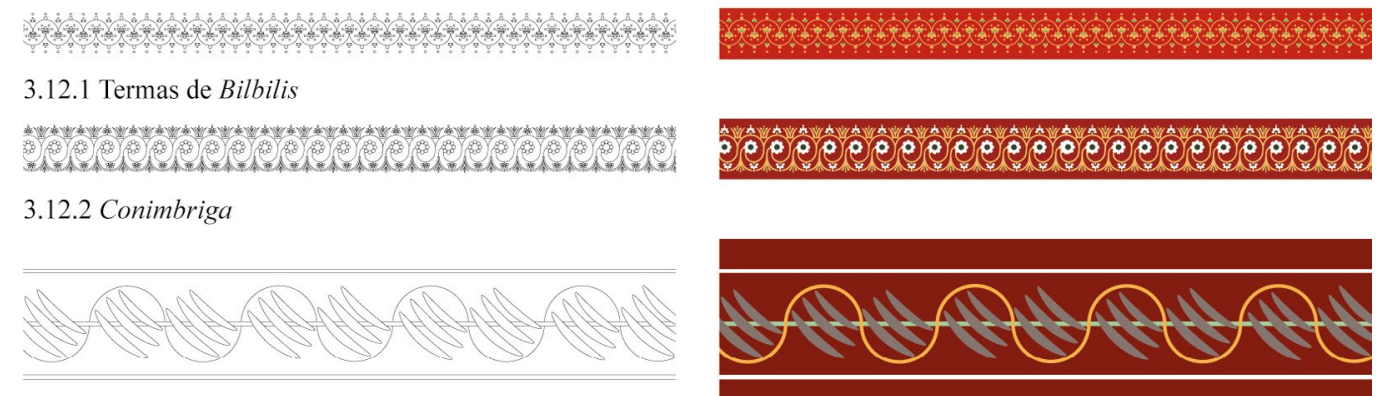

3.12.3 Calle Suárez Somonte (Mérida)

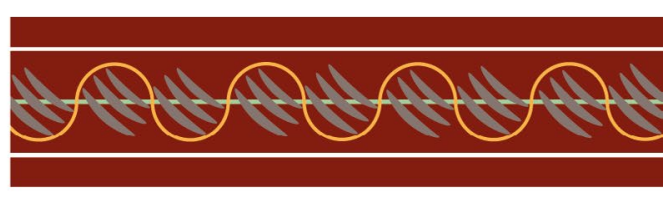

\section{Semicírculos contrapuestos con alternancia}
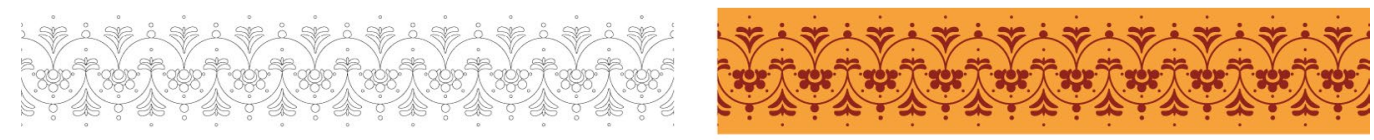

3.13.1 Castro Chao Samartín (Asturias)
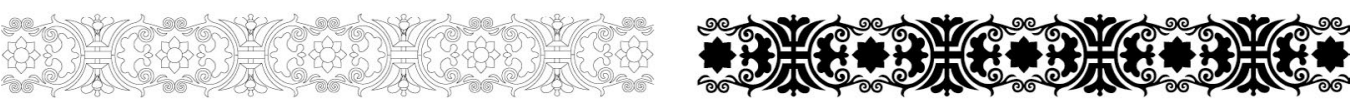

3.13.2 Casa dos Repuxos (Conimbriga)

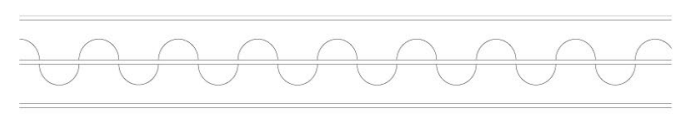

3.13.3 Casa del Anfiteatro (Mérida)
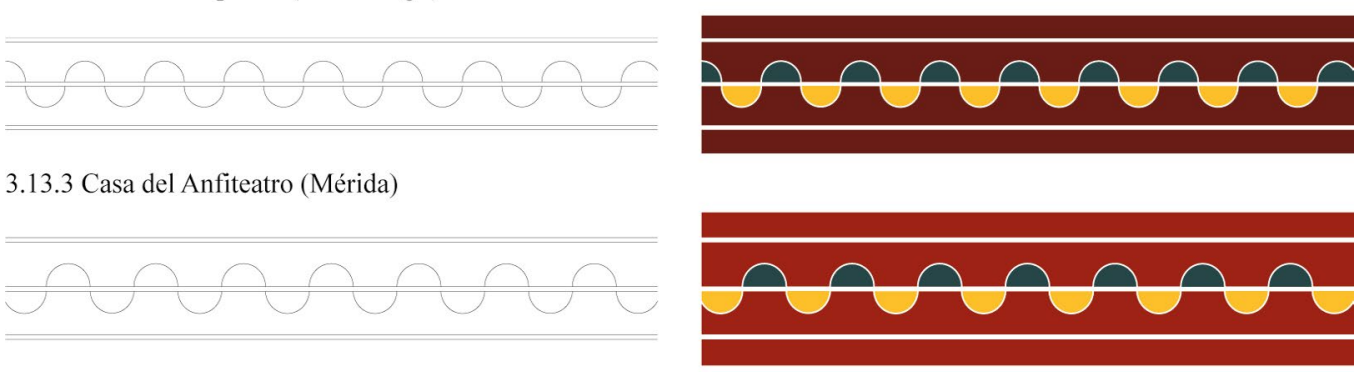

3.13.4 Barrio del Foro del Molinete (Cartagena)

Figura 10: Orlas caladas del grupo de círculos, tres cuartos de círculo y semicírculos. Fuente: elaborada por los autores

\section{III.3.13. Semicírculos contrapuestos con alternancia}

Dentro de esta variante encontramos, en primer lugar, la hallada en el castro Chao Samartín (Gago Muñiz, 2014; e.p.). Esta, realizada en rojo sobre fondo amarillo, está compuesta por dos bandas de semicírculos contrapuestos que, en la parte interna, alternan media roseta con cinco pétalos coronados con gotas y dos bifolios superpuestos con una gota en la parte superior como remate en la tangencia de los semicírculos. Hacia el exterior, ambos lados presentan, en la zona central del semicírculo, dos gotas superpuestas, y en la tangencia, dos bifolios superpuestos con una gota, dándole una anchura total de 11,4 cm (Fig. 10.3.13.1). Entre los paralelos citamos únicamente los de Bilbilis en la variante anterior, dado que son los únicos que hacen uso de este tipo de esquema. En este caso, si bien se ha empleado el compás para el trazo preparatorio de los semicírculos, estos presentan la incisión en todo su recorrido, lo que implica que no se utilizó un brazo con pincel. En lo que respecta a su cronología, fue fechada en torno a mediados del siglo I d. C. (Gago Muñiz, 2014; e.p.).

El segundo ejemplar es una orla procedente de la casa dos Repuxos de Conimbriga (Nunes Pedroso, 2005: 365, fig. 7$)^{28}$, compuesta por dos trazos de un semicírculo cortado que simulan un motivo egiptizante coronados por un bifolio, contrapuestos en posición vertical y unidos por un filete vertical. Estos quedan a su vez enlazados con el resto de motivos por un filete en posición horizontal más ancho que el anterior que une con dos semicírculos en disposición horizontal, contrapuestos entre sí y rematados en sus extremos mediante cuatro volutas, dos al interior y dos al exterior, así como cuatro finos tallos, dos al interior y dos al exterior. En

28. En este caso no disponemos de fotografías en color ni indicaciones acerca de la paleta cromática empleada, por lo que hemos indicado el modelo en blanco y negro. 
el espacio interno de los semicírculos se suceden dos formas similares a una palmeta y una roseta en la parte central, con una anchura total de 8,5 cm (Fig. 10.3.13.2). En lo que respecta a los paralelos, únicamente citamos un caso recogido por Barbet cuya procedencia no está indicada (1981: fig. 25, 113a). Como podemos ver, son escasos los ejemplos similares a este a pesar del hecho de que el repertorio ornamental se repite en otro tipo de esquemas, en especial la presencia de bifolios y volutas, aunque sí existe un caso con un esquema parecido procedente del Museo Archeologico Nazionale di Aquileia fechado entre época neroniana y época flavia (Salvadori et al., 2016: 244-245, fig. 1) y otro donde encontramos un motivo similar de filetes cruzados con un motivo de semicírculos cortados procedente de la casa «C» de la Médiathèque de Narbona (Hathaway et al., 2014: 280), fechado a finales del siglo I d. C. En cuanto a su cronología, la construcción de la casa se fecha en el siglo I d. C. y se ha documentado una gran reforma que tiene lugar entre finales del siglo e inicios del siglo II d. C. (Alarcão, 1999; Correia, 1997; 1999), lo que unido a la calidad de la orla permite plantear que corresponda a la segunda mitad del siglo I d. C.

Por último, un caso particular es el de la casa del Anfiteatro de Mérida (Abad Casal, 1982b: 71-72, fig. 88) y del piso superior de la habitación 11 del Edificio del Atrio en el Barrio del Foro romano del Molinete en Cartagena (Fernández Díaz et al., 2014: lám. CLVI, fig. 3). En ambos casos se trata de una orla idéntica que hace uso del mismo cromatismo, con una ligera variación en las dimensiones. La orla está formada por dos filetes blancos que encierran una sucesión de semicírculos contrapuestos en alternancia de verde y amarillo, en el caso de Mérida con los semicírculos verdes hacia el interior y con una anchura total de 9,4 $\mathrm{cm}$, y en Cartagena de $10,5 \mathrm{~cm}$, alternando entre el interior y el exterior en función del panel (Fig. 10.3.13.3 y 3.13.4). En el caso de Cartagena, la orla presenta una línea incisa en la parte central, mientras que en la de Mérida carece de cualquier tipo de trazo preparatorio. En lo que respecta a los paralelos, encontramos un ejemplar idéntico procedente de la habitación 2 de la Hang Haus de Éfeso (Zimmermann y Landstätter, 2011: fig. 186), que en este caso se fecha en el segundo cuarto del siglo III d. C., lo que demuestra la continuidad en el uso de este tipo de esquemas a lo largo del tiempo, así como un desarrollo más temprano en las provincias occidentales. El caso de Mérida fue fechado en el siglo II d. C. (Abad Casal, 1982b), si bien pensamos que puede matizarse en torno a la primera mitad del siglo II d. C., mientras que en Cartagena el conjunto fue fechado en época adrianea (Fernández Díaz et al., 2014: 481), lo que plantea que se trate de la obra de un mismo taller o de un taller que conoce la obra de Carthago Nova, dado el hecho de que no se han documentado más paralelos de este tipo en otros contextos y que debió existir una relación desde finales del siglo I d. C. entre ambas ciudades tal y como se documenta en la producción en relieve. Así mismo, el hallazgo de esparto empleado como material constructivo en el reverso de una cornisa de la Casa del Mitreo, perteneciente a un conjunto fechado entre finales del siglo I d. C. e inicios del II. d. C. contribuye a reforzar esta hipótesis dada la inexistencia de este tipo de cultivos en el área extremeña y que, sin embargo, encontramos en gran cantidad en el ager Carthaginensis (Fernández Díaz et al., e.p.).

A todos estos ejemplos debemos sumar cuatro fragmentos, el primero procedente de la excavación del Palau de les Corts de Valencia y los tres restantes del vertedero de Blanes (UUEE 1248, 1535) que no han podido ser restituidos dada la falta de información, pero que formarían parte de las variantes de este grupo.

\section{III.4. TiPo 4: HeXÁGONOS}

Esta categoría cuenta únicamente con un ejemplar, si bien sus características no permitían encuadrarlo en ninguno de los grupos restantes y el esquema constituye un tipo diferenciable como para ser integrado en el último apartado. En este caso se trata de una orla de hexágonos sin alternancia, si bien es posible que existan otros modelos de hexágonos con alternancia que no se han identificado hasta la fecha en Hispania, dado que se han podido identificar otra serie de formas geométricas como los pentágonos, con un ejemplar recogido por Barbet, pero cuya procedencia no se ha especificado (Barbet, 1981: fig. 17, 65a). Las características de este esquema permiten plantear que se trate de una transformación a partir de un esquema de octógonos, con la pérdida de dos lados en los extremos superior e inferior que lo diferencian del citado esquema, algo que podría deberse a un error en las dimensiones que obliga a ajustar la forma o al gusto del comitente.

El ejemplar procede de las intervenciones realizadas durante el siglo XX en la casa de la Alcazaba de Mérida y no cuenta con ninguna información acerca de la zona de hallazgo o su contexto estratigráfico, lo que limita establecer una cronología a criterios técnicoestilísticos. La orla, de 7,3 cm de anchura sobre fondo rojo, presenta cuatro filetes, dos azules exteriores y dos amarillos interiores, estos últimos enmarcando en su interior hexágonos amarillos de 5,2 cm de lado en cuyo interior se encierra un segundo hexágono azul de $4 \mathrm{~cm}$ de lado con una gota central y cuatro palmetas contrapuestas con una gota en la punta (Fig. 11.4.1). En el espacio generado entre los hexágonos encontramos una línea amarilla formando un semicírculo con una gota en su interior. Este esquema, si bien no cuenta con paralelos dentro de la producción pompeyana, refleja igualmente elementos que encontramos en otros esquemas como en algunos de los ejemplos ya señalados de orlas y cenefas con triángulos o los que analizaremos en el grupo de los octógonos, lo que permite observar una clara adopción de elementos propios de los modelos itálicos. No obstante, el empleo de filetes azules junto al amarillo es un 
elemento ampliamente repetido en la producción de orlas flavias que encontramos en Augusta Emerita, lo que permite plantear la hipótesis de una cronología de finales del siglo I d. C. Así mismo, el fondo rojo del panel que decora permite observar la superposición de pigmento rojo y amarillo con el objetivo de falsear el color dando la impresión de un brillo propio del rojo cinabrio, algo que se ha podido documentar en la ciudad en conjuntos de finales del siglo I d. C., en concreto en la casa del $\mathrm{Mitreo}^{29}$.

\section{III.5. TIPO 5: OCTÓGONOS ${ }^{30}$}

En el caso de los esquemas de octógonos encontramos únicamente dos variantes, una sin alternancia (5.1) y otra con alternancia (5.2). La morfología de este tipo de orla sugiere que estemos ante una esquematización o transformación de los modelos basados en círculos, pudiendo citar un único caso de este tipo con alternancia en Pompeya, procedente de la estancia 59 de la casa del Centenario (IX 8, 6) (Barbet, 1981: fig. 17, 60a), que servirá de paralelo para todos nuestros ejemplares. No obstante, debemos tener en cuenta que la amplitud que encontramos en Hispania, con ejemplos tanto de esquemas sin alternancia como con alternancia, indican que estemos ante un tipo de orla que, si bien tiene un origen campano, tuvo más aceptación en Hispania, probablemente debido a una aparición más tardía fruto de una nueva moda que en Pompeya no llegó a desarrollarse en gran medida. Así mismo, la totalidad de ejemplares que hemos documentado se corresponden con orlas caladas que se circunscriben al área emeritense, lo que refuerza esta idea. Por ello, los paralelos para este tipo deberemos basarlos en los modelos encontrados entre los esquemas de círculos, a pesar del hecho de que es posible distinguir claramente una intencionalidad de aportar lados rectos a esta forma en lugar de un perfil circular.

\section{III.5.1. Octógonos sin alternancia}

Dentro de esta variante encontramos seis ejemplares, todos ellos de morfología muy similar tanto en dimensiones como en motivos decorativos, los cuatro primeros procedentes del vertedero de Blanes. El primero, de la UE 1433, está formado por cuatro filetes, los externos azules y los internos amarillos que encierran octógonos de $5 \mathrm{~cm}$ de anchura decorados en $\mathrm{su}$ interior por una gota central rodeada por cuatro gotas ovaladas con un apéndice circular. Estas quedan coronadas por una gota y otras cuatro que se disponen en el espacio entre las esquinas de cada gota ovalada,

29. Se trata de un conjunto en proceso de estudio.

30. Este grupo se corresponde con el tipo 60 del grupo VIII de Barbet (1981). todo ello en amarillo y con una anchura total de 8,5 cm (Fig. 11.5.1.1). Al margen del anteriormente señalado de Pompeya, hay un paralelo similar procedente de la Hang Haus 2 de Éfeso fechado en época trajanea, si bien este carece de la sucesión de semicírculos del filete exterior y la unión entre los octógonos en los laterales queda interrumpida y rellenada mediante una gota (Zimmermann y Landstätter, 2011: 44). En lo que respecta a su cronología, la UE fue datada entre los años 50 y 100 d. C., por lo que, en base a sus características técnico-estilísticas, optamos por darle una cronología de inicios de época flavia, con un carácter que muestra una mezcla entre los modelos itálicos y el gusto local o una nueva moda.

El segundo ejemplar, de la misma unidad, está formado igualmente por cuatro filetes, los dos externos azules y los internos amarillos que encierran octógonos de $8 \mathrm{~cm}$ de lado que encierran dentro un segundo octógono en color azul, de $6 \mathrm{~cm}$ de anchura decorado al interior mediante un círculo amarillo con 8 gotas amarillas y una gota azul central. Junto a esto, el espacio generado entre los octógonos mayores está decorado con una pequeña gota amarilla, todo ello con una anchura total de 12,2 cm (Fig. 11.5.1.2).

El tercer ejemplar, procedente de la UE 860, presenta el mismo cromatismo en sus cuatro filetes, encerrando octógonos de $6,1 \mathrm{~cm}$ de anchura decorados al interior con un círculo amarillo rodeado por cuatro semicírculos del mismo color cuya parte inferior presenta un trazo verde. Los semicírculos quedan coronados por una gota amarilla y cuatro gotas dispuestas en las esquinas. Junto a esto, los filetes azules presentan, hacia el interior, una sucesión de triángulos amarillos a modo de dientes, dando a la orla una anchura total de $11,1 \mathrm{~cm}$ (Fig. 11.5.1.3). En relación a los paralelos de estos dos últimos ejemplos, remitimos a los anteriormente indicados. En lo que respecta a su cronología, dada la datación del contexto y sus características técnico-estilísticas, optamos por una datación en época flavia.

El último de los ejemplares de Blanes de esta variante, cuya unidad se desconoce, presenta similitudes con el primer y tercer modelo desarrollados. Cuenta con cuatro filetes, los dos externos azules, en este caso más claros que los anteriormente detallados, y los dos internos amarillos, de 5,6 cm decorados al interior con una gota central y cuatro gotas ovaladas con apéndice alrededor, rematadas en las esquinas con una gota. El filete azul presenta, hacia el interior, una sucesión de gotas ovaladas con apéndice del mismo tamaño que las que encontramos en los octógonos, con una anchura total de $8,5 \mathrm{~cm}$ (Fig. 11.5.1.4). En este caso, al no contar con un contexto al que asociarlo, únicamente podemos proponer una cronología en base a sus características técnico-estilísticas, que por su proximidad a la morfología de los modelos de época flavia permite situarlo en dicho período.

Junto a estos, contamos con una orla procedente de las UUEE 56 y 94 del vertedero de la calle Cabo Verde. La orla presenta cuatro filetes, los dos externos 


\section{Hexágonos}

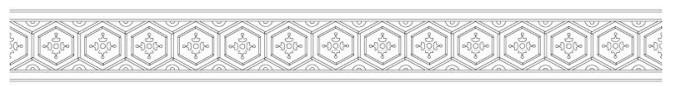

4.1 Casa de la Alcazaba (Mérida)

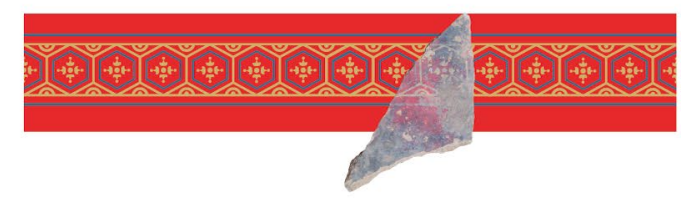

Octógonos sin alternancia

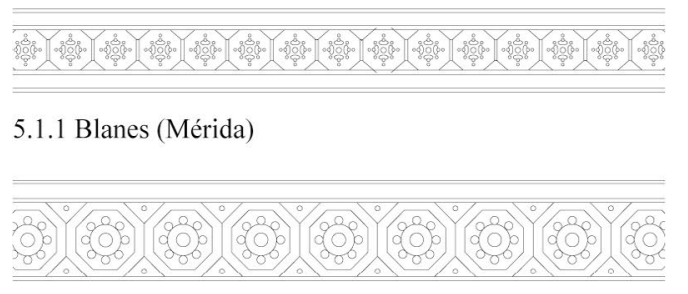

5.1.2 Blanes (Mérida)

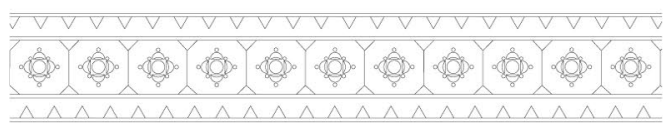

5.1.3 Blanes (Mérida)

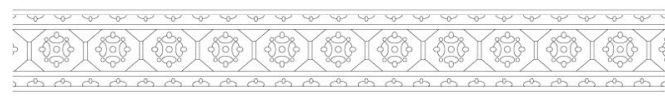

5.1.4 Blanes (Mérida)

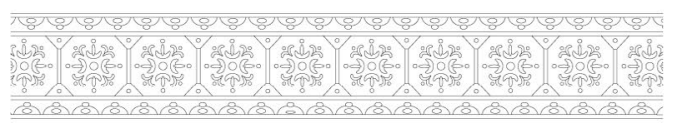

5.1.5 Cabo Verde (Mérida)

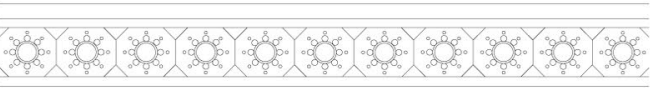

5.1.6 Casa del Mitreo (Mérida)
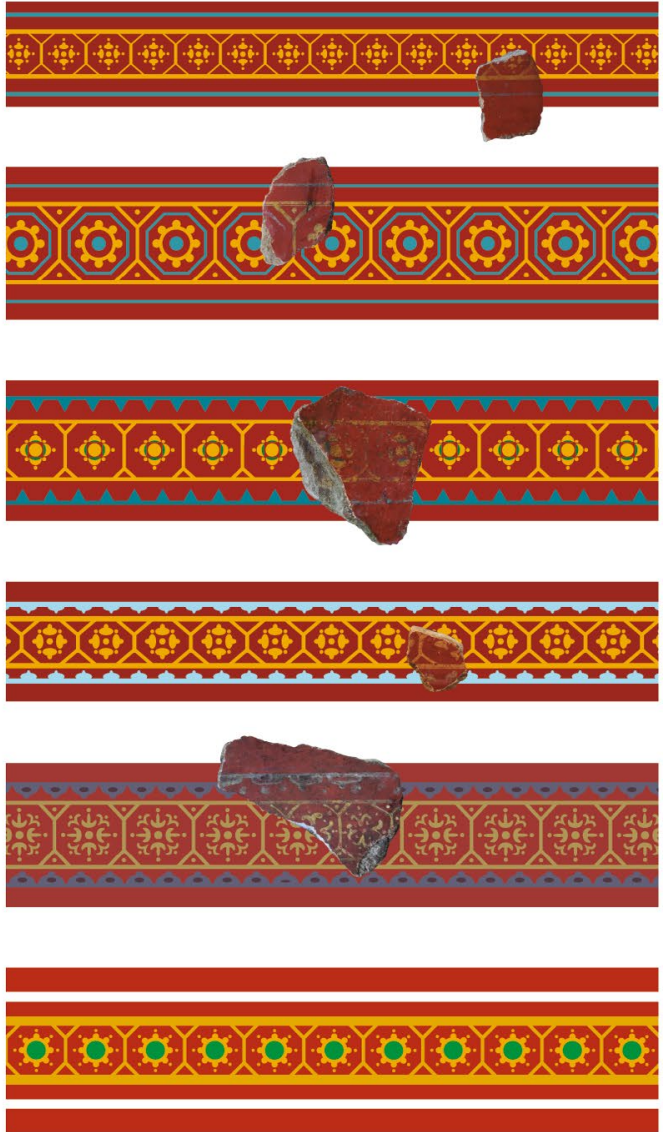

Octógonos con alternancia

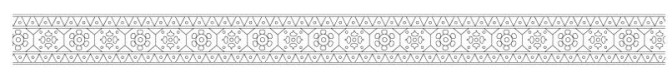

5.2.1 Blanes (Mérida)

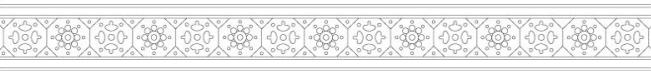

5.2.2 Casa del Mitreo (Mérida)

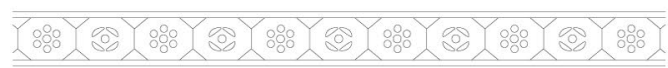

5.2.3 Blanes (Mérida)

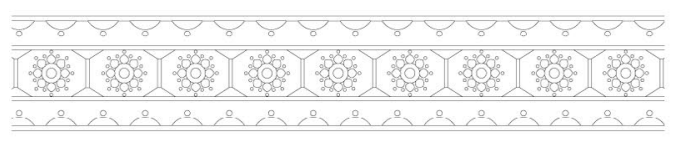

5.2.4 Blanes (Mérida)
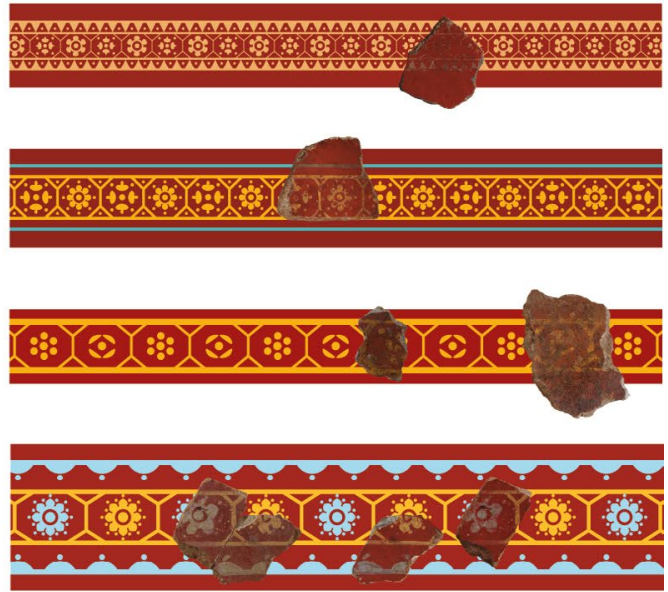


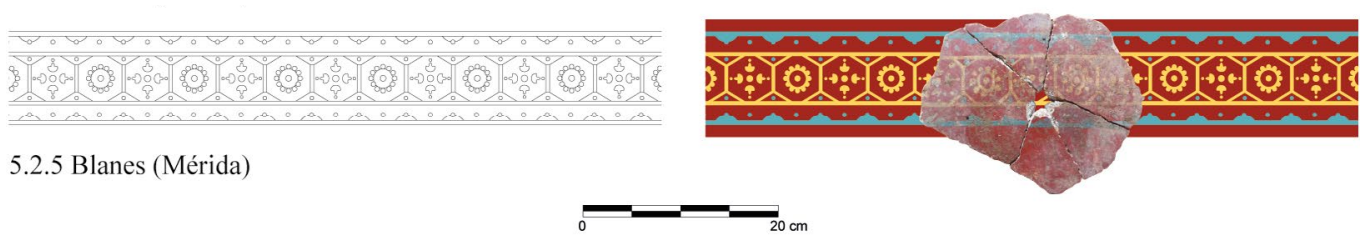

Figura 11: Orlas caladas de los grupos de hexágonos y octógonos. Fuente: elaborada por los autores

azules y los internos amarillos con octógonos de 7,3 cm de anchura que encierran una gota central rodeada de cuatro trifolios esquemáticos coronados por una gota y que en cada esquina están rematados por un bifolio con una gota, todo ello en amarillo. Junto a esto, los espacios generados entre cada octógono quedan rematados por una gota. El filete azul presenta, hacia el interior, una sucesión de semicírculos con apéndice que, en la parte central, están decorados mediante un pequeño óvalo en color más oscuro, todo ello con una anchura total de 10,7 cm (Fig. 11.5.1.5). En lo que respecta a los paralelos, remitimos a los anteriormente indicados. En este caso, dado que forma parte del mismo conjunto que las orlas 1.1.13 y 2.2.18, hemos establecido su cronología para época flavia.

El último ejemplar proviene de la casa del Mitreo, en concreto de la denominada habitación de las pinturas. En cuanto a cromatismo, se separa ligeramente de los anteriores, con cuatro filetes, los externos blancos y los internos amarillos, con octógonos de $6,1 \mathrm{~cm}$ de anchura que encierran un óvalo de fondo verde y borde amarillo rodeado por ocho gotas amarillas cada una coronada por un punto en el mismo color, con una anchura total de $12 \mathrm{~cm}$ (Fig. 11.5.1.6). En lo que respecta a los paralelos, remitimos a los anteriormente indicados. En este caso, el conjunto fue fechado entre finales del siglo I e inicios del siglo II d. C. (Abad Casal, 1982b), si bien pensamos que la presencia de bandas verdes de encuadramiento para los interpaneles, un elemento característico de los conjuntos de época flavia, la diferencia cromática de las orlas, así como la peor calidad de este ejemplar en relación a los anteriores, permite situarlo más concretamente en los últimos años del siglo I d. C.

\section{III.5.2. Octógonos con alternancia}

En lo que respecta a estas orlas, contamos con cinco ejemplos, cuatro de ellos procedentes de Blanes y el quinto de la casa del Mitreo. Si atendemos a sus características técnico-estilísticas, probablemente el más antiguo de todos se corresponda con uno de los procedentes de Blanes, en concreto de la UE 1535. Se trata de una orla calada formada por cuatro filetes amarillos sobre fondo rojo cuya parte central está decorada con octógonos que alternan, por un lado, una roseta con seis pétalos y una gota central y, por otro, una gota central flanqueada por cuatro gotas ovaladas con apéndice y una pequeña gota en los extremos entre cada gota ovalada. Junto a esto, los filetes externos presentan, hacia el interior, una alternancia de triángulos a modo de dentículos y gotas, todo ello en amarillo y con una anchura total de 5,1 cm (Fig. 11.5.2.1). En lo que respecta a los paralelos, remitimos a los indicados en la variante anterior. En este caso la UE se fecha entre los años 80-100 d. C. en base al material cerámico, por lo que creemos acertado, teniendo en cuenta sus características técnico-estilísticas, datarlo entre época neroniana y época flavia.

Algo posterior es probablemente el de la casa del Mitreo, que presenta una cronología similar al resto de casos de Blanes que desarrollaremos a continuación. En este caso procede de las intervenciones realizadas en 1991, si bien no contamos con demasiada información acerca del contexto o su ubicación exacta, con el único dato de una cata en la parte exterior de la casa. Esta orla está compuesta por cuatro filetes, los dos externos azules y los internos amarillos, con octógonos de 4,4 $\mathrm{cm}$ de lado decorados, por un lado, con una gota central flanqueada por cuatro gotas ovaladas con apéndice y cuatro pequeñas gotas en las esquinas $\mathrm{y}$, por otro, con un círculo decorado en su interior por una gota y rodeado por ocho gotas coronadas cada una por gotas más pequeñas, todo ello en amarillo. Junto a esto, en los espacios triangulares que se generan se dispone una gota del mismo color, dando a la orla una anchura total de $6,7 \mathrm{~cm}$ (Fig. 11.5.2.2). En relación a los paralelos, remitimos a los indicados en la variante anterior. En lo que respecta a su cronología, dada la fecha de construcción de la casa, fijada en la segunda mitad del siglo I d. C., probablemente a inicios de la década de los años 70, parece claro que debe datarse en época flavia, más aún si tenemos en cuenta la similitud tanto a nivel técnico como cromático con el resto de ejemplares de esa época de la ciudad.

El segundo de los ejemplares de Blanes procede de la UE 925. Se trata de una orla calada compuesta por dos filetes amarillos sobre fondo rojo que encierran una sucesión de octógonos ligeramente alargados donde alternan, por un lado, una flor realizada con siete gotas $\mathrm{y}$, por otro, un motivo similar a una roseta con una gota central y cuatro trazos flanqueándola, todo en color amarillo y con una anchura total de $5,5 \mathrm{~cm}$ (Fig. 11.5.2.3). En lo que respecta a los paralelos, remitimos a los indicados en la variante anterior. En este caso la UE presenta el mismo tipo de material que encontramos en las UUEE 1470 y 1535 , que en conjunto se fechan entre el 80 d. C. y época adrianea, por lo que es difícil establecer una cronología clara, si bien pensamos que podría ubicarse, al igual que el resto de ejemplares, en torno a época flavia. 
El tercero, procedente de la UE 1535, presenta cuatro filetes, los dos externos azules y los internos amarillos, que encierran octógonos de 7,5 $\mathrm{cm}$ de lado ligeramente achatados, decorados con un círculo amarillo con una gota central y ocho pétalos coronados por gotas de pequeño tamaño tanto en la punta como en el espacio entre pétalo y pétalo. Este motivo se repite en todos los octógonos, alternando entre color amarillo y azul. El filete azul queda decorado hacia el interior por semicírculos coronados con una gota azul, con una anchura total de $11,8 \mathrm{~cm}$ (Fig. 11.5.2.4). En lo que respecta a los paralelos, remitimos a los indicados en la variante anterior. En este caso, la cronología del contexto es la misma que hemos señalado para el primer ejemplar de esta variante, si bien las características y la paleta cromática nos llevan a situarlo directamente a inicios de época flavia.

El último está formado por cuatro filetes, los dos externos azules y los internos amarillos, con octógonos de $5 \mathrm{~cm}$ de lado, que en los casos superior e inferior son ligeramente más pequeños que el resto, adoptando casi una forma hexagonal. En el interior se alterna, por un lado, una gota rodeada por cuatro trifolios esquemáticos coronados por una pequeña gota $y$, por otro, un círculo con una gota central rodeado por doce gotas del mismo tamaño generando un motivo similar a una flor. El espacio generado entre cada octógono está decorado con una gota azul. Junto a esto, el filete azul presenta hacia el interior una alternancia de semicírculos con apéndice redondo y una gota azul del mismo tamaño que es la que decora los espacios entre octógonos, dándole una anchura total de 9,7 cm (Fig. 11.5.2.5). En lo
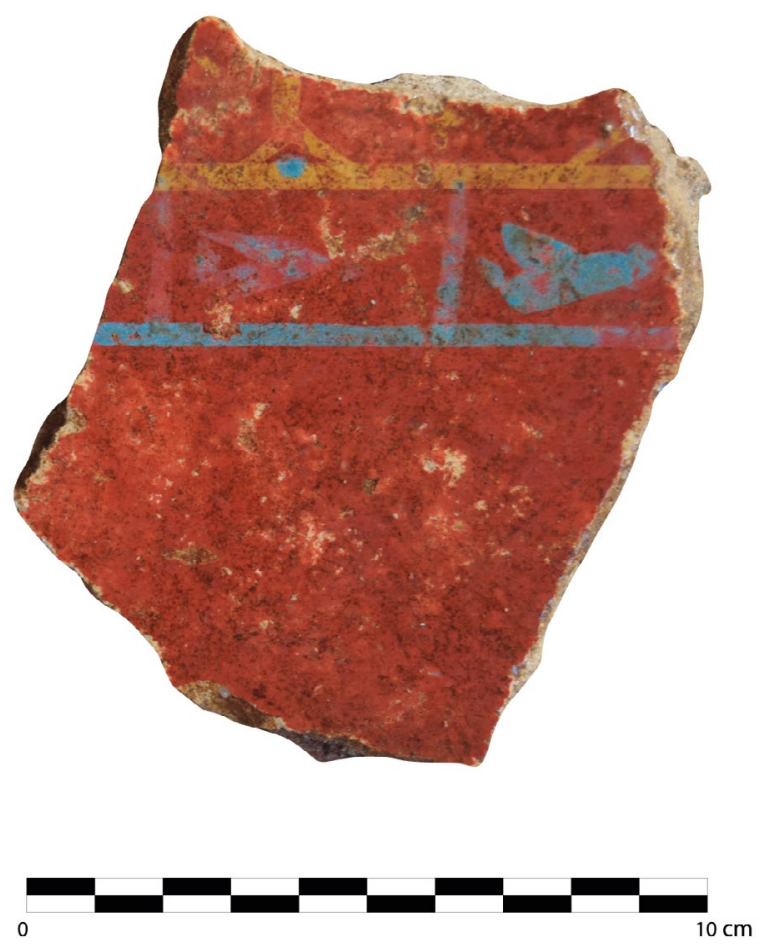

Figura 12 Fragmento de orla con esquema de octógonos que presenta un motivo de pájaros en color azul hacia el exterior. Fuente: elaborada por los autores que respecta a los paralelos, remitimos a los indicados en la variante anterior. Si bien para este último caso no contamos con un contexto al que poder asociarlo, parece claro que por sus características y similitud al resto de ejemplares debe situarse en torno a época flavia.

Además de todos estos debemos incluir un fragmento descontextualizado procedente del vertedero de Blanes que formaría parte de alguna de las variantes de este grupo pero que, dada su parcialidad, no ha sido posible restituir. Este es especialmente interesante dado que conserva el motivo que decora el filete exterior, que muestra, hacia el interior, una figura similar a un ave hacia la derecha, siendo el único caso documentado hasta el momento que presenta decoración figurada como elemento secundario (Fig. 12).

\section{III.6. TIPO 6: Motivos EN «S» O EN VOLUTAS ${ }^{31}$}

En lo que respecta a los motivos en S o en volutas, la variedad es bastante limitada, pudiendo adscribir casi todos los ejemplos a las variantes que definió Barbet para Pompeya, por lo que hemos decidido adoptar la terminología empleada para su clasificación incluyendo dos variantes nuevas, pudiendo encontrar «S tadas dos a dos sin alternancia en posición horizontal (6.1), «S» enfrentadas contrapuestas dos a dos sin alternancia en posición vertical (6.2), «S» enfrentadas contrapuestas dos a dos sin alternancia en posición horizontal (6.3), «S» enfrentadas con motivos superpuestos en alternancia en posición horizontal (6.4) y «S» enfrentadas dos a dos con alternancia en posición oblicua (6.5).

III.6.1. «S» enfrentadas dos a dos sin alternancia en posición horizontal

Dentro de la primera variante encontramos dos ejemplares. El más antiguo, procedente de la tumba de Servilia en la necrópolis de Carmona (Abad Casal, 1982b: 193, fig. 304; Fernández Díaz, 2010; Baceiredo Rodríguez y Fernández Gómez, 2012), por lo que, al igual que el resto, dada la datación de la tumba en la segunda mitad del siglo I d. C. (Rodríguez Temiño et al., 2012: 139), deben fecharse en época neroniana. Se trata de una orla calada azul ${ }^{32}$ sobre fondo amarillo, compuesta por dos filetes que enmarcan una sucesión de «S» enfrentadas dos a dos que presentan, en su parte central, una superposición de tres bifolios y una gota roja situada en la

31. Este grupo y sus variantes se corresponden con los tipos 160-162 del grupo XIII de Barbet (1981).

32. En lo que respecta al color azul, los dibujos de Rodríguez Jaldón señalan que se trataba de un tono verde, sin embargo, las fotografías recogidas por Abad Casal (1982b) y Fernández Díaz (2010) muestran un tono azul claro tanto para este caso como para el resto de los que emplean tonalidades verdes. 
unión entre los dos trazos en su giro hacia el exterior. Junto a esto, el espacio generado en la confluencia entre cada grupo de «S» se encuentra decorado en azul. En la cara exterior de las «S» se desarrolla un tallo que finaliza en otro bifolio, así como una pequeña gota roja en la zona en la que se unen las «S». Estas se encuentran enmarcadas, a su vez por dos líneas de motivos que quedan igualmente en el interior de los filetes, formados por dos trazos negros separados entre sí y un triángulo azul, dando a la orla una anchura total de 9,2 cm (Fig. 13.6.1.1). Así mismo, esta orla deja ver de manera clara la presencia de marcas preparatorias a base de líneas incisas que delimitan el motivo central. En lo que respecta a sus paralelos, los más cercanos los encontramos en el peristilo de la casa delle Nozze d'Argento (V 2, i) (Ehrhardt, 2004) y en el tablinum de la casa di Apolo (VI 2, 22) en Pompeya, así como en un ejemplar recogido por Zahn (Barbet, 1981: fig. $35,162 \mathrm{a}, \mathrm{b}$ y c) si bien en ambos casos muestran una sucesión de «S» enfrentadas y contrapuestas dos a dos, mientras que en este únicamente se disponen en posición enfrentada, aunque en todos lo hacen en posición horizontal. A estos sumamos el de uno de los paneles de la villa romana de Positano (Jacobelli, 2018), que en este caso si presenta una sucesión de dos grupos de «S» enfrentadas dos a dos, pero se ven alternadas con figuras de cisnes y grifos. Más similares en cuanto a su disposición son los ejemplares que hacen uso de motivos cordiformes, pudiendo señalar todos los modelos del tipo 173 de Barbet (Barbet, 1981: fig. 37), sin embargo, queda claro que en nuestro caso se trata de motivos en forma de «S», por lo que vemos una mezcla entre ambos tipos de esquemas.

El segundo modelo procede de la UE 925 de Blanes y presenta unas características muy similares al anterior, en este caso enmarcado por dos filetes blancos. El interior de la orla está compuesto por una sucesión de «S» enfrentadas dos a dos en amarillo que cuentan, en el espacio generado en el interior de las « $\mathrm{S} »$, con una vaina azul con un trazo en amarillo rematado con una gota azul, todo ellos sobre fondo rojo y con una anchura total de 7,1 cm (Fig. 13.6.1.2). Junto a esto, el espacio generado en la superposición de las «S» se encuentra decorado con una gota blanca y una verde superpuesta. En lo que respecta a sus paralelos, remitimos a los citados en el ejemplo anterior. En cuanto a la datación, esta unidad contaba con fragmentos de diversos conjuntos que también se encuentran en las UUEE 1470 y 1535 , con una horquilla cronológica entre el $80 \mathrm{~d}$. C. y época adrianea, por lo que parece factible que, en base a las características y la similitud con el ejemplar anterior, pueda ubicarse en época flavia.

III.6.2. «S» enfrentadas contrapuestas dos a dos sin alternancia en posición vertical

La segunda variante presenta un solo ejemplar, procedente de la domus de Avinyó de Barcelona (Fernández
Díaz y Suárez Escribano, 2018: 27, fig. 4). En este caso se trata igualmente de una orla calada formada por cuatro filetes ocres sobre fondo rojo que enmarcan una sucesión de «S» enfrentadas y contrapuestas dos a dos decoradas mediante pequeños tallos en su parte superior e inferior interna, así como mediante un trazo que une la parte de las «S» que se encuentra contrapuesta. Junto a esto, en la parte enfrentada de las «S» se desarrolla un pequeño tallo que culmina en una gota a la que se superpone una palmeta de pequeñas dimensiones, todo ello en amarillo y con una anchura total de 10,6 cm (Fig. 13.6.2.1). Debemos remitir nuevamente a algunos de los paralelos de los ejemplares anteriores, como el procedente de la estancia 53 de la villa de San Marco en Stabia (Barbet, 1981: fig. 35, 160c; 1999), al que añadimos dos recogidos por Zhan (Barbet, 1981: fig. 35, 160a y b). En lo que respecta su datación, al igual que en la orla 3.4 .3 correspondiente a otro panel de esta misma estancia, se ha fijado a finales del siglo I d. C., debido a la calidad que presentan, si bien algunos de los elementos de los interpaneles y el empleo del color, sigue en uso hasta mediados del siglo II d. C. (Fernández Díaz y Suárez Escribano, 2018: 27).

III.6.3. «S» enfrentadas contrapuestas dos a dos sin alternancia en posición horizontal

La tercera variante ofrece dos ejemplares, ambas orlas del vertedero de Blanes en Mérida. La primera procedente de la UE 1471, carece de filetes de encuadramiento y está compuesta por una sucesión de «S» enfrentadas y contrapuestas dos a dos en amarillo que presentan en uno de sus extremos un tallo que brota hacia el exterior, mientras que el extremo contrario queda coronado en la parte central mediante dos gotas superpuestas, una blanca y otra verde y en los extremos por un elemento con forma de media luna y un apéndice de idéntico color. Junto a esto, el espacio interior entre las «S» queda decorado por una vaina blanca con una gota verde y dos pétalos que sobresalen a cada lado, con una anchura total de 7,4 cm y todo ello sobre fondo rojo (Fig. 13.6.3.1). En este caso, los paralelos más similares proceden del peristilo de la casa delle Nozze d'Argento (V 2, i) (Ehrhardt, 2004), del tablinum de la casa di Apolo (VI 2, 22) y, especialmente, del ejemplar recogido por Zahn (Barbet, 1981: fig. 35, 162a, b y c) pero que, al margen de la paleta cromática, se diferencia en el motivo ornamental que decora la parte interna, así como en la ausencia de filetes. En lo que respecta a su cronología, el contexto fue fechado entre época trajanea y adrianea, lo que permite establecer una datación en torno a época flavia.

El último ejemplar, procedente de la UE 925 y similar a los citados de Blanes, especialmente al 6.1.2. cuenta con cuatro filetes, los dos exteriores azules y los internos amarillos, con una sucesión de «S» de menor 
"S" enfrentadas dos a dos sin alternancia en posición horizontal

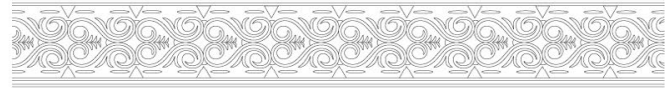

6.1.1 Tumba de Servilia (Carmona)

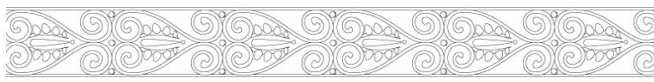

6.1.2 Blanes (Mérida)
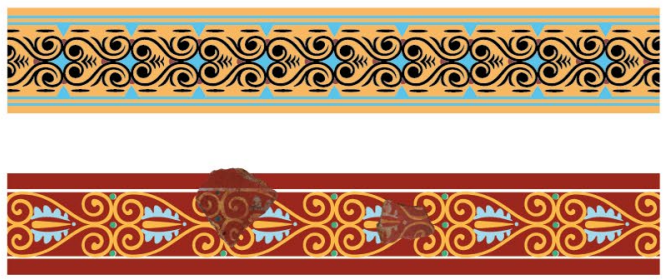

"S" enfrentadas contrapuestas dos a dos sin alternancia en posición vertical

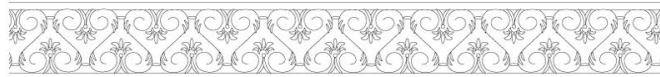

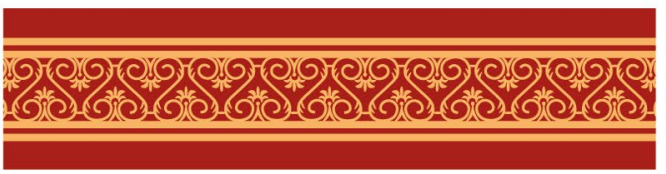

6.2.1 Domus de Avinyó (Barcelona)

"S" enfrentadas contrapuestas dos a dos sin alternancia en posición horizontal
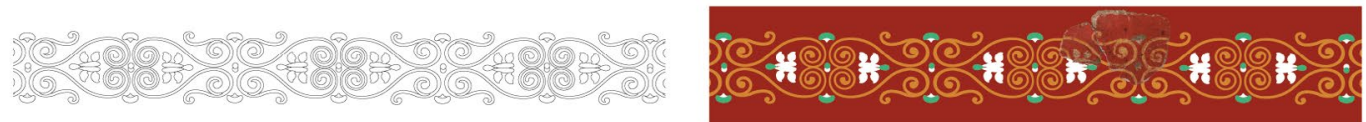

6.3.1 Blanes (Mérida)
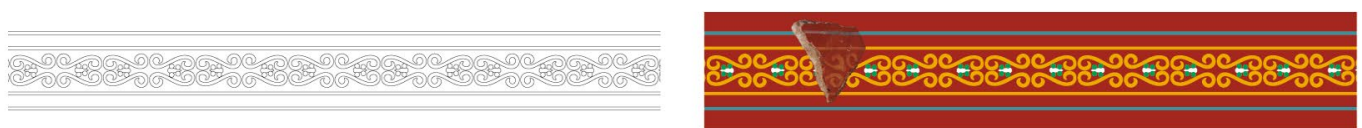

6.3.2 Blanes (Mérida)

"S" enfrentadas con motivos superpuestos en alternancia en posición horizontal
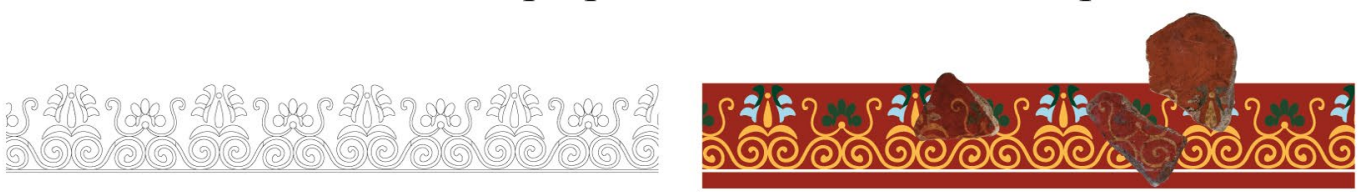

6.4.1 Blanes (Mérida)

"S" enfrentadas dos a dos en alternancia en posición oblicua
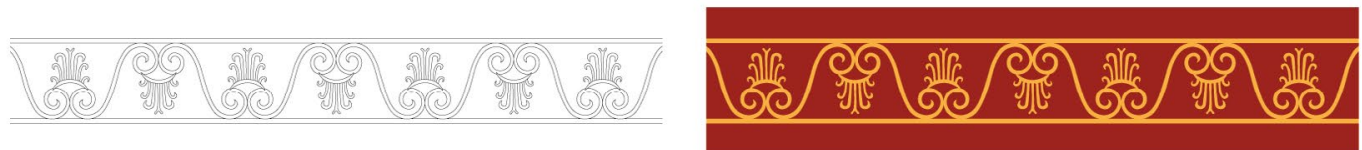

6.5.1 Blanes (Mérida)

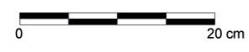

Figura 13: Orlas caladas del grupo de motivos en «S». Fuente: elaborada por los autores

tamaño que los anteriores y sin la decoración de gotas verdes y blancas que hemos visto, si bien conserva en el espacio interior pequeñas vainas blancas con gotas verdes, todo ello sobre fondo rojo y con una anchura total de $8 \mathrm{~cm}$ (Fig. 13.6.3.2). Al igual que el ejemplar anterior, indicamos los mismos paralelos, y en cuanto a la datación, esta unidad contaba con fragmentos de diversos conjuntos que también se encuentran en las UUEE 1470 y 1535, con una horquilla cronológica entre el $80 \mathrm{~d}$. C. y época adrianea, por lo que parece factible que, en base a las características y la similitud con el ejemplar anterior, pueda ubicarse en época flavia. 
III.6.4. «S» enfrentadas con motivos superpuestos en alternancia en posición horizontal

En la cuarta variante encontramos igualmente un solo ejemplar, procedente en este caso de la UE 925 del vertedero de Blanes en Mérida. Se trata de una orla formada por un solo filete blanco al que se superpone una sucesión de «S» amarillas enfrentadas que aparecen coronadas por una alternancia de motivos. Por un lado, encontramos un bifolio con una vaina azul con sus extremos en verde, rematada con tres pétalos a cada lado y un tallo amarillo central coronado por una gota. Por otro lado, dos «S» en posición vertical unidas por su parte inferior junto a una gota, a la que se superpone una palmeta verde con cinco hojas, dando a la orla una anchura total de $9 \mathrm{~cm}$ (Fig. 13.6.4.1). En relación a los paralelos, no contamos con ningún ejemplar similar, dado que la combinación de elementos no es muy usual, así como tampoco lo son las dimensiones de las «S», en este caso más estrechas y achatadas que en el resto, pudiendo citar únicamente un caso procedente de la Ancienne Chambre des Métiers (colline Sainte-Croix) que presenta medias «S» entrelazadas en posición horizontal y que se fecha a finales del siglo I d. C. (Allag et al., 2014: 216). En lo que respecta a su datación, tal y como hemos indicado para otros ejemplos procedentes de esta misma unidad, el margen cronológico entre época flavia y época adrianea, así como sus características técnico-estilísticas, permiten fecharlo probablemente a mediados de época flavia.

III.6.5. «S» enfrentadas dos a dos en alternancia en posición oblicua

La última variante cuenta con un ejemplar procedente de la estancia 11 de la domus de Salvius en Cartagena (Fernández Díaz, 2008), una orla formada por dos filetes amarillos sobre fondo rojo que enmarcan una sucesión de «S» enfrentadas en posición oblicua que, en su unión, quedan coronadas por una palmeta en el mismo color, quedando dispuesta boca arriba y boca abajo en función de la posición de las «S». En total, la orla presenta una anchura de 8,7 cm (Fig. 13.6.4.2). Este tipo encuentra diversos paralelos en el ámbito pompeyano como el recogido por Zhan (Barbet, 1981: fig. 35, 161a), el más similar de todos, o el procedente de la estancia 53 de la villa de San Marco en Stabia, si bien no tan decorado (Barbet, 1981: fig. 35, 160b; 1999), siendo también un esquema bastante repetido en conjunción con otros elementos y con diversas disposiciones en el estuco (Fernández Díaz, 2008: 329). En lo que respecta a su cronología, el conjunto al que pertenece fue datado entre los años 50-60 d. C.

Como podemos observar, existe una tendencia a la vegetalización de este tipo de orlas ya sea mediante la inclusión de pequeños tallos como de palmetas y vainas florales, algo que, si bien encontramos también en algunos ejemplos pompeyanos, se realiza de manera distinta, mostrando una vez más la mano del artesano a la hora de adaptar los modelos a los gustos del comitente y con el fin de ofrecer nuevas opciones que eviten repetir esquemas de manera idéntica.

\section{III.7. TIPO 7: MOTIVOS CORDIFORMES ${ }^{33}$}

La representación de motivos cordiformes cuenta con un número limitado de variantes entre los ejemplos hispanos identificados, señalando únicamente los superpuestos sin alternancia (7.1) y los contrapuestos sin alternancia (7.2), si bien los ejemplares recogidos de Pompeya demuestran la existencia de otra serie de ejemplares como son los motivos cordiformes sin alternancia (no contrapuestos), los superpuestos con alternancia de motivo y/o forma y los contrapuestos con alternancia de motivo y/o forma, lo que indica la posibilidad de existencia de ejemplares de este tipo que, hasta la fecha, no han sido identificados en Hispania.

III.7.1. Motivos cordiformes superpuestos sin alternancia

Dentro de esta variante, el ejemplar más antiguo se corresponde con una cenefa calada procedente de la UE 1542 de Blanes, de fondo violáceo sobre un panel amarillo y con $4,5 \mathrm{~cm}$ de anchura. Presenta cuatro filetes, los dos externos blancos y los internos azules que enmarcan una sucesión de formas acorazonadas que encierran dos bifolios superpuestos, el segundo de menor tamaño, coronados por una gota (Fig. 14.7.1.1). En este caso, al igual que otros de Blanes y de Cabo Verde, no puede descartarse la presencia de trazos pintados en blanco dado el estado de algunos de los fragmentos. Este modelo cuenta con gran cantidad de paralelos como los procedentes del atrio de la casa di Fabius Amandus (I 7, 2-3) (Maiuri, 1938), la estancia 18 de la casa del Menandro (I 10, 4) (Stefani, 2003; Ling, 2005), la estancia «D» de la casa del Poeta Tragico (VI 8, 3) (Rizzo, 1935) o la estancia «D» de la casa di Fabius Rufus (VII 16, 22) de Pompeya (Barbet, 1981: fig. 37, 173a, h, i y j), especialmente al primero y al último. Así mismo, también citamos el procedente de la villa romana de Positano (Jacobelli, 2018), que presenta una palmeta en lugar de bifolios. En lo que respecta a su cronología, el contexto ha sido fechado entre época trajanea y adrianea, si bien sus características se asemejan a modelos puramente pompeyanos y no parece claro que pueda adscribirse a época flavia si tenemos en cuenta las características de los ejemplares de esa época que veremos a continuación, por lo que podría situarse entre finales de época neroniana e inicios del período flavio.

33. Este grupo y sus varianes se corresponden con los tipos 170175 del grupo XIII de Barbet (1981). 
Caso distinto es el del ejemplar procedente de las UUEE 925 y 1515, una orla calada sobre fondo rojo de $8,4 \mathrm{~cm}$ de anchura que presenta cuatro filetes, los dos externos azules y los internos amarillos (Fig. 14.7.1.2). Estos enmarcan una sucesión de motivos cordiformes superpuestos con una palmeta en su interior siguiendo el modelo anterior, pero más próximo por su morfología a una serie de ejemplares recogidos por Zahn (Barbet, 1981: fig. 37,173 b, c y e) y a un caso procedente de la estancia 18 de la casa del Menandro (I 10,4) (Barbet, 1981: fig. 37, 173g; Stefani, 2003; Ling, 2005). Junto a esto, la orla presenta sobre los filetes azules una sucesión de semicírculos con una gota en el interior y sobre el mismo que alternan con una pirueta. La presencia de elementos decorativos en una segunda banda que cierra la orla por sus extremos no es un motivo extraño en los ejemplos pompeyanos, si bien en la mayoría de los casos estos se limitan a líneas de gotas u ondas. En este sentido, su presencia en la orla emeritense plantea que se trate de un elemento propio del gusto local, lo que, junto al empleo de los tonos azules que se documentan en otros ejemplos de finales del siglo I e inicios del siglo II d. C. en Mérida, podría fecharlo en época flavia. En este caso, los datos del contexto no permiten acotar la cronología, dado que cuenta con materiales de una horquilla que comprende desde la primera mitad del siglo I hasta inicios del siglo II d. C. y el material cerámico permite fecharla entre el $80 \mathrm{~d}$. C. y época adrianea.

III.7.2. Motivos cordiformes contrapuestos sin alternancia

El único ejemplar de esta variante procede de las UUEE 925, 1515 y 1535 de Blanes. Es una orla calada de $5,4 \mathrm{~cm}$ de anchura sobre fondo rojo, con cuatro filetes, los dos externos azules y los internos amarillos que encierran una sucesión de formas acorazonadas con una palmeta amarilla en su interior coronada por una gota (Fig. 14.7.2.1). Se trata de un tipo de orla que cuenta con pocos paralelos, pudiendo citar dos ejemplos del segundo peristilo de la casa dei Capitelli Colorati (VII 4, 31/51) de Pompeya y del conjunto «A» de la casa del Rilievo di Telefo (Ins. Orientalis I.2) de Herculano (Barbet, 1981: fig. 36, 170a y b) y uno procedente de la excavación de la piazza Fontana en Milán (Ceresa Mori y Pagani, 2010: fig. 3), siendo el primero y el tercero los más parecidos. En este caso, la cronología del contexto, fechado entre los años 80-100 d. C., permite suficiente margen para asociar esta orla a una producción itálica o local. El empleo de un filete azul de cierre exterior rompe con la policromía que encontramos en el de Pompeya, que presenta el mismo cromatismo salvo el azul, lo que plantea que, en este caso, nos encontremos frente a una producción bien de un taller itálico que introduce modificaciones en base a los gustos o modas locales, bien ante un taller local que haga uso de esquemas itálicos incluyendo concesiones al gusto emeritense. En cualquier caso, parece claro que se encuentra en el tránsito entre la producción itálica y el mundo local, lo que indica su pertenencia a un momento avanzado del reinado de Nerón o inicios de época flavia, algo factible si tenemos en cuenta que las cronologías de las UUEE se mueven entre los años 80 y 100 d. C.

Además de todos los tipos descritos incluimos un fragmento de la UE 1471 que, por su parcialidad, no ha podido ser restituido pero que probablemente formaría parte de alguna de las dos primeras variantes y podría fecharse en torno a época flavia.

\section{III.8. TIPo 8: Motivos SOBRE LÍNEAS ${ }^{34}$}

En el caso de los motivos sobre líneas, la variedad es bastante amplia como para establecer variantes en función de los motivos, si bien observamos una diferencia entre los motivos con alternancia (8.1) y los motivos sin alternancia (8.2), en todos los casos dispuestos sobre uno o dos filetes y en ocasiones tanto por encima como por debajo. Así mismo, algunos ejemplos que hacen uso de motivos que tienen cabida en otras categorías, han sido colocados en estas dado que creemos que es más coherente ponerlos en relación con motivos similares y no basarlo únicamente en la ausencia de un filete superior de cierre.

\section{III.8.1. Motivos sobre líneas sin alternancia}

Dentro de esta variante, el primero de ellos procede de un conjunto excavado en los años 80 de la denominada Huerta de Otero en Mérida, en la que la ausencia de una metodología de excavación moderna impide conocer información acerca del contexto y su cronología. No obstante, se conserva gran parte de la zona media del conjunto, lo que ha permitido fecharlo. En este caso encontramos un doble filete amarillo, el superior con una sucesión de dos bifolios superpuestos coronados por una gota del mismo color, con una anchura total de 4,2 cm (Fig. 14.8.1.1). Este tipo encuentra diversos paralelos como los del zócalo del atrio y de la zona media de las estancias 8 y 17 de la casa del Menandro (I 10,4) (Stefani, 2003; Ling, 2005), del zócalo de la estancia 16 de la casa dei Dioscuri (VI 9,6) en este caso con un solo filete o el procedente del cubiculum junto al tablinum de la casa del Principe di Napoli (VI 15, 8) (Strocka, 1984). Esta orla forma parte de un conjunto de paneles e interpaneles, decorados estos últimos con una serie de estructuras arquitectónicas de gran calidad que sugieren su pertenencia al IV estilo, probablemente entre época claudia y neroniana, si bien no puede asegurarse dada la ausencia de un contexto claro.

34. Este grupo y sus variantes se corresponden con los tipos 26-34 de los grupos IV y V de Barbet (1981). 


\section{Motivos cordiformes superpuestos sin alternancia}

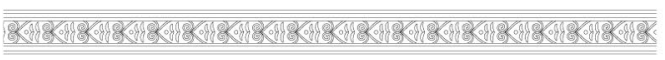

7.1.1 Blanes (Mérida)

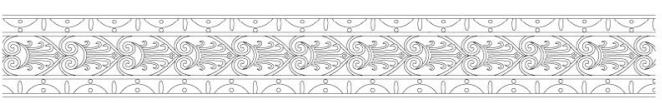

7.1.2 Blanes (Mérida)

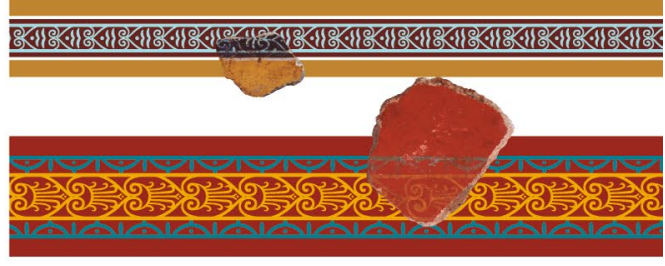

Motivos cordiformes contrapuestos sin alternancia
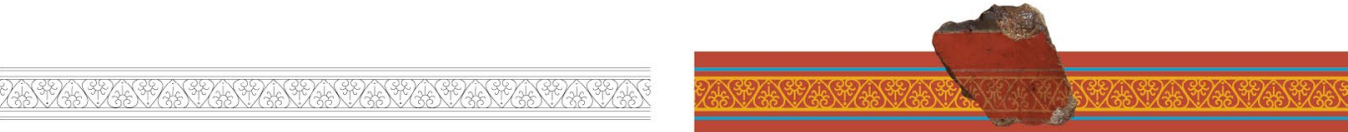

7.2.1 Blanes (Mérida)

Motivos sobre líneas sin alternancia

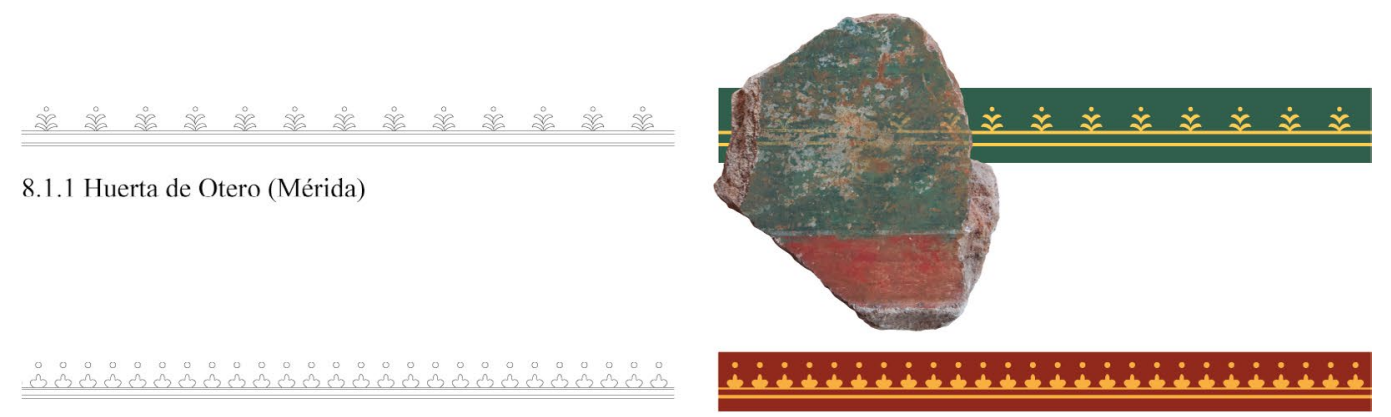

8.1.2 Casa del Pretorio (Arcobriga)

Motivos sobre líneas con alternancia

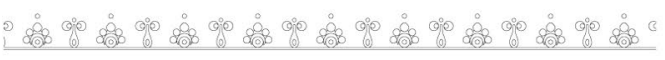

8.2.1 Cabo Verde (Mérida)

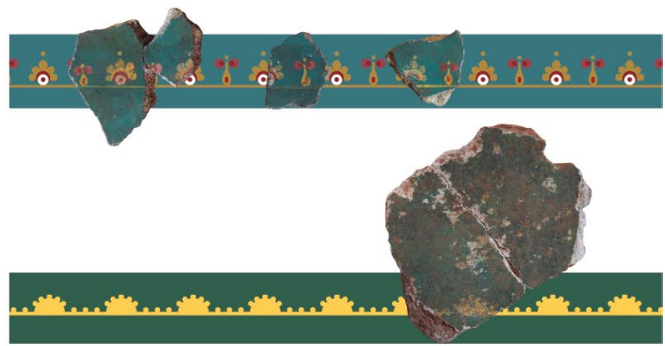

8.2.2 Huerta de Otero (Mérida)

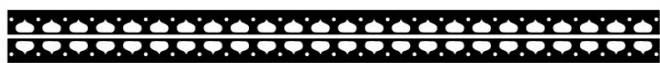

8.2.3 Termas de Bilbilis

8.2.4 Blanes (Mérida)

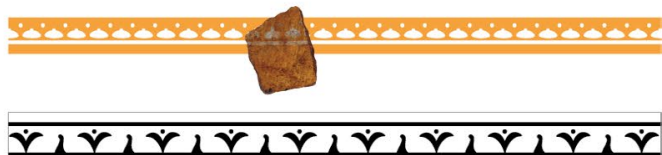

8.2.5 Arcóbriga

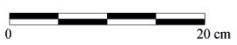

Figura 14: Cenefas y orlas caladas de los grupos de motivos cordiformes y motivos sobre líneas. Fuente: elaborada por los autores

En segundo y último lugar, encontramos un ejemplar en la casa del Pretorio de Arcobriga (Guiral Pelegrín y Mostalac Carrillo, 1992), una orla amarilla sobre un panel rojo formada por un doble filete que cuenta, sobre el superior, con una sucesión de pequeños trifolios $u$ hojas trilobuladas, a medio camino 
entre el ejemplar de la Huerta de Otero y los de Blanes y Bilbilis que analizaremos a continuación, por lo que parece claro que se trata de una esquematización de dichos motivos, con unas dimensiones totales de 3,7 $\mathrm{cm}$ de anchura (Fig. 14.8.1.2). Cuenta con algunos paralelos como los de la casa degli Amorini Dorati (VI 16, 7) (Seiler, 1992), la casa dei Vettii (V 15, 1) (Archer, 1982) y la casa di Meleagro (VI 9, 2) (Barbet, 1981: fig. 6, 33e y f) en Pompeya, así como en Marsala (Barresi, 2014: lám. CXLVI, fig. 6), de un conjunto del IV estilo, aunque también aparece combinado con otros motivos en gran cantidad de ejemplos. Por su parte, en las provincias encontramos un mismo patrón, con ejemplos en los que aparecen por separado como un único motivo y combinado con otros elementos. De este modo, como elemento único lo encontramos en el Quartier Clérisseau y la avenue Jean-Jaurès en Nimes (Boislève, 2014: 659-660, lám. CLXXXVII, fig. 2), fechados en la segunda mitad del siglo I d. C., en una domus de Clermont-Ferrand (Puy-de-Dôme) de época flavia (Groetembril y Ollivier, 2013: 358-359), en el espacio 6a de la domus de La Fontainotte en Grand (Lorraine, Vosges) (Froeliger y Mondy, 2017: 75, fig. 6), entre el último cuarto del siglo I e inicios del siglo II d. C., en la rue Saint-Patrice de Bayeux (Amadei y Bujard, 2007) de inicios del siglo II d. C., en Les Hauts de Saint-Just (Helly, 1980), de inicios del siglo II d. C., en la ínsula 27 de Xanten (Jansen et al., 2001: fig. 26), de la primera mitad del siglo II d. C., en la villa de Vichten (Krier et al., 2002), de época adrianea, y en la curia del foro de Vieux (Boislève y Jardel, 2014: 632-633, lám. CLXXXIII, fig. 2), de mediados del siglo II d. C. A estos sumamos también los de las termas de la legión en Vindonissa y de la legión en la ínsula 5 de Augst, un ejemplar de la villa de Oberweningen y los de la villa de Contigny en Lausanne, fechadas entre el 60-90 d. C. (Fuchs y Dubois, 1997: 180). Por su parte, lo encontramos junto a otros motivos en ejemplares como los de la estancia «D» y el peristilo de Clos de la Lombarde (Sabrié et al., 1987), en todos los casos hacia el exterior de la misma. Tal y como vemos en gran cantidad de los ejemplares aquí recogidos, en Hispania encontramos una predilección por este motivo decorativo como complemento de las orlas que se fechan en época flavia, siendo Mérida el caso que más registra, lo que parece indicar una respuesta fruto del gusto provincial o una moda propia de dicho período. En cualquier caso, este ejemplar se fecha en las primeras décadas de la segunda mitad del siglo I d. C. (Guiral Pelegrín y Mostalac Carrillo, 1992).

\section{III.8.2. Motivos sobre líneas con alternancia}

En lo que respecta a esta variante, el primero de los ejemplos procede del vertedero de la calle Cabo Verde de Mérida, en concreto de la UE 65. A diferencia de los ejemplares de otro tipo que hemos descrito de esta unidad, en este caso se encuentra asociado a un conjunto del III estilo, lo que lo convertiría en un modelo temprano de este elemento decorativo para la pintura provincial. La orla, de 3,6 cm de anchura, se desarrolla sobre un filete amarillo y fondo verde azulado, con una alternancia de un capullo amarillo con una gota roja en su interior que en la parte superior queda flanqueado por dos pétalos rosas con una gota roja y una gota amarilla en la parte superior. El segundo elemento con el que alterna está compuesto por un círculo blanco dentro del cual se desarrolla una gota roja y sobre el que se superpone una media luna roja y un tocado en amarillo con cuatro gotas del mismo color, dos a cada lado y un pétalo amarillo en la parte central, coronado por una gota (Fig. 14.8.2.1). Este tipo lo encontramos, con motivos más esquematizados, en la extensión de la Préfecture rue Saint-Jacques de Toulouse, fechado a mediados del siglo I d. C. (Sabrié y Sabrié, 2003) y en una domus de Clermont-Ferrand (Puy-de-Dôme), de época flavia (Groetembril y Ollivier, 2013: 358-359). En lo que respecta a la cronología, la UE se fecha entre época claudia y flavia, formando parte de un conjunto del III estilo final que, probablemente, pueda fecharse en el segundo cuarto del siglo I d. C.

El segundo ejemplar de esta variante procede del mismo conjunto que el primer modelo de este grupo hallado en la Huerta de Otero, en este caso de otro de los paneles de la zona media. Se trata de una orla sobre filete amarillo dispuesto en un panel verde, compuesta por una sucesión de semicírculos coronados por 5 gotas amarillas que alternan con una sucesión de tres gotas amarillas y una anchura total de $2,3 \mathrm{~cm}$ (Fig. 14.8.2.2). En relación a los paralelos, no contamos con ningún ejemplar similar en el repertorio pompeyano, si bien podemos citar algunos casos que presentan al menos un elemento similar a los semicírculos, como los de la casa di Arrius Crescens (III 4, 2) o de la estancia 39 de la casa del Centenario (IX 8, 6) en Pompeya (Barbet, 1981: fig. 6, 33b y c), así como, ya en las provincias, un ejemplar hallado en la avenida Jean-Jaurès de Nimes (Boislève, 2014: 659-660, lám. CLXXXVII, fig. 2), fechado en la segunda mitad del siglo I d. C., uno de la villa de Contigny en Lausanne, fechado entre el 60-90 d. C. (Fuchs y Dubois, 1997: 180), uno de la domus de Vésone en Périgueux (Barbet et al., 2012: 80, fig. 34) y de la extensión de la Préfecture rue Saint-Jacques de Toulouse fechado a mediados del siglo I d. C. (Sabrié y Sabrié, 2003), si bien presentan motivos distintos. Esta orla forma parte de un conjunto de paneles e interpaneles, decorados estos últimos con una serie de estructuras arquitectónicas de gran calidad que sugieren su pertenencia clara al IV estilo, probablemente entre época claudia y neroniana, aunque no es posible corroborarlo dada la falta de un contexto claro.

Similar cronología presenta el tercero de los ejemplos de esta variante, procedente del zócalo del conjunto A hallado en la estancia $\mathrm{M}$ de las termas de Bilbilis (Guiral Pelegrín y Martín-Bueno, 1996: fig. 
33). En este caso se trata de un filete blanco que presenta una sucesión de gotas con un pequeño apéndice que alternan con pequeños puntos a la altura del mismo y que se disponen a ambos lados del filete, con una anchura total de en torno a $4 \mathrm{~cm}$ (Fig. 14.8.2.3). En lo que respecta a los paralelos, remitimos a los referidos para la orla de Arcobriga analizada en la variante anterior. Al igual que en el resto de orlas de este conjunto, fue fechado en los primeros años de la segunda mitad del siglo I d. C. (Guiral Pelegrín y Martín-Bueno, 1996: 111).

Similar al anterior encontramos un cuarto ejemplo dentro de esta variante procedente de las UUEE 925, 1470 y 1471 del vertedero de Blanes en Mérida, formado por un filete con gotas con apéndice en la parte superior que alternan con pequeños puntos, todo ellos en blanco sobre fondo amarillo, con una anchura de 2,6 cm (Fig. 14.8.2.4). En este caso, desconocemos si se trata únicamente de un filete con dicho motivo o este esquema podría repetirse por debajo, dado que únicamente contamos con dos fragmentos en mal estado, uno con una guirnalda debajo de la orla, que podría sugerir que esta fuera el motivo central enmarcado por dos filetes. En cualquier caso, la morfología es idéntica al ejemplar de Bilbilis y por tanto también los paralelos, si bien la cronología debe ser algo posterior, probablemente en torno a finales del reinado de Nerón o inicios de época flavia en base a la cronología de los contextos, que se fecha entre el año $80 \mathrm{~d}$. C. y época adrianea. De este modo, al contrario de lo que se pensaba (Guiral Pelegrín y Martín-Bueno, 1996: 111), este tipo de decoración rebasa los límites del siglo I d. C.

Por último, contamos con un ejemplar de similar cronología a los anteriores procedente de Arcobriga, del que, en este caso, no contamos con información acerca de su cromatismo. La orla esta compuesta por dos filetes que encierran una sucesión de bifolios coronados por una gota que alternan con otra gota alargada ligeramente curva, todo ello con una anchura total de $3,6 \mathrm{~cm}$ (Fig. 14.8.2.5). En lo que respecta a los paralelos, citamos los anteriormente referidos, con la única salvedad del motivo de la gota alargada, del cual no encontramos ningun caso similar. En cuanto a su cronología, se ha señalado su pertenencia al IV estilo (Guiral Pelegrín y Mostalac Carrillo, 1992).

\section{III.9. TIPO 9: MEANDROS $^{35}$}

En lo que respecta a este tipo de orlas caladas, únicamente contamos con dos ejemplos que permiten establecer una variante sin alternancia. No obstante, es posible la existencia de otra variante con alternancia que no se haya documentado en base a los modelos

35. Este grupo se corresponde con el tipo 10 del grupo II de Barbet (1981). existentes que podemos identificar en la decoración arquitectónica, tanto en frisos como en cornisas, así como en la producción musivaria, si bien en este último caso no encontramos alternancia en las bandas, citando únicamente ejemplos arquitectónicos como los propileos de la Acrópolis de Atenas, donde se conservan diversos modelos de meandros con alternancia (Jones, 1856: lám. XV).

Los ejemplares conservados proceden en ambos casos del vertedero de Blanes en Mérida, lo que impide poder asociarlos, al menos en el segundo de los casos, a un conjunto que permita definir claramente su encuadramiento cronológico y estilístico más allá de sus características técnicas. El primero, procedente de la UE 1262 y parcialmente conservado, permite restituir una cenefa calada de $5,3 \mathrm{~cm}$ de anchura de fondo violáceo sobre un panel amarillo correspondiente a un conjunto del IV estilo del que se conserva también el zócalo y otras dos cenefas y una orla que han sido previamente analizadas. La cenefa presenta cuatro filetes blancos, de los que los dos internos enmarcan el meandro blanco (Fig. 15.9.1). Las características de este conjunto plantean de manera clara su pertenencia al IV estilo pompeyano, dada la gran calidad en la ejecución, así como la presencia de una cenefa en el zócalo que, en Hispania, no se emplea en conjuntos de época flavia. No obstante, los datos del contexto no permiten precisar la cronología, dado que se ha fechado a finales del siglo III d. C., planteando la existencia de remociones posteriores en el propio vertedero o que este conjunto siguiera en uso durante un largo período de tiempo tras su ejecución, algo que no es de extrañar si tenemos en cuenta la pervivencia de conjuntos del I estilo pompeyano en los ambientes pompeyanos hasta la erupción del Vesubio.

El segundo ejemplar, procedente de las UUEE 785 y 1471, constituye una orla calada sobre fondo rojo de $8,6 \mathrm{~cm}$ de anchura y enmarcada por dos filetes azules en cuyo interior se desarrolla un meandro amarillo (Fig. 15.9.2). En lo que respecta a su datación, el empleo combinado de azul y amarillo que encontramos en la gran mayoría de orlas caladas flavias de Mérida, plantea que se trate de un ejemplar de finales del siglo I d. C. A ello sumamos la cronología del contexto, que en base al material cerámico analizado permite fecharlo entre época trajanea y adrianea. Si tenemos en cuenta la necesidad de un margen cronológico entre la ejecución del conjunto y su amortización, parece factible fecharlo en época flavia. En cuanto a los paralelos, ambos encuentran similitudes en las orlas caladas del tablinum de la casa delle Nozze d'Argento (V 2, i) (Ehrhardt, 2004) y del techo de la casa di C. Julius Polybius (IX 13, 1-3) (Barbet, 1981: fig. 2, 10a y 10b; Ciarallo y De Carolis, 2001), si bien no presenta el mismo desarrollo, con un acentuado espacio entre cada cruce de filetes. A estas sumamos, fuera del ámbito pompeyano, un ejemplar del Museo Archeologico Nazionale di Aquilea fechado entre época neroniana y flavia (Salvadori et al., 2016: 244-245, fig. 1). 
A pesar del escaso número de ejemplares conservados de este tipo, parece clara la existencia de una evolución dentro del mismo que tiende al engrosamiento, con una diferencia de $2 \mathrm{~cm}$ en un período de entre 25-50 años, mientras que la calidad es bastante similar entre ambos casos.

\section{III.10. TIPO 10: ÓvaLos ${ }^{36}$}

En el caso de las orlas caladas a base de óvalos, únicamente diferenciamos una variante con alternancia de motivos al igual que hiciera Barbet para el caso de Pompeya (1981: Fig. 35, 156), si bien no descartamos la existencia de otros esquemas hasta el momento no identificados en territorio hispano.

Los dos primeros ejemplares proceden de Valencia, en concreto del edificio del Palau de les Corts, si bien presentan notables diferencias entre sí. La primera es una orla calada con cuatro filetes amarillos que encierran una alternancia de cuatro volutas contrapuestas dos a dos de doble tallo en su parte central, uno vuelto hacia fuera y el otro rematado hacia dentro por una gota amarilla. Las volutas convergen en un rombo de fondo verde y borde blanco flanqueado arriba y abajo por dos óvalos verdes y a izquierda y derecha por dos gotas blancas y dos gotas ovaladas amarillas. Todo ello alterna con cuatro trifolios de fondo verde y borde blanco que encierran en su interior un óvalo de idéntico color rodeado por una serie de gotas blancas a modo de perlas, con una anchura total de 10,3 cm (Fig. 15.10.1). Este modelo cuenta con varios paralelos, dos de ellos de la villa de San Marco, en concreto de las estancias 25 y 53, este último el más similar de todos, y de la villa di Varano (Barbet, 1981: fig. 35 156a, b y c; 1999. Junto a estos, contamos también con otros paralelos en el ámbito provincial, como los de Commungy (Drack, 1950: fig. 156).

El segundo de los ejemplares difiere tanto de este modelo como del resto de modelos de este tipo. Se trata de una orla calada formada por dos filetes amarillos que encierran un óvalo verde y de borde blanco rodeado por gotas blancas a modo de perlas. El óvalo se encuentra rodeado en cada uno de sus extremos por dos bifolios superpuestos con una gota amarilla, mientras que de las esquinas brotan hojas puntiagudas. Junto a esto, en el espacio generado entre cada uno se desarrolla un círculo de fondo verde y borde blanco rodeado de gotas blancas a modo de perlas que se superponen al filete de encuadramiento de la orla, con una anchura total de $16,9 \mathrm{~cm}$ (Fig. 15.10.2). No contamos con paralelos claros, dado que, si bien el repertorio ornamental es el mismo que encontramos dentro de este y de otros esquemas, la forma en que se conjugan difiere de los que encontramos en el área

36. Este grupo se corresponde con el tipo 156 del tipo XII de Barbet (1981). campana. En lo que respecta a su cronología, ambas orlas se asocian a la fase flavia del edificio (Calvo Gálvez et al., 1998).

A estos ejemplares sumamos uno procedente de la villa romana del Parque de las Naciones en la Albufereta, Alicante (Rosser Limiñana, 1992: 150151), una orla calada compuesta por cuatro filetes amarillos que enmarcan en su interior una sucesión de volutas contrapuestas dos a dos que parten de un ovalo central con dos pequeños tallos a cada lado. Las volutas cuentan con tres tallos, de los cuales, el primero, brota de su extremo superior y los dos segundos giran hacia el interior. La parte superior queda coronada por un trazo, todo ello en amarillo, y las volutas rematadas en su parte superior por dos pequeñas gotas blancas a los lados de los tallos superiores. Esta sucesión de volutas alterna con un óvalo azul rodeado de gotas blancas de pequeño tamaño a modo de perlas y cuatro trazos que simulan pequeñas hojas alargadas del mismo color que se disponen en los laterales hacia las volutas, con una anchura total de 10,1 cm (Fig. 15.10.3). En relación a los paralelos, encontramos la misma dificultad que en el caso anterior, dado que la disposición de los motivos decorativos no guarda similitud con otros ejemplos del área pompeyana ni de las provincias. En lo que respecta a su cronología, su estudio no arrojó una fecha más allá de su encuadramiento dentro del período altoimperial debido a la falta de información del contexto, en ese momento sin finalizar el estudio, por lo que no es posible establecer una cronología clara. No obstante, la calidad en la ejecución, así como el resto de fragmentos del conjunto permiten plantear una cronología de la primera mitad del siglo II d. C.

Por último, contamos con dos ejemplares de cenefas de la villa romana de Los Torrejones en Yecla, en concreto de la habitación 1 del Sector II (Fernández Díaz, 1999b: 65, figs. 7 y 8), con una forma muy similar a la primera de las orlas de Valencia. En este caso se trata de dos modelos idénticos que únicamente difieren en el color empleado, el primero amarillo sobre fondo rojo y el segundo rojo sobre fondo amarillo. Ambos presentan dos filetes que encierran una alternancia de volutas dobles enfrentadas con doble tallo, uno de ellos hacia el exterior y el otro vuelto al interior. Las volutas convergen en un rombo de borde amarillo en el primer caso y rojo en el segundo, cuyo interior es verde y queda rematado en sus esquinas por gotas que, en la parte superior e inferior, quedan coronadas por un bifolio con una gota. De las esquinas brota, a su vez, una línea con un óvalo que finaliza en un elemento vegetal esquematizado. De esta forma, en el espacio generado en la alternancia de las volutas se desarrolla un óvalo verde con borde blanco en el primer caso y rojo en el segundo, rodeado de gotas a modo de perlas del mismo color en función del caso, coronado en los extremos superior e inferior por un bifolio con una gota, todo ello con una anchura total de $12,5 \mathrm{~cm}$ (Fig. 15.10.4 y 10.5). Dadas sus características, remitimos a los paralelos citados para el primero de los 


\section{Meandros}
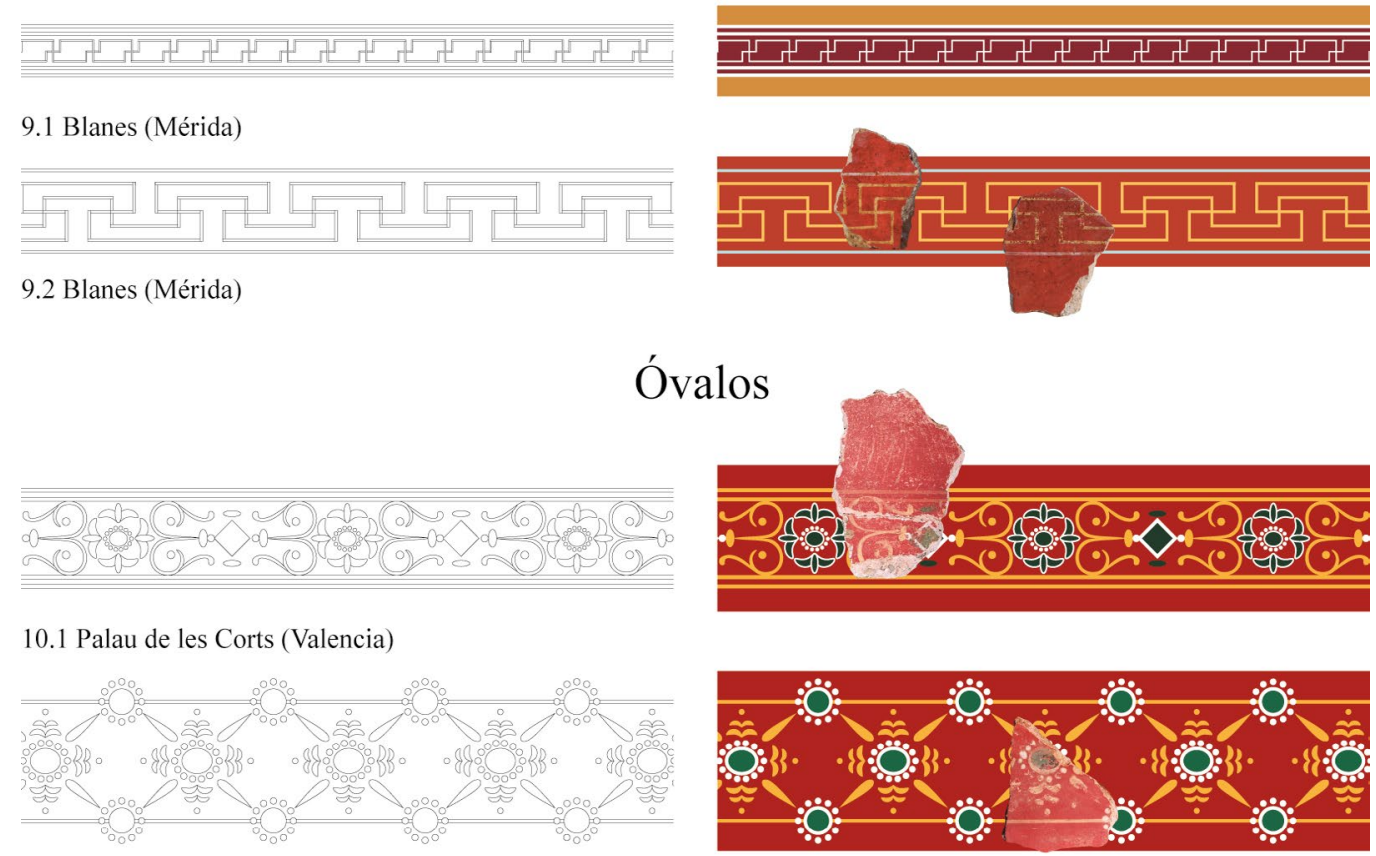

10.2 Palau de les Corts (Valencia)
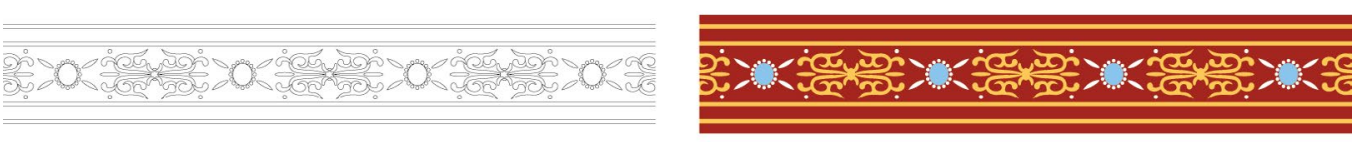

10.3 Parque de las Naciones (Albufereta, Alicante)
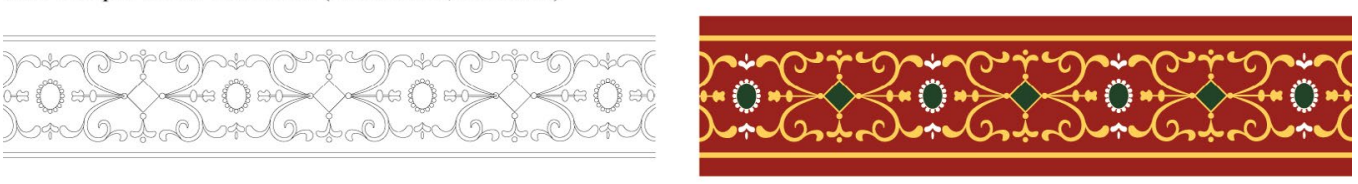

10.4 Villa de Los Torrejones (Yecla)
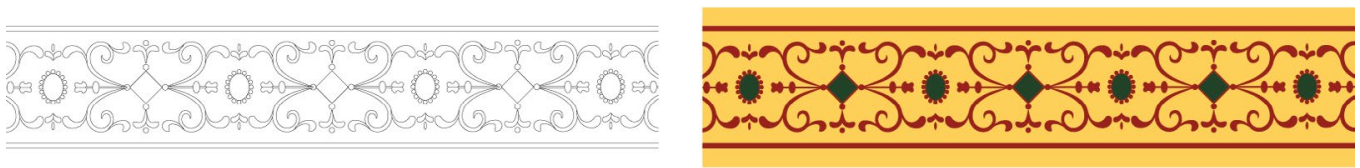

10.5 Villa de Los Torrejones (Yecla)

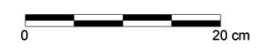

Figura 15: Cenefas y orlas caladas de los grupos de meandros y óvalos. Fuente: elaborada por los autores

ejemplares procedentes de Valencia, si bien podemos decir que el esquema de Los Torrejones guarda aún mayor similitud con los ejemplos campanos. En lo que respecta a la cronología, fueron fechados en torno a época adrianea en base a la estrecha relación del sistema en red de la zona superior con otro procedente del Barrio del Foro romano del Molinete en Cartagena, probablemente obra de un mismo taller (Fernández Díaz, 1999b; 2009: 68, Fernández Díaz et al., 2014: 479-481).

A todos estos ejemplos sumamos dos fragmentos de la calle Parejos de Mérida y la excavación del Palau de les Corts de Valencia que, dado su estado de conservación, no es posible restituir, pero que podrían formar parte de este grupo, con una cronología entre época flavia y la primera mitad del siglo II d. C.

\section{III.11. TIPO 11: FeStONES Y ONDAS ${ }^{37}$}

En lo que respecta estas orlas, no encontramos gran variedad de formas dentro de la producción hispana, si bien para el caso pompeyano los ejemplos son más numerosos y amplios en su morfología, señalando únicamente la presencia de la variante sin alternancia tanto para festones (11.1) como para ondas (11.2) con o sin decoración superpuesta, con un único ejemplar que combina ambos elementos (11.3). No obstante, al igual que en los casos anteriores, no se puede descartar la presencia de otras variantes, que en el caso de

37. Este grupo y sus variantes se corresponden con los tipos 1-5 del grupo I y 20-25 del grupo III de Barbet (1981). 
Pompeya suman un total de 5 , que no hayan podido ser identificadas hasta la fecha en Hispania.

\section{III.11.1. Festones sin alternancia}

Dentro de esta variante encontramos, en primer lugar, un ejemplar procedente de la casa del Pretorio de Arcobriga (Guiral Pelegrín y Mostalac Carrillo, 1992), una orla calada sobre fondo rojo formado por un filete blanco al que se superpone una sucesión de gotas con apéndice coronadas por una gota. Por encima de estas, una sucesión de festones con una gota central y una gota sobre la unión entre cada uno, a los que se superpone, en el espacio que queda, un bifolio coronado por una gota, todo ello blanco y con una anchura total de 6,5 cm (Fig. 16.11.1.1). Entre los paralelos de este tipo citamos el del techo «G» de la casa di C. Julius Polybius (IX 13, 1-3) (Barbet, 1981: fig. 3, 20d; Ciarallo y De Carolis, 2001) en Pompeya, así como el del criptopórtico de Alife (Varriale, 2014: lám. CLXVII, fig. 1C), de la segunda mitad del siglo I d. C. En el caso de las provincias citamos el del techo de la estancia $\langle\mathrm{H} »$ de la maison à Portiques de Clos de la Lombarde en Narbona, fechado en las primeras décadas de la segunda mitad del siglo I d. C. (Sabrié y Demore, 1991), el del tepidarium de las termas de Windisch en Suiza (Drack, 1950: 120 y 217, figs. 123 y 133; Fuchs, 1989), del último cuarto del siglo I d. C. y el de Die (Drôme), fechado en la segunda mitad del siglo I d. C. (Boislève y Ronco, 2016: 51-53, fig. 7). En lo que respecta a su cronología, se ha fechado en la segunda mitad del siglo I d. C. (Íñiguez Berrozpe, 2014: 839-840).

El segundo ejemplar procede de la casa del Mitreo de Mérida. Se trata de una cenefa calada de fondo violáceo sobre un campo amarillo, que cuenta con dos filetes azules que enmarcan una sucesión de gotas con apéndice o gotas trilobuladas, probablemente esquematización de unas hojas bifolias o trifolias, a las que se superpone una banda de festones en amarillo coronada por una sucesión de gotas del mismo color, con una anchura total de 4,9 cm (Fig. 16.11.1.2). En relación a los paralelos, remitimos a los anteriormente señalados dada su similitud, a los que sumamos los de las termas de la legión en Vindonissa, fechados entre el 60-90 d. C. y que son los más similares (Fuchs y Dubois, 1997: 180). En lo que respecta a su cronología, la cenefa fue hallada en el transcurso de las excavaciones desarrolladas en el año 2019 junto a una gran cantidad de fragmentos de diversos conjuntos que probablemente fueron amortizados en un área junto al peristilo de la casa. Si bien el material cerámico aún se encuentra en fase de estudio, la práctica totalidad de los fragmentos pictóricos remiten a una producción de finales del siglo I o inicios del II d. C. No obstante, existe una gran ausencia de fragmentos que permitan asociarlo a un conjunto concreto, siendo la mayoría de fondo rojo. A pesar de no haberse documentado ningún conjunto fechable en época neroniana dentro de la casa, la aparición de esta cenefa dentro de un contexto de vertido de escombros impide descartar su atribución a dicha cronología.

Por último, encontramos tres ejemplos muy similares en su ejecución procedentes el primero de la casa del Mitreo y los últimos del vertedero de Blanes, que dadas sus características podrían estar mostrando el trabajo de un mismo taller, aunque la gran fragmentariedad de los conjuntos impide corroborarlo con el resto de elementos. El primero procede de uno de los espacios contiguos a las fauces de la casa, al igual que sucede con el ejemplar que hemos descrito dentro de las orlas de triángulos, pero en este caso la calidad y cromatismo plantea que se trate de dos conjuntos distintos, por lo que es probable que no formaran parte del mismo espacio. En cualquier caso, el informe de excavación no aporta mayor información acerca de la zona exacta en la que aparecieron los fragmentos para poder vincularlo a un espacio concreto. La orla presenta un filete blanco seguido de un segundo filete negro más ancho sobre el que se apoya una gota amarilla, quedando por encima una palmeta con 5 pétalos trilobulados que se suceden conectados mediante un trazo curvo amarillo a modo de festón, todo ello sobre un fondo rojo y con una anchura de $9 \mathrm{~cm}$ (Fig. 16.11.1.3). Este tipo de orla cuenta con paralelos como el del corredor 8 de la villa di Varano y el del peristilo 1 de la villa de San Marco en Stabia (Barbet, 1999), el de la estancia 12 de la casa del Salone Nero de Herculano (VI 13) (Esposito, 2014), un ejemplar de Pompeya depositado en el Museo Archeologico Nazionale di Napoli recogido por Zahn (Barbet, 1981: fig. 4, 25d) y otro también de Pompeya conservado en el Museo del Louvre (Barbet, 1981: fig. 3, 20e). A diferencia de nuestros ejemplares, todos ellos presentan alternancia de motivos, a excepción del último que presenta filetes en ambos extremos. Al margen de estos también encontramos otros como el de la excavación de Vigna Barberini en el Palatino que presenta el espacio intermedio decorado con un color distinto (Boldrighini, 2003: fig. 160). Para este ejemplar el inicio de la actividad de la casa a partir de la segunda mitad del siglo I d. C., probablemente en torno a los años 70, así como la calidad en la ejecución, plantea una cronología de época flavia.

En el caso de los dos ejemplos procedentes de Blanes, el primero de ellos, de las UUEE 925 y 1471, presenta un triple filete, el interior verde y los exteriores blancos, sobre el que se dispone un motivo de palmetas de cinco hojas amarillas trilobuladas con una gota en la parte superior y otra en la parte inferior, conectadas entre sí mediante trazos en el mismo color a modo de festones. Todo ello se dispone sobre un fondo rojo, siguiendo el modelo que encontramos en la casa del Mitreo y con una anchura total de 7,6 $\mathrm{cm}$ (Fig. 16.11.1.4). En el caso del segundo ejemplar, procedente de la UE 1535, presenta el mismo esquema, con la excepción de que el motivo de palmeta presenta 
Festones sin alternancia
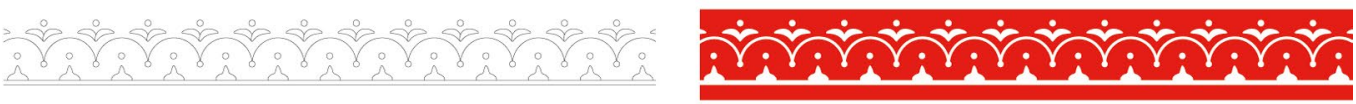

11.1.1 Casa del Pretorio (Arcobriga)
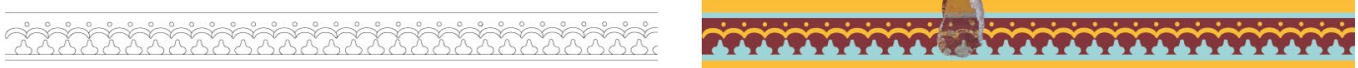

11.1.2 Casa del Mitreo (Mérida)
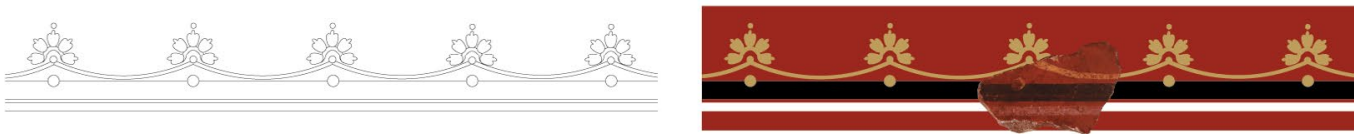

11.1.3 Casa del Mitreo (Mérida)
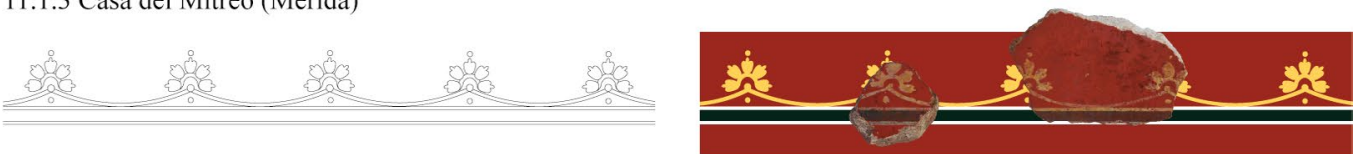

11.1.4 Blanes (Mérida)
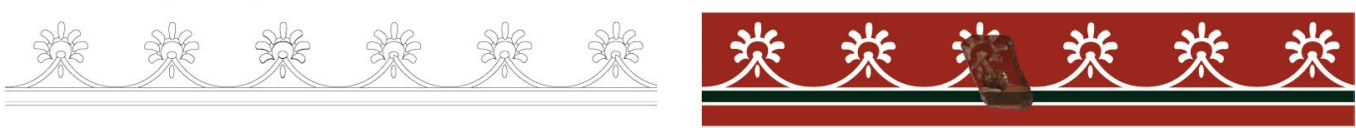

11.1.5 Blanes (Mérida)

Ondas sin alternancia

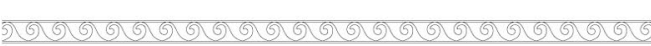

11.2.1 Cabo Verde (Mérida)

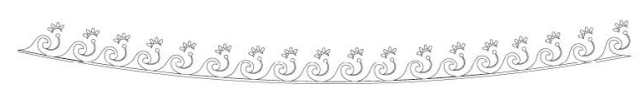

11.2.2 Cabo Verde (Mérida)

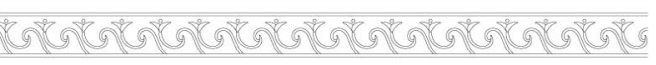

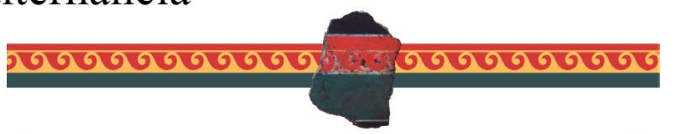

11.2.3 Blanes (Mérida)

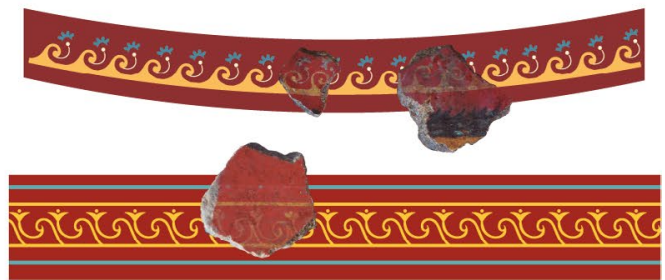

Festones y ondas combinadas sin alternancia
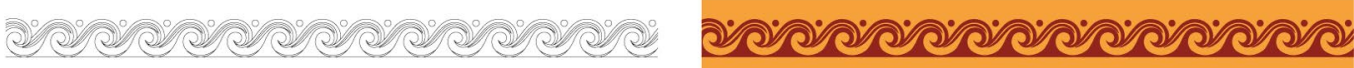

11.3.1 Castro Chao Samartin (Asturias)
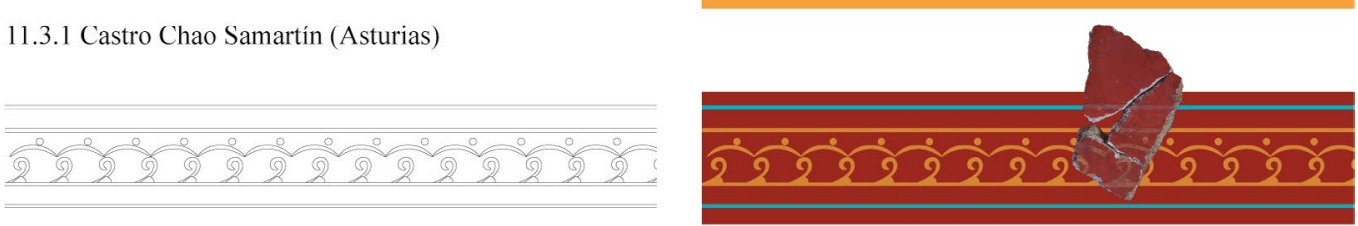

11.3.2 Blanes (Mérida)

\section{Motivos longiformes}
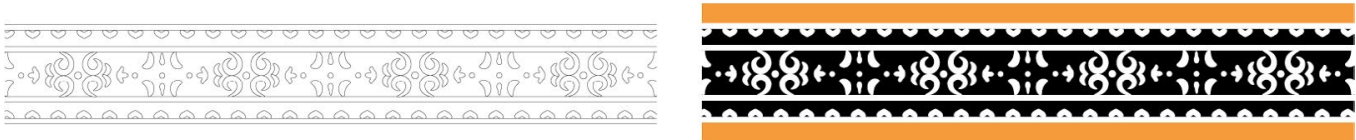

12.1 Calle Añón (Zaragoza)

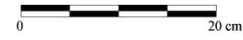

Figura 16: Cenefas y orlas caladas de los grupos de festones, ondas y motivos longiformes. Fuente: elaborada por los autores 
siete pétalos lisos y la gota que se desarrolla por debajo es alargada, al tiempo que el trazo que une los distintos motivos presenta un mayor peralte en su unión que en el anterior modelo, todo ello en color blanco y con una anchura total de $8,7 \mathrm{~cm}$ (Fig. 16.11.1.5). Para ambos casos remitimos a los paralelos anteriormente mencionados, con una cronología en torno a época flavia en base a los contextos de ambas unidades, que se fechan entre el 80 d. C. y época adrianea. Así mismo, es probable que ambos fragmentos pudieran formar parte de un mismo conjunto dada la gran similitud tanto a nivel cromático como técnico y al hecho de que ambas unidades comparten material de varios conjuntos.

\section{III.11.2. Ondas sin alternancia}

Dentro de esta variante encontramos tres ejemplares, siendo el más antiguo el que procede de la UE 64 del vertedero de la calle Cabo Verde de Mérida, y que puede formar parte del mismo conjunto que el ejemplar 3.8.1 que hemos descrito dentro del tipo de círculos, semicírculos y tres cuartos de círculo. En este caso, se trata de una orla de ondas amarillas cuya parte superior queda delimitada por un filete del mismo color, quedando todo sobre un fondo rojo cinabrio con una anchura total de 2,3 cm que limita con un fondo verde (Fig. 16.11.2.1). Este tipo encuentra ejemplares ya desde el III estilo pompeyano, donde se emplea para enmarcar frisos y escenas, especialmente en los techos, como sucede en el conjunto de la estancia superior de la casa de Augusto en el Palatino (Iacopi, 2007). Para el IV estilo encontramos algunos ejemplos como el del techo de la sala 14 de la villa de San Marco en Stabia (Barbet, 1999), el ala «i» de la casa dei Vettii (V 15, 1) (Archer, 1982) o el techo «H» de la casa di C. Julius Polybius (IX 13, 1-3) (Ciarallo y De Carolis, 2001) en Pompeya, si bien en el caso del primero y el tercero, estos presentan una serie de trazos curvos en la parte superior, así como otra serie de elementos decorativos, mientras que en el segundo cuenta con un pequeño apéndice curvo y un motivo decorativo en la parte superior. A estos añadimos el de Boscoreale (Strocka, 1991), el de Marsala (Barresi, 2014: lám. CXLVI, fig. 6), también del IV estilo, y los de la villa de Nerón en Subiaco y de la casa Belleza en el Aventino (Boldrighini, 2003: fig. 108), que presentan dos filas superpuestas de ondas contrapuestas. Junto a estos, ya en las provincias, contamos con el de la rue de Catalogne en Narbona (Aude), fechado entre el III estilo final y el IV (Sabrié, 2013: 43, fig. 12d) y el de la casa A de la Médiathèque de Narbona (Hathaway et al., 2014: 275), de la segunda mitad del siglo I d. C. Como hemos señalado anteriormente, existen dudas respecto a su cronología, dado que, si bien no ha podido encajarse con ningún otro fragmento, parece claro que podría estar relacionado con el conjunto al que pertenece el ejemplar 3.8.1 en base a sus características técnicas y que, por tanto, podría situarse en la transición entre el III y IV estilo, probablemente a inicios del reinado de
Claudio. En cualquier caso, la cronología del contexto permite corroborar esta hipótesis (Pérez Maestro, 2004; 2007).

El segundo ejemplo procede igualmente del vertedero de la calle Cabo Verde, en este caso de la UE 65. Se trata de una orla de ondas amarillas que se dispone sobre un filete curvo del mismo color y que en su cresta presenta un tallo blanco y curvo hacia el lado opuesto coronado por una pequeña palmeta azul, todo ello sobre campo rojo y con una anchura total de $4,2 \mathrm{~cm}$ (Fig. 16.11.2.2). Cuenta con diversos paralelos como el del ala «i» de la casa dei Vettii (VI 15, 1) (Archer, 1982), la estancia 14 de la casa della Fontana Piccola (VI 8, 23) (Fröhlich, 1996), el techo «H» de la casa di C. Julius Polybius (IX 13, 1-3) (Ciarallo y De Carolis, 2001), de la estancia «B» de la casa di Loreius Tiburtinus (II 2, 2) (Maiuri, 1947) y la casa del Menandro (I 10, 4) (Stefani, 2003; Ling, 2005) en Pompeya, así como de la villa di Varano en Stabia, si bien nuestro ejemplar carece de filete de cierre por su extremo superior y no aparece combinado con festones ni semicírculos. Así mismo, encontramos también dos paralelos en la exedra «M» y del triclinium de la casa del Principe di Napoli (VI 15, 8) (Strocka, 1984) y uno ubicado en los cortinajes de la zona superior del conjunto de la villa romana de Positano (Jacobelli, 2018), a los que sumamos, en las provincias, el de las termas de la legión en Vindonissa, fechado entre el 60-90 d. C. (Fuchs y Dubois, 1997: 180). En lo que respecta a su cronología, la presencia en los fragmentos de una guirnalda vegetal verde y negra a la que se asocia la orla, si bien parcialmente conservada, plantea la hipótesis de un panel con decoración de paños, los denominados panneli a drappo, que encontramos en ejemplos como en el triclinium de la casa IX 1, 7 y en el vestíbulo de la casa dell'Orso (VII 2, 45) (Ehrhardt, 1988) de Pompeya, la estancia 9 de la casa del Tramezzo di Legno (III 1, 1) (Esposito, 2014) en Herculano o, en las provincias, en la domus del Monte Sacro en Cartagena (Fernández Díaz y Castillo Alcántara, e.p.) y que se fechan en torno a época neroniana.

El tercer ejemplo, cuya unidad se desconoce, procede del vertedero de Blanes. Se trata de una orla calada formada por cuatro filetes, dos externos azules y dos internos amarillos, que encierran una sucesión de ondas que se entrelazan con un tallo del mismo color que finaliza en un bifolio con una gota amarilla, todo ello sobre un campo rojo y con una anchura total de $8,1 \mathrm{~cm}$ (Fig. 16.11.2.3). Este ejemplar presenta características similares al anterior y, por tanto, remitimos a los paralelos anteriores para su comparación, señalando que, en este caso, la onda presenta menor anchura y el tallo entrelazado adquiere un perfil curvo para finalizar de manera recta, con una sensación general de esquematismo en comparación con el resto de ejemplares. El fragmento al que corresponde esta orla forma parte de una caja que no contaba con ninguna unidad y por tanto resulta imposible asociarlo a un contexto que permita definir una cronología. No obstante, las características 
técnico-estilísticas plantean una cronología al menos de época flavia en base a sus dimensiones, calidad y empleo del color azul combinado con el rojo y amarillo que encontramos en gran cantidad de orlas de Mérida.

\section{III.11.3. Festones y ondas combinadas sin alternancia}

Por último, debemos incluir dos ejemplares que forman parte de esta variante. El primero procede del castro Chao Samartín en Asturias y se trata de una orla calada compuesta por ondas que en su parte superior estan entrelazadas mediante una sucesión de festones con una gota entre cada uno, todo ello en color rojo y con una anchura de 3,9 cm (Fig. 16.11.3.1). En lo que respecta a los paralelos, no encontramos dentro del repertorio pompeyano ningun caso similar, dado que todos cuentan con festones no entrelazados con las ondas. En cuanto a su cronología, al igual que el resto de orlas del yacimiento, se ha fechado en torno a mediados del siglo I d.C. (Gago Muñiz, 2007: 445).

El segundo, procedente de la UE 1360 de Blanes, es una orla calada que presenta cuatro filetes, los externos azules y los internos amarillos, que encierran una sucesión de ondas con una pequeña cuña en su parte inferior derecha. Por encima se superpone una sucesión de festones coronados por una línea de gotas del mismo color, con una anchura total de $10,5 \mathrm{~cm}$ (Fig. 16.11.3.2). Este tipo cuenta con diversos paralelos entre los que citamos los anteriormente referidos para el fragmento de la calle Cabo Verde, más similar por la presencia de los festones a los de la exedra «M» de la casa del Principe di Napoli (VI $15,8)$ (Strocka, 1984), el ala «i» de la casa dei Vettii (VI 15, 1) (Archer, 1982), las salas 18 y 19 de la casa del Menandro (I 10, 4) (Stefani, 2003; Ling, 2005) y el techo «H» de la casa di C. Julius Polybius (IX 13, 1-3) (Ciarallo y De Carolis, 2001), siendo los más cercanos los ejemplares custodiados en el Museo del Louvre (Barbet, 1981: fig. 3, 20f, g y especialmente h). A estos, añadimos el de la domus de Vésone en Périgueaux (Barbet et al., 2012: 75, fig. 24). En lo que respecta a su cronología, como hemos señalado para otros ejemplares de esta unidad, encontramos un amplio margen en base al material del contexto, sin embargo, las dimensiones, calidad y cromatismo nos llevan a plantear una cronología flavia.

\section{III.12. TIPO 12: MotIVOS LONGIFORMES ${ }^{38}$}

De la variante de motivos longiformes únicamente contamos con un ejemplar en Hispania que podría encuadrarse en una variante con alternancia. No obstante, en el caso de Pompeya se han constatado modelos

38. Este grupo se corresponde con el tipo 180 del grupo XIV de Barbet (1981). tanto con alternancia como sin alternancia, si bien esta distinción no fue especificada por Barbet en su clasificación. En cualquier caso, cabe indicar la posibilidad de la existencia de otras variantes no documentadas hasta la fecha para ámbito hispano.

El ejemplar en cuestión procede de la zona media del triclinum de la domus de la calle Añón de Zaragoza (Guiral Pelegrín et al., 2019: 230, fig. 11), de la que hemos visto el resto de ejemplares anteriormente (2.2.9 y 3.5.1). En este caso, se trata de una cenefa calada de fondo negro sobre panel amarillo, formada por cuatro filetes blancos que enmarcan, en la parte central, una sucesión de dos volutas dobles contrapuestas con una gota entre ellas y rematadas hacia el exterior por un bifolio y un trifolio superpuesto con una gota. Este elemento alterna con una sucesión de tres trazos, los externos curvos hacia fuera y el interno recto, que se repiten arriba y abajo y presentan entre ellos una gota. Junto a esto, los filetes externos presentan, hacia el interior, una sucesión de formas cordiformes blancas, todo ello con una anchura total de 10,2 cm (Fig. 16.12.1). Al contrario que en el resto de casos del mismo conjunto, no se ha documentado aquí ningún trazo preparatorio, si bien ello puede deberse al estado de conservación, dado que no parece lógica su ausencia en un panel y no en otro. El paralelo más cercano, aunque no idéntico, a nuestro ejemplar es el de la exedra 23 de la casa del Menandro (I 10,4), fechado por Ling en el IV estilo maduro posterior al terremoto del año $62 \mathrm{~d}$. C. (Barbet, 1981: fig. 38, 180d; Stefani, 2003; Ling, 2005). No obstante, en nuestro caso, las medidas son superiores a todos los ejemplares del grupo de motivos longiformes, al tiempo que presenta una combinación de motivos que no se detecta en el mismo, lo que plantea que se trate de un modelo evolucionado del repertorio campano que se da en las provincias (Guiral Pelegrín et al., 2019: 236). En cualquier caso, al igual que el resto del conjunto, se ha fechado en época flavia.

\section{III.13. TIPO 13: Motivos VEGETALES}

La variedad de elementos vegetales existentes, así como la forma de los mismos, hace imposible establecer variantes dentro de esta categoría, si bien es cierto que todos los ejemplares siguen un mismo patrón, ya sea mediante la representación de una filete o guirnalda central con flores, pétalos o joyas, o mediante la combinación de estas directamente sobre el fondo del panel, sin contar con un filete sobre el que se apoyen o broten ${ }^{39}$.

39. En lo que respecta a los paralelos de este grupo, la gran variedad que encontramos dentro de las representaciones vegetales, así como su mayor escasez frente a otro tipo de esquemas, impide aportar ejemplos en la mayoría de los casos. 
Los más antiguos son los procedentes de la UE 1262 y de las UUEE 1200 y 1535 del vertedero de Blanes, dos cenefas caladas de fondo violáceo sobre panel amarillo enmarcadas por cuatro filetes blancos. En ambos casos, encontramos al interior un filete marrón-verdoso sobre el que se desarrolla una sucesión de trifolios de color similar, en uno de los casos con un trazo verde, del que sale un pequeño tallo que lo une al filete central, que actúa a modo de tronco. Junto a esto, del trifolio parten dos pequeños tallos que rematan en un círculo del mismo color con un trazo verde, ambos con una anchura total de $5,3 \mathrm{~cm}$ (Fig. 17.13.1 y 13.2). Si bien los dos casos presentan un diseño similar, encontramos pequeñas variaciones en las dimensiones de los elementos, así como en el tono de los colores y la separación entre los filetes. No obstante, parece claro que pudieran formar parte de paneles distintos de un mismo conjunto al que pertenecen los ejemplares 3.4.1 y 9.1, por lo que han sido fechados igualmente en época neroniana, hipótesis que creemos clara si tenemos en cuenta la cronología que ofrece la UE 1535, fechada entre el 80 y 100 d. C. y la imposibilidad de asociarlo a la cronología de la UE 1262, de finales del siglo III d. C.

El tercer ejemplar, procedente de las UUEE 925 y 1433 de Blanes, presenta el mismo cromatismo y forma en su encuadramiento, si bien el diseño vegetal cambia ligeramente. En este caso, encontramos que el filete central es blanco y sobre él se desarrolla una sucesión de bifolios verde azulado de los que parten dos tallos, uno a cada lado del filete, que culminan en dos círculos del mismo color con un trazo blanco, con una anchura total de 4,6 cm (Fig. 17.13.3). En lo que respecta a la cronología, dado que las UUEE se fechan en su conjunto entre el año 50 y el $100 \mathrm{~d}$. C., proponemos una datación de época neroniana en base a sus características.

El cuarto ejemplar procede de la intervención llevada a cabo en la Plaza de Armas del Alcázar Real de Écija, que permitió sacar a la luz los restos de la denominada domus de los Fabii (Ordoñez Agulla y García-Dils de la Vega, 2017; Carrasco Gómez et al., 2016; Loschi, e.p.). Se trata de una orla calada que carece de filetes de encuadramiento, dispuesta sobre un filete amarillo y compuesta por una sucesión de hojas de hiedra del mismo color, con una anchura total de 2,9 $\mathrm{cm}$ (Fig. 17.13.4). En lo que respecta a su cronología, el conjunto ha sido datado en la segunda mitad del siglo I d. C. (Loschi, e.p.).

El quinto ejemplar procede de la casa del Mitreo de Mérida y fue recuperado en las intervenciones llevadas a cabo en 1994. Se trata de una orla compuesta por cuatro filetes, los dos externos azules y los internos amarillos, que encuadran una sucesión de tallos vegetales amarillos con pequeñas hojas verdes y amarillas generando una fina tira vegetal que, en su parte central, presenta un círculo amarillo de borde blanco con una gota en cada extremo. En el interior se desarrolla una pequeña gota central rodeada por cuatro gotas con apéndice coronadas por otra gota de pequeño tamaño, todo ello sobre fondo rojo y con una anchura total de 7 $\mathrm{cm}$ (Fig. 17.13.5). Al igual que el resto de ejemplares de la casa del Mitreo, dado que su fundación ha sido fijada en torno a los años 70 del siglo I d. C., debemos plantear una cronología flavia, si bien la calidad que presenta permite sugerir que sea anterior a otros como los de la denominada habitación de las pinturas (2.2.20, 3.5.4 y 13.7) o las de la habitación del incendio (1.3.1 y 2.2.16).

El resto de casos presentan gradualmente un menor detalle, tendiendo todos al esquematismo. El siguiente ejemplar, probablemente de cronología similar al anterior, procede de las UUEE 1412 y 1535 del vertedero de Blanes en Mérida y está formado por cuatro filetes, los externos azules y los internos amarillos, que encuadran un fino tallo azul verdoso sobre el que se desarrolla una sucesión de hojas verdes con dos volutas amarillas que se disponen a izquierda y derecha, todo ello sobre un fondo rojo y con una anchura de $7,1 \mathrm{~cm}$ (Fig. 17.13.6). La cronología de ambos contextos, que se mueven entre el $80 \mathrm{~d}$. C. e inicios del siglo II d. C., así como sus características, plantean una datación para época flavia.

Algo posterior a estos ejemplares es el procedente de la denominada habitación de las pinturas de la casa del Mitreo. Pesenta el mismo esquema que el resto de paneles, con cuatro filetes, los externos blancos y los internos amarillos, desarrollándose en su interior una sucesión de tallos con una hoja amarilla de cinco puntas que presenta un trazo verde, intercalado con dos gotas con trazos en verde, dando muestras de un esquematismo más evidente que en los ejemplares anteriores. La anchura total de la orla es de $12 \mathrm{~cm}$ (Fig. 17.13.7). Como el resto del conjunto, fue fechado entre finales del siglo I e inicios del siglo II d. C. (Abad Casal, 1982b: 52-53, fig. 31), pudiendo perfilar la cronología probablemente a los últimos años del siglo I d. C.

Otro ejemplar esquemático lo encontramos en la UE 1292 del vertedero de Blanes. Se trata de una cenefa calada de fondo anaranjado sobre un campo amarillo, enmarcada por cuatro filetes, los externos blancos y los internos azules, que encierran un filete azul en torno al que se sucede una hoja de cinco puntas con un trazo curvo que la une a la siguiente hoja y cuya posición varía de forma contrapuesta. La cenefa presenta un total de 8,3 cm de anchura (Fig. 17.13.8). En lo que respecta a su cronología, la datación del contexto y las características técnico-estilísticas del esquema plantean una fecha entre finales del siglo I e inicios del II d. C.

Más complejo es el procedente del edificio del Palau de les Corts de Valencia, una orla calada sobre fondo rojo compuesta por dos líneas de perlas y piruetas que enmarcan una roseta de borde azul y fondo verde con diez pétalos, flanqueada en sus laterales superior e inferior por un bifolio amarillo con una gota. A izquierda y derecha se desarrolla una gota con 
un bifolio de mayores dimensiones del que parte una vaina verde y blanca con tres pétalos a cada lado y un tallo amarillo central, ambas contrapuestas entre sí y que se unen a un segundo motivo compuesto por cuatro pétalos en blanco y azul, dos de pequeñas dimensiones y dos con forma trilobular, que flanquean una gota de borde amarillo y centro blanco, rodeado por cuatro tallos amarillos y puntiagudos. En total la orla presenta una anchura de 11,5 cm (Fig. 17.13.9). Encontramos un modelo similar en la casa del Grand Triclinium en Clos de la Lombarde fechado entre finales del siglo I e inicios del siglo II d. C. (Sabrié y Sabrié, 2011). En lo que respecta a su cronología, el contexto fue fechado en época flavia (Calvo Gálvez et al., 1998).

El siguiente ejemplar procede de las denominadas casas del solar del Museo Nacional de Arte Romano de Mérida (Hernández Ramírez, 1993; 1999). Se trata de una orla calada sobre fondo rojo enmarcada por dos filetes blancos, en cuyo interior se desarrolla una sucesión de trifolios blancos que alternan en su interior trazos verdes y anaranjados y junto a los que se disponen dos hojas que también alternan en verde y naranja respectivamente. En la parte central y en las esquinas de la orla, las hojas quedan interrumpidas por una joya de borde blanco con gotas alrededor y centro verde, adoptando una forma ovalada con la parte superior más ancha que la inferior. Los filetes presentan, hacia el exterior, una sucesión de gotas blancas coronadas por gotas de menor tamaño, todo ello con una anchura total de 15,5 cm (Fig. 17.13.10). En lo que respecta a su cronología, el conjunto se dispone sobre otro conjunto de una primera fase decorativa compuesto por un zócalo de zancudas que fue fechado entre finales del IV estilo y época flavia (Hernández Ramírez, 1993; 1999), aunque pensamos que podría fecharse directamente hacia mediados de época flavia, por lo que este ejemplar parece factible datarlo en la primera mitad del siglo II d. C.

Procedente del mismo solar, pero en otra estancia, encontramos una orla calada sobre fondo amarillo enmarcada por dos filetes rojos, que encierran una guirnalda negra con hojas verdes que se desarrolla de manera recta, con una anchura total de $9 \mathrm{~cm}$ (Hernández Ramírez, 1993; 1999) (Fig. 17.13.11). La orla se desarrolla hasta el límite del panel por uno de sus lados, el derecho en el caso del panel izquierdo y el izquierdo en el caso del panel derecho, de manera que crean la ilusión de una interrupción mediante el interpanel. En relación a los paralelos, se trata de un motivo que procede de las representaciones de guirnaldas tanto de candelabros vegetales ubicados en interpaneles como asociados a arquitecturas ficticias, que se representan desde el II estilo y que posteriormente se emplean como parte de cenefas y orlas con ejemplos como los del peristilo de la casa dei Vettii (VI 15, 1) (Archer, 1982) o el de la estancia 15 de la casa del Menandro (I 10, 4) (Stefani, 2003; Ling, 2005). En lo que respecta a su cronología, la escasez de datos respecto a la intervención limita la interpretación a su caracterización técnico-estilística, que permite datarlo entre finales del siglo I e inicios del siglo II d. C.

A estos sumamos el ejemplar procedente de una casa situada bajo la Plaza de Santocildes de Astorga, denominado como las pinturas pompeyanas, que fueron recuperadas en las Excavaciones del Plan Nacional de 1954-1955 bajo la dirección de José María Luengo y Manuel Chamoso (Luengo Martínez, 1962: 167-169; Abad Casal, 1982b: fig. 137-140, fig. 206). Se trata de una orla compuesta por tres filetes verdes que enmarcan un tercer filete sobre el que se desarrolla una sucesión de formas ovaladas, quedando decorada hacia el exterior por una sucesión de óvalos del mismo color más pequeños, con una anchura total de $16,4 \mathrm{~cm}$ aproximadamente (Fig. 17.13.12). Al contrario que la mayoría de los ejemplares, este se dispone enmarcando una sucesión de paneles más anchos que altos que se disponen en el zócalo, aunque la morfología, disposición y dimensiones se asemejan a otros modelos ya analizados. En lo que respecta a su cronología, fue fechado entre los años 100-140 d. C. (Luengo Martínez, 1962: 167-169; Abad Casal, 1982b: 137-140).

Otro ejemplo de orla calada es el procedente de la domus de G. Iulius Silvanus de Segóbriga (Cebrián Fernández y Fernández Díaz, 2004: 143; Guiral Pelegrín et al., 2014: 279), compuesta por cuatro filetes amarillos sobre fondo verde que encierran un motivo vegetal parcialmente conservado pero que deja ver la presencia de un bifolio al que se superponen dos gotas amarillas, por lo que probablemente siga un esquema similar al último ejemplar que describiremos a continuación. En este caso, además, conservamos parte de una de las esquinas que permite ver una decoración de dos gotas blancas y una gota ovalada azul en los espacios de pequeño tamaño generados por la unión de los filetes de los laterales, mientras que la parte central cuenta con un círculo de borde blanco y centro azul con gotas blancas alrededor. La orla cuenta con una anchura total de $12 \mathrm{~cm}$ y presenta un trazo preparatorio inciso en la parte central coincidiendo con el motivo vegetal, pero no se aprecia en al resto de filetes (Fig. 17.13.13). Fue datada, junto al resto del conjunto, a finales del siglo II d. C. (Cebrián Fernández y Fernández Díaz, 2004: 144; Guiral Pelegrín et al., 2014: 279), por lo que también se encuentra próximo al siguiente ejemplar.

El último caso forma parte de un techo procedente de la Alcudia de Elche (Ramos Fernández, 1975: 188189; Abad Casal, 1982b: 32, fig. 8). Se trata de una orla de fondo rosa que cuenta con tres filetes, los dos inferiores decorados hacia el interior con una sucesión de semicírculos. En la parte interior se desarrolla una sucesión de círculos blancos con una gota verde al interior y gotas blancas alrededor que alternan con tres bifolios superpuestos en horizontal coronados por una gota blanca, todo ello con una anchura de 17,8 cm (Fig. 17.13.14). Este es, junto al de Astorga, uno 


\section{Motivos vegetales}

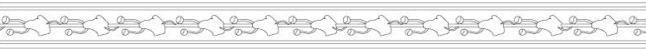

13.1 Blanes (Mérida)

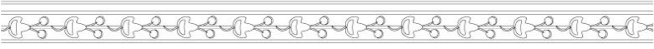

13.2 Blanes (Mérida)

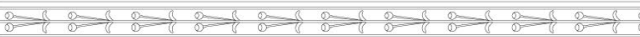

13.3 Blanes (Mérida)

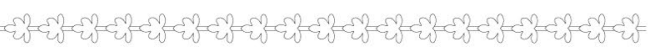

13.4 Domus de los Fabii (Écija)

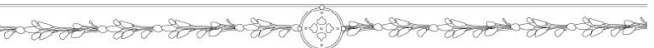

13.5 Casa del Mitreo (Mérida)

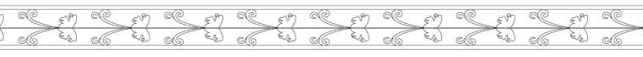

13.6 Blanes (Mérida)

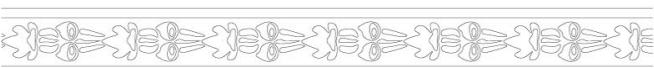

13.7 Casa del Mitreo (Mérida)

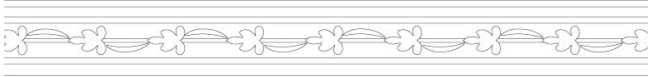

13.8 Blanes (Mérida)

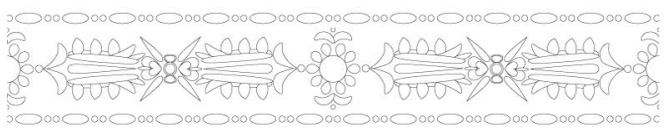

13.9 Palau de les Corts (Valencia)

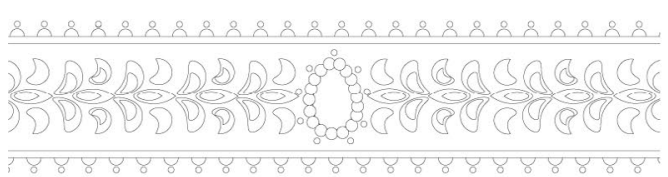

13.10 Solar del MNAR (Mérida)

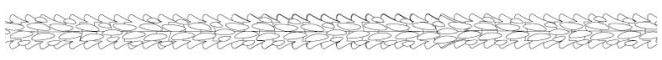

13.11 Solar del MNAR (Mérida)

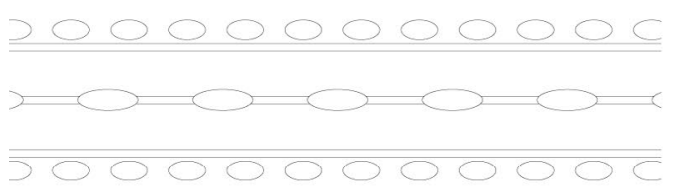

13.12 Plaza de Santocildes (Astorga)
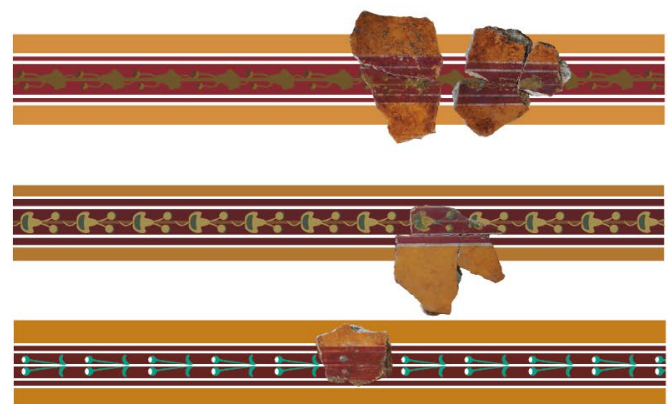

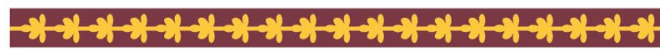
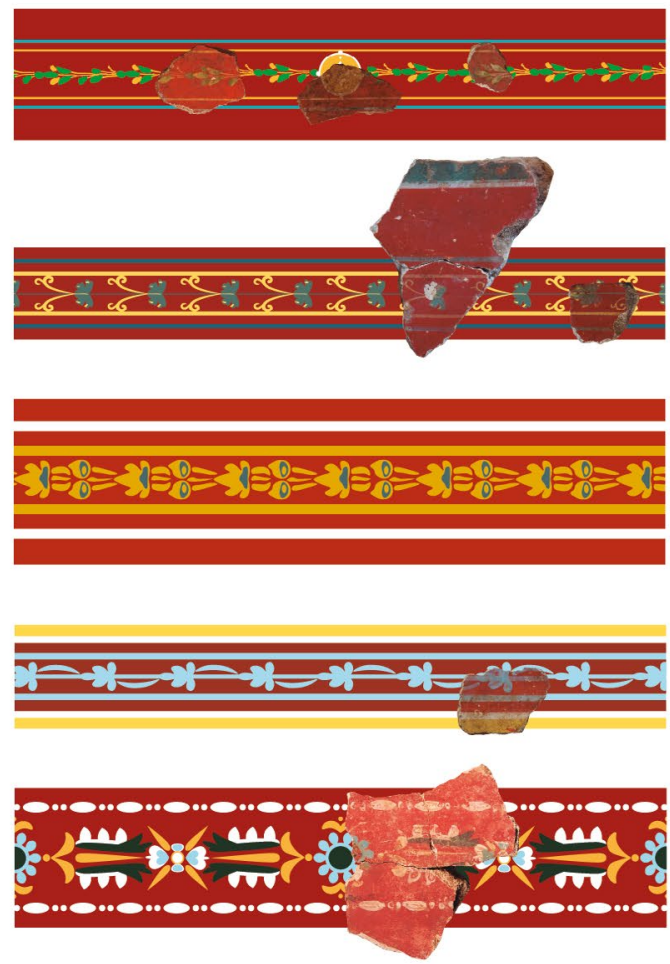

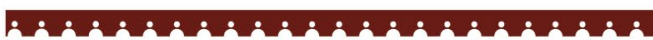
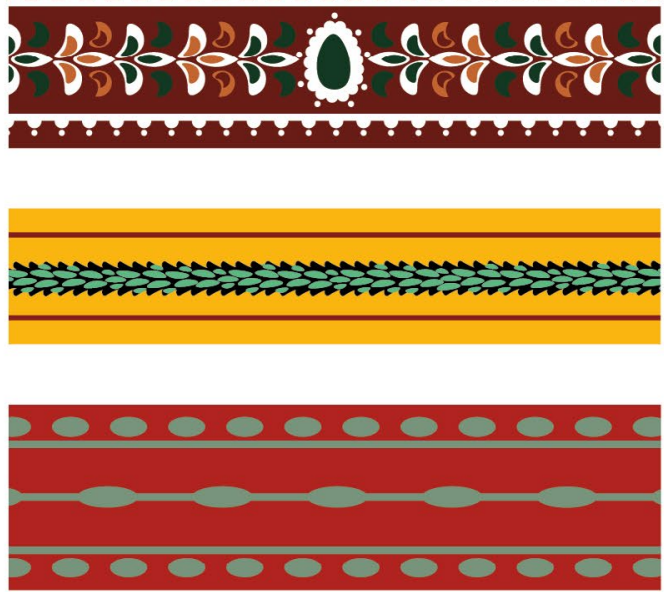


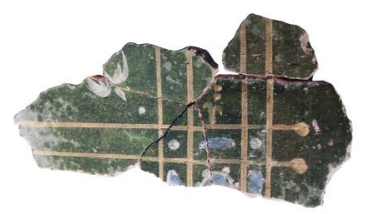

13.13 Domus de G. Iulius Silvanus (Segobriga)
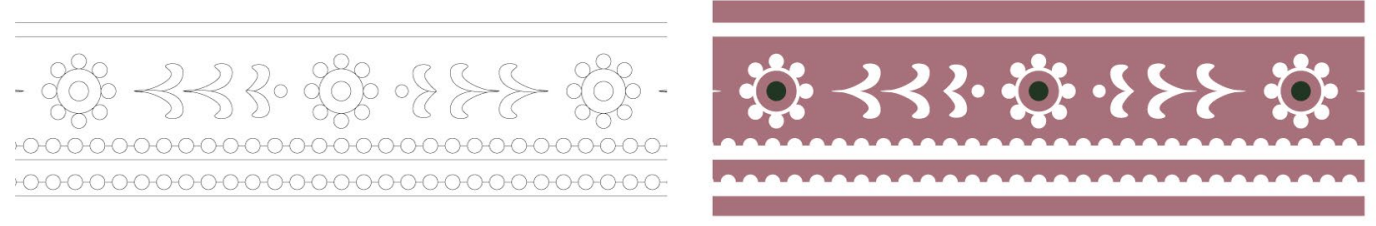

13.14 Alcudia de Elche

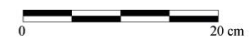

Figura 17: Cenefas y orlas caladas del grupo de motivos vegetales. Fuente: elaborada por los autores

de los más esquemáticos del repertorio, fechado entre los siglos II y III d. C. en base a la estratigrafía de las casas del sector en el que fue hallado el conjunto (Ramos Fernández, 1975: 188-189; Abad Casal, 1982b: 32, fig. 8).

\section{III.14. TIPO 14: VARIA}

Dentro de este último tipo hemos incluido todas aquellas orlas o cenefas que, por su morfología y características, no es posible asociar a ninguno de los grupos anteriores, si bien ello no implica la inexistencia de paralelos en territorio itálico o en las provincias, aunque en el caso de Pompeya no se han identificado.

El más antiguo procede de las UUEE 22 y 65 del vertedero de la calle Cabo Verde de Mérida, compuesto por una banda de color grisáceo sobre un fondo azul verdoso. Sobre la banda se desarrolla una sucesión de cuadrados de borde rojo burdeos con cuatro gotas en las esquinas que alterna con dos motivos con forma de «M» en posición horizontal flanqueados arriba y abajo por una pequeña gota, todo ello en color rojo. Entre dichos motivos se ubican dos bifolios enfrentados con un trazo curvo sobre ellos y en color rojo burdeos. En la parte central, un círculo de borde rojo burdeos con cuatro gotas en los extremos, todo ello con una anchura total de 4,3 cm (Fig. 18.14.1). Se trata de una banda decorativa dispuesta en posición vertical que forma parte de un conjunto del III estilo y que, dadas sus características, no puede ser incluido en la categoría de cenefas y orlas de cuadriláteros, si bien guarda similitud con un paralelo procedente del peristilo de la casa dei Cervi de Herculano (IV 21) (Esposito, 2014). No obstante, se ha incluido aquí dado que se trata de uno de los ejemplares más antiguos de este tipo de decoración en la Península Ibérica y que constituye un precedente en el III estilo de la típica cenefa calada posterior. En lo que respecta a su cronología, su adscripción a un conjunto de arquitecturas ficticias sobre fondo verde de una zona media cuyas características permiten ubicarlo de manera clara en el III estilo, así como la cronología del contexto, fechado entre época claudia y neroniana (Pérez Maestro, 2007), permite plantear una datación para el conjunto de entre época tiberiana y época de Calígula, siendo probablemente el más antiguo de los identificados hasta la fecha en Mérida.

Algo posterior a esta encontramos un ejemplar procedente de la tumba de Servilia en la necrópolis de Carmona (Abad Casal, 1982b: 195, fig. 308; Fernández Díaz, 2010; Baceiredo Rodríguez y Fernández Gómez, 2012), que, al igual que el resto de casos de esta tumba, debe fecharse en torno a época de Nerón (Rodríguez Temiño et al., 2012: 139). Se trata de una orla sobre fondo amarillo, compuesta por cuatro filetes negros que enmarcan una sucesión de círculos compuestos por gotas azules que en sus extremos superior e inferior cuentan con un triángulo del mismo color flanqueado por dos volutas negras. Este motivo alterna con dos palmetas azules más oscuro enfrentadas entre sí y que en el espacio entre ambas quedan rematadas por dos bifolios enfrentados. Sobre los filetes internos, hacia el exterior, se desarrolla una alternancia de gotas y bifolios dispuestos bajo la palmeta y el triángulo respectivamente. Por último, los filetes externos presentan, hacia el exterior, una sucesión de triángulos negros rematados con una gota ovalada y otra gota circular entre los que se desarrolla una alternancia de una media luna azul y una gota negra, con una anchura total de 9 cm (Fig. 18.14.2). En lo que respecta a los paralelos, no contamos con ningún ejemplar similar a pesar del hecho de contar con un repertorio ornamental común con otros esquemas, si bien en este caso se conjugan con un marcado carácter recargado.

El tercer ejemplar se encuentra parcialmente conservado, por lo que es probable que pudiera adscribirse a alguno de los tipos anteriores, no obstante, hemos decidido incluirlo aquí. Se trata de una orla procedente de una de las estancias de las casas del 


\section{Varia}

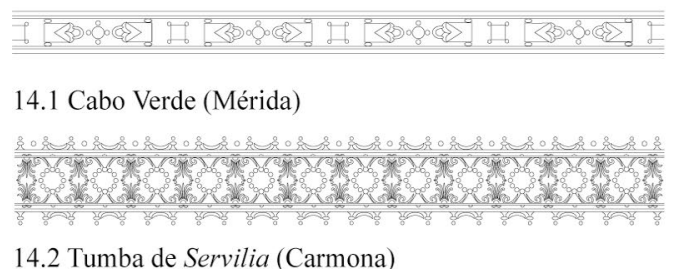

Servilia (Carmona)

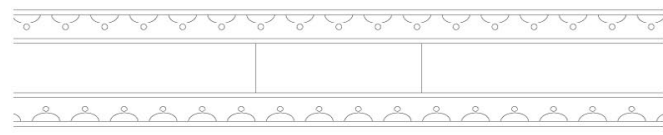

14.3 Solar del MNAR (Mérida)

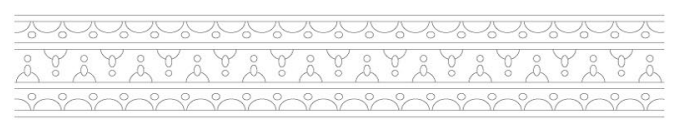

14.4 Casa de la Fortuna (Cartagena)

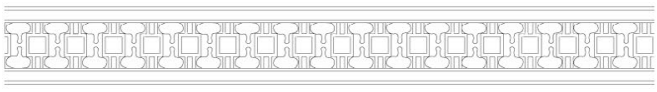

14.5 Villa de Portmán (Cartagena-La Unión)

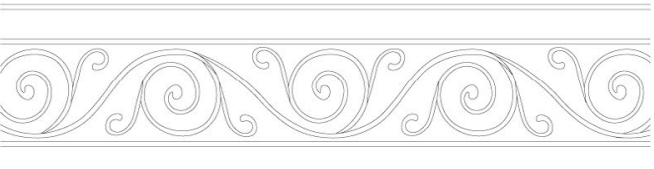

14.6 Casa basílica (Mérida)
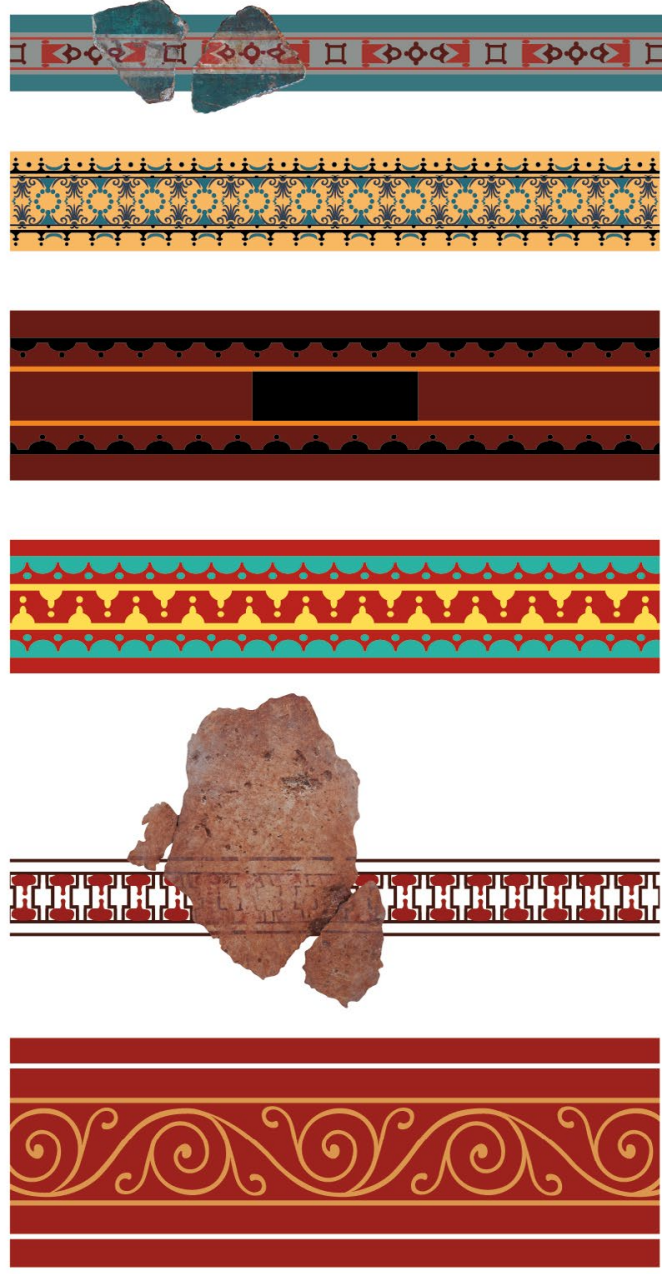

Figura 18: Cenefas y orlas caladas no adscribibles a los grupos anteriores. Fuente: elaborada por los autores

solar del Museo Nacional de Arte Romano de Mérida (Hernández Ramírez, 1993; 1999), compuesta por cuatro filetes, los externos negros y los internos amarillos. En la parte central únicamente se conserva un rectángulo en negro, mientras que sobre los filetes externos se desarrolla, hacia el interior, una sucesión de semicírculos coronados por una gota del mismo color, todo ello sobre fondo rojo y con una anchura total de $12 \mathrm{~cm}$ (Fig. 18.14.3). La presencia de formas cuadrangulares en la parte central de cada lado de la orla se repite en algunos conjuntos de la zona campana, como es el caso del triclinium de la casa del Principe di Napoli (VI 15, 8) (Strocka, 1984), si bien el resto de la decoración no puede comparase con nuestro ejemplar dada la ausencia de la decoración interna. En relación a su cronología, parece claro que este debe fecharse época flavia, dado que se encuentra por debajo de una segunda fase pictórica que también cuenta con una orla que hemos descrito más arriba (13.10) y cuya cronología responde a la primera mitad del siglo II d. C.
El cuarto ejemplar procede de la casa de la Fortuna de Cartagena (Fernández Díaz, 2001: fig. 5; 2008: fig. 44), probablemente del triclinium, y constituye una orla calada compuesta por cuatro filetes, los externos de color verde-azulado y los internos amarillos que encierran una sucesión de semicírculos contrapuestos en alternancia con un apéndice coronado por una gota. Los filetes externos presentan, hacia el interior, una sucesión de semicírculos con una gota en el espacio entre cada uno de estos, con una anchura total de 10,4 cm (Fig. 18.14.4). Al igual que el resto de casos de este grupo, no cuenta con paralelos similares en el área campana, si bien es cierto que, nuevamente, hace uso de motivos decorativos que aparecen comúnmente asociados a otros esquemas tanto en la producción itálica posterior al año $62 \mathrm{~d}$. C. como en la local, como podemos ver en otros ejemplares de las casas del Principe di Napoli (VI 15, 8) (Strocka, 1984), la del Championnet (VIII 2,1) (De Vos, 1977) o la di Ganimede (VII 13,4) (De Vos, 1982) en Pompeya. No obstante, el hecho de que en esta ocasión se emplee como elemento principal 
permite pensar en una elaboración local a partir de los gustos del comitente o la libre ejecución del artesano. En este caso la orla se ornamenta interiormente por un elemento que encontramos en otras variantes como las de motivos sobre líneas y los que decoran los filetes externos de muchos modelos de época flavia, también presentes en nuestro ejemplar, lo que permite proponer una datación en torno a dicho período, algo que corrobora el propio contexto, así como el resto de conjuntos de la casa (Fernández Díaz, 2001: 11-12; 2008: 303-307).

El quinto ejemplar procede la habitación 8 de la villa romana de Portmán. Esta orla, dispuesta sobre un panel blanco, está formada por cuatro filetes rojo burdeos que enmarcan una sucesión de filetes en posición vertical que parten de los filetes internos generando un espacio cuadrangular mediante su unión con otra serie de seis filetes. En el espacio generado entre esos se disponen gotas ovaladas con apéndice en color rojo enfrentadas, con una anchura total de $7,9 \mathrm{~cm}$ (Fig. 18.14.5). En lo que respecta a los paralelos, no encontramos ningún ejemplar similar a este en la producción itálica ni en la provincial, pudiendo señalar únicamente la presencia de gotas con apéndice como un elemento que, como señalamos en otros casos, se encuentra especialmente presente en la producción local en Hispania, en concreto en la pintura flavia y de inicios del siglo II d. C. en enclaves como Augusta Emerita, por lo que parece claro situar este ejemplar dentro de la producción provincial y en concreto la local del ager carthaginensis. Así mismo, la constatación de que las estancias de la terraza superior de la villa no se construyen hasta finales del siglo I d. C. (Fernández Díaz et al., 2019) permiten plantear una cronología de la primera mitad del siglo II d. C. para las pinturas de la habitación 8 .

El último ejemplar es el más tardío del repertorio, procedente de la denominada casa basílica de Mérida (Abad Casal, 1982b: 40-46; Hernández Ramírez, 1993; Mostalac Carrillo, 1997), compuesta por cuatro filetes, los externos blancos y los internos amarillos, que enmarcan una sucesión de volutas alternas contrapuestas con un tallo hacia el exterior unidas entre sí por un trazo curvo que recorre la orla, todo ello sobre un panel rojo y con una anchura total de $18 \mathrm{~cm}$ (Fig. 18.14.6). En lo que respecta a los paralelos de este modelo, si bien no encontramos ningún ejemplar similar, parece claro que el modelo remite a una transformación de los esquemas de «S» enfrentadas unidos a los de semicírculos contrapuestos, aunque tampoco sigue ninguno de los patrones de estas variantes. Junto a esto, también encontramos similitudes con las representaciones de roleos que se desarrollan en conjuntos desde el II al IV estilo pompeyano, aunque más esquematizados. En cualquier caso, el conjunto ha sido fechado a finales del siglo IV d. C. en base a los paralelos estilísticos de las representaciones figuradas del ábside, así como a la documentación epigráfica, que señala una reforma del teatro entre los años 333-335 d. C. y, por tanto, imposibilita su construcción hasta al menos la segunda mitad del siglo IV d. C. (Abad Casal, 1982b: 40; Hernández Ramírez, 1993; Mostalac Carrillo, 1997: 597-600).

Además de toda esta serie de ejemplares, contamos con un grupo procedente en su totalidad de Mérida y repartido entre los vertederos de la calle Cabo Verde, Blanes y la domus de la calle Parejos, cuyo estado de conservación no permite asociarlos con ningún grupo concreto ni plantear una restitución. En cualquier caso, la totalidad de los ejemplares parece poder encajarse entre el IV estilo y la producción de época flavia en base a sus características técnico-estilísticas, a excepción del grupo de la calle Cabo Verde, que formaría parte del mismo conjunto que el primer ejemplar de este grupo y que hemos fechado en el III estilo.

\section{CONCLUSIONES}

En líneas generales, si bien con una muestra inferior en número a los ejemplares procedentes de Pompeya, observamos la existencia de una misma tendencia o preferencia en la representación de cenefas y orlas caladas en Hispania. En este sentido destacan, en primer lugar, las que hacen uso de esquemas de círculos, semicírculos y tres cuartos de círculo, con 48 ejemplos que suponen el $27 \%$ del total analizado, entre los que destacan los esquemas de semicírculos en sus distintas variantes, algo que también sucede en el caso de Pompeya, donde este tipo supone el más numeroso de todos. En segundo lugar, se encuentran las cenefas y orlas a base de cuadriláteros, con 32 ejemplares que suponen el 18\% del total, algo en lo que difiere con respecto al caso pompeyano, donde los triángulos suponen el segundo grupo más numeroso respecto al total. No obstante, dado que en el caso de Hispania esta diferencia viene marcada únicamente por 8 ejemplares con respecto al tercer grupo, el de los triángulos, que tiene 25 casos que suponen el 14\%, no podemos determinar que ello indique una preferencia clara de un modelo frente a otro como sí podemos señalar para el caso de los círculos, semicírculos y tres cuartos de círculo, muy superiores al resto. En menor medida encontramos las cenefas y orlas con esquemas de motivos vegetales, con 12 ejemplos que suponen el 7\%, para las cuales debemos tener en cuenta que, dado que Barbet no recoge este tipo, no podemos conocer si la cantidad responde a una tendencia concreta que se repetiría en ambos casos o es algo que podría mostrar una preferencia en uno $\mathrm{u}$ otro ámbito. Un caso especial lo encontramos en las orlas de octógonos, con 12 ejemplares que suponen un $7 \%$ sobre el total, un número mucho mayor que el que encontramos en Pompeya y que, además, se circunscribe íntegramente al área emeritense. En este caso, ello podría estar indicando, tal y como sugeríamos, que se trate de un modelo con poca aceptación en el área pompeyana pero que, sin embargo, encuentre una amplia difusión en ámbito provincial, en este caso limitado a 
Hispania y en concreto a Mérida, dado que en el resto de las provincias occidentales tampoco se documentan y únicamente lo encontramos en las orientales a partir del siglo II d. C. (Zimmermann y Ladstätter, 2011). Si tenemos en cuenta la diferencia cronológica existente entre los ejemplares de Mérida y el de Éfeso, los primeros fechados en su mayoría a inicios de época flavia y el segundo de época trajanea, parece factible plantear una llegada ligeramente anterior de estos modelos y su transformación y adaptación a los gustos locales en las provincias occidentales en comparación con las orientales, o un mayor uso a lo largo del tiempo en estas últimas, dado que para época trajanea son escasos los ejemplos de orlas caladas que hemos podido recoger y ninguno con un esquema de octógonos.

A parte del último grupo, que incluye ejemplares de muy diversas formas, el resto de grupos cuenta con una cantidad de esquemas por debajo de 10 y que oscila entre el 1 y el 5\%, muy inferiores a lo que se ha documentado en Pompeya y que permiten, en conjunto, observar una clara tendencia a la representación de esquemas geométricos con distintas variantes en lo que respecta a la ornamentación interna y externa (Fig. 19 y 20$)$.

Si comparamos esta tendencia con lo que encontramos en las provincias occidentales, podemos determinar que hay una clara predilección por los esquemas de círculos, tres cuartos de círculos y semicírculos, especialmente de estos últimos, tal y como reflejan los distintos trabajos publicados (Fuchs y Dubois, 1997; Barbet, 2008; Allag et al., 2014; Strocka, 2014; Boislève y Jardel, 2014; Froeliger y Mondy, 2017). No obstante, encontramos un dato interesante si comparamos la producción hispana con las cenefas y orlas de la Gallia, dado que, si bien en ambos casos predominan este tipo de esquemas, los modelos de triángulos y cuadriláteros cuentan con muy pocos ejemplares en el territorio galo en contraposición a lo que hemos podido documentar para Hispania; gran parte de ellos se concentran en Mérida, pero también están representados en la Baetica y la Tarraconensis. Por otro lado, encontramos en la Gallia un número de orlas con esquemas sobre filetes muy superior al que conservamos en Hispania. Si bien es cierto que el estado de conservación de los contextos en las provincias dista mucho del ámbito campano y, por tanto, no contamos con tantos elementos, parece clara la existencia, bien de un gusto distinto, bien de la influencia de talleres distintos entre las provincias que lleva a la mayor difusión de unos u otros modelos.

En lo que respecta a su empleo a lo largo del tiempo, para el caso de Hispania parece claro que, en líneas generales, encontramos una continuidad en el uso de los esquemas sin alteraciones entre época neroniana y época flavia, si bien a partir del siglo II d. C., no contamos con modelos de triángulos, octógonos, «S», motivos cordiformes o meandros y el número de esquemas de cuadriláteros, círculos, tres cuartos de círculos y semicírculos se ve significativamente reducido. En contraposición, a partir de época flavia y durante el siglo II d. C. perduran y tienen mayor presencia los esquemas de óvalos y vegetales, debido a cambios en las modas imperantes que se reflejan en otra serie de elementos como los candelabros y los sistemas de relación continua que también se vegetalizan, así como, probablemente a que, por su morfología, permiten de manera más fácil la integración y adaptación de motivos de formas diversas que puedan contentar los gustos de los comitentes locales. Si comparamos esta situación con las provincias occidentales podemos observar una tendencia similar en la que, en esta ocasión, son los esquemas sobre líneas los que adquieren una mayor perduración dado su uso más extendido en detrimento de los modelos de triángulos o cuadriláteros. Por otro lado, los esquemas de círculos, tres cuartos de círculos y semicírculos siguen la misma evolución que en Hispania, al igual que encontramos una presencia importante de esquemas de óvalos y motivos vegetales durante el siglo II d. C.

De este modo, si bien impera la adopción de esquemas itálicos que posteriormente se ven transformados por los talleres locales, el gusto provincial se manifiesta desde el primer momento a la hora de elegir los motivos ornamentales de factura itálica. En el caso de Hispania, es más fácilmente analizable en Mérida dada la gran cantidad de esquemas que conserva muy ligados a la tradición itálica. Ello parece responder al hecho de que, a diferencia de ciudades como Tarraco, también capital de provincia o Carthago Nova, Augusta Emerita tiene una fundación más tardía y no cuenta con una tradición pictórica desde época tardo-republicana como las otras. Ello va a provocar una aparición más lenta de los talleres locales que no aparecen hasta la segunda mitad del siglo I d. C., y una perduración de la estética itálica en la obra pictórica de la ciudad, que hace que la transformación local sea más lenta que si hubiera habido talleres locales con anterioridad, en contraposición con lo que ocurre en esa misma fecha en otras ciudades de Hispania. Caso similar encontramos en el resto de provincias occidentales, donde el mayor número de cenefas y orlas caladas se da en territorios que, durante la difusión del IV estilo, se encontraban estrechamente vinculados al ámbito itálico, como sucede en la provincia Narbonense a diferencia del resto de la zona gala donde el número es mucho menor o casi inexistente, en Germania o en Suiza, donde la presencia de este motivo se extiende entre época flavia y trajanea (Fuchs y Dubois, 1997: 179).

Así mismo, en lo que respecta a los motivos secundarios, los bifolios, trifolios, gotas, rosetas y palmetas son los más repetidos en todo el repertorio, con la diferencia de que mientras en el ámbito pompeyano muchos de los esquemas adquieren un carácter más fino en su ejecución y complejo en su conjugación, en las provincias occidentales se aprecia una tendencia a la sencillez en los modelos a partir de época flavia. Junto a esto, en nuestro caso encontramos además una particularidad bien representada en Augusta Emerita, donde la tendencia general es la adopción de semicírculos y 


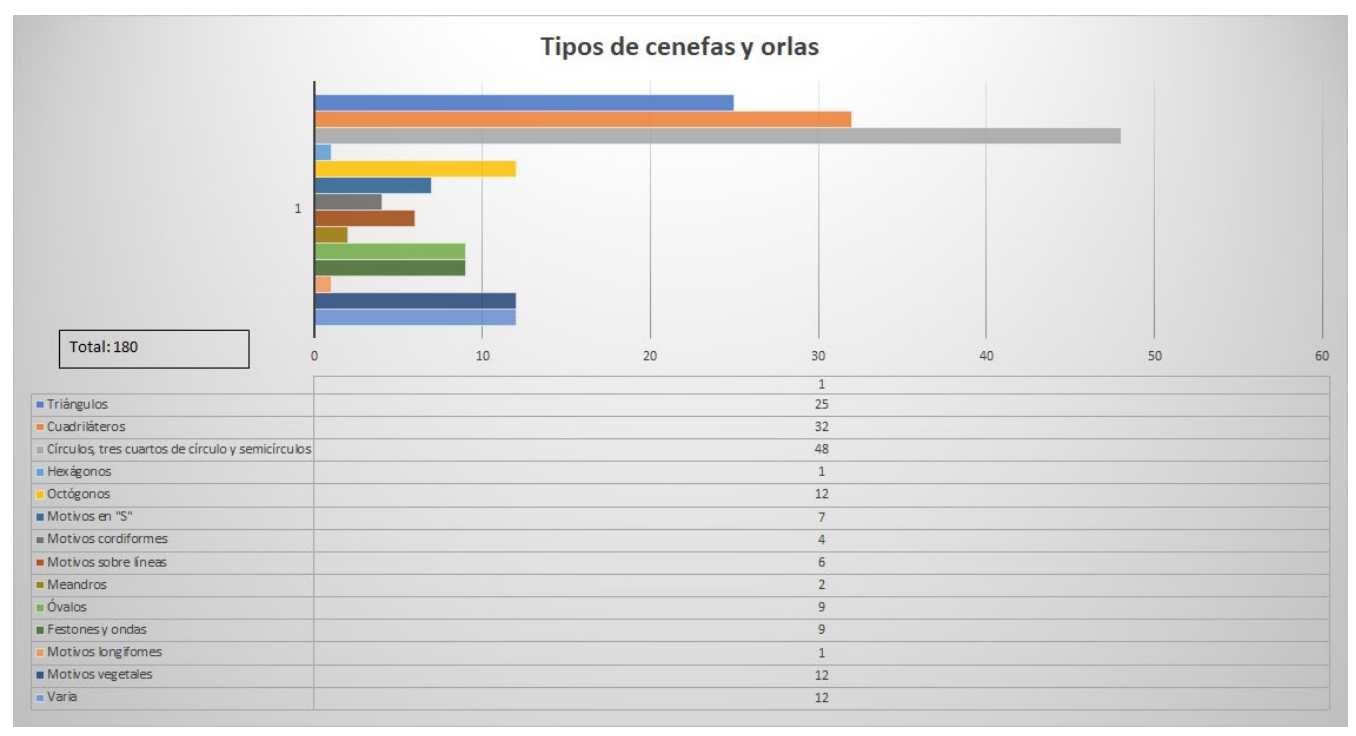

Figura 19: Cantidad de cenefas y orlas caladas por grupos. Fuente: elaborada por los autores

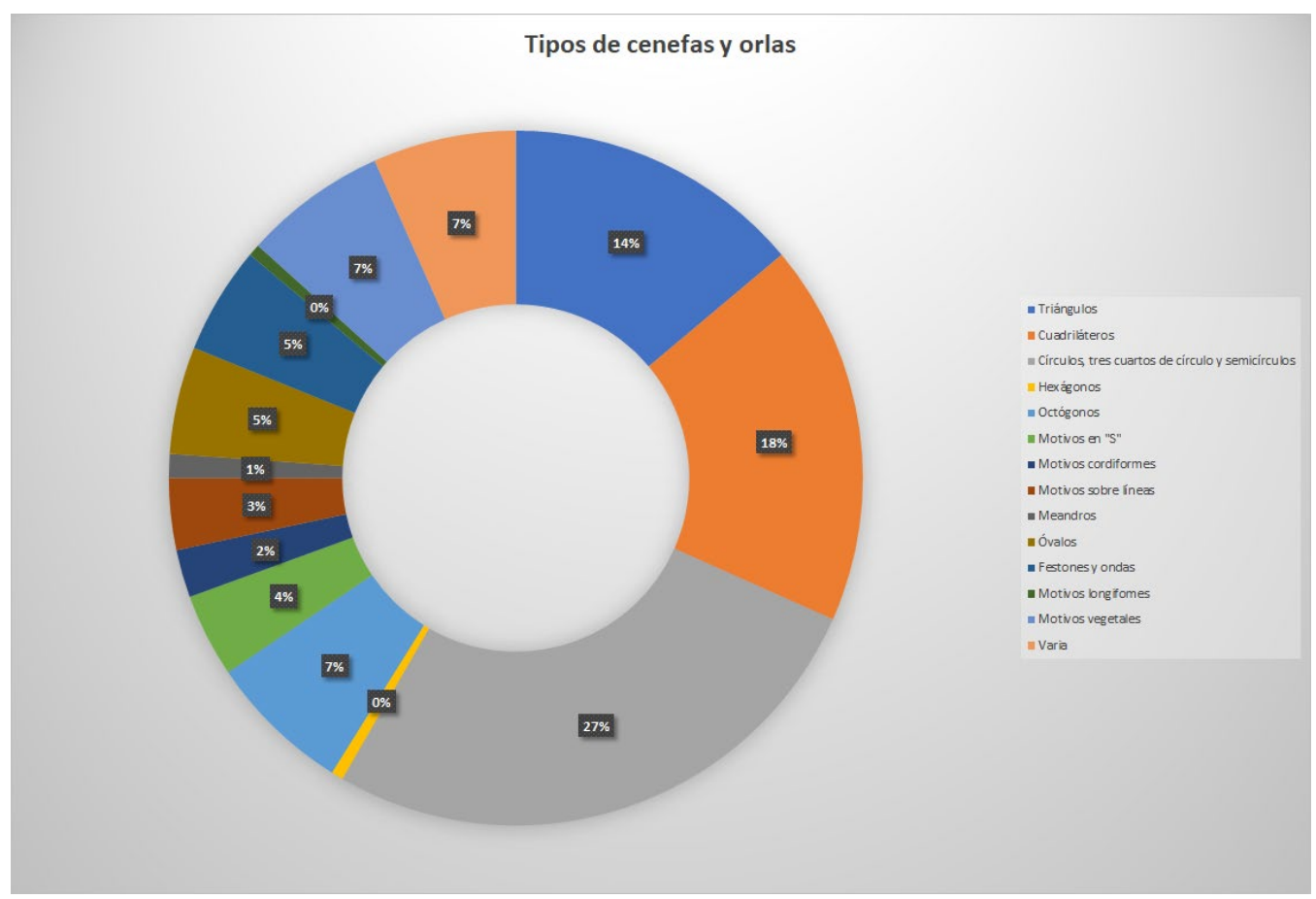

Figura 20: Porcentaje de ejemplares de cada grupo sobre el total. Fuente: elaborada por los autores

gotas para la ornamentación exterior de cenefas y orlas que entendemos como un signo del gusto local o una moda dada su repetición en la mayoría de ejemplos y que marca una diferencia con respecto a otros enclaves. En este sentido, baste señalar el caso de Carthago Nova, donde los conjuntos tienden a la desaparición de las cenefas y orlas, con un escaso número documentado. En cualquier caso, parece evidente que el proceso de desaparición de este motivo ornamental comienza entre finales del siglo I e inicios del siglo II d. C. para generalizarse en torno a mediados del siglo II $\mathrm{d}$. C. Junto a esto, en cuanto a los trazos preparatorios, si bien solo hemos podido documentar un número limitado de ejemplares en donde se conservan, especialmente en los esquemas de círculos y semicírculos y casi siempre mediante compás, su ausencia en el resto de casos no debe entenderse como una carencia de los mismos, pudiendo no apreciarse por su estado de conservación, especialmente en el caso de trazos preparatorios pintados, dado que parece obvio que debieron emplearse para una gran cantidad de los casos analizados.

En lo que respecta a la combinación de colores y motivos, encontramos que, si bien para el caso de Pompeya y Herculano los ejemplos más refinados se desarrollaban sobre fondos negros (Barbet, 1981: 935936), en los conjuntos hispanos esta relación no es tan 


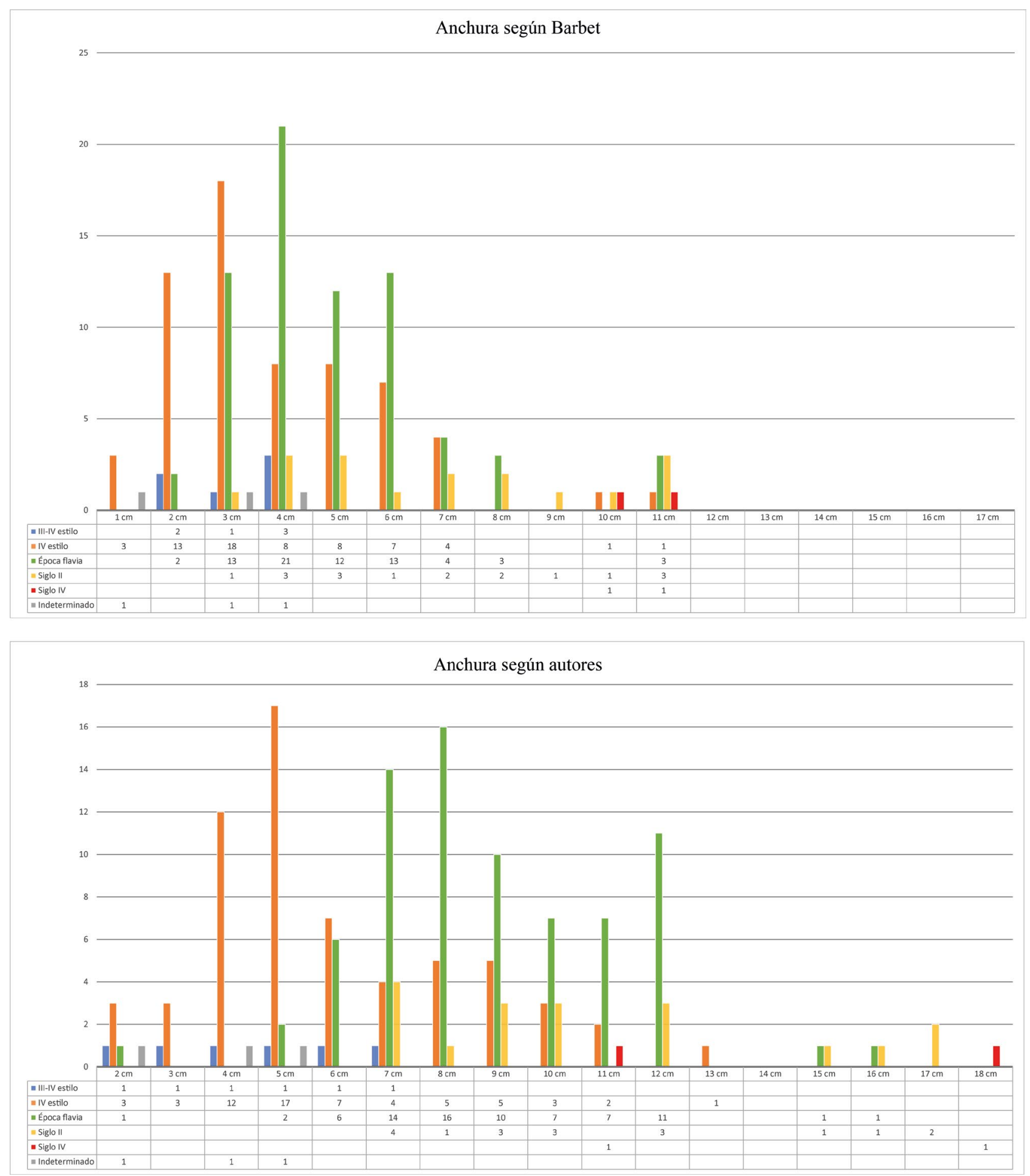

Figura 21: Dimensiones de las cenefas y orlas en función de su cronología según los criterios empleados por Barbet y los criterios empleados por los autores. Fuente: elaborada por los autores

clara, constatando casos de gran calidad tanto sobre fondos negros como sobre fondos verdes, rojos y amarillos. No obstante, si tenemos en cuenta la cantidad de ejemplos por cada color, son las cenefas y orlas sobre fondo amarillo las que mayor calidad presentan sobre el total, especialmente en los ejemplos procedentes de Carmona y de los vertederos de Mérida. En cualquier caso, son los fondos rojos y amarillos los que aglutinan la gran mayoría de los ejemplos, con una gran diversidad de formas y calidad en la ejecución, algo que se repite con respecto a lo que encontramos en Pompeya y que parece responder al gusto que por estos colores se impone para la decoración de paneles a partir del IV estilo y que continúa, especialmente en el caso de los rojos, hasta el siglo II d. C. A partir de este momento, encontramos mayor diversidad en 
el color de los fondos, así como en los esquemas y motivos decorativos, plenamente locales y adaptados al gusto de la sociedad hispana, pudiendo señalar los fondos blancos de la villa romana de Portmán ${ }^{40} \mathrm{o}$ el fondo rosa de un techo procedente de Elche (Ramos Fernández, 1975: 188-189). Junto a esto, se aprecia, especialmente en el caso de Mérida, un gusto por la combinación de los rojos y amarillos con los azules, ampliamente extendidos en los ejemplares sobre fondo rojo y en algunos casos sobre fondo amarillo, algo que difiere de la mayoría de ejemplos que encontramos en Pompeya. Ello permite plantear la hipótesis de que el uso del azul para los filetes de encuadramiento exterior de las orlas y para los motivos decorativos del interior pueda ser una concesión al gusto local o una moda que estaría indicando un momento de transición en la producción de cenefas y orlas caladas itálicas a modelos propios, permitiendo situarlos entre época flavia y los primeros años del siglo II d. C.

En líneas generales observamos que esta tendencia se sigue en el resto de provincias occidentales, donde predomina el uso de fondos rojos y el empleo del amarillo para los motivos y filetes de las orlas, combinados parar los detalles y motivos secundarios con los blancos, verdes y azules, mientras que a partir del siglo II d. C. también los encontramos en gran medida sobre fondos blancos.

Uno de los aspectos que más se ha referido como diferenciador cronológico a la hora de fechar cenefas y orlas caladas han sido las dimensiones, dada la tendencia hacia el aumento que se ha podido detectar en las producciones a partir de época flavia. No obstante, los datos extraídos del análisis de todos los ejemplares recogidos, permiten plantear una nueva percepción a este respecto. En este sentido, el principal referente ha sido siempre la producción pompeyana que, gracias al trabajo de Barbet (1981), permitió establecer para el motivo central una horquilla de entre 2 y $6,2 \mathrm{~cm}$ de anchura para los ejemplares de los distintos grupos, si bien la mayoría de los esquemas de los grandes grupos, triángulos, cuadriláteros y círculos, se ubican entre los 3 y $5 \mathrm{~cm}$, siendo los más pequeños los motivos sobre líneas y los festones, en general entre los 2 y $3 \mathrm{~cm}$ de anchura. Ello ha permitido comparar los casos provinciales y determinar el seguimiento o no de los cánones itálicos, a lo que era necesario sumar otra serie de aspectos del conjunto para establecer la datación. El estudio que hemos realizado empleando una metodología de medición que incluye todos los elementos que rodean al motivo central como parte de la cenefa u orla permite corroborar la existencia de una tendencia al incremento de las dimensiones que, en el caso de Hispania, se hace patente ya desde mediados del siglo I d. C., con ejemplares como los de la tumba de Servilia o los del castro Chao Samartín que sobrepasan los cánones campanos, pudiendo llegar a los 10 u 11

40. Este conjunto se encuentra en fase de estudio. cm en algunos casos como el ejemplar 1.1.3 procedente de Blanes. No obstante, si hacemos uso de los criterios empleados por Barbet para la medición, contando únicamente la anchura del motivo central, encontramos que la gran mayoría de los ejemplares analizados entran dentro de los cánones pompeyanos, con un predominio de las cenefeas y orlas entre los 3 y $6 \mathrm{~cm}$ hasta el siglo II d. C. (Fig. 21). De este modo, algunos ejemplos entre el III y IV estilo presentan, incluso, dimensiones inferiores a los paralelos del área campana, como sucede, por ejemplo, con el ejemplar 1.1.2 y el paralelo procedente de la casa degli Amanti de Pompeya (I 10, 11). Junto a esto, podemos incluir ejemplos fechados en el siglo II d. C., con o sin el mismo repertorio ornamental, como el procedente del Parque de las Naciones de Alicante (Rosser Limiñana, 1992: 152) o uno de los ejemplares de la habitación 8 de la villa romana de Portmán que, teniendo en cuenta estos criterios, medirían 5,2 y 4,7 $\mathrm{cm}$ respectivamente.

A partir de época flavia, la ejecución de orlas caladas seguirá desarrollándose en gran parte de los contextos hispanos, a excepción de casos como el Carthago Nova -no así en su territorio-, desapareciendo casi por completo la representación de cenefas caladas. Si tenemos en cuenta los criterios empleados para la medición de las orlas que hemos utilizado a lo largo de este trabajo, podemos observar la existencia de una clara tendencia al aumento de las dimensiones, que en la mayoría de los casos oscila entre los 7 y los $12 \mathrm{~cm}$, con algunas excepciones como el ejemplar 10.2 procedente de Valencia, que alcanza los $16,9 \mathrm{~cm}$. No obstante, si hacemos uso de los criterios utilizados por Barbet, la gran mayoría de ejemplares fechados entre época flavia y el siglo IV d. C. o bien entrarían dentro de los cánones pompeyanos, o bien mostrarían un ligero aumento de las dimensiones, en muchos de los casos entre 1 y $1,5 \mathrm{~cm}$, con algunas excepciones especialmente en los ejemplares más tardíos. Esto se encuentra en contraposición con los datos que podemos extraer del empleo de este criterio sobre los ejemplares de Pompeya, que permiten ver cómo la mayoría de estos cuentan con una anchura entre los 5 y $7 \mathrm{~cm}$, con escasos ejemplos que superan los $8 \mathrm{~cm}$, algo coherente si tenemos en cuenta el poco desarrollo de los filetes y motivos externos en la práctica totalidad de los casos.

De este modo podemos concluir que, si comparamos los datos obtenidos mediante la aplicación de los dos criterios -medidas del motivo central y medidas totales-, aunque existe una tendencia general al incremento de dimensiones, en el caso del motivo central, la escasez de aumento del mismo implica que debamos hablar de una imitación de los modelos itálicos hasta bien entrado el siglo II d. C., con solo 12 ejemplares que muestran unas dimensiones superiores a $8 \mathrm{~cm}$, mientras que 30 experimentan un ligero aumento que no sobrepasa $1,5 \mathrm{~cm}$ (Fig. 21).

Por otro lado, si aceptamos como parte integrante de las cenefas y orlas caladas todos aquellos elementos que las ornamentan hacia el exterior, sí observamos de 
manera especial un incremento de las dimensiones que no responde al motivo central si no a la ornamentación externa. Por tanto, parece evidente que, mientras que existe una tendencia a la imitación de las dimensiones y motivos centrales, es el ornamento exterior el que adquiere un mayor protagonismo a partir de época flavia a la hora de mostrar las innovaciones y cambios fruto de los gustos y modas imperantes. No hay que olvidar que el aumento de las dimensiones es un fenómeno que se observa también en muchos otros motivos de la pintura mural como por ejemplo los filetes triples, por tanto, se trata de una moda común y generalizada en todo el Imperio.

Finalmente, debemos indicar que, si bien hay algunos autores que al igual que nosotros han tratado de identificar talleres a través de la forma y/o ejecución de las orlas y cenefas caladas, otros han puesto este recurso en tela de jucio. No obstante, y aunque habría que incluir y analizar muchos más elementos o motivos decorativos de la pintura mural, además de las orlas y cenefas, así como las composiciones en las que se insertan, para corroborar la existencia de talleres, especialmente a partir de la segunda mitad del siglo I y durante el siglo II d. C., podemos afirmar la existencia de talleres itálicos para ciertos casos. Se trata de las cenefas y orlas 1.1.1, 1.1.2, 2.2.4-2.2.8, 3.8.1, 11.2.1, 11.2.2 y 14.1 de la calle Cabo Verde, las cenefas y orlas 2.4.2, 3.4.1, 3.11.1, 9.1, 13.1 y 13.2 de Blanes o las orlas 8.1.1 y 8.2.2 de la Huerta de Otero, si bien no se puede diferenciar de manera clara el número de estos. Distinto es el caso de los talleres locales, para los cuales podemos documentar, al menos, el caso de las habitaciones 7 y 8 de la terraza superior de la villa romana de Portmán y las procedentes de la casa del Anfiteatro de Mérida y del Edificio del Atrio del Molinete en Cartagena, donde si estaríamos ante el trabajo de dos talleres. Por otra parte, en el caso de las orlas que encontramos en Blanes y la Casa del Mitreo, la falta de datos del resto del conjunto del primer caso, no permiten corroborarlo completamente, pero es la hipótesis más factible.

Concluimos indicando que es evidente la existencia de unos parámetros claros en la elección de los esquemas, motivos ornamentales, colores y dimensiones de las cenefas y orlas caladas en las provincias desde su adopción aún dentro de los cánones puramente itálicos hasta su desarrollo final en el marco de la producción local y provincial, algo que responde a la acción combinada de la moda imperante, los gustos locales y la pericia técnica del artesanado.

\section{REFERENCIAS}

Abad Casal, L. (1982a). Aspectos técnicos de la pintura mural romana. Lucentum, II, 173-198. DOI: https://doi. org/10.14198/LVCENTVM1982.1.06

Abad Casal, L. (1982b). La pintura romana en España. (Tesis doctoral). Universidad de Sevilla-Universidad de
Alicante. Alicante. Recuperado de https://rua.ua.es/dspace/ handle/10045/21902

Abad Casal, L. y Bendala Galán, M. (1975). La tumba de Servilia de la necrópolis de Carmona: su decoración pictórica. Habis, 6, 295-326. Recuperado de: http://institucional. us.es/revistas/habis/6/16\%20abad\%20casal.pdf

Alarcão, J. (1999). Conimbriga, O Chão Escutado. Lisboa: Edicarte.

Allag, C. (1982). Enduits peints de Ribemont-sur-Ancre. Gallia, 40.1, 107-122. DOI: https://doi.org/10.3406/ galia.1982.1855

Allag, C., Mondy, M. y Coutelas, A. (2014). Ancienne Chambre des Métiers (colline Sainte-Croix). En D. Heckenbenner y M. Mondy (Eds.). Pictor 4. Les décors peints et stuqués dans la cité des Médiomatriques. IerIIIe siècle p.C. I. Metz-Divodurum. (pp. 93-104). Burdeos: Ausonius Editions.

Allag, C. y Kleitz, F. (2018). Chartres (Eure-et-Loir). Le décor au dieu Océan. En J. Boislève, A. Dardenay y F. Monier (Eds.). Pictor 7. Peintures et stucs d'époque romaine. Études toichographologiques (pp. 353-364). Burdeos: Ausonius Éditions.

Álvarez Sáenz de Buruaga, J. (1974). Una casa romana con valiosas pinturas de Mérida. Habis, 5, 169-188. Recuperado de: http://institucional.us.es/revistas/habis/5/12\%20 alvarez $\% 20$ saez.pdf

Amadei, B. y Bujard, S. (2007). Les peintures de la rue Saint-Patrice à Bayeux (Calvados). En C. Guiral Pelegrín (Ed.). Circulación de temas y sistemas decorativos en la pintura mural antigua. Actas del IX congreso de la AIPMA (Zaragoza-Calatayud 2004) (pp. 423-426). Zaragoza: UNED-Institución Fernando el Católico.

Angiolillo, S. y Giuman, M. (2014): Pitture dalla Casa dei Mosaici di Iasos. En N. Zimmermann (Ed.). Antike malerei zwischen lokalstil und zetstil. Akten des IX Internationale Kolloquiums der AIPMA (Association Internationale pour la Peinture Murale Antique) (Éfeso, 2010) (pp. 177-184). Viena: Verlag der Österreichischen Akademie der Wissenschaften. DOI: https://doi.org/10.26530/oapen_574664

Archer, W.C. (1982). The Paintings of the Casa dei Vettii in Pompeii. Ann Arbor: University Microfilms International.

Baceiredo Rodríguez, M. I. y Fernández Gómez, F. (2012). El pintor Rodríguez Jaldón y la necrópolis de Carmona. En A. Caballos Rufino (Ed.). Carmona romana (pp. 99-114). Carmona: Ayuntamiento de Carmona, Delegación de Cultura - Universidad de Sevilla.

Barbet, A. (1981). Les bordures ajourées dans le IVe style de Pompéi. Essai de typologie. Mélanges de l'École Française de Rome. Antiquités, 93, 2, 917-998. DOI: https://doi. org/10.3406/mefr.1981.1302

Barbet, A. (1985). La peinture murale romaine. Les styles décoratifs pompéiens. París: Picard.

Barbet, A. (1999). La Villa San Marco a Stabia. Nápoles: Centre Jean Bérard. 
Barbet, A. (2008). La peinture murale en Gaule romaine. París: Picard.

Barbet, A. y Allag, C. (1972). Techniques de préparation des parois dans la peinture murale romaine. Mélanges de l'École Française de Rome. Antiquité, 48, 935-1096. DOI: https:// doi.org/10.3406/mefr.1972.938

Barbet, A., Douaud, R., Lanièpce, V. y Ory, F. (1997). Imitations d'opus sectile et décors à réseau: essai de terminologie. Bulletin de liaison, 12, 1-76. Recuperado de: https:// hal.inria.fr/hal-00622799/

Barbet, A., Allonsius, C., Bujard, S., Dagand, P., Groetembril, S., Lefèvre, J.-F.,... y Lemoigne, L. (2012). Peintures de Périgueux. Édifice de la rue des Bouquets ou la domus de Vésone. V.- Les peintures fragmentaires. Aquintania, 28, 49-98. Recuperado de: https://aquitania.u-bordeaux-montaigne.fr/ jumi/pdf/106.pdf

Barresi, P. (2014). La pittura parietale in Sicilia in età romana En N. Zimmermann (Ed.). Antike malerei zwischen lokalstil und zetstil. Akten des IX Internationale Kolloquiums der AIPMA (Association Internationale pour la Peinture Murale Antique) (Éfeso, 2010) (pp. 423-428). Viena: Verlag der Österreichischen Akademie der Wissenschaften. DOI: https://doi.org/10.26530/oapen_574664

Barrientos Vera T. y Guiral Pelegrín C. (2007). La decoración en relieve de Mérida: un taller del s. I d. C. En C. Guiral Pelegrín (Ed.). Circulación de temas y sistemas decorativos en la pintura mural antigua. Actas del IX Congreso Internacional de la AIPMA (Zaragoza-Calatayud) (pp. 165172). Zaragoza: UNED - Institución Fernando el Católico.

Bejarano Osorio, A. (2004). Una domus extramuros en los límites de la ciudad: nuevos aspectos de la urbanística y el trazado de la muralla de Augusta Emerita en la zona nororiental. Mérida, excavaciones arqueológicas, 10, 233256. Recuperado de: https://biblioteca.consorciomerida. org/pdf/23514_Bejarano\%20A.'Domus\%20extramuros'. Memoria\%202004\%20N\%C2\%BA\%2010.pdf

Bejarano Osorio, A., Bustamante Álvarez, M. y Castillo Alcántara, G. (e.p.). Novedades Arqueológicas en torno a la Casa del Mitreo (Mérida), un sitio excepcional para el estudio de pintura en Hispania. En A. Fernández Díaz y G. Castillo Alcántara (Eds.). La pintura romana en Hispania. Del trabajo de campo a la musealización. Murcia: Editum.

Boislève, J. (2014). Nouvelles découvertes à Nîmes (Gard, France), 54 décors issus des fouilles du Parking Jean-Jaurès et de la Percée Clérisseau. En N. Zimmermann (Ed.). Antike malerei zwischen lokalstil und zetstil. Akten des IX Internationale Kolloquiums der AIPMA (Association Internationale pour la Peinture Murale Antique) (Éfeso, 2010) (pp. 657-662). Viena: Verlag der Österreichischen Akademie der Wissenschaften. DOI: https://doi.org/10.26530/ oapen_574664

Boislève, J. y Jardel, K. (2014). Imitations de marbres du forum de Vieux (Calvados, France), quelques particularités de la seconde moitié du II s. ap. J.-C. En N. Zimmermann (Ed.). Antike malerei zwischen lokalstil und zetstil. Akten des IX Internationale Kolloquiums der AIPMA (Association Internationale pour la Peinture Murale Antique) (Éfeso, 2010) (pp. 631-636). Viena: Verlag der Österreichischen
Akademie der Wissenschaften. DOI: https://doi.org/10.26530/ oapen 574664

Boislève, J. y Ronco, C. (2016). Pan, Bacchus et le sphinx. Une peinture murale d'époque romaine découverte à Die (Drôme). En J. Boislève, A. Dardenay y F. Monier (Eds.). Pictor 5. Peintures et stucs d'époque romaine. Une archéologie du décor (pp. 37-58). Burdeos: Ausonius Éditions.

Boldrighini, F. (2003). Domus picta: le decorazioni di Casa Belleza sull'Aventino. Roma: Electa.

Bragantini, I., De Vos, M. y Parise Badoni, F. (1981). Pitture e pavimenti di Pompei: 1. Regioni I, II, III. Repertorio delle fotografie del Gabinetto Fotografico Nazionale. Roma: Istituto Centrale per il catalogo e la documentazione.

Busse, D. (2014). Römische Wandamelerei im Saarland (Deutschland). Erste Untersuchungen zur Wandmalereiausstattung der gallo-römischen Villa von Reinheim. En J. Boislève, A. Dardenay y F. Monier (Eds.). Pictor 3. Peintures et stucs d'époque romaine. Révéler l'architecture par l'étude du décor (pp. 61-66). Burdeos: Ausonius Éditions.

Calvo Gálvez, M., Marín Jordá, C., Martínez García, R., y Matamoros de Villa, C. (1998). De Valentia a les Corts, Valencia, Palau de les Corts. Valencia: Corts Valencianes.

Carrasco Gómez, I., Martín Pradas, A. y Jiménez Hernández, A. (2016). Una introducción a la pintura mural en la colonia Augusta Firma Astigi. En A. Martín Pradas e I. Carrasco Gómez (Coords.). Actas de las XIII Jornadas de Protección del Patrimonio Histórico de Écija (Écija, 2015) (pp. 95-113). Écija: Asociación de amigos de Écija.

Cebrián Fernández, R. y Fernández Díaz, A. (2004). Un techo pintado en la domus de G. Iulius Silvanus en Segobriga (Saelices, Cuenca, Conventus Carthaginensis. En L. Borhy (Ed.). Plafonds et voûtes à l'époque Antique: actes du VIIIe Colloque International de l'Association International pour la Peinture Murale Antique (AIPMA) (Budapest, 2001) (pp. 137-146). Budapest: Pytheas.

Ceresa Mori, A. y Pagani, C. (2010). Gli intonaci dipinto dallo scabo di piazza Fontana a Milano. En I. Bragantini (Ed.). Atti del X Congresso Internazionale - Association International pour la Peinture Murale Antique (AIPMA) (Nápoles, 2007) (pp. 417-428). Nápoles: Università degli studi di Napoli L'Orientale.

Ciarallo, A. y De Carolis, E. (2001). La Casa di Giulio Polibio: studi interdisciplinari. Pompeya: Centro Studi Arti Figurative-Universidad de Tokio.

Correia, V. H. (1997). Nouvelles recherches à Conimbriga. En R. Étienne y F. Mayet (Eds.). Itinéraires Lusitaniens. Trente années de collaboration archéologique luso-française (Burdeos, 1995) (pp. 35-48). París: De Boccard.

Correia, V. H. (1999). Desenvolvimentos recentes da investigação arqueológica em Conimbriga. En V. Álvarez Palenzuela. (Ed.). Jornadas de cultura Hispano Portuguesa (pp. 11-31). Madrid: Universidad Autónoma de Madrid, Facultad de Filosofía y Letras.

De Vos, M. (1977). Primo stile figurato e maturo quarto stile negli scarichi proveniente dalle macerei del terremoto del 62 
d. C. a Pompei. Mededelingen van het Nederlands Instituut te Rome, 39, 29-47.

De Vos, M. (1982). Die Casa di Ganimede in Pomeji VII, 13, 4. Pavimenti e pitture. Terzo e quarto stile negli scarichi trovati sotti i pavimenti. Mitteilungen des Deutschen Archäologischen Instituts. Römische Abteilung, 89, 315-352.

Drack, W. (1950). Die römische Wandamalerei der Schweiz. Basilea: Verlag Birkhäuser.

Ehrhardt, W. (1988). Casa dell'Orso: (VII 2, 44-46). Häuser in Pompeji. Munich: Hirmer.

Ehrhardt, W. (1998). Casa di Paquius Proculus (I 7, 1.20). Häuser in Pompeji. Munich: Hirmer.

Ehrhardt, W. (2004). Casa delle Nozze d'argento (V 2, i). Häuser in Pompeji. Munich: Hirmer.

Eristov, H. (1979). Corpus des faux-marbres peints à Pompéi. Mélanges de l'École Française de Rome. Antiquité, 91(2), 693-771. DOI: https://doi.org/10.3406/mefr.1979.1211

Eristov, H. (1994). Les éléments architecturaux dans la peinture campanienne du quatrième style. Mélanges de l'École Française de Rome. Antiquité, 187, 5-255. Recuperado de: www.persee.fr/doc/efr_0000-0000_1994_mon_187_1

Esposito, D. (2009). Le officine pittoriche di IV stile a Pompei: dinamiche produttive ed economico-sociali. Roma: L'Erma di Bretschneider.

Esposito, D. (2014). La pittura di Ercolano. Roma: L'Erma di Bretschneider.

Falzone, S. (2007). Ornata aedificia: pitture parietali dalle case Ostiensi. Roma: Libreria dello stato, Istituto poligrafico e zecca dello stato.

Fernández Díaz, A. (1997). Estudio de las pinturas murales en la villa romana de la Huerta del Paturro en Portmán. Anales de prehistoria y arqueología, 13, 181-210. Recuperado de: https://revistas.um.es/apa/article/view/62971/60681

Fernández Díaz, A. (1999a). La villa romana de Portmán: programa decorativo-ornamental y otros elementos para su estudio. Murcia: Diego Marín.

Fernández Díaz, A. (1999b). La pintura mural de la villa romana de los Torrejones (Yecla, Murcia). AnMurcia, 15, 57-86. Recuperado de: https://revistas.um.es/apa/article/ view/62311/60041

Fernández Díaz, A. (2001). El programa pictórico de la casa de la Fortuna. En E. Ruiz Valderas (Coord.). La casa romana en Carthago Nova: arquitectura privada y programas decorativos (pp. 83-130). Murcia: Tabularium.

Fernández Díaz A. (2007). Coexistencia de modas decorativas en la pintura mural del siglo I d. C. en el sureste peninsular. La presencia de un posible taller. En C. Guiral Pelegrín (Ed.). Circulación de temas y sistemas decorativos en la pintura mural antigua. Actas del IX Congreso Internacional de la AIPMA (Zaragoza-Calatayud, 2004) (pp. 173-183). Zaragoza: UNED - Institución Fernando el Católico.
Fernández Díaz, A. (2008). La pintura mural romana de Carthago Nova. Evolución del programa pictórico a través de los estilos, talleres y otras técnicas decorativas. 2 vols. Murcia: Museo Arqueológico de Murcia.

Fernández Díaz, A. (2009). Yecla en el contexto de época romana. En F. J. Muñoz López (Ed.). Yecla. Memorias de su identidad (pp. 63-71). Murcia: Editum.

Fernández Díaz, A. (2010). Pintura. En P. León-Castro Alonso (Coord.). Arte romano de la Bética. Mosaico, Pintura, Manufacturas (pp. 191-274). Sevilla: Fundación Focus Abengoa.

Fernández Díaz, A., Noguera Celdrán, J. M. y Suárez Escribano, L. (2014). Novedades sobre la gran arquitectura de Carthago Nova y sus ciclos pictóricos. En N. Zimmermann (Ed.). Antike malerei zwischen lokalstil und zetstil. Akten des IX Internationale Kolloquiums der AIPMA (Association Internationale pour la Peinture Murale Antique) (Éfeso, 2010) (pp. 473-484). Viena: Verlag der Österreichischen Akademie der Wissenschaften. DOI: https:// doi.org/10.26530/oapen 574664

Fernández Díaz, A. y Suárez Escribano, L. (2018). Les pintures de la domus d'Avinyó de Barcelona. En AA.VV. La Domus d'Avinyó. El luxe d'una casa de Barcino (pp. 21-56). MUHBA Documents, 13. Barcelona: Ayuntamiento de Barcelona.

Fernández Díaz, A., Suárez Escribano, L. y Castillo Alcántara, G. (2019). Huerto del tío Paturro, Cartagena-La Unión. En J. M. Noguera Celdrán, L. E. de Miquel Santed y S. Martínez Sánchez (Eds.). Villae. Vida y producción rural en el sureste de Hispania (pp. 198-201). Murcia: Región de Murcia, Museo Arqueológico de Murcia.

Fernández Díaz, A., Castillo Alcántara, G. y Bejarano Osorio, A. (e.p.). La décoration picturale et en estuc du viridarium d'une maison hors des murs d'Emerita Augusta. En J. Boislève, A. Dardenay y F. Monier (Eds.). Pictor 8. Peintures et stucs d'époque romaine. Burdeos: Ausonius Éditions.

Fernández Díaz A., Castillo Alcántara, G., Heras Mora, F. J. y Bustamante Álvarez, M. (e.p.). El vertedero de Blanes (Mérida): un contexto privilegiado para el estudio de la decoración mural de Augusta Emerita desde una perspectiva multidisciplinar. En A. Corallini (Ed.). Pareti dipinte. Dallo scavo alla valorizzazione (Nápoles 2019). Nápoles.

Fernández Díaz, A, y Castillo Alcántara, G. (e.p.). Les décors peints du Monte Sacro à Carthagène (Espagne). En J. Boislève, A. Dardenay y F. Monier (Eds.). Pictor 9. Peintures et stucs d'époque romaine. Burdeos: Ausonius Éditions.

Forrer, R. (1927). Strasbourg-Argentorate préhistorique, gallo-romain et mérovingien. Estrasburgo: Istra.

Frizot, M. (1981). Les peintures murales de Hongrie. Revue Archéologique, 261-276.

Froeliger, N. y Mondy, M. (2017). Les décors à fond blanc du couloir 2-7 et des espaces 6 de la domus de La Fontainotte à Grand (Lorraine, Vosges). En J. Boislève, A. Dardenay y F. Monier (Eds.). Pictor 6. Peintures et stucs d'époque romaine. Études toichographologiques (pp. 69-84). Burdeos: Ausonius Éditions. 
Fröhlich, T. (1996). Casa della Fontana Piccola. Häuser in Pompeji. Munich: Hirmer.

Fuchs, M. (1989). Peintures romaines dans les collections suisses. Bulletin de Liaison, 9. París: École Normale Supérieure, CNRS.

Fuchs, M. (1993). Ouvertures sur la peinture viticole de Baugy romain. Archäologie der Schweiz, 16, 118-126.

Fuchs, M. y Dubois, Y. (1997). Peintures et graffiti à la villa romaine de Contigny, Lausanne. Annuaire de la Société Suisse de Préhistoire et d'Archéologie, 80, 173-186.

Gago Muñiz, O. (2007). Pintura mural en el Castro Chao Samartín (Grandas de Salime, Asturias). En C. Guiral Pelegrín (Ed.). Circulación de temas y sistemas decorativos en la pintura mural antigua. Actas del IX Congreso Internacional de la AIPMA (Zaragoza-Calatayud, 2004) (pp. 443-446). Zaragoza: UNED - Institución Fernando el Católico.

Gago Muñiz, O. (2014). Pinturas murales del Castro Chao Samartín. Triclinio de la domus romana. En N. Zimmermann (Ed.). Antike malerei zwischen lokalstil und zetstil. Akten des IX Internationale Kolloquiums der AIPMA (Association Internationale pour la Peinture Murale Antique) (Éfeso, 2010) (pp. 601-606). Viena: Verlag der Österreichischen Akademie der Wissenschaften. DOI: https://doi.org/10.26530/ oapen_574664

Gago Muñiz, O. (e.p.). La pintura romana en los castros, el ejemplo del Chao Samartin (Asturias). En A. Fernández Díaz y G. Castillo Alcántara (Eds.). La pintura romana en Hispania. Del trabajo de campo a la musealización. Murcia: Editum.

Gallo, A. y Tessuto, F. (1989). Note su alcune cornici in stucco di IV stile a Pompei. Rivista di studi pompeiani, 3, 155-164. DOI: https://doi.org/10.1400/262617

Gogräfe, R. (2004). Flach- und Tonnendecken in der östlichen provincia Belgica und der nördlichen Germania superior. En L. Borhy (Ed.). Plafonds et voûtes à l'époque Antique: actes du VIIIe Colloque International de l'Association International pour la Peinture Murale Antique (AIPMA) (Budapest, 2001) (pp. 221-231). Budapest: Pytheas.

Grimaldi, M. (2009). La casa di Marco Fabio Rufo a Pompei. En A. Corallini (Ed.). Vesuviana: archeologie a confronto: atti del Convegno Internazionale (Bolonia, 2008) (pp. 447461). Bolonia: Ante Quem.

Groetembril, S. y Ollivier, J. (2013). Les peintures murales d'une domus du Ier siècle à Clermont-Ferrand (Puy-deDôme), rue de l'Oratorie. En J. Boislève, A. Dardenay y F. Monier (Eds.). Pictor 1. Peintures et stucs d'époque romaine. De la fouille au musée (pp. 351-368). Burdeos: Ausonius Éditions.

Gruaz, A. (1985). Les peintures du Vieil Évreux et du fanum de Cracouville. En A. Barbet (Coord.). Peinture murale en Gaule. Actes des séminaires de l'Association Française pour le Peinture Murale Antique (Lisieux, 1982 - Burdeos, 1983) (pp. 55-64). Oxford: British Archaeological Reports.

Guiral Pelegrín, C., Mostalac Carrillo, A. y Cisneros Cunchillos, M. (1986). Algunas consideraciones sobre la imitación del mármol moteado en la pintura romana en España. Boletín del Museo de Zaragoza, 5, 259-288.

Guiral Pelegrín, C. y Mostalac Carrillo, A. (1992). La pintura mural romana de Arcobriga (Monreal de Ariza, Zaragoza). En J. L. Jiménez Salvador (Ed.). I Coloquio de pintura mural romana en España (Valencia - Alicante, 1989) (pp. 99-105). Valencia: Ministerio de cultura - Departament de Prehistòria i Arqueologia de la Universitat de València.

Guiral Pelegrín, C. y Martín-Bueno, M. (1996). Bilbilis I. Decoración pictórica y estucos ornamentales. Zaragoza: Institución Fernando el Católico.

Guiral Pelegrín, C., Fernández Díaz, A. y Cánovas Ubera, A. (2014). En torno a los estilos locales en la pintura romana: el caso de Hispania en el siglo II d. C. En N. Zimmermann (Ed.). Antike malerei zwischen lokalstil und zetstil. Akten des IX Internationale Kolloquiums der AIPMA (Association Internationale pour la Peinture Murale Antique) (Éfeso, 2010) (pp. 277-288). Viena: Verlag der Österreichischen Akademie der Wissenschaften. DOI: 10.26530/oapen_574664

Guiral Pelegrín, C., Íñiguez Berrozpe, L. y Mostalac Carrillo, A. (2019). La domus de la calle Añón de Caesar Augusta (Zaragoza) y el programa decorativo del triclinium. Lucentum, XXXVIII, 215-241. DOI: https://doi.org/10.14198/ LVCENTVM2019.38.10

Hathaway, N., Sabrié, R. y Spühler, A. (2014). Les peintures de la Médtiathèque à Narbonne (Aude). En J. Boislève, A. Dardenay y F. Monier (Eds.). Pictor 3. Peintures et stucs d'époque romaine. Révéler l'architecture par l'étude du décor (pp. 267-286). Burdeos: Ausonius Éditions.

Heckenbenner, D. (1983). Un décor architectural peint: la pièce 89 de la villa I de Saint Ulrich (Moselle). En Y. Burnaud y J. P. Bertaux (Dirs.). Études d'architecture gallo-romaine (pp. 129-135). Nancy: Preses universitaires de Nancy.

Helly, B. (1980). Étude préliminaire sur les peintures murales gallo-romaines de Lyon. En Peinture murale en Gaule. Actes des séminaires de l'AFPMA 1979 (pp. 5-26). Dijon: Centre de recherches sur les techniques gréco-romaines, Université de Dijon.

Hernández Ramírez, J. (1993). La pintura mural romana de Mérida inserta en la estructura urbana y doméstica de la ciudad. (Tesis doctoral inédita). UNED. Madrid.

Hernández Ramírez, J. (1996). Estudio del repertorio ornamental y análisis iconográfico de las pinturas de la casa de la calle Suárez Somonte (Mérida). Revista de estudios extremeños, 52(2), 441-462.

Hernández Ramírez, J. (1999). Las pinturas murales de la cripta del Museo Nacional de Arte Romano (Mérida). Revista de estudios extremeños, 55(3), 859-936.

Iacopi, I. (2007). La Casa di Augusto. Le pitture. Milán: Mondadori Electa.

Íñiguez Berrozpe, L. (2014). La pintura mural romana de ámbito doméstico en el conventus Caesaraugustanus durante el siglo I $d$. C. Talleres y comitentes. (Tesis doctoral inédita). Universidad de Zaragoza. Zaragoza. 
Jacobelli, L. (2018). La specificità espressive nella decorazione della villa romana di Positano. En Y. Dubois y U. Niffeler (Eds.). Pictores per provincias II - Status Quaestionis. Actes du 13 e Colloque de l'Association Internationale pour la Peinture Murale Antique (AIPMA) (Lausanne, 2016) (pp. 433-444). Antiqua, 55. Basilea: Archäologie Schweiz.

Jansen, B., Schreiter, Ch. y Zelle, M. (2001). Die römischen Wandmalereien aus den Stadtgebiet der Colonia Ulpia Traiana. Xantener Berichte, Band 11, Grabung, Forschung, Präsentation. Maguncia: Philipp von Zabern.

Jones, O. (1856). The Grammar of ornament. Londres: Day and Son.

Kenner, H. y Praschniker, C. (1947). Der Baderbezirk von Virunum. Viena: R. M. Rohrer.

Krier, J., Groetembril, S. y Nunes Pedroso, R. (2002). Les peintures romaines de Vichten. Archéologia, 395, 44-55.

Ling, R. (2005). The Insula of the Menander at Pompeii. Volme II- The Decorations. Oxford: Clarendon Press.

Loschi, I. (e.p.). Las decoraciones pintadas de Colonia Augusta Firma Astigi (Écija, Sevilla). En A. Fernández Díaz y G. Castillo Alcántara (Eds.). La pintura romana en Hispania. Del trabajo de campo a la musealización. Murcia: Editum.

Luengo Martínez, J. M. (1962). Astorga romana (Excavaciones del Plan Nacional 1954-1955). Noticiario Arqueológico Hispánico, 5, 152-177.

Maiuri, A. (1938). Le pitture delle case di «M. Fabius Amandio» del «Sacerdos Amandus»e di «P. Cornelius Teges»: (Reg. I, Ins. 7). Roma: Istituto poligrafico dello stato.

Maiuri, A. (1947). La casa di Loreio Tiburtino e la villa di Diomede in Pompei. Roma: Libreria dello stato.

Monraval Sapiña, J. M. (1992). La pintura mural romana en el País Valenciano. Estado de la investigación y nuevos hallazgos. Metodología de excavación-recuperación. En J. L. Jiménez Salvador (Ed.). I Coloquio de pintura mural romana en España (Valencia-Alicante, 1989) (pp. 43-60). Valencia: Ministerio de cultura - Departament de Prehistòria i Arqueologia de la Universitat de València.

Mostalac Carrillo, A. (1997). El programa pictórico de la estancia absidiada F de la Casa Basílica de Mérida. En R. Teja y C. Pérez González (Eds.). Congreso Internacional La Hispania de Teodosio. Vol 2. (Segovia, 1995) (pp. 581-604). Valladolid: Consejería de Educación y Cultura - Universidad SEK.

Nieto Prieto, F. J. (1979-1980). Repertorio de la pintura mural romana de Ampurias. Ampurias, 41-42, 279-342.

Nunes Pedroso, R. (1999). I soffitti e le volte dipinti. Plafonds du portique supérieur. En A. Barbet (Coord.). La Villa de San Marco à Stabia (pp. 267-291). Nápoles: Centre Jean Bérard.

Nunes Pedroso, R. (2005). Pintura mural luso-romana. $O$ Arqueólogo Portugués, Serie IV, 23, 321-366.

Ordoñez Agulla, S. y García-Dils de la Vega, S. (2017). Colonia Augusta Firma Astigi (Écija, Sevilla). Novedades arqueológicas y epigráficas. Gerión, 35(2), 573-596. DOI: https://doi.org/10.5209/GERI.59925

Pappalardo, U. y Grimaldi, M. (2018). Pompei. La villa imperiale. Collana Pompei Volume IV. Nápoles: Valtrend Editore.

Pérez Maestro, C. (2004). Análisis de la terra sigillata marmorata documentada en un vertedero de época Altoimperial en Augusta Emerita. Mérida. Excavaciones arqueológicas, 7, 361-367. Recuperado de: https://biblioteca.consorciomerida.org/pdf/14720 P\%C3\%A9rez\%20 C.-'Sigillata'_Memoria\%202001\%20n\%C2\%BA\%207.pdf

Pérez Maestro, C. (2007). Un área de vertedero/puticulum de época altoimperial localizado extramuros en la zona noreste de la ciudad. Intervención arqueológica realizada en el solar situado en la Calle Cabo Verde s/n. Mérida. Excavaciones arqueológicas, 10, 153-170. Recuperado de: https://biblioteca.consorciomerida.org/pdf/24009 Perez\%20C.\%27Puticulum\%27.Memoria\%202004\%20 N\%C2\%BA\%2010.pdf

Peters, W. J. Th. y Moormann, E. M. (1993). La decorazioni parietali di IV stile. En W. J. Th. Peters (Ed.). La casa di Marcus Lucretius Fronto e le sue pitture (pp. 279-379). Ámsterdam: Thesis Publishers.

Ramos Fernández, R. (1975). De Helike a Illici. Alicante: Excma. Diputación de Alicante.

Reusch, W. (1966). Wandamalereien und Mosaikboden eines Peristylhauses in Bereich der Trierer Kaiserthermen. Trierer Zeitschrigt für Geschichte und Kunst der Trierer Landes und seiner Nachbargebiete, 29, 187-235.

Rizzo, G. E. (1935). Le pitture della casa del poeta tragico. Roma: Istituto poligrafico dello stato.

Riemenschneider, U. (1986). Pompejanische Ornamentbänder des Vierten Stils. Boreas, 9, 105-112.

Rodríguez Temiño, I., Jiménez Hernández, A., González Acuña, D. y Ruiz Cecilia, J. I. (2012). Avance de las nuevas investigaciones en la necrópolis romana de Carmona. Spal, 21, 127-151. DOI: https://doi.org/10.12795/spal.2012.i21.08

Rosser Limiñana, P. (1992). Avance preliminar del hallazgo de pinturas y estucos decorados en la villa romana del «Parque de las Naciones» (Albufereta, Alicante). En J. L. Jiménez Salvador (Ed.). I Coloquio de pintura mural romana en España (Valencia-Alicante, 1989) (pp. 149-153). Valencia: Ministerio de cultura - Departament de Prehistòria i Arqueologia de la Universitat de València.

Sabrié, R. (2013). Décors des IIe, IIIe et IVe styles de la rue $\mathrm{D}$ du Clos de la Lombarde à Narbonne. En J. Boislève, A. Dardenay y F. Monier (Eds.). Pictor 1. Peintures et stucs d'époque romaine. De la fouille au musée (pp. 27-45). Burdeos: Ausonius Éditions.

Sabrié, M., Sabrié, R. y Solier, Y. (1987). La maison à portiques du Clos de la Lombarde à Narbonne et sa décoration murale. Revue archéologique de Narbonnaise, 16. París: Éditions du CNRS.

Sabrié, M. y Demore, M. (1991). Peintures romaines à Narbonne, décorations murales de l'antique province de 
Narbonnaise. Catalogue de l'exposition. Narbona: Ville de Narbonne.

Sabrié, M. y Sabrié, R. (2011). La Maison au Grand Triclinium du Clos de la Lombarde à Narbonne. Montagnac: Monique Mergoil Editions.

Salvadori, M., De Nicolo, N., Didoné, A. y Salvo, G. (2016). Aquileia, frammenti di affresco dagli scavi della Casa delle Bestie ferite e della Casa di Tito Macro. En J. Boislève, A. Dardenay y F. Monier (Eds.). Pictor 5. Peintures et stucs d'epoque romaine. Une archéologie du décor (243-258). Burdeos: Ausonius Éditions.

Scarano Ussani, V. (2005). Moregine. Suburbio «portuale» di Pompei. Nápoles: Loffredo Editore.

Seiler, F. (1992). Casa degli Amorini dorati: (VI 16, 7.38). Häuser in Pompeji. Munich: Hirmer.

Spinazzola, V. y Aurigemma, S. (1953). Pompei alla luce degli scavi nouvi di Via dell'Abbondanza (anni 1910-1923). Roma: Libreria dello stato.

Stefani, G. (2003). Menander: la Casa del Menandro di Pompei. Roma: Electa.

Steiner, P. (1927). Römische Wandmalerei in Trier. Trierer Zeitschrigt für Geschichte und Kunst der Trierer Landes und seiner Nachbargebiete, 2, 54-68.

Strocka, V. M. (1984). Casa del Principe di Napoli (VI 15, 7-8). Häuser in Pompeji. Munich: Hirmer.

Strocka, V. M (1991). Casa del Labirinto: (VI, 11, 8-10). Häuser in Pompeji. Munich: Hirmer.
Strocka, V. M. (2014). Der Vierte pompejanische Stil als Zeitstil und als Lokalstil». En N. Zimmermann (Ed.). Antike malerei zwischen lokalstil und zetstil. Akten des IX Internationale Kolloquiums der AIPMA (Association Internationale pour la Peinture Murale Antique) (Éfeso, 2010) (pp. 29-40). Viena: Verlag der Österreichischen Akademie der Wissenschaften. DOI: https://doi.org/10.26530/oapen_574664

Thomas, B. (1964). Römische Villen in Panonian. Beiträge zur pannonischen Siedlungsgeschichte. Budapest: Akadémiai Kiadó.

Tomás García, J. (2018). Restudying Roman wall painting in Portugal today: testimonies, particularities and idiosyncrasies. En Y. Dubois y U. Niffeler (Eds.). Pictores per provincias II - Status Quaestionis. Actes du 12e Colloque de l'Association Internationale pour la Peinture Murale Antique (AIPMA) (Lausanne, 2016) (pp. 701-710). Antiqua, 55. Basilea: Archäologie Schweiz.

Varriale, I. (2014). Le decorazioni pittoriche dai recenti scavi del Criptoportico di Alife. En N. Zimmermann (Ed.). Antike malerei zwischen lokalstil und zetstil. Akten des IX Internationale Kolloquiums der AIPMA (Association Internationale pour la Peinture Murale Antique) (Éfeso, 2010) (pp. 525-530). Viena: Verlag der Österreichischen Akademie der Wissenschaften. DOI: https://doi.org/10.26530/ oapen_574664

Zahn, W. (1842-1844). Die schönsten Ornamente und merkwürdigsten Gemälde aus Pompeji, Herculanum und Stabiae. 2 vols. Berlín: G. Reimer.

Zimmermann, N. y Ladstätter, S. (2011). Wandmalerei in Ephesos: von hellenistischer bis in byzantinische Zeit. Viena: Phoibos Verlag. 